DOCUMENTOS OCASIONALES

\title{
Actores, aprovechamiento de madera y mercados en la Amazonía peruana
}

\author{
Elena Mejía
}

Walter Cano

Wil de Jong

Pablo Pacheco

Sandra Tapia

Johanna Morocho

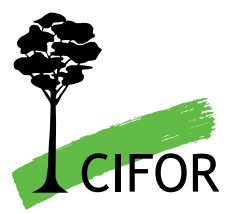





\title{
Actores, aprovechamiento de madera y mercados en la Amazonía peruana
}

\author{
Elena Mejía \\ Quito-Ecuador \\ Walter Cano \\ Cobija-Bolivia \\ Wil de Jong \\ Universidad de Kyoto \\ Pablo Pacheco \\ Centro para la Investigación Forestal Internacional (CIFOR) \\ Sandra Tapia \\ Tabatinga-Brasil \\ Johanna Morocho \\ Universidad la Molina
}


Documentos Ocasionales 145

(C) 2015 Centro para la Investigación Forestal Internacional (CIFOR)

(c) (i) Los contenidos de esta publicación están bajo licencia Creative Commons Attribution 4.0 International (CC BY 4.0), http://creativecommons.org/licenses/by/4.0/

ISBN 978-602-387-020-2

DOI: $10.17528 /$ cifor/005863

Mejía E, Cano W, de Jong W, Pacheco P, Tapia S y Morocho J. 2015. Actores, aprovechamiento de madera y mercados en la Amazonía peruana. Documentos Ocasionales 145. Bogor, Indonesia: CIFOR.

Foto por Tomas Munita

Puerto "La Papelera” en Ucayali, Perú.

Mapas por Carlos Mazabanda

\author{
CIFOR \\ Jl. CIFOR, Situ Gede \\ Bogor Barat 16115 \\ Indonesia \\ $\mathrm{T}+62(251) 8622-622$ \\ $F+62(251) 8622-100$ \\ E cifor@cgiar.org
}

\title{
cifor.org
}

Quisiéramos agradecer a todos los donantes que apoyaron esta investigación a través de sus contribuciones al Fondo de CGIAR. Para ver la lista de donantes del Fondo, visite: http://www.cgiar.org/who-we-are/cgiar-fund/fund-donors-2/

Cualquier opinión vertida en este documento es de los autores. No refleja necesariamente las opiniones de CIFOR, de las instituciones para las que los autores trabajan o de los financiadores. 


\section{Contenido}

$\begin{array}{ll}\text { Agradecimientos } & \text { ix }\end{array}$

$\begin{array}{ll}\text { Resumen ejecutivo } & \mathbf{x}\end{array}$

1 Introducción 1

2 Elementos de contexto $\quad \mathbf{4}$

2.1 Cambio de uso del suelo, poblaciones y tenencia 4

2.2 El sector forestal en el Perú 9

2.3 Gobernanza e institucionalidad del control forestal en el Perú 13

$\begin{array}{ll}2.4 \text { La inversión pública y privada } & 17\end{array}$

3 Centros de producción y circuitos de la madera

3.1 Ucayali: Producción y circuitos de comercialización 20

3.2 Loreto: Producción y circuitos de comercialización 32

3.3 Madre de Dios: Producción y circuitos de comercialización 38

$\begin{array}{ll}3.4 & \text { Circuitos internacionales }\end{array}$

4 Factores asociados con la ilegalidad en el aprovechamiento forestal 51

4.1 Acceso informal al bosque y corta ilegal $\quad 51$

4.2 Mecanismos para sobrepasar las barreras legales $\quad 52$

4.3 Habilitación y créditos informales $\quad 56$

4.4 Interacciones entre el aprovechamiento formal e informal 57

5 Costos y beneficio en el aprovechamiento y comercialización de la madera 59

5.1 Costos y beneficios del aprovechamiento forestal 59

$\begin{array}{ll}5.2 & \text { Costos y beneficios de la comercialización de la madera }\end{array}$

$\begin{array}{lll}5.3 & \text { Rentabilidad versus eficiencia } & 70\end{array}$

6 Discusión $\quad 72$

$\begin{array}{lll}7 & \text { Conclusiones } & 75\end{array}$

8 Referencias $\quad 76$

Anexos

$\begin{array}{lll}1 & \text { Actores entrevistados por actividad y regiones de estudio } & 79\end{array}$

2 Principales instrumentos legales para la adjudicación de tierras $\quad 80$

$3 \quad$ El manejo del sector forestal en el marco de la nueva Ley forestal 81

Precios máximos y mínimos para las principales especies aprovechadas
por los extractores

Precio máximo y mínimo de las principales especies comercializadas por
pequeños productores

$6 \quad \begin{aligned} & \text { Precios máximos y mínimos de las principales especies comercializadas por } \\ & \text { intermediarios }\end{aligned}$ 


\section{Lista de figuras, mapas, cuadros, y recuadros}

\section{Figuras}

1 Producción de madera por rubros en la última década en el Perú (en miles de $\mathrm{m}^{3}$ ) $\quad 10$

2 Madera aserrada de las especies más comercializadas en el Perú (en miles de $\mathrm{m}^{3}$ ) 11

3 Intermediación de los actores 13

4 Sistema de control forestal implementado en el Perú con la nueva Ley

Forestal y de Fauna Silvestre

5 Madera autorizada por zafra y movilizada entre 2003 y 2012 según título habilitante a través de las oficinas técnicas de Ucayali (miles de $\mathrm{m}^{3}$ )

6 Diez principales especies extraída por pequeños productores y pequeños extractores en el bajo Ucayali en las zonas de Iparía, Utiquinía y Callería

7 Frecuencia de las diez principales especies comercializadas por extractores, productores e intermediarios en la zona del Alto Ucayali

8 Frecuencia de las diez principales especies comercializadas por extractores e intermediarios en la zona de Padre Abad y Puerto Inca

9 Datos aglomerados de madera movilizada entre 2003 y 2013 según modalidad de corta a través de las oficinas de Loreto (miles de $\mathrm{m}^{3}$ )

10 Madera autorizada por zafra y movilizada entre 2003 y 2012 según modalidad de corta a través de las oficinas técnicas de Madre de Dios (en miles de $\mathrm{m}^{3}$ )

11 Frecuencia de las diez principales especies comercializadas por extractores e intermediarios en la provincia de Tambopata

12 Frecuencia de las nueve principales especies comercializadas por extractores, intermediarios y productores en la provincia de Tahuamanu

13 Conflictos de los concesionarios con la autoridad $(\mathrm{n}=22)$

14 Conflictos de los extractores con la autoridad forestal y de control $(\mathrm{n}=110)$

15 Conflictos de los intermediarios con la autoridad $(\mathrm{n}=250)$

16 Principales sitios donde los extractores realizan zafras

17 Porcentaje de costos de las operaciones de extracción según tamaño de extractor

19 Destino de venta de la madera ofertada por comunidades y productores

20 Distribución de costos entre productores que aprovechan directamente y con ayuda de terceros en predios privados $(\mathrm{n}=107)$

22 Distribución de los costos de la comercialización de la madera según el tamaño de los intermediarios

\section{Mapas}

1 Departamentos de estudio y lugares de levantamiento de información 3

2 Mapa de la deforestación acumulada

3 Circuitos de comercialización de la madera provenientes de Loreto, Ucayali y Madre de Dios

4 Principales destinos a nivel de distrito de la madera producida en Ucayali

5 Principales destinos a nivel de distritos de la madera producida en Loreto

6 Principales destino a nivel de distrito de la madera producida en Madre de Dios

\section{Cuadros}

1 Uso del suelo en el Perú según el Censo Agropecuario de 2012 (en miles de ha) 4

2 Población urbana y rural entre 2000-2015 (años seleccionados) 6

3 Cambios en las unidades de producción en 1994 y $2012 \quad 6$ 
Tenencia de los bosques en la Amazonía $\quad 6$

Modalidades actuales de tenencia y acceso a recursos forestales 8

Concesiones forestales en la Amazonía 9

Indicadores macroeconómicos para el período 2009-2013 (millones de USD) 10

Principales mercados de la madera según su transformación en el Perú $\quad 12$

$\begin{array}{ll}\text { Pagos por aprovechamiento según tipo de especies } & 16\end{array}$

10 Distribución del cobro por derecho de aprovechamiento forestal 17

11 Tasas de interés de los principales financistas de operaciones forestales 18

12 Valor Agregado Bruto (VAB) en 2012

13 Producción por proveedores y compradores en Ucayali de 2009 a 2012

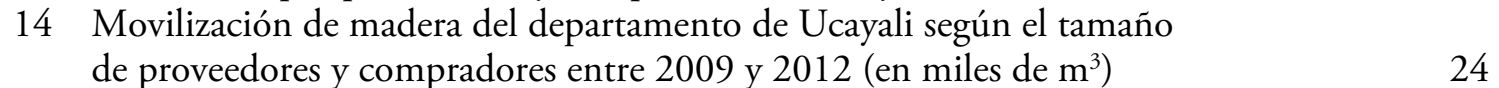

15 Tipo de origen y destino entre 2009 y 2012 en Ucayali según guía
de transporte forestal (en porcentajes)

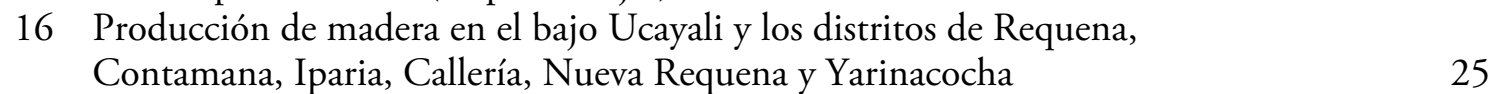

17 Volúmenes de las principales especies aprovechadas en la zona del Bajo Ucayali 26

18 Principales destinos de la madera proveniente de Bajo Ucayali 27

19 Producción de madera en las provincias de Atalaya y el distrito de Masisea 28

20 Volúmenes de las principales especies aprovechadas en la zona del Bajo Ucayali 28

21 Principales destinos de la madera proveniente del Alto Ucayali 29

22 Producción de madera en las provincias de Puerto Inca y Padre Abad 30

Volúmenes de las principales especies aprovechadas en las provincias
de Puerto Inca y Padre Abad

24 Principales destinos de la madera producida en Padre Abad y Puerto Inca 32

25 Proveedores y compradores de madera en Loreto según producción entre 2009 y 201234

26 Movilización de madera en Loreto según tamaño de proveedores y compradores entre 2009 y $2012 \quad 34$

27 Tipo de origen y destino según guía de movilización entre 2009 y 2012 en Loreto (en porcentajes)

28 Zafras registradas en Islandia, Caballo Cocha y San Pablo en la provincia de Mariscal Ramón Castilla, Loreto 36

29 Especies aprovechadas en la región del Yavarí, Loreto 36

30 Zafras registradas en la oficina de Alto Amazonas, entre 2009 y 2012

31 Principales destinos de la madera producida en Alto Amazonas 37

32 Volúmenes de las principales especies aprovechadas en la zona de Alto Amazonas 38

33 Movilización de madera según tamaño proveedor y comprador entre 2009 y $2012 \quad 39$

34 Tipo de origen y destino según guía de movilización entre 2009 y 2012 en Madre de Dios (en porcentajes) 41

35 Producción de madera en la provincia de Tambopata 41

36 Volúmenes de las principales especies de la madera producida en Tambopata 42

37 Principales destinos de la madera producida en Tambopata 43

38 Producción de madera en las provincias de Tambopata con destino al corredor

39 Volúmenes de las principales especies aprovechadas en Tambopata con destino Arequipa y otros destinos

40 Principales destinos de la madera producida en Tambopata con destino Arequipa y otros destinos

$\begin{array}{lll}41 & \text { Producción de madera en la provincia de Tahuamanu } & 46 \\ 42 & \text { Volúmenes de las principales especies extraídas en Tahuamanu } & 46\end{array}$

43 Principales destinos de la madera producida en Tahuamanu 46

44 Principales vendedores (exportadores) y destinos finales entre 2009 y 2012
(en miles de USD FOB) 
45 Principales vendedores (exportadores) y destinos finales entre 2009 y 2012 (en miles de $\mathrm{m}^{3}$ )

46 Características de los extractores según su tamaño

47 Rentabilidad según tipo de madera y productos predominantes en los mercados de madera analizados (USD $/ \mathrm{m}^{3}$ )

48 Análisis costo beneficio por tamaño de extractor (en $\mathrm{USD} / \mathrm{m}^{3}$ )

49 Características de los extractores según su tamaño

50 Análisis de costo beneficio por tamaño de extractor-transformador (USD/m ${ }^{3}$ )

51 Características de las operaciones conducidas en pequeńas concesiones

52 Análisis de costo beneficio por tipo de concesionario $\left(\mathrm{m}^{3}\right)$

53 Características de los productores según su participación en el aprovechamiento

54 Análisis costo-beneficio según participación de los pequeños productores en el aprovechamiento dentro de sus tierras $\left(\mathrm{USD} / \mathrm{m}^{3}\right)$

55 Venta de madera según tipo de negociación en comunidades indígenas 66

56 Características de los intermediarios por tamaño $\quad 67$

57 Costos y beneficios por tipo de madera y producto (USD $\left./ \mathrm{m}^{3}\right) \quad 69$

58 Costos y beneficios por tamaño de intermediarios $\left(\mathrm{USD} / \mathrm{m}^{3}\right) \quad 69$

59 Análisis de costos-beneficios para las empresas exportadoras (USD $\left./ \mathrm{m}^{3}\right) \quad 70$

60 Rentabilidad de los diferentes actores

\section{Recuadros}

1 El caso de la comunidad Puerto Alegre del distrito de Masisea, Ucayali 29

2 Pequeńos extractores y comunidades nativas de Yurimaguas 38

3 El caso de la concesiones de Padre Abad, Ucayali

4 El caso de la bolaina $\quad 55$

5 Pasos para transportar ilegalmente madera de Ucayali a Lima 56

6 Habilitación en comunidades indígenas $\quad 57$ 


\section{Lista de acrónimos y abreviaciones}

ADEX

Asociación de Exportadores

AGROBANCO

Banco Agropecuario

AIDER

Asociación para la Investigación y Desarrollo Regional

ATFFS

Administración Técnica Forestal y Fauna Silvestre

BID

Banco Interamericano de Desarrollo

BPP

Bosques de Producción Permanente

CEPAL

Comisión Económica para América Latina y el Caribe

CIFOR

Centro para la Investigación Forestal Internacional

CITES

COMTRADE

Convención sobre el Comercio Internacional de Especies Amenazadas de Fauna y Flora Silvestres

DAF

Base de datos internacional de Estadísticas del Comercio de las Naciones Unidas

DAR

Derecho de Aprovechamiento Forestal

DGFFS

Derecho y Ambiente

EIA

FAO

Dirección General Forestal y Fauna Silvestre

FLEGT

Agencia de Investigación Ambiental

Organización de las Naciones Unidas para la Alimentación y Agricultura

Plan de acción de la Unión Europea (UE) para la Aplicación de Leyes, Gobernanza y Comercio Forestales

FOB

Precio en puerto de carga convenido

FSC

Certificación del Consejo de Administración Forestal

GTF

Guía de Transporte Forestal

IBC

Instituto del Bien Común

ICEX

España Centro de Exportaciones e Inversiones

IED

Inversiones Extranjeras Directas

IGV

Impuesto Gravado al Valor

ILD

Instituto Libertad y Democracia

INEI

Instituto Nacional de Estadísticas e Informática

INRENA

Instituto de Recursos Naturales

ITTO

Organización Internacional de las Maderas Tropicales

MEF

Ministerio de Economía y Finanzas

MFS

Manejo Forestal Sostenible

MINAG

Ministerio de Agricultura y Riego 
MINAGRI

MINAM

MINCETUR

OEA

OSINFOR

PCA

PGMF

PIB

PNFFS

POA

PRMRFFS

REDD

RUC

SERFOR

SINIA

SUNAT

SUTRAN

TLC

$\mathrm{VAB}$
Antiguas siglas del Ministerio de Agricultura y Riego

Ministerio de Medio Ambiente

Ministerio de Comercio Exterior y Turismo

Organización de Estados Americanos

Organismo de Supervisión de los Recursos Forestales y de Fauna Silvestre

Parcelas de corta anual

Plan General de Manejo Forestal

Producto interno bruto

Política Nacional Forestal y de Fauna Silvestre

Planes operativos anuales

Programa Regional de Manejo de los Recursos Forestales y de Fauna Silvestre de Loreto

Programa de Reducción de Emisiones de Carbono causadas por la Deforestación y la Degradación de los Bosques

Registro Único del Contribuyente

Servicio Nacional Forestal y de Fauna Silvestre

Sistema Nacional de Información Ambiental

Superintendencia Nacional de Aduanas y de Administración Tributaria

Superintendencia de Transporte Terrestre de Personas, Carga y Mercancía

Tratado de Libre Comercio

Valor Agregado Bruto 


\section{Agradecimientos}

Deseamos expresar nuestro agradecimiento por la valiosa colaboración proporcionada por el Ministerio de Agricultura y Riego (MINAG) a través del Servicio Nacional Forestal y de Fauna Silvestre (SERFOR) y el Ministerio de Ambiente (MINAM). Hacemos extensivo nuestro agradecimiento a las organizaciones regionales como las Direcciones Forestales y de Fauna Silvestre de Ucayali, Loreto, Madre de Dios, Piura, Chiclayo, Arequipa, Ica y Cusco, las Oficinas Técnicas de Yurimaguas, Islandia, Aguaytia y Nueva Requena, la Cámara Forestal Nacional capítulo Ucayali, la Universidad Nacional de Ucayali, la Universidad Nacional de Iquitos y la Universidad Nacional de Madre de Dios. Durante el trabajo en campo se contó con el valioso aporte de las organizaciones de la sociedad civil como la Mesa de Concertación Forestal de Ucayali y las Asociaciones de Pequeños Extractores de Ucayali y Yurimaguas. También queremos agradecer a los miembros de las comunidades nativas y campesinas, así como a sus autoridades, quienes proporcionaron información para la realización del presente estudio. Este trabajo ha sido posible gracias al soporte del Programa de Investigación del CGIAR sobre Bosques, Árboles y Agroforestería (CRP-FTA). A todos ellos expresamos nuestra profunda gratitud por el apoyo recibido. Finalmente, queremos resaltar la valiosa colaboración y expresar nuestro agradecimiento a Carlos Cornejo, César Sabogal y Julio Ugarte quienes realizaron la revisión de este documento y brindaron importantes sugerencias. 


\section{Resumen ejecutivo}

El Perú tiene aproximadamente 74 millones de hectáreas con bosques, ocupando el noveno lugar a nivel mundial entre los países considerando sus áreas de bosque (FAO, 2015). La mayor parte de estos son bosques tropicales y se encuentran en la Amazonía, donde son aprovechados por diferentes actores, sobre todo para la extracción de madera (Ministerio del Ambiente, 2011). Para las familias que habitan en las zonas rurales de la Amazonía peruana, la venta de madera es un ingreso importante entre los ingresos rurales, y constituye una salvaguarda a la pobreza (Porro et al., 2014). No obstante, la madera constituye un negocio lucrativo para otros actores de la sociedad rural, como los extractores e intermediarios, quienes satisfacen una creciente demanda dentro y fuera del país (Putzel, 2009; Sears y Pinedo-Vasquez, 2011).

El abastecimiento de los mercados urbanos nacionales e internacionales, es un reto importante tanto para los proveedores y compradores, y requiere de una logística que articula una extensa red de actores que extraen y comercializan diferentes volúmenes de madera de diferentes especies. Esta demanda se enfoca en veinte especies maderables principales, de las cuales ocho son maderas de alto valor comercial o duras, que son maderas de lento crecimiento. Este estudio analiza las redes de comercialización que se establecen en la Amazonía peruana. De acuerdo a las guías de transporte forestal (GTF), desde el lado de la oferta, un 29\% de los proveedores, o extractores de gran escala, movilizaron el $81 \%$ del volumen de madera entre 2009 y 2012. Estos actores consiguen legalizar sus actividades de aprovechamiento, ejercer un cierto control sobre los precios, y en algunos casos, transformar la madera acumulada en productos terminados. Desde el lado de la demanda, el $6 \%$ de los compradores de madera operan en gran escala y, en el período mencionado, acumularon el $60 \%$ de la producción movilizada a las zonas industriales cercanas a Lima. La alta concentración de la oferta y demanda de madera en el Perú ha sido reportada anteriormente por Dablin (2014), Burneo (2011) y Comité PIF (2013).
De forma complementaria a la información oficial utilizada en este trabajo, que solo incluye la oferta legal de madera, también se obtuvieron datos de campo que fueron recolectados entre julio de 2013 y marzo de 2014 en los principales puertos de acopio de las zonas de estudio en la Amazonía peruana. Los resultados sugieren que existe una participación importante de los pequeños productores, extractores e intermediarios en la provisión de madera a los compradores medianos y grandes. La madera de pequeñas extracciones se realiza al margen de las regulaciones, por lo que no sigue los parámetros técnicos establecidos y hace uso de prácticas manuales como el uso de la motosierra. Esta madera es legalizada utilizando varios mecanismos de blanqueo. Según nuestros datos, la madera movilizada de forma totalmente informal alcanza un $62 \%$ del total registrado. Esta madera, una vez legalizada, pasa con la ayuda de intermediarios a ser parte de las reservas de los proveedores y compradores medianos y grandes. Los actores pequeños obtienen la rentabilidad más baja en la venta de madera debido a que enfrentan retos más grandes para optar por financiamiento y formalizar sus operaciones; sin embargo, el bajo costo de oportunidad de su mano de obra en otras actividades hace atractiva la corta de madera.

Son varios los factores que han influido para que la política y regulaciones forestales asuman que únicamente las operaciones en gran escala son una opción viable en el sector forestal. Esto en parte se debe a la idea bastante común, que fue ampliamente aceptada hasta hace poco por funcionarios públicos, expertos de organizaciones internacionales y proyectos de desarrollo, de que el manejo forestal sostenible era posible solo cuando se realizaba en grandes extensiones de bosque, y mejor si estaba articulado a mercados internacionales, que pagaban mejor por madera originada en bosques manejados. No obstante, tal como lo demuestra el caso peruano, el aprovechamiento de madera en pequeña escala vinculado al mercado nacional brinda la posibilidad de integrar un número significativo de familias excluidas del manejo forestal sostenible y que dependen de forma significativa de los bosques para su subsistencia. 


\section{Introducción}

\author{
"En Perú solo hay sanciones administrativas \\ y cualquier denuncia por tala ilegal culmina \\ pagando la multa. Aqui se puede ser talador \\ ilegal por siglos, ya que este es un negocio \\ rentable. Al talador no hay que reprimirle, es \\ necesario darle hectáreas de bosques para que se \\ vuelva legal, si al talador ilegal se le organiza y \\ ofrece bosques legales, se termina el negocio ilegal"

\section{Antonio Brack (Exministro del Ambiente del Perú)}

El Gobierno del Perú regula el aprovechamiento forestal a través de unidades de concesión, áreas con permisos y áreas bajo autorizaciones adjudicadas a personas jurídicas o naturales en zonas forestales identificadas dentro del patrimonio natural del Estado, tanto en tierras colectivas como particulares. Estas adjudicaciones son reconocidas como áreas de manejo formal y sostenible de los bosques, que constituyen criterios que definen la gobernanza forestal en el Perú. Sin embargo, a pesar de los esfuerzos de la sociedad civil y el Gobierno Peruano para regularizar la extracción y movilización de madera en el Perú, distintos reportes han reconocido la importante persistencia de la tala ilegal de madera, sobre todo en la Amazonía peruana (Ministerio del Ambiente, 2011; EIA, 2012; Finer et al., 2014; OSINFOR, 2014).

Todavía son pocos los estudios en el Perú que analizan los factores que impulsan el comercio ilegal de madera, el que, como se conoce, involucra a un grupo diverso de actores: pequeños productores y extractores de diverso tamaño, entre grandes, medianos y pequeños. Estos actores enfrentan varias barreras, ya sean financieras, técnicas y legales, para realizar aprovechamiento legal, por lo que deben acudir a diversas estrategias que combinan prácticas legales e ilegales (Sears y Pinedo-Vasquez, 2011; Finer et al., 2014). Mayor atención se ha dedicado a analizar la existencia del fenómeno de la ilegalidad en la extracción forestal como una práctica que impide la conservación del bosque, pese a que no existe evidencia sólida para asegurar que las prácticas legales garanticen la sostenibilidad del bosque en el largo plazo (OSINFOR, 2014).

La ilegalidad en el sector forestal es un fenómeno complejo porque existen varias prácticas consideradas legales (o formales) que tienen su origen en prácticas ilegales (o informales). Las actividades ilegales son aquellas que contravienen la legislación vigente, y también incluyen prácticas informales que son aquellas que no han sido sancionadas legalmente (Sindzingre, 2006). Por eso, los conceptos de ilegal e informal tienden a usarse de forma intercambiable. Algunos estudios sostienen que la informalidad se debe a imprecisiones legales que excluyen las prácticas tradicionales de uso del bosque, o tienden a penalizarlas, lo que las convierte en ilegales. Asimismo, las fallas institucionales que limitan la obtención de permisos de corta, o alteran los incentivos para su puesta en práctica, tienden a generar situaciones de ilegalidad (Smith et al., 2006; Zambrano et al., 2010; Sears y PinedoVasquez, 2011; Cardozo, 2013; Mejia y Pacheco, 2013; Reboredo, 2013; Jong et al., 2014).

Existe aún poca información relacionada a las interacciones formales/legales e informales/ilegales entre los actores dentro de las redes de comercio de madera, aunque algunos estudios han analizado situaciones específicas, como en Loreto (Sears y Pinedo-Vasquez, 2011) y Ucayali (Cuellar, 2004).

A pesar de que varias acciones del Estado y la sociedad civil han tratado de frenar la ilegalidad, muchas veces intentando erradicar prácticas informales, la realidad es que la producción ilegal de madera proveniente de bosques nativos de la Amazonía ha persistido en los últimos años debido a una creciente demanda urbana (Ministerio de Agricultura, 2014), la que esta principalmente vinculada con el sector de la construcción tanto en 
los mercados nacionales e internacionales (Putzel, 2009; Putzel et al., 2013). La distribución de los beneficios a lo largo de la cadena de valor de la madera es poco conocida, y, por lo general, los pequeños productores y extractores tienen mayor dificultad para obtener un mayor valor, lo que afecta especialmente a los extractores informales, aunque la información disponible es poco concluyente (Cossío et al., 2011; Cardozo, 2013).

El presente estudio analiza las interacciones entre los actores forestales en la Amazonía peruana a lo largo de los principales circuitos de comercialización de madera proveniente de los bosques nativos de los departamentos de Loreto, Ucayali y Madre de Dios (Mapa 1). Asimismo, el análisis ofrece una descripción de la situación del sector ilegal e informal, en especial el vinculado con las actividades extractivas forestales en pequeña escala que involucran a pequeńos productores, extractores, intermediarios y transformadores, quienes usualmente trabajan por fuera de las normativa forestal, pero son parte importante del sistema de aprovechamiento de madera que abastece a los mercados urbanos nacionales y de exportación.

Este documento está organizado en seis partes incluyendo esta introducción. La segunda parte describe el contexto del sector forestal en el Perú, así como los principales aspectos legales e institucionales. La tercera parte analiza los principales circuitos de comercialización de madera, incluyendo tres circuitos entre Ucayali y el norte-centro del país, dos circuitos entre Loreto y el centro del país y tres circuitos desde Madre de Dios y el sur de Perú. La cuarta parte examina las estrategias de los actores para evadir el sistema legal. La quinta parte analiza los costos relacionados con las distintas operaciones forestales (pequeñas, medianas y grandes), así como los beneficios obtenidos. Finalmente, la última parte presenta las conclusiones de este trabajo.

Este trabajo se basa en información secundaria y primaria proveniente de diversas fuentes. El análisis sobre circuitos de madera, que se realiza en la tercera parte, se basa en datos oficiales del Ministerio de Agricultura a través de las guías de transporte forestal (GTF), las que han sido contrastadas con datos disponibles en la Superintendencia Nacional de Aduanas y de Administración Tributaria (SUNAT) a través del Registro Único del Contribuyente (RUC) para caracterizar el tamańo de los proveedores y compradores. La cuarta y quinta parte se basan en información primaria de 783 entrevistas semiestructuradas, realizadas entre los meses de julio de 2013 y abril de 2014 a los diferentes actores del aprovechamiento y comercialización. Estas abarcaron temas de mercados, créditos, redes de comercio, costos y beneficios de su actividad e interacción con la autoridad de control.

Las entrevistas se realizaron tanto en las áreas rurales como urbanas. En las áreas rurales, con la ayuda de informantes claves, se seleccionaron los principales puertos reconocidos como centros de acopio de la madera en su tránsito a los mercados, las subcuencas proveedoras de estos puertos y las principales comunidades o sectores de abastecimiento. En el lado urbano, con ayuda del análisis de las guías de transporte forestal, se establecieron los principales destinos tanto de ciudades intermedias como mercados finales en Lima, Piura, Chiclayo, Arequipa, Ica y Cusco. En estas ciudades se priorizaron los clústeres o zonas industriales para el levantamiento de datos a través de entrevistas a compradores y transformadores de madera en estas ciudades. Los sitios seleccionados para la recolección de datos, tanto en las áreas urbanas y rurales se detallan en el Mapa 1. 


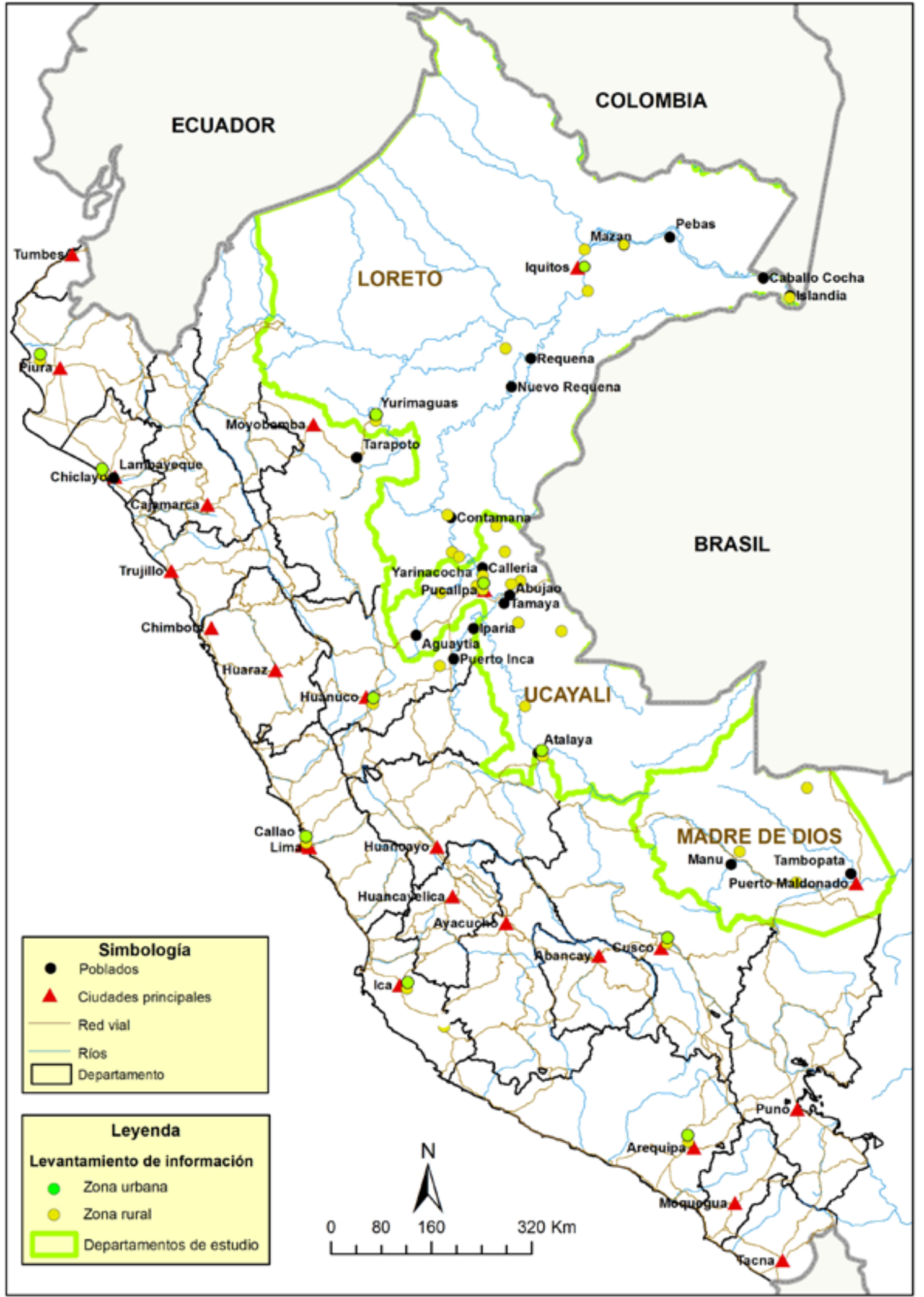

Mapa 1. Departamentos de estudio y lugares de levantamiento de información

Fuente: Elaboración propia de los autores. 


\section{Elementos de contexto}

\subsection{Cambio de uso del suelo, poblaciones y tenencia}

\subsubsection{Las dinámicas de uso del suelo}

El Perú tiene una superficie de 128 millones de hectáreas divididas en tres regiones naturales: la Selva (Amazonía o región amazónica), que cubre 75,7 millones de hectáreas; la Costa, con 13,6 millones de hectáreas, y la Sierra, con 39,2 millones de hectáreas. La región amazónica es el territorio más extenso, que contiene el $82 \%$ de montes y bosques, como lo muestra el Cuadro 1 (Ministerio del Ambiente, 2011; FAO, 2013).

En la Amazonía, los cambios de uso de suelo han sido drásticos, y las tierras con bosques han sufrido una notable disminución de su cobertura. La deforestación anual en el período entre 2006 y 2011 fue del 0,7\%, inferior a la observada entre 2001 y 2005, cuando se tenía una pérdida anual de 2,1\% . Según el Ministerio del Ambiente (2013), la distribución de la deforestación a nivel departamental ha variado en los diferentes períodos, antes de 2000 y de 2000 a 2009. Así, los departamentos de San Martín, Amazonas y Junín, que ocuparon los primeros puestos hasta el año 2000, presentan una tendencia clara hacia un descenso de su deforestación para el período 2000 a 2009. Por otro lado, Loreto, Cusco y Ucayali muestran tendencias hacia mayores tasas de deforestación. En el caso de Madre de Dios, existe una tendencia hacia el incremento de la deforestación, aunque en niveles inferiores a los observados en los departamentos de Loreto y Ucayali (Mapa 2).

Los predios rurales individuales son los que tienen la tasa anual más alta de deforestación con un $2,27 \%$ entre los años 2000 y 2009, mientras que la deforestación en tierras colectivas ha sido entre $0,11 \%-0,29 \%$ en el mismo período ${ }^{1}$.

Cuadro 1. Uso del suelo en el Perú según el Censo Agropecuario de 2012 (en miles de ha)

\begin{tabular}{|c|c|c|c|c|c|c|c|c|c|}
\hline & $\begin{array}{l}\text { Superficie } \\
\text { con } \\
\text { cultivos }\end{array}$ & $\begin{array}{l}\text { Superficie } \\
\text { agrícola } \\
\text { sin cultivo } \\
\text { y va a ser } \\
\text { sembrada }\end{array}$ & $\begin{array}{l}\text { Superficie } \\
\text { agrícola } \\
\text { sin cultivo } \\
\text { y no va } \\
\text { a ser } \\
\text { sembrada }\end{array}$ & $\begin{array}{c}\text { Superficie } \\
\text { agrícola } \\
\text { en } \\
\text { descanso }\end{array}$ & $\begin{array}{c}\text { Pastos } \\
\text { naturales } \\
\text { manejados }\end{array}$ & $\begin{array}{c}\text { Pastos } \\
\text { naturales } \\
\text { no } \\
\text { manejados }\end{array}$ & $\begin{array}{l}\text { Montes y } \\
\text { bosques }\end{array}$ & $\begin{array}{l}\text { Otros } \\
\text { usos }\end{array}$ & Total \\
\hline Selva & 1595,6 & 310,9 & 235,7 & & 261,0 & 477,3 & 8939,9 & 211,6 & $12.032,0$ \\
\hline Sierra & 1603,8 & 691,7 & 237,7 & 762,8 & 1262,6 & $14.288,2$ & 1554,6 & 1867,9 & $22.269,3$ \\
\hline Costa & 956,3 & 429,0 & 301,5 & & 35,7 & 1694,0 & 444,7 & 579,9 & 4441,2 \\
\hline Total & 4155,7 & 1431,6 & 774,9 & 762.8 & 1559,3 & $16.459,5$ & $10.939,3$ & 2659,4 & $38.742,5$ \\
\hline \multicolumn{10}{|c|}{ En porcentaje } \\
\hline Selva & $38 \%$ & $22 \%$ & $30 \%$ & $0 \%$ & $17 \%$ & $3 \%$ & $82 \%$ & $8 \%$ & $31 \%$ \\
\hline Sierra & $39 \%$ & $48 \%$ & $31 \%$ & $100 \%$ & $81 \%$ & $87 \%$ & $14 \%$ & $70 \%$ & $57 \%$ \\
\hline Costa & $23 \%$ & $30 \%$ & $39 \%$ & $0 \%$ & $2 \%$ & $10 \%$ & $4 \%$ & $22 \%$ & $11 \%$ \\
\hline Total & $100 \%$ & $100 \%$ & $100 \%$ & $100 \%$ & $100 \%$ & $100 \%$ & $100 \%$ & $100 \%$ & $100 \%$ \\
\hline
\end{tabular}

Fuente: Elaboración propia con base en datos de INEI (2012). 


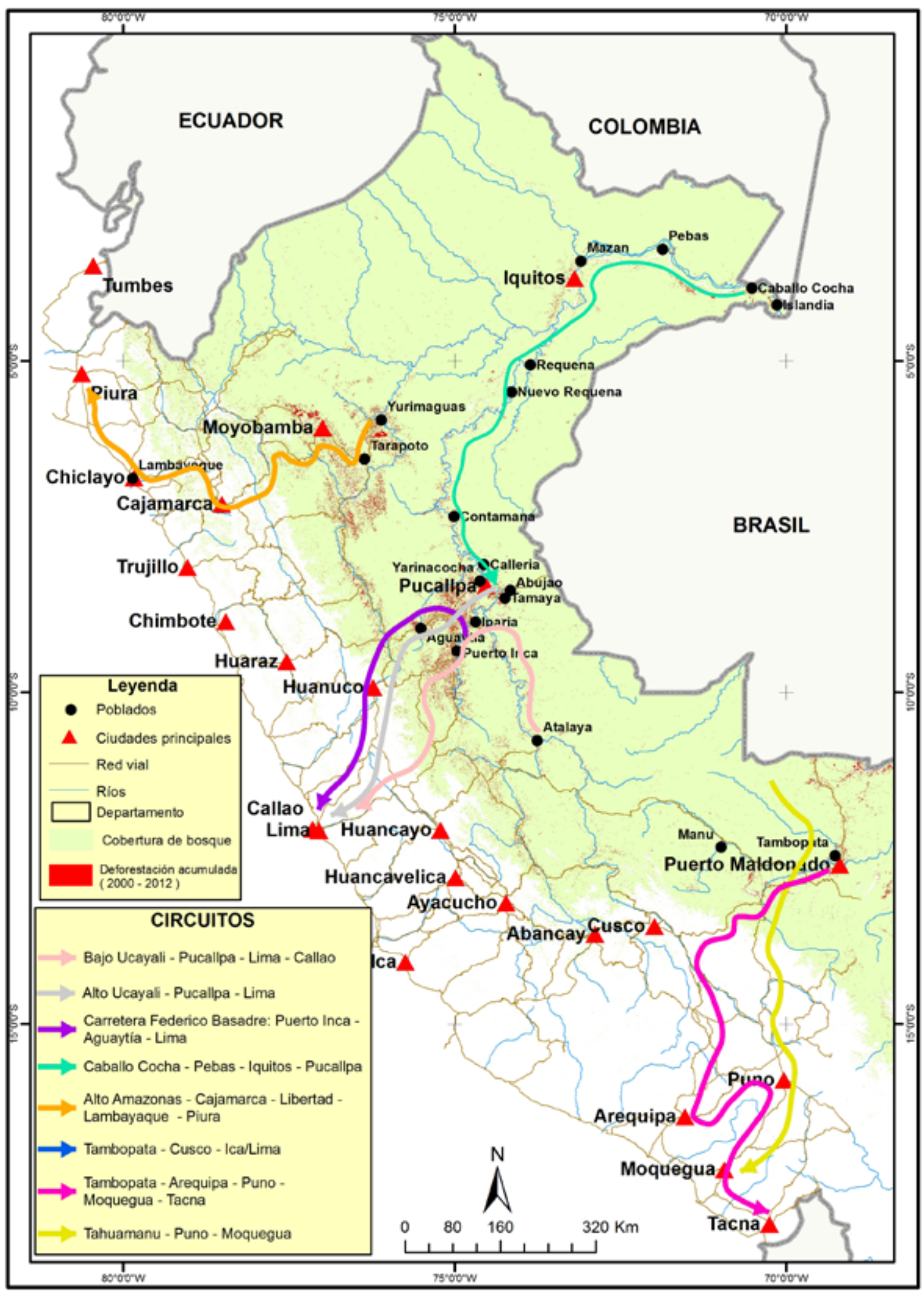

\section{Mapa 2. Mapa de la deforestación acumulada}

Fuente: Elaboración propia de los autores con base en información de Hansen (2014). 
Cuadro 2. Población urbana y rural entre 2000-2015 (años seleccionados)

\begin{tabular}{|c|c|c|c|c|c|c|}
\hline \multirow[t]{2}{*}{ Región } & \multicolumn{2}{|c|}{$\begin{array}{l}\text { Población rural } \\
\text { (miles) }\end{array}$} & \multirow[t]{2}{*}{$\begin{array}{c}\text { Cambio } \\
\text { Población (en \%) }\end{array}$} & \multicolumn{2}{|c|}{$\begin{array}{l}\text { Población rural } \\
\text { (miles) }\end{array}$} & \multirow[t]{2}{*}{$\begin{array}{c}\text { Cambio } \\
\text { población (en \%) }\end{array}$} \\
\hline & 2000 & 2007 & & 2008 & $2015^{a}$ & \\
\hline Amazonía & 1121 & 1081 & 1,0 & 1072 & 994 & $(0,9)$ \\
\hline Costa & 2472 & 2236 & $(0,9)$ & 2199 & 1966 & $(0,9)$ \\
\hline Sierra & 4704 & 4570 & $(1,0)$ & 4540 & 4298 & $(0,9)$ \\
\hline \multirow[t]{3}{*}{ Total } & 8296 & 7887 & $(1,0)$ & 7811 & 7258 & $(0,9)$ \\
\hline & \multicolumn{2}{|c|}{$\begin{array}{l}\text { Población urbana } \\
\text { (miles) }\end{array}$} & & \multicolumn{2}{|c|}{$\begin{array}{l}\text { Población urbana } \\
\text { (miles) }\end{array}$} & \\
\hline & 2000 & 2007 & & 2008 & $2015^{a}$ & \\
\hline Amazonía & 1253 & 1572 & 1,3 & 1619 & 1942 & 1,2 \\
\hline Sierra & 12.660 & 14.426 & 1,1 & 14.659 & 16.375 & 1,1 \\
\hline Costa & 3773 & 4596 & 1,2 & 4717 & 5577 & 1,2 \\
\hline Total & 17.687 & 20.594 & 1,2 & 20.996 & 23.894 & 1,1 \\
\hline
\end{tabular}

Fuente: Elaboración propia con base a los datos de los censos poblacionales reportados por INEI (2009, 2012).

Nota: a) Estimaciones de INEI.

Cuadro 3. Cambios en las unidades de producción en 1994 y 2012

\begin{tabular}{lcccccc}
\hline & \multicolumn{2}{c}{ Sierra } & \multicolumn{3}{c}{ Costa } & \multicolumn{2}{c}{ Amazonía } \\
\cline { 2 - 6 } & 1994 & $\mathbf{2 0 1 2}$ & $\mathbf{1 9 9 4}$ & $\mathbf{2 0 1 2}$ & $\mathbf{1 9 9 4}$ & $\mathbf{2 0 1 2}$ \\
\hline Unidades agropecuarias (miles de hectáreas) & 1200 & 1444 & 250 & 357,6 & 300 & 458,9 \\
Tamaño promedio de la unidad agropecuaria (hectáreas) & 0,1 a 5 & 0,1 a 5 & 0,1 a 5 & 0,1 a 5 & 5,1 a 50 & 0,1 a 5 \\
\hline
\end{tabular}

Fuente: Elaboración propia con base en los censos agropecuarios de 1994 y 2012 INEl.

\section{Cuadro 4. Tenencia de los bosques en la Amazonía}

\begin{tabular}{llrr}
\hline $\begin{array}{l}\text { Tipo de } \\
\text { tenencia }\end{array}$ & Modalidad & $\begin{array}{c}\text { Millones de } \\
\text { hectáreas }\end{array}$ & Porcentaje \\
\hline Pública & Total de área de bosques de producción permanente & 9,3 & $12,7 \%$ \\
& Concesiones forestales bajo uso dentro de BPP & 7,4 & $10,1 \%$ \\
& Concesiones no maderables ${ }^{a}$ & 1,7 & $2,3 \%$ \\
\hline Indígena & Tierra de bosques de producción permanente en reserva & 8,8 & $12,0 \%$ \\
& Tierras forestales designadas a comunidades nativas & 10,6 & $14,5 \%$ \\
& Reservas territoriales a favor de indígenas en aislamiento & 1,7 & $2,3 \%$ \\
\hline Privada & Tierras forestales en comunidades campesinas & 3,5 & $4,8 \%$ \\
\hline Otros & Áreas de conservación & 21,7 & $29,6 \%$ \\
& Bosques sin categoría territorial & 17,8 & $24,3 \%$ \\
\hline
\end{tabular}

Fuente: Elaboración propia con base en (Sabogal y Sobrevilla, 2008; Molnar et al., 2011; Ministerio del Ambiente, 2011 ; SINIA, 2014).

Nota: a) Abarcan las áreas aprobadas dentro de concesiones para ecoturismo, conservación, otros productos del bosque, forestación y reforestación y fauna silvestre. b) Bosques en áreas naturales protegidas, áreas de conservación privada, áreas de conservación regional. 
Diversos autores señalan la agricultura de pequeña escala como la mayor causa de deforestación en la Amazonía y la tala ilegal como una causa asociada (Álvarez y Naughton-Travez, 2003; IBC, 2012; Dourojeanni et al., 2009; Climate Investment Funds, 2013; Ministerio del Ambiente, 2013). No obstante, Ugarte (2005) indica que es difícil comparar los datos de deforestación debido al uso de diferentes metodologías para su cálculo. El Ministerio del Ambiente (2013) indica que el 75\% de la deforestación se explica por la apertura de áreas para cultivo equivalentes a media hectárea; el $24 \%$, por áreas de menos de una hectárea; y el $1 \%$ de la deforestación sucede en áreas equivalentes o mayores a 10 hectáreas que se destinarían posiblemente a actividades como agricultura industrial o ganadería extensiva.

\subsubsection{Población y tenencia}

Desde los años 1970, con la migración masiva a la Amazonía que estimuló la posesión de tierras públicas, la adjudicación legal de dichas tierras se volvió un problema para los diferentes gobiernos de turno, quienes tuvieron dificultades para titular las nuevas propiedades debido a que la velocidad de los asentamientos superaba la capacidad burocrática de respuesta del Estado (CEPAL, 1999; McKechnie, 2006; Burneo, 2011; Wiig, 2013). Las posibilidades de que los migrantes obtuvieran tierras para el cultivo, impulsadas por la apertura de caminos, fueron los principales incentivos que despertaron una importante colonización espontanea hacia la Amazonía, la cual se exacerbó aún más en la década de los setenta con la promoción de la producción forestal ${ }^{2}$ y los bajos índices de desarrollo económico de la región Andina $^{3}$ (Eguren, 2004; Ugarte, 2005; Rudel et al., 2009; Burneo, 2011; Piu y Menton, 2013).

A pesar de las acciones de titulación y el ordenamiento territorial por parte del Gobierno y organismos internacionales como el Banco Mundial y el Banco Interamericano de Desarrollo

2 Hasta el año 2012 se registraron en la Amazonía peruana $4244 \mathrm{~km}$ de carreteras. Disponible en http://www.proviasnac. gob.pe/frmconservacion. aspx?idmenu=646

3 Aún en la actualidad, datos del año 2010, muestran que los índices de pobreza fueron de $49 \%$ en la sierra y $37 \%$ en la selva. En la zona rural de la sierra, llegó al 61\% de la población en pobreza y $29 \%$ en extrema pobreza mientras que en la selva rural las tasas fueron del $46 \%$ en pobreza y $18 \%$ en extrema pobreza, respectivamente. realizados entre los años $1970^{4}$ y $1990^{5}$, estos no lograron regular los problemas de uso o tenencia del suelo. Lo cual no pudo evitar, por ejemplo, el cambio de bosques a tierras productivas como establece la legislación. Hasta la actualidad el sistema de titulación en Perú no ha podido homologar sus normas de tenencia de tierras agrícola y de bosques, para responder a la necesidades de la población Amazónica (Piu y Menton, 2013).

En este sentido, debido a las migraciones desde la región Andina la población rural creció más en la Amazonía que en el resto de las regiones del Perú (Ugarte, 2005). Sin embargo, en años recientes la población rural ha mermado, como lo muestra el Cuadro 2; aunque, en número absolutos, la población en la Amazonía sigue en crecimiento.

La disminución en población rural entre 2008 y 2015 podría deberse a la migración de los jóvenes a las zonas urbanas ${ }^{6}$ sumada a la fragmentación de la tierra en unidades más pequeñas, como lo muestra el Cuadro 3. En general, las áreas de producción en promedio en Sierra y Costa han oscilado entre 0,1 y 5 hectáreas. La Amazonía ha sido la única región que ha sufrido un cambio importante, pasando de un promedio de unidad productiva de 5,1 a 50 hectáreas a un promedio de 0,1 a 5 hectáreas.

\subsubsection{Tenencia de los bosques en la Amazonía}

Para normar el uso de suelo y el uso de las áreas forestales el Estado reconoce bosques públicos, indígenas y privados, además de las áreas de conservación (Cuadro 4). Taylor (2006) anota que en Perú es difícil el acceso a los recursos forestales debido a que estos tienen diferentes regímenes de tenencia, y cada uno cuenta con leyes e instituciones independientes que en muchos casos son incongruentes. A pesar de que las diferentes leyes de uso del suelo desde 1961 y

4 Promulgación de la Ley de Comunidades Nativas y Promoción Agraria de las Regiones de la Selva Alta y Selva Baja No. 20653 en 1970.

5 El ILD en el año 1990 analizó que, a pesar de la redistribución de las unidades de producción durante la Reforma Agraria, el 90\% de estas no tenían título de propiedad, por lo cual, junto al BID apoyó la titulación de 1,5 millones de unidades de tierra que mayormente se encontraban en zonas periurbanas.

6 Datos de INEI (2012), muestran una disminución del 1,1 en la población rural de edades entre 20 y 24 años. 


\section{Cuadro 5. Modalidades actuales de tenencia y acceso a recursos forestales}

\begin{tabular}{|c|c|c|}
\hline $\begin{array}{l}\text { Tipo de } \\
\text { aprovechamiento }\end{array}$ & Modalidad & Condiciones de uso \\
\hline \multirow[t]{4}{*}{$\begin{array}{l}\text { Aprovechamiento } \\
\text { forestal con fines } \\
\text { maderables }\end{array}$} & $\begin{array}{l}\text { Concesiones forestales con } \\
\text { fines maderables de } 5000 \text { a } \\
40.000 \text { hectáreas }\end{array}$ & $\begin{array}{l}\text { Contratos por } 40 \text { años, renovables mediante concurso } \\
\text { público, pago anual de derechos de aprovechamiento } \\
\text { por hectárea y elaboración de un Plan General de Manejo } \\
\text { Forestal y Planes operativos anuales }\end{array}$ \\
\hline & Bosques locales & No se definen en la nueva Ley \\
\hline & $\begin{array}{l}\text { Permisos y autorizaciones } \\
\text { de aprovechamiento forestal } \\
\text { para comunidades nativas y } \\
\text { campesinas }\end{array}$ & $\begin{array}{l}\text { Requiere la presentación de planes de manejo forestal, } \\
\text { planes operativos anuales y una propuesta técnica. Pago } \\
\text { por metro cúbico al estado natural de extracción. }\end{array}$ \\
\hline & $\begin{array}{l}\text { Permisos de aprovechamiento } \\
\text { forestal en predios privados }\end{array}$ & $\begin{array}{l}\text { Permisos anuales de aprovechamiento forestal mediante } \\
\text { la presentación de planes operativos anuales. Pago por } \\
\text { metro cúbico de madera al estado natural de extracción. El } \\
\text { área total que abarca este sistema varía según las regiones } \\
\text { y períodos, y generalmente se incrementa mucho en } \\
\text { períodos secos. }\end{array}$ \\
\hline \multirow{3}{*}{$\begin{array}{l}\text { Aprovechamiento } \\
\text { de productos } \\
\text { forestales no } \\
\text { maderables }\end{array}$} & $\begin{array}{l}\text { Concesiones para productos } \\
\text { forestales diferentes de la } \\
\text { madera }\end{array}$ & $\begin{array}{l}\text { Tienen vigencia de hasta cuarenta años renovables en una } \\
\text { superficie máxima de } 10.000 \text { hectáreas. }\end{array}$ \\
\hline & $\begin{array}{l}\text { Concesiones para } \\
\text { conservación }\end{array}$ & $\begin{array}{l}\text { No existe límite de extensión y se sustenta en el estudio } \\
\text { técnico y la propuesta presentada a la autoridad forestal y } \\
\text { de fauna silvestre. }\end{array}$ \\
\hline & Concesiones para ecoturismo & $\begin{array}{l}\text { El aprovechamiento está sujeto al pago por derecho de } \\
\text { aprovechamiento. Tienen vigencia hasta de cuarenta años } \\
\text { renovables en una superficie máxima de } 10.000 \text { hectáreas. }\end{array}$ \\
\hline
\end{tabular}

Fuente: Elaboración propia con base de información disponible en la Ley № 29763.

posteriormente las leyes forestales desde el año 2000 han intentado subsanar estos temas, los conflictos por uso persisten en un $24 \%$ de los bosques (Ministerio del Ambiente, 2011).

La Constitución Política de 1993 estipula que salvo los derechos legalmente adquiridos, los bosques y en general todas las fuentes naturales de riqueza pertenecen al Estado. Se reconocen también las áreas naturales protegidas por la Ley Forestal y de Fauna Silvestre $\left(\mathrm{N}^{\circ} 27308\right)$ como parte del patrimonio natural del Estado, aunque como de posible concesión según las normas de protección ambiental. Sunderlin et al. (2008) estiman que el Estado peruano ha adjudicado alrededor del $80 \%$ de las tierras con bosque en la Amazonía para la explotación de petróleo y gas y el $20 \%$ para usos maderables y no maderables. Desde el año 2000, el aprovechamiento de productos maderables y no maderables es posible a través de diferentes modalidades de tenencia (Molnar et al., 2011; FAO, 2012) (ver Cuadro 5). El Anexo 2 proporciona el detalle de las normas que rigen la adjudicación de tierras y bosques.
Las concesiones son el mecanismo por el cual el Estado, a través de los gobiernos regionales, otorga en áreas de dominio público el derecho para el aprovechamiento sostenible de los recursos forestales y de fauna silvestre y el derecho de uso y disfrute de dichos recursos naturales. Este incluye la propiedad de los frutos y productos extraídos legalmente, así como para todo tipo de actividad forestal, incluyendo, según los casos, la producción de madera, de productos forestales diferentes de la madera y el desarrollo de actividades de ecoturismo o con fines de conservación (Cuadro 6). El solicitante de concesión forestal debe acreditar su capacidad técnica y financiera para manejar sosteniblemente la unidad concesionada.

En la actualidad, las concesiones no maderables de castaña y shiringa son mayores en número que las maderables. Según Cossío et al. (2014), las concesiones castañeras en Madre de Dios ofrecen la oportunidad de extraer madera y, curiosamente, de ellas se ha extraído mayor cantidad de madera por hectárea que de las concesiones forestales. Todas las 
Cuadro 6. Concesiones forestales en la Amazonía

\begin{tabular}{lcc}
\hline Departamento & $\begin{array}{c}\text { Área concesionada } \\
\text { (miles de hectáreas) }\end{array}$ & Número de concesiones \\
\hline Huánuco & 200,0 & 47,0 \\
Junín & 400,0 & 7,0 \\
Loreto & 2700,0 & 252,0 \\
Madre de Dios & 1200,0 & 85,0 \\
Pasco & 80,0 & 1,0 \\
San Martín & 500,0 & 37,0 \\
Ucayali & 2500,0 & 152,0 \\
\hline Total de concesiones forestales & $\mathbf{7 3 0 0 , 0}$ & $\mathbf{5 8 1 , 0}$ \\
Total de concesiones no maderables ${ }^{\text {a }}$ & - & $\mathbf{1 0 0 8 , 0}$ \\
\hline
\end{tabular}

Fuente: Elaboración propia con base en (Molnar et al., 2011).

Nota: a) Dentro de las concesiones no maderables de castaña y shiringa también se puede realizar extracción de madera.

modalidades deben contar con un plan general de manejo forestal (PGMF) que realiza una proyección de los árboles a ser extraídos, especificando el área precisa para un período de cinco años. Una vez que el PGMF es aprobado, el concesionario presenta un plan operativo anual (POA) para cada año de operación (o zafra), donde especifica (con coordenadas geográficas) la ubicación de cada árbol que se extraerá. Según la Ley Forestal, la concesión puede ser subdividida en parcelas de corta anual (PCA), donde cada parcela equivale a un POA (EIA, 2012).

Además de las concesiones, el aprovechamiento forestal en la Amazonía se realiza en áreas colectivas de comunidades indígenas y en predios rurales. Las primeras poseen bosques más extensos y ocupan el $27 \%$ del total del territorio amazónico, distribuido en 1345 comunidades, siendo las etnias más numerosas la Asháninca, en la Selva Central, con 88.703 habitantes y la Aguaruna en la Selva Norte, con 55.366 habitantes (INEI, 2008; Ministerio del Ambiente, 2011; Sears y Pinedo-Vasquez, 2011; Chavez, 2013;).

Los predios privados, al contrario, pertenecen a campesinos mestizos quienes son generalmente migrantes de la sierra que se asentaron en las orillas de los ríos (ribereńos). Estos se asocian con empresas forestales para realizar aprovechamientos en sus bosques. Por lo general, estas empresas realizan planes e inventarios para legalizar más de una propiedad adyacente, lo que les permite generar el volumen necesario para realizar una operación rentable. Según el Ministerio del Ambiente, (2014) entre 2009 y 2011 se habilitaron 5626 permisos y autorizaciones forestales en el Perú.

\subsection{El sector forestal en el Perú}

\subsubsection{La economía forestal}

La economía del Perú ha crecido un 7.5\% anualmente desde el año 2006 gracias a la extracción de recursos y la agricultura (Climate Investment Funds, 2013). El sector agrícola-forestal ha contribuido en los últimos cinco años en promedio con un 5,6\% al PIB Nacional (Cuadro 7). Según estimaciones del sector privado, el sector forestal por sí solo tendría una contribución del 1,1\%, aunque se desconoce el valor real de la balanza nacional de ventas (ADEX, 2011). El 99\% de la industria forestal emplea bosques y especies nativas (Ministerio del Ambiente, 2011). Los datos oficiales disponibles muestran que la industria de la madera y muebles ha disminuido su participación al PIB de un $0,4 \%$ en 2004 a un $0,2 \%$ en $2012^{7}$. En el período 2011-2012 se reconoce un crecimiento del sector silvícola ${ }^{8}$, pasando de un $0,6 \%$ a un $5,3 \%$, presumiblemente por la mayor extracción de madera rolliza en dicho período (SINIA, 2012; INEI, 2013). Los mercados externos son el destino del 15\% de la producción total de madera, reservada para los mercados de China, Estados

\footnotetext{
7 El cálculo del Valor Bruto de Producción a precios corrientes del subsector silvícola se determina evolucionando el valor de la madera rolliza a precios constantes con el Índice de Precios al por Mayor de aserraderos (Banco Central de Reserva del Perú, 2014).

8 El cálculo del Valor Bruto de Producción a precios constantes del subsector silvícola se determina multiplicando el volumen de producción de madera rolliza por el precio del año base (Banco Central de Reserva del Perú, 2014).
} 
Unidos y Europa en forma de pisos, chapados, contrachapados y madera aserrada (ITTO, 2013). Sin embargo, el mercado interno concentra el $85 \%$ de la producción total y su destino principal es la industria del mueble y el sector de la construcción de los principales centros urbanos, en especial Lima (AIDER, 2012; Torres, 2012).

El sector de transformación primaria de la madera está liderado por aserraderos y reaserraderos, además de algunas industrias como las de tableros (triplay-contrachapados), postes de madera y chapas decorativas. Claramente se ve reflejado el liderazgo que representa la producción de madera rolliza en la lista de extracción forestal, así como las especies de madera blandablanda (Figura 1). Por otro lado, la transformación secundaria está marcada por el sector industrial de muebles y de pisos (parqué) y que se abastece principalmente de madera dura y semidura de especies como shihuahuaco (Dipteryx micrantha), quinilla (Manilkara bidentata), capirona (Capirona decorticans), entre otras (Figura 2) (Proinversión, 2005; Arroyo et al., 2011; AIDER, 2012).

Cuadro 7. Indicadores macroeconómicos para el período 2009-2013 (millones de USD)

\begin{tabular}{lrrrrr}
\hline & 2009 & $\mathbf{2 0 1 0}$ & $\mathbf{2 0 1 1}$ & $\mathbf{2 0 1 2}$ & $\mathbf{2 0 1 3}$ \\
\hline Producto interno bruto & & & & & \\
\hline PIB total & $125.922,9$ & $136.564,3$ & $145.375,7$ & $154.026,1$ & $162.893,9$ \\
PIB agricultura y silvicultura & 7454,6 & 7773,6 & 8092,1 & 8568,2 & 8692,8 \\
PIB construcción & $12.834,3$ & $14.435,7$ & $15.726,4$ & $16.863,6$ & $17.851,5$ \\
PIB agricultura y silvicultura/total (\%) & $5,9 \%$ & $5,7 \%$ & $5,6 \%$ & $5,6 \%$ & $5,3 \%$ \\
\hline Comercio exterior & & & & & \\
\hline Exportaciones totales & $27.070,5$ & $35.803,1$ & $46.376,0$ & $46.366,7$ & $42.176,8$ \\
Exportaciones de productos forestales & 335,8 & 359,2 & 401,7 & 438,1 & 425,7 \\
Exportaciones forestales/totales (\%) & $1,2 \%$ & $1,0 \%$ & $0,9 \%$ & $0,9 \%$ & $1,0 \%$ \\
Importaciones de productos forestales & 2647,6 & 3365,9 & 3818,6 & 3866,1 & 3866,1 \\
Balanza forestal & $-2311,7$ & $-3006,7$ & $-3416,9$ & $-3428,0$ & $-3440,4$ \\
\hline
\end{tabular}

Fuente: Elaboración propia con base en (INEI, 2013; Banco Central de Reserva del Perú, 2014; FAO, 2013).

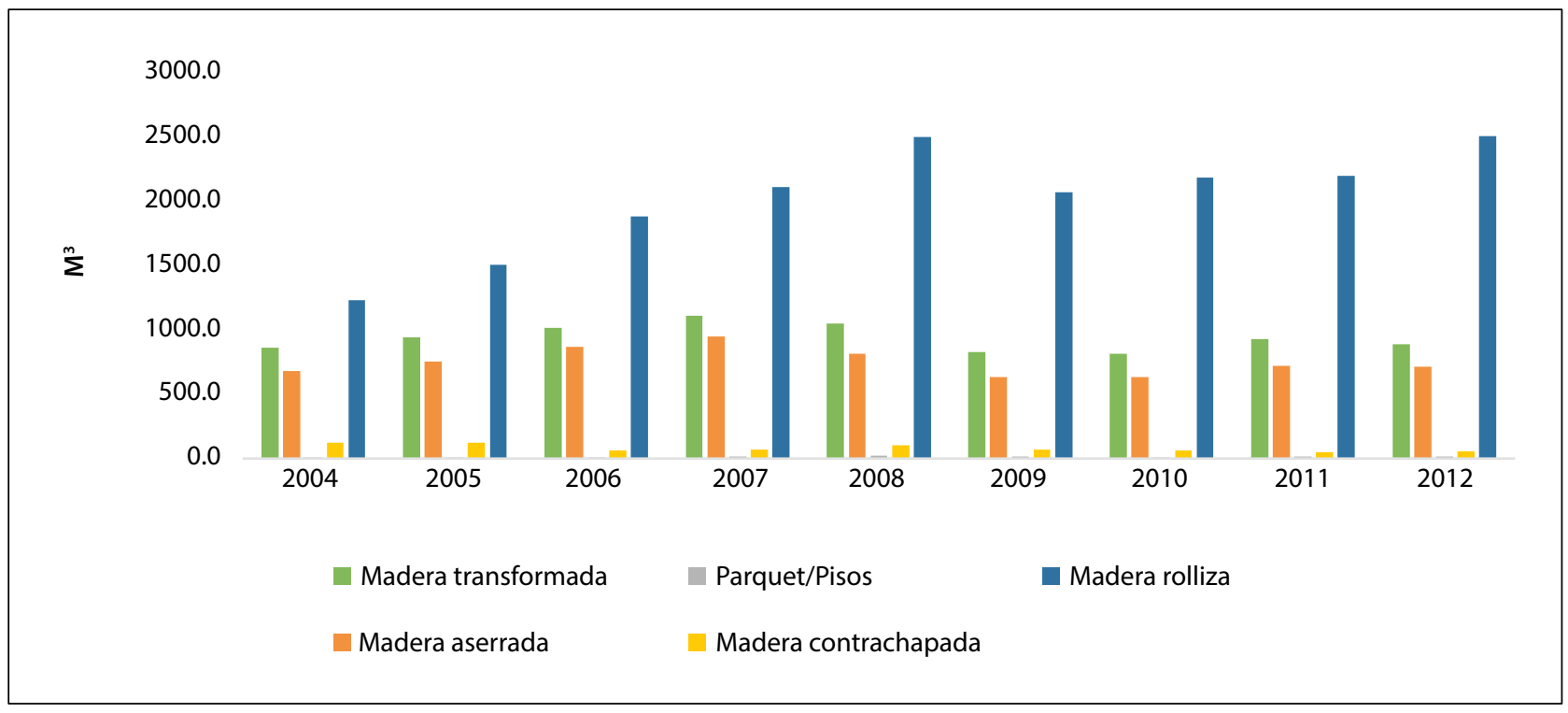

Figura 1. Producción de madera por rubros en la última década en el Perú (en miles de $\mathrm{m}^{3}$ )

Fuente: Ministerio de Agricultura (2013), SINIA (2012), datos propios recolectados en las Direcciones de Bosques y Fauna Silvestre durante 2013-2014. 


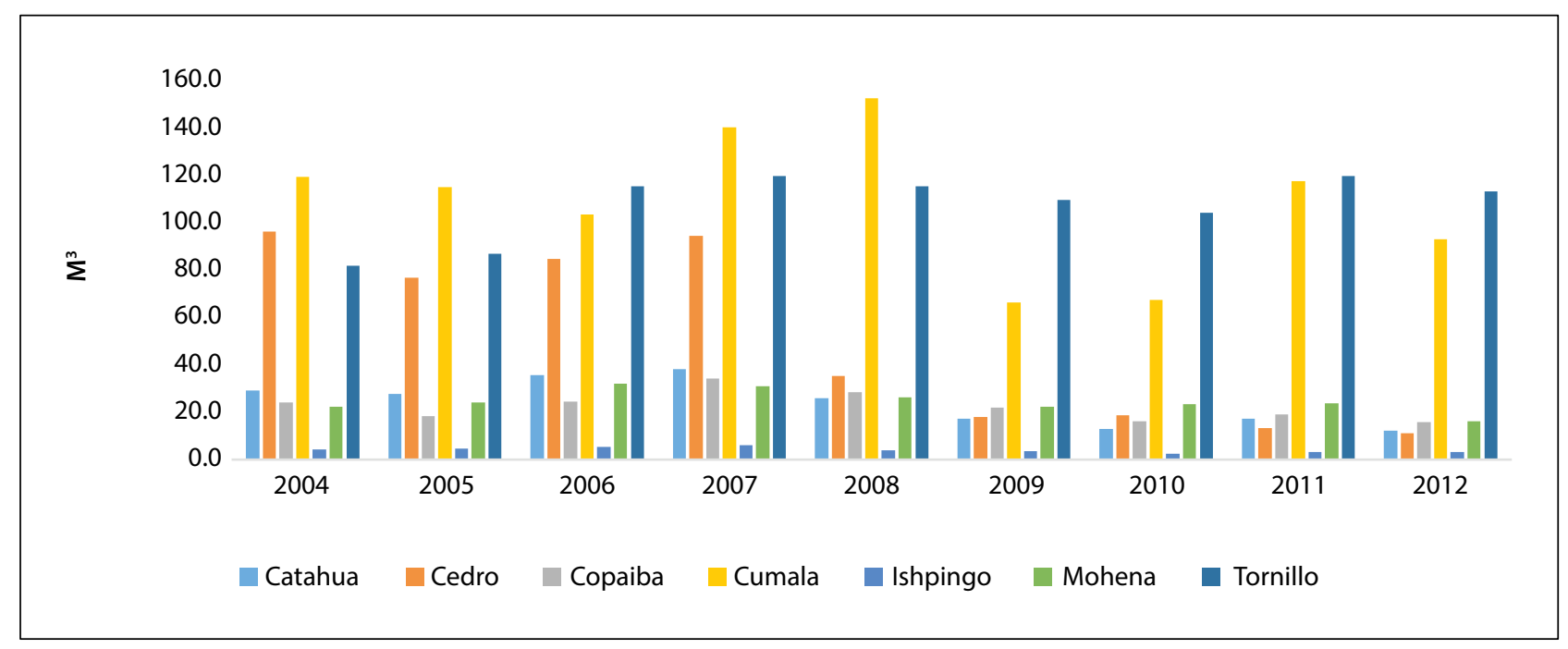

Figura 2. Madera aserrada de las especies más comercializadas en el Perú (en miles de $\mathbf{m}^{3}$ )

Fuente: Elaboración propia con base en datos del Ministerio de Agricultura (2013).

Los principales mercados de la madera están asociados a los principales centros urbanos del país. Es así que el mercado Norte de Perú se abastece de los departamentos de Loreto y San Martín, los mercados centrales como el de Lima e Ica reciben madera de Ucayali y de la selva central. Los destinos del sur como Arequipa y Puno reciben madera de Madre de Dios. Cada uno de estos circuitos suplementa a diferentes industrias, como detalla el Cuadro 8.

\subsubsection{Los actores y redes de intermediación en el sector forestal}

El sector forestal en el Perú está formado por redes de actores encargados de suplir a los mercados urbanos. Entre estos se reconocen tres grupos principales: los pequeños productores rurales, los extractores encargados de la corta de madera y los intermediarios que realizan transacciones de comercio, además de fungir como compradores y transformadores. Todos estos actores, según el volumen con que trabajan, son distinguidos como muy pequeños, pequeños, medianos, grandes y muy grandes.

Los pequeños productores realizan pequeñas cortas, por lo general dentro de sus propiedades o comunidades. El comercio de madera representa uno de los ingresos forestales más importantes en la región amazónica para los productores rurales (Porro et al., 2014). En el caso de este estudio, el $75 \%$ de los pequeños productores se dedican principalmente a la agricultura y el $25 \%$ a la pesca y extracción de madera como actividades principales. Así mismo, la ocupación secundaria principal es la extracción de madera $(60 \%)$, la ganadería $(25 \%)$ y la pesca $(15 \%)^{9}$. El $85 \%$ de los entrevistados tienen algún tipo de posesión sobre su tierra, aunque solo el $20 \%$ manifestó poseer título de propiedad o certificado de posesión y el otro $65 \%$ simplemente afirmó vivir en el lugar por más de 5 años.

Los extractores generalmente se dedican como actividad principal a la extracción de madera. Entre estos, los más pequeños están considerados dentro de los actores ilegales debido a que sus prácticas de corta no siguen la normativa forestal. Los medianos trabajan con concesiones o también con permisos y autorizaciones y entrelazan prácticas informales. Estos actores utilizan maquinaria para el aprovechamiento de madera y mayor personal. Finalmente, los más grandes tienen áreas adjudicadas y trabajan de manera continua, cuentan con sus propios depósitos y sitios de transformación; también compran madera de otros pequeños extractores. En general, según los datos de este estudio, el 36\% de los extractores aprovechan madera desde hace 4 a 8 ańos; el $22 \%$, hace más de 15 años; el $21 \%$ tienen menos de tres años en la actividad; y el 20\%, de 9 a 15 ańos en la actividad. Los grandes extractores siempre se han dedicado

9 Datos recolectados en este estudio. 
Cuadro 8. Principales mercados de la madera según su transformación en el Perú

\begin{tabular}{|c|c|c|c|c|c|}
\hline Región & $\begin{array}{l}\text { Tipos de } \\
\text { bosques }\end{array}$ & $\begin{array}{l}\text { Materia } \\
\text { prima }\end{array}$ & Industria primaria & $\begin{array}{l}\text { Industria secundaria y } \\
\text { recuperación }^{\text {b }}\end{array}$ & $\begin{array}{l}\text { Mercados } \\
\text { principales }\end{array}$ \\
\hline \multirow[t]{2}{*}{$\begin{array}{l}\text { Amazonía } \\
\text { Norte } \\
\text { Amazonas, } \\
\text { San Marín }\end{array}$} & \multirow[t]{2}{*}{$\begin{array}{l}\text { Bosques } \\
\text { naturales }\end{array}$} & $\begin{array}{l}\text { Madera } \\
\text { rolliza } \\
\text { Madera } \\
\text { aserrada }\end{array}$ & $\begin{array}{l}\text { Aserradero local-nacional } \\
\text { Madera aserrada } \\
\text { dimensionada Secado, }\end{array}$ & $\begin{array}{l}\text { Industria del mueble } \\
\text { Cepillado y empaquetado } \\
\text { Industria de embarcaciones } \\
\text { Comercial, corta y larga angosta } \\
\text { Tablones, tablas y tablillas }\end{array}$ & $\begin{array}{l}\text { Trujillo } \\
\text { Chiclayo } \\
\text { Piura }\end{array}$ \\
\hline & & $\begin{array}{l}\text { Madera } \\
\text { aserrada }\end{array}$ & $\begin{array}{l}\text { Aserradero local-nacional } \\
\text { Secado, cepillado, } \\
\text { moldeado y embalado }\end{array}$ & $\begin{array}{l}\text { Industria de piso } \\
\text { Bloques de 6" } \\
\text { Frisas, decking o piso exterior, } \\
\text { machimbrados piso interior. }\end{array}$ & $\begin{array}{l}\text { Trujillo } \\
\text { Chiclayo } \\
\text { Piura } \\
\text { Mercado } \\
\text { internacional }\end{array}$ \\
\hline \multirow[t]{4}{*}{$\begin{array}{l}\text { Amazonía } \\
\text { Centro } \\
\text { Ucayali }\end{array}$} & \multirow[t]{3}{*}{$\begin{array}{l}\text { Bosques } \\
\text { naturales }\end{array}$} & $\begin{array}{l}\text { Madera } \\
\text { aserrada }\end{array}$ & $\begin{array}{l}\text { Aserradero local-nacional } \\
\text { Comercial, corta y larga } \\
\text { angosta }\end{array}$ & $\begin{array}{l}\text { Industria del mueble } \\
\text { Industria de embarcaciones } \\
\text { Industria de Carrocerías } \\
\text { Industria de materiales de } \\
\text { construcción. Puertas y } \\
\text { ventanas. } \\
\text { Escaleras }\end{array}$ & $\begin{array}{l}\text { Lima, Villa El } \\
\text { Salvador, San Juan } \\
\text { de Lurigancho, } \\
\text { San Martín de } \\
\text { Porres } \\
\text { Estados Unidos, } \\
\text { Italia, Panamá } \\
\end{array}$ \\
\hline & & $\begin{array}{l}\text { Madera } \\
\text { aserrada }\end{array}$ & Aserradero local-nacional & $\begin{array}{l}\text { Secado, cepillado, moldeado y } \\
\text { embalado } \\
\text { Bloques de 6" } \\
\text { Frisas, decking o pisos } \\
\text { exteriores, machihembrados o } \\
\text { pisos interiores }\end{array}$ & $\begin{array}{l}\text { China } \\
\text { Estados Unidos } \\
\text { México } \\
\text { República } \\
\text { Dominicana }\end{array}$ \\
\hline & & $\begin{array}{l}\text { Madera } \\
\text { rolliza }\end{array}$ & $\begin{array}{l}\text { Aserradero local-nacional } \\
\text { Industria de tableros y } \\
\text { enchapes (triplay) } \\
\text { Industria de durmientes } \\
\text { Industria de } \\
\text { contrachapados }\end{array}$ & $\begin{array}{l}\text { Industria de parihuela } \\
\text { Tablones, tablas y tablillas } \\
\text { Industria de paqueterías }\end{array}$ & $\begin{array}{l}\text { Lima, Arequipa } \\
\text { México, Estados } \\
\text { Unidos } \\
\text { Ecuador, Puerto } \\
\text { Rico } \\
\text { Venezuela }\end{array}$ \\
\hline & $\begin{array}{l}\text { Plantaciones } \\
\text { forestales y } \\
\text { regeneración }\end{array}$ & $\begin{array}{l}\text { Madera } \\
\text { rolliza }\end{array}$ & & $\begin{array}{l}\text { Industria de casas prefabricadas } \\
\text { (bolaina) } \\
\text { Industria de palos de helado }\end{array}$ & Lima \\
\hline \multirow[t]{4}{*}{$\begin{array}{l}\text { Amazonía } \\
\text { Sur } \\
\text { Madre de } \\
\text { Dios }\end{array}$} & \multirow[t]{3}{*}{$\begin{array}{l}\text { Bosques } \\
\text { naturales }\end{array}$} & $\begin{array}{l}\text { Madera } \\
\text { aserrada } \\
\text { Comercial, } \\
\text { corta } \\
\text { y larga } \\
\text { angosta }\end{array}$ & Aserradero local-nacional & $\begin{array}{l}\text { Industria del mueble } \\
\text { cepillado y empaquetado } \\
\text { Industria de embarcaciones } \\
\text { Comercial, corta y larga angosta } \\
\text { Tablones, tablas y tablillas }\end{array}$ & $\begin{array}{l}\text { Cusco, Juliaca, } \\
\text { Puno, Arequipa } \\
\text { Lima }\end{array}$ \\
\hline & & $\begin{array}{l}\text { Madera } \\
\text { aserrada } \\
\text { Bloques } \\
\text { de 6" }\end{array}$ & Aserradero local-nacional & $\begin{array}{l}\text { Industria de pisos } \\
\text { Secado, cepillado, moldeado y } \\
\text { embalado } \\
\text { Frisas, decking o pisos } \\
\text { exteriores, machihembrados o } \\
\text { pisos interiores }\end{array}$ & $\begin{array}{l}\text { China (Hong } \\
\text { Kong) }\end{array}$ \\
\hline & & $\begin{array}{l}\text { Madera } \\
\text { rolliza }\end{array}$ & Aserradero local-nacional & $\begin{array}{l}\text { Industria de paquetería } \\
\text { Listones }\end{array}$ & Varios de la costa \\
\hline & $\begin{array}{l}\text { Plantaciones } \\
\text { forestales y } \\
\text { regeneración }\end{array}$ & $\begin{array}{l}\text { Madera } \\
\text { rolliza }\end{array}$ & Aserradero local-nacional & Aserrado de tablillas & $\begin{array}{l}\text { Cusco, Juliaca, } \\
\text { Puno, Arequipa } \\
\text { Chile }\end{array}$ \\
\hline
\end{tabular}

Fuente: Elaboración propia con base en (Falconí, 2004; MINCETUR, 2005; WWF-Perú, 2005; WWF-Perú, 2005; Gironda, 2008; AIDER, 2012). Nota: a) Aserrío, reaserrío, desbobinado, corte plano con cuchilla fija, chipiado, torneado de madera en rollo, secado y preservación. b) Estructura de madera, cobertura de madera, carpintería de obra, pisos de madera, muebles, envases, empaques, embalajes, parihuelas, carrocerías, embarcaciones. 


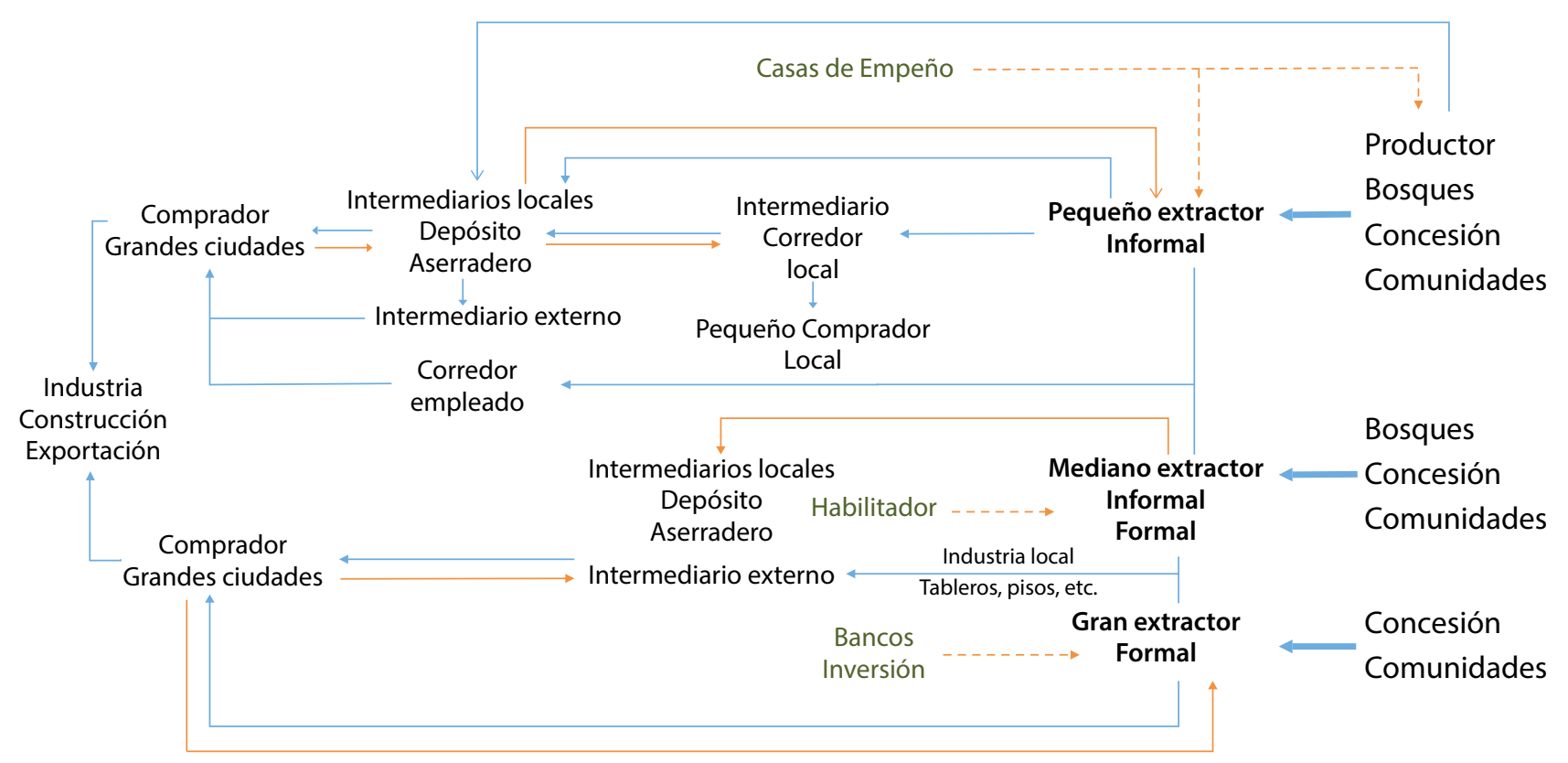

Figura 3. Intermediación de los actores

Nota: Las líneas azules representan entregas, y las rojas, pedidos.

a la madera; los medianos se dedicaban antes a la actividad de motoaserrío (37\%), como agricultor/ jornalero (33\%) u otros (29\%); y los pequeños se dedicaban a ser motoaserradores/jornaleros (56\%), agricultores $(36 \%)$ y otros $(8 \%)^{10}$.

Los intermediarios participan en diferentes redes de comercio dependiendo de su cercanía o lejanía a las ciudades principales. La naturaleza del intermediario en la Amazonía peruana es variada, debido a que estos actores están claramente vinculados con ciertos nichos de mercado específicos que responden a productos como tablillas, madera aserrada, etc. Los intermediarios se diferencian por el volumen promedio de madera que comercializan durante un año y el tipo de intermediación que realizan. Los pequeños intermediarios trabajan por lo general en los puertos ubicando madera de ciertas especies para compradores especializados ${ }^{11} \mathrm{o}$ empresas acopiadoras de madera. Los intermediarios medianos están ubicados en las urbes de las ciudades amazónicas y muchos trabajan para compradores de las ciudades principales como Lima o Piura. Los grandes acopiadores de madera son empresas ubicadas en los centros urbanos, que posteriormente distribuyen madera a diferentes sitios de Perú.

10 Datos recolectados para este estudio.

11 Estos compradores, por lo general, vienen de empresas o depósitos en Lima, Piura, Ica, Arequipa con pedidos de especies como bolaina, shihuahuaco y quinilla.
Otros intermediarios compran madera y la transforman, debido a que por lo general cuentan con su propia maquinaria de aserrío. En este grupo existen actores muy pequeños, que son los carpinteros. Los pequeños intermediarios son los que proveen con producción en cadena de piezas o a veces simplemente prestan los servicios de aserrío a terceros, se ubican cerca de las zonas de acopio de madera como puertos o carreteras de salida de la madera. Los medianos cuentan con mejor capacidad de planta y producen productos más elaborados, llegando en alguno de los casos a exportar. Los grandes, por lo general, manejan la corta y la transformación debido a que sus operaciones están verticalizadas. La Figura 3 resume el funcionamiento de las redes de producción y comercio de madera.

\subsection{Gobernanza e institucionalidad del control forestal en el Perú}

El control de los recursos forestales siempre ha estado a cargo del Estado a través del Ministerio de Agricultura y probablemente inicia en el año de 1963 con la creación del Servicio Forestal y de Caza $^{12}$, entidad encargada de regular la protección y el aprovechamiento racional de bosques y terrenos forestales. Por tratarse de un sector en desarrollo, las disposiciones normativas tuvieron un corto

12 Decreto Ley $\mathrm{N}^{\circ} 14552$. 
alcance; no obstante, se crearon los primeros catastros forestales para establecer la tenencia de bosque público y privado. Además, se estableció por primera vez el Fondo Forestal Nacional, compuesto por los cánones de exploración y arrendamiento de tierras forestales. Por tratarse de un sector en desarrollo, las disposiciones normativas tuvieron un corto alcance; no obstante, se crearon los primeros catastros forestales para establecer la tenencia de bosque público y privado. Además, se estableció por primera vez el Fondo Forestal Nacional, compuesto por los cánones de exploración y arrendamiento de tierras forestales (García, 2014).

Posteriormente, en 1975, la Ley Forestal y de Fauna Silvestre ${ }^{13}$ creó la Policía Forestal del Perú y el sistema unificado de Registro General Forestal y de Fauna Silvestre. En este último las industrias forestales debían proporcionar información sobre los volúmenes procesados y los contratistas sobre los estudios en las áreas contratadas (García, 2014).

En el año 2000 se modificó el sistema de contratos de $1000 \mathrm{ha}^{14}$ a concesiones forestales de hasta 50.000 ha. La Ley N ${ }^{\circ} 27308$ implementó a varios actores como corresponsables del manejo del bosque incluyendo a las fuerzas armadas y gobiernos regionales. Los gobiernos regionales recibieron en 2007 todas las competencias forestales (Galarza y Serna, 2005; García, 2014). En el año 2008 se creó el Organismo de Supervisión de los Recursos Forestales y de Fauna Silvestre (OSINFOR), como organismo independiente de control, y por entonces el Instituto Nacional de Recursos Naturales (INRENA) —que regía el manejo y supervisión del recurso forestal ${ }^{15}$ pasó a ser la Dirección Nacional Forestal y de Fauna Silvestre (DNFFS) ${ }^{16}$.

13 Decreto Ley $\mathrm{N}^{\circ} 21147$.

14 Previo a la promulgación de la Ley Forestal Nº 27308, para otorgar contratos de extracción forestal en superficies mayores de 1000 ha, se pedía al interesado presentar un estudio de factibilidad técnico-económica (en la reglamentación se interpretó como plan de manejo forestal), se preparaban términos de referencia. Las superficies mayores de 50.000 ha requieren un Decreto Supremo.

15 Decreto Supremo N ${ }^{\circ}$ 030-2008-AG. Fusionan el Instituto Nacional de Recursos Naturales (INRENA) al Ministerio de Agricultura - MINAG (11/12/08).

16 El Reglamento de Organización y Funciones del Ministerio de Agricultura (Decreto Supremo No 031-2008-AG) restableció la Dirección General Forestal y de Fauna Silvestre, esta vez, integrada por tres unidades orgánicas: la Dirección de Promoción Forestal y de Fauna Silvestre, la Dirección de Gestión Forestal y de Fauna Silvestre, y la Dirección de Información, Control Forestal y de Fauna Silvestre.
Después de los sucesos ocurridos el 5 de junio de 2009 en Bagua ${ }^{17}$, el Gobierno peruano inició un proceso participativo que contempló, entre otros aspectos, la revisión de la normatividad del sector forestal con miras a su actualización. Este proceso de revisión culminó en 2011 con la aprobación de la Ley $N^{\circ} 29763$, que cambió la DNFFS por el Servicio Forestal y de Fauna Silvestre (SERFOR) ${ }^{18}$. Este nuevo organismo se constituye como el ente rector del Sistema Nacional de Gestión Forestal y de Fauna Silvestre (SINAFOR), encargándose de dictar las normas y establecer los procedimientos relacionados a su ámbito. Además, coordina, con las oficinas descentralizadas de las regiones, los procesos administrativos forestales y su operación técnica y correcto funcionamiento.

Dentro del Plan Nacional Forestal y de Fauna Silvestre que menciona la Ley $\mathrm{N}^{\circ} 29763$ se desarrollan disposiciones en: (i) prevención y control de la deforestación; y (ii) prevención y lucha contra la tala ilegal y la captura, caza y comercio ilegal de fauna silvestre, entre otros aspectos, en concordancia con los lineamientos de la Política Nacional del Ambiente citados anteriormente. Asimismo, se articula con lo dispuesto en el Plan Nacional de Acción Ambiental (PLANAA) PERÚ 2011-2021, el cual establece, entre las metas prioritarias para el año 2021:

- Meta 4: Bosques y Cambio Climático.

"Reducción a cero de la tasa de deforestación en 54 millones de hectáreas de bosques primarios bajo diversas categorías de ordenamiento territorial contribuyendo, conjuntamente con otras iniciativas, a reducir el $47,5 \%$ de las emisiones de gases de efecto invernadero (GEI) en el país, generados por el cambio de uso de la tierra; así como a disminuir la vulnerabilidad frente al cambio climático".

- Meta 5: Diversidad Biológica. "Conservación y aprovechamiento sostenible de la diversidad de ecosistemas, especies y recursos genéticos del país; incrementando en $80 \%$ la superficie de producción orgánica; en $70 \%$ el valor de las

17 Para mayor detalle, revisar el Informe Final "Ajumaish Junikchamu Ati, Para que nunca más vuelva a suceder", elaborado por la Comisión Especial para investigar y analizar los sucesos de Bagua creada mediante Resolución Ministerial $\mathrm{N}^{\circ}$ 0664-2009-AG. Se puede acceder al referido informe en: http://servindi.org/pdf/Informe_final_de_la_commision_ especial_sucesos_de_agua.pdf.

18 Ley N ${ }^{\circ}$ 29763. Ley Forestal y de Fauna Silvestre. Artículo 13. Se crea el Servicio Nacional Forestal y de Fauna Silvestre (SERFOR) (22/07/11). 

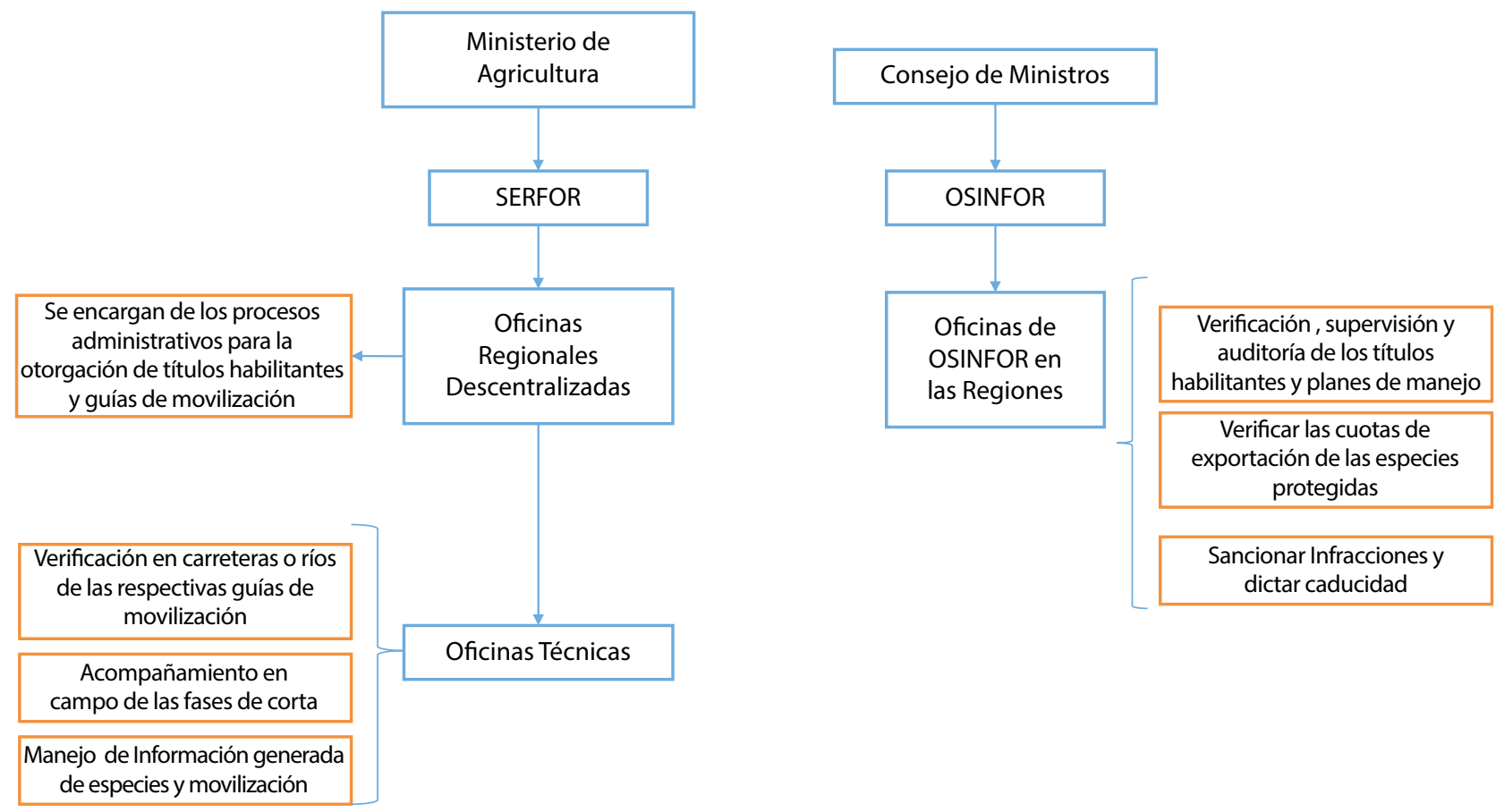

Figura 4. Sistema de control forestal implementado en el Perú con la nueva Ley Forestal y de Fauna Silvestre

Fuente: Ministerio de Agricultura (2014) y Osinfor (2014).

exportaciones de productos del biocomercio, en $50 \%$ las inversiones en econegocios y en 100\% el valor de los bienes y/o servicios de Áreas Naturales Protegidas (ANP)".

Con respecto al transporte, transformación, comercialización y exportación de productos forestales y de fauna silvestre, la Ley establece un conjunto de obligaciones y prohibiciones que es necesario resaltar debido a que no se incorporaban completamente en las anteriores leyes forestales:

- En el caso de plantas de transformación de productos forestales (aserraderos) y de fauna silvestre, sus titulares deben verificar el origen de los productos que transforman.

- Está prohibida la exportación con fines comerciales o industriales de madera en troza, excepto cuando estos productos provengan de plantaciones debidamente autorizadas ${ }^{19}$.

- Sumado a lo anterior, la Ley introduce el concepto de "cadena de custodia de los productos forestales y de fauna silvestre", la cual implica que la autoridad forestal desarrolle mecanismos transparentes para verificar el origen legal de las especies en todas las etapas de su producción (extracción, transporte,

19 Cfr. Artículos 122 de la Ley N²9763. Ley Forestal y de Fauna Silvestre. transformación y exportación), con el fin de rastrear de manera confiable los especímenes forestales y de fauna silvestre. Asimismo, se establece el deber de la autoridad forestal de promover la certificación forestal que permita registrar y controlar debidamente todas las etapas del proceso productivo, lo cual permitirá demostrar la legalidad del producto exportado ${ }^{20}$.

En este marco, en el año 2012 se publicó el documento de trabajo "Nueva Ley Forestal y de Fauna Silvestre: por un aprovechamiento sostenible, equitativo y competitivo de los bosques en el Perú" como herramienta para el proceso de elaboración del reglamento de la aprobada Ley $\mathrm{N}^{\circ}$ 29763. Los principales problemas vislumbrados por el documento de trabajo en torno al control forestal se detallan a continuación:

- Deforestación de casi la décima parte de los bosques del Perú: siendo la principal causa el cambio de uso de tierras provocado principalmente por la inmigración de personas que proceden a talar y quemar de bosques con el fin de lograr el reconocimiento de la tenencia de tierras o para desarrollar actividades agropecuarias en dichas tierras.

20 Cfr. Artículos 127 de la Ley N ${ }^{\circ}$ 29763. Ley Forestal y de Fauna Silvestre. 
- Predominio de las prácticas de corrupción en el sector forestal. El limitado control en los bosques, en el transporte y en las plantas de transformación, todo lo cual favoreció el mantenimiento de un mercado ilegal de madera.

- Débil institucionalidad pública por carecer de disposiciones para que los pequeńos extractores puedan acceder legalmente a los bosques, normas para cortar las cadenas de financiamiento informal de la actividad legal e ilegal, incrementar la transparencia, simplificar los procedimientos administrativos, entre otros.

- Procesos de reconocimiento de tierras de comunidades inconclusos, lo que genera inseguridad jurídica, desalienta la inversión, promueve la invasión y el tráfico de dichas tierras.

- Actividades perjudiciales en áreas boscosas, tales como contrabando, producción y tráfico ilícito de drogas, financiamiento de remanentes subversivos, cobro de cupos, tenencia ilegal de armas, trata de personas, trabajo forzado y semiesclavitud, atentados contra la integridad de personas, contra la propiedad pública y privada, entre otras.

Los problemas del sector se esperan corregir con la implementación de la actual Ley (Anexo 3). El nuevo esquema de control está dirigido por dos organismos independientes entre sí: SERFOR y OSINFOR. El flujo de trabajo de estas instituciones se detalla en la Figura 4. La supervisión y fiscalización de los títulos habilitantes otorgados por la autoridad regional para el aprovechamiento de los recursos forestales estará a cargo del OSINFOR y las cuestiones administrativas las verificará el SERFOR (García, 2014).

Para asumir los costos que genera el esquema de supervisión y administración forestal, el acceso al bosque para su aprovechamiento comercial está sujeto al pago del Derecho de Aprovechamiento Forestal (DAF) que representa el precio de la madera al estado natural. El DAF es un monto en dólares americanos por hectárea concesionada o, a su vez, también representa el pago en pie por la madera aprovechada en otras modalidades de corta (Galarza y La Serna, 2005; FAO, 2012). Según datos de FAO (2012), desde el año 2007 se han recaudado aproximadamente USD 15 millones por motivos de este pago, provenientes el 49,8\% de las concesiones forestales, $49,7 \%$ de permisos y autorizaciones y $1,4 \%$ de concesiones no maderables.

\section{Cuadro 9. Pagos por aprovechamiento según tipo de especies}

\begin{tabular}{|c|c|c|c|}
\hline Categoría & Tipo & $\begin{array}{l}\text { Pago en } \\
\text { nuevos } \\
\text { soles } / \mathrm{m}^{3}\end{array}$ & Especies (ej.) \\
\hline A & $\begin{array}{l}\text { Altamente } \\
\text { valiosas }\end{array}$ & 50 & Caoba, cedro \\
\hline B & Valiosas & 30 & $\begin{array}{l}\text { Tornillo, } \\
\text { shihuahuco }\end{array}$ \\
\hline C & Intermedias & 4 & $\begin{array}{l}\text { Moenas, } \\
\text { catahua }\end{array}$ \\
\hline D & Potenciales & 2 & Varias \\
\hline$E$ & $\begin{array}{l}\text { Otras } \\
\text { especies }\end{array}$ & 1 & Varias \\
\hline
\end{tabular}

Fuente: (FAO, 2012).

Actualmente las extracciones maderables pagan un DAF en función del área total concesionada, en promedio USD 1,5/ha (mín. $=0,65$; máx. $=1,80)^{21}$, además de los costos de legalización que oscilan entre USD 3500 y USD 5300 por POA $^{22}$. Existen incentivos en forma de descuentos del DAF para concesiones certificadas y verticalizadas en su producción ${ }^{23}$. Las otras modalidades de corta como permisos y autorizaciones pagan el valor en pie por metro cúbico en nuevos soles, según las especies extraídas como lo indica el Cuadro 9.

Otras recaudaciones se realizan por conceptos administrativos relacionados a la aprobación de planes generales de manejo forestal (PGMF), aprobaciones de planes operativos anuales (POA), permisos y autorizaciones y la emisión de guías forestales. Según FAO (2012), los departamentos de la región amazónica han recaudado un promedio de USD 80.000 dólares anuales por estos rubros. Sin embargo, las oficinas de Ucayali, Loreto y Madre de Dios necesitarían para cumplir con sus planes operativos en promedio

21 Información proporcionada por el actual SERFOR disponible en http://serfor.gob.pe/portal/pdf/proced_admin/ rde.015-22014-serfor-de-poi.pdf.

22 Información proporcionada por Ingenieros Forestales que realizan procesos de legalización en las zonas de estudio.

23 Artículo 31.3 El Ministerio de Agricultura establecerá una reducción porcentual en el pago de los derechos de aprovechamiento para aquellas concesiones que involucren proyectos integrales de extracción, transformación en plantas de procesamiento ubicadas en el ámbito regional de la concesión y comercialización de productos forestales con valor agregado, en las condiciones que establece el reglamento. 
Cuadro 10. Distribución del cobro por derecho de aprovechamiento forestal

\begin{tabular}{lccc}
\hline $\begin{array}{l}\text { Modalidad de } \\
\text { aprovechamiento }\end{array}$ & $\begin{array}{c}\text { Gobierno } \\
\text { regional }\end{array}$ & $\begin{array}{c}\text { Autoridad } \\
\text { forestal }\end{array}$ & $\begin{array}{c}\text { Autoridad } \\
\text { de fontrol }\end{array}$ \\
\hline $\begin{array}{l}\text { Concesiones } \\
\text { forestales }\end{array}$ & $60 \%$ & $30 \%$ & $10 \%$ \\
$\begin{array}{l}\text { Otros derechos de } \\
\text { aprovechamiento }\end{array}$ & $60 \%$ & $40 \%$ & \\
$\begin{array}{l}\text { Multas e } \\
\text { infracciones }\end{array}$ & & $25 \%$ & $75 \%$ \\
\hline
\end{tabular}

Nota: Las infracciones son sancionadas con multa no menor de un décimo $(0,1)$ ni mayor de seiscientas $(600)$ Unidades Impositivas Tributarias vigentes a la fecha. El pago que deberá cumplirse dependerá de la gravedad de la infracción, sin perjuicio de las acciones civiles y/o penales a que hubiere lugar.

USD 8 millones/año ${ }^{24}$ para cubrir los costos de personal y costos operativos para realizar las inspecciones oculares a las zonas donde se encuentran las cortas aprobadas, y que muchas veces no se realizan conforme a los calendarios establecidos por falta de presupuesto. Este rubro significaría el $80 \%$ del presupuesto total del SERFOR, que es de USD 30 millones/año y que actualmente es destinado, en su mayoría, a cubrir costos relacionados a mejorar las oficinas técnicas descentralizadas. ${ }^{25}$ Por su parte, OSINFOR cuenta con un presupuesto de USD 7,1 millones/año, que es distribuido entre las operaciones de las oficinas descentralizadas ${ }^{26}$.

Con la transferencia de funciones a los Gobiernos Regionales en el año 2007 y su paulatina ejecución hasta la fecha, se espera que el DAF pueda ayudar a mejorar los ingresos y las capacidades para desarrollar acciones de vigilancia y control. La distribución se detalla en el Cuadro 10.

\subsection{La inversión pública y privada}

Con la implementación de la Ley del Fomento de las Inversiones en la década de 1990 y la firma de tratados de Libre Comercio en la década de 2000, los capitales externos entraron y establecieron su posicionamiento en el sector forestal que

24 Entrevista realizada con representantes de las oficinas regionales de Ucayali y Loreto.

25 Entrevista con representante de SERFOR en Lima, Perú.

26 Información disponible en http://www.osinfor.gob.pe/ portal/data/recurso/archivos/rp_065-2013-osinfor_pia2014.pdf. previamente se desarrollaba exclusivamente con dinero nacional. Los capitales que llegaron fueron principalmente de origen chino y estadounidense. En 2012, la CEPAL afirmó que el Perú fue el primer receptor de inversiones extranjeras en la región, pero el rubro forestal recibió únicamente el 0,01\%. Según Hajek et al. (2012), en los últimos años no ha existido inversión significativa en el sector, reduciéndose prácticamente a tres nuevos emprendimientos de aserrío. Según algunos autores nacionales, esta inversión no se ha enfocado en mejorar los procesos de corta y transformación de la madera, sino más bien en generar más planes de corta que se realizan sin mejoras (Southgate y Elgegren, 1995; Proinversión, 2005; Torres, 2012).

La poca inversión pública que existe sobre el sector forestal está dirigida a los empresarios, debido a que las políticas del Estado buscan dar impulso al sector exportador. Estas políticas también han pasado por varios altibajos debido a que, en el afán de impulsar el libre mercado, el acceso al bosque hasta el año 2000 era poco regulado (Burneo, 2011). La ley marco para la inversión privada promueve un Estado liberal que evite barreras al comercio. En esta misma línea, el Decreto Legislativo № 662 favorece la inversión extranjera suscribiendo contratos en los cuales se entregan incentivos desde USD 0,5 a 2 millones provenientes del sistema financiero nacional a empresas que deseen invertir en el Perú, además de contar con libertad absoluta para mover divisas y competir en igualdad de condiciones con empresas peruanas (Hajek et al., 2012).

El Gobierno peruano ha declarado de interés prioritario la inversión y el desarrollo del sector agrario a través de la promulgación de la Ley 27360 , estableciendo incentivos que son aplicables a las personas naturales o jurídicas que desarrollen cultivos y/o actividades pecuarias, incluyendo plantaciones forestales, pero ninguna actividad de manejo de bosques (ICEX, 2013). Sin embargo, la llamada Ley de la Amazonía aplica incentivos al sector, exonerando del 5\% al 10\% del impuesto a la renta a quienes se dedican a actividades de extracción y transformación forestal ${ }^{27}$, además de

27 Artículo 31.5: El Estado implementa mecanismos de estímulos complementarios a los beneficios otorgados en la Ley No 27037, Ley de Promoción de la Inversión en la Amazonía, a las actividades de aprovechamiento y transformación de recursos naturales y de fauna silvestre que generen mayor valor agregado y promuevan la conservación de la diversidad biológica del bosque. 


\section{Cuadro 11. Tasas de interés de los principales financistas de operaciones forestales}

\begin{tabular}{|c|c|c|}
\hline $\begin{array}{l}\text { Entidad } \\
\text { financiera }\end{array}$ & Intereses & Tipos de usuarios \\
\hline Bancos & $18-25 \%$ anual & Exportadores \\
\hline Agrobanco & $18-23 \%$ anual & $\begin{array}{l}\text { Concesionarios } \\
\text { grandes }\end{array}$ \\
\hline Cajas & $22 \%$ anual & Actores medianos \\
\hline $\begin{array}{l}\text { Casas de } \\
\text { empeño }\end{array}$ & $20 \%$ mensual & Actores pequeños \\
\hline Cambistas & $1 \%$ diario & $\begin{array}{l}\text { Actores pequeños y } \\
\text { medianos }\end{array}$ \\
\hline
\end{tabular}

Fuente: Elaboración propia con base en entrevistas conducidas entre julio de 2013 y marzo de 2014.

la exoneración total del Impuesto Gravado al Valor (IGV), siempre y cuando los servicios se presten en la región amazónica y otras acciones conocidas como el drawback, que es un régimen aduanero que permite obtener la restitución total o parcial de los derechos arancelarios (Ministerio de Relaciones Exteriores, 2013).

A pesar de estos incentivos, el financiamiento es todavía uno de los principales cuellos de botella para la inversión en el sector forestal, en especial para medianos y pequeños operadores. Un porcentaje importante de empresas y concesionarios, al no contar con los recursos financieros en forma oportuna y competitiva, no cumplen sus programas de producción, cierran sus balances con pérdida y/o sin utilidades, generando un calificativo de sector de alto riesgo, lo cual reduce aún más sus posibilidades de acceso al financiamiento (Hajek et al., 2012). A pesar de que existen servicios formales de créditos, las garantías y requisitos son poco accesibles para la mayoría de los actores. En este sentido, los servicios financieros en el sector forestal también se nutren de créditos informales ${ }^{28} \mathrm{y}$ en algunos casos de iniciativas privadas para pequeñas y medianas empresas (Thomson, 2014). El Cuadro 11 muestra las principales entidades de crédito para las operaciones de aprovechamiento de madera.

En el nuevo marco legal de la Ley $\mathrm{N}^{\circ} 29763$, dentro de la Política Nacional Forestal y de Fauna Silvestre (PNFFS) se plantea la revalorización del aporte del sector forestal al PIB nacional. ${ }^{29}$ Sin embargo, como sustento de estas políticas, se ha elaborado el Plan de Inversión Forestal (PIF), que es un fondo de incentivos relacionados a REDD+y con un enfoque más centrado en la conservación ${ }^{30}$ (Hajek et al., 2012; Ministerio de Relaciones Exteriores, 2013). Freitas (2012) y Urban y Ullilén (2011) reconocen que este enfoque exclusivo de conservación en el Perú dificulta que el sector forestal sea impulsado adecuadamente. A pesar de estas afirmaciones, el Gobierno ha manifestado que durante 2015 destinará mayores aportes al sector forestal de la región amazónica, en especial el de las plantaciones forestales (Ministerio de Agricultura, 2014).
28 Con base en entrevistas realizadas a las casas prendarias en Pucallpa durante diciembre 2013 y marzo 2014.

29 Tomado de El Comercio, 12 de Agosto de 2013. La exportación forestal alcanzaría los USD 5000 millones en diez años. Disponible en http://elcomercio.pe/economia/ peru/exportacion-forestal-llegar-us5-mil-mlls-diez-anosnoticia-1616716.

30 El PIF es financiado por el Banco Interamericano de Desarrollo en alianza con el Banco Mundial. A través del Ministerio de Finanzas busca financiar proyectos en temas relacionados a la conservación. 


\section{Centros de producción y circuitos de la madera}

Los centros más importantes de producción, comercialización y transporte de madera en el Perú están concentrados en las tres ciudades amazónicas más grandes: Pucallpa en Ucayali, Iquitos en Loreto y Puerto Maldonado en Madre de Dios. Estas ciudades se encuentran localizadas en las rutas fluviales y terrestres más importantes, por lo que constituyen los principales circuitos de comercialización de la madera proveniente de los bosques nativos de la Amazonía peruana. La importancia económica del sector para las economías locales es significativa (Cuadro 12). Es importante indicar que estos datos podrían estar subestimados debido a la falta de cuantificación de la contribución de las actividades madereras informales.

El proceso de descentralización implementado en el año 2009 permitió que los departamentos de Loreto, Ucayali y Madre de Dios adoptaran algunas competencias forestales, las que se han ido implementando progresivamente. La descentralización hizo posible que sean las regiones las que se encarguen de vigilar y controlar la extracción maderera en las concesiones forestales otorgadas en la jurisdicción del departamento. Las funciones principales de la autoridad forestal en cada departamento son: aprobar los POA de los concesionarios, otorgar las resoluciones directorales con las autorizaciones correspondientes de las zafras anuales de extracción forestal, y emitir la guía de transporte forestal (GTF) de la madera extraída. Cada oficina de la autoridad forestal regional cuenta con puestos de control o subsedes en donde se realizan las funciones de verificación ${ }^{31}$.

Los proveedores y compradores en el Perú deben tener un Registro Único del Contribuyente (RUC) que proporciona la SUNAT. El número RUC

31 Información obtenida en entrevistas con las Autoridades Regionales. es necesario para emitir las guías de transporte forestal de madera proveniente de todas las modalidades de cortas. Una guía forestal incluye un listado de las trozas previamente marcadas y codificadas. Los concesionarios tienen la facultad de generar GTF siempre que transporten trozas y no madera aserrada. Para las otras modalidades de corta — como permisos y autorizaciones-, son las oficinas regionales las que deben aprobar y entregar las GTF con base en los POA y restar el volumen movilizado del volumen aprobado. El procedimiento de descargo de volúmenes de un POA puede llevar hasta ocho años debido a que los ejecutores no cortan toda la madera aprobada en el plan en el mismo año. Por ejemplo, existen volúmenes remanentes de zafras de 2004 que siguen siendo movilizados en el 2012. Los descargos de volúmenes son registrados por las oficinas técnicas en una computadora que tiene información como el número de guía, origen, titular, tipo de madera, carga en metros cúbicos, destino de la madera y observaciones generales. La centralización de estos datos en una sola base ocurre en ciertos sitios mejor que en otros debido a la disponibilidad de internet.

Las GTF son elaboradas a mano y tienen una duración variable según la distancia de destino, además de servir como un comprobante del peso de la carga, que es regulado por la Superintendencia de Transporte Terrestre de Personas, Carga y Mercancía (SUTRAN). Las guías forestales constituyen en sí un filtro en el control de la madera transportada. Las guías son permutadas entre quienes emiten y quienes reciben madera, cuando esta pasa de trozas a madera aserrada. Por ejemplo, las guías de concesiones son emitidas por el concesionario, quienes movilizan las trozas hasta un puerto donde, por lo general, la madera es aserrada. Para transportar la madera aserrada, las GTF originales deben ser sustituidas por otras en las oficinas técnicas antes de una revisión ocular de los técnicos. Cuando la madera 
Cuadro 12. Valor Agregado Bruto (VAB) en 2012

\begin{tabular}{lccc}
\hline & $\begin{array}{c}\text { VAB } \\
\text { USD }\end{array}$ & $\begin{array}{c}\text { Crecimiento 2003- } \\
\text { 2012 (en \%) }\end{array}$ & $\begin{array}{c}\text { Participación respecto al total } \\
\text { del VAB nacional (en \%) }\end{array}$ \\
\hline Total VAB por departamento & & & \\
\hline Loreto & 1437,3 & 4,6 & 2,1 \\
Ucayali & 781,5 & 5,5 & 1,2 \\
Madre de Dios & 245,8 & 4,4 & 0,4 \\
\hline Agricultura, caza y silvicultura & & & $\mathrm{Nd}$ \\
\hline Loreto & 193,4 & 2,1 & $\mathrm{Nd}$ \\
Ucayali & 137 & 4,4 & $\mathrm{Nd}$ \\
\hline Madre de Dios & 22,8 & 0,3 & \\
\hline
\end{tabular}

Fuente: Con base en Banco Central del Perú, 2012.

Nota: a) EI VAB se define como el Producto Bruto Interno (PBI) menos los impuestos a la producción y derechos a la importación.

no proviene de concesiones, son las oficinas técnicas las que emiten las GTF tanto para madera en troza como transformada.

La madera sale de las zonas de aprovechamiento de Loreto, Ucayali y Madre de Dios primero a través de los ríos y después por las carreteras. En el caso de Madre de Dios, el transporte se realiza con más frecuencia por la nueva vía transoceánica que vincula este departamento con Brasil. Esta carretera permitió la comunicación de importantes áreas de extracción de madera, reduciendo sustancialmente los costos de transporte y las etapas de carga y descarga de madera cuando el uso de embarcaciones era inevitable, sobre todo para cruzar el río Madre de Dios. Según los datos disponibles en las GTF, el 1\% de la madera transformada en los departamentos en estudio fue movilizada a través de los ríos y el $99 \%$ se movilizó por carreteras. Los trayectos fluviales y terrestres de la producción y la comercialización de madera hacia los destinos principales se pueden ver en el Mapa 3.

\subsection{Ucayali: Producción y circuitos de comercialización}

Ucayali es el mayor centro maderero de la Amazonía peruana debido a su localización geográfica en el centro de la selva peruana y por contar con la carretera Federico Basadre, principal eje de vinculación del departamento con la ciudad de Lima. La mayor cantidad de madera se origina en concesiones y permisos en comunidades indígenas (Figura 5). Los circuitos de transporte de madera son terrestres y fluviales, por lo cual se puede apreciar un vasto comercio en diferentes lugares, aunque la mayoría de los intermediarios y transformadores están en su capital Pucallpa, lugar donde se concentran las principales industrias de transformación primaria y secundaria.

La madera proveniente de Ucayali tiene circuitos relativamente largos de comercialización y llega a mercados finales distantes (Mapa 4), siendo la ciudad de Lima el principal centro de destino de la madera. En esta ciudad se concentran las zonas industriales más grandes de procesamiento de madera como Villa María, Villa Salvador y otros en Lurín, así como la demanda más significativa de madera y derivados debido al constante crecimiento de la población urbana y periurbana. Las especies que se comercializan se detallan más adelante.

En el caso de Ucayali, diez empresas aglomeran el $24 \%$ de la producción total y los principales compradores concentran el $22 \%$ de la demanda que, en comparación con las otras zonas, tiene una distribución más amplia del comercio de madera a nivel nacional. Esto se debe a que existe una industria prominente en la ciudad de Pucallpa que permite a varios actores entrar en el negocio de la madera, aunque, según los datos de la SUNAT, estas empresas, que son por lo general pequeñas, operan en promedio tres ańos antes de desaparecer. El Cuadro 13 detalla la producción de madera entre 2009 y 2012 y presenta la acumulación de madera por proveedores y compradores. 


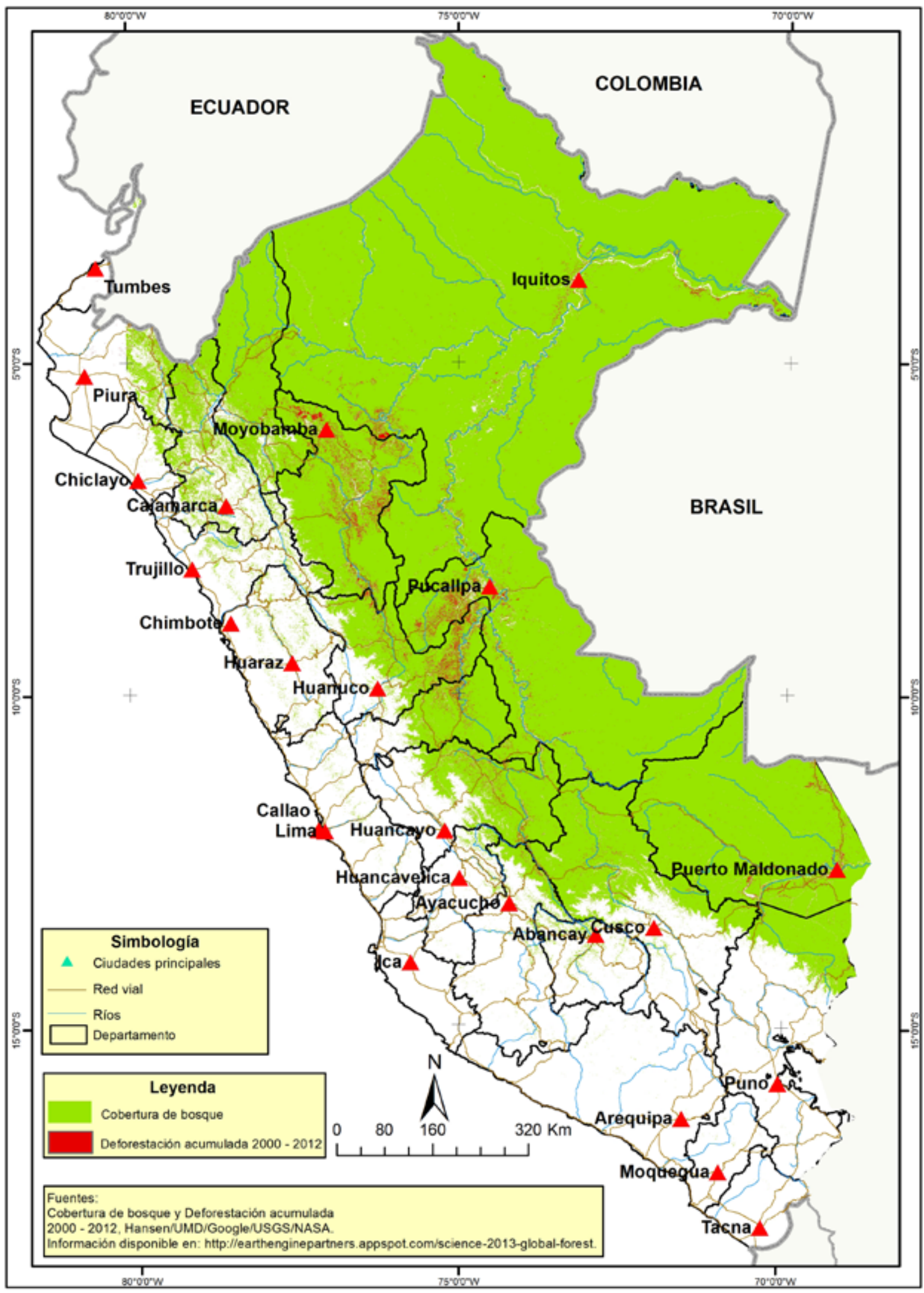

Mapa 3. Circuitos de comercialización de la madera provenientes de Loreto, Ucayali y Madre de Dios Fuente: Elaboración propia de los autores con base en información de las guías de transporte forestal. 


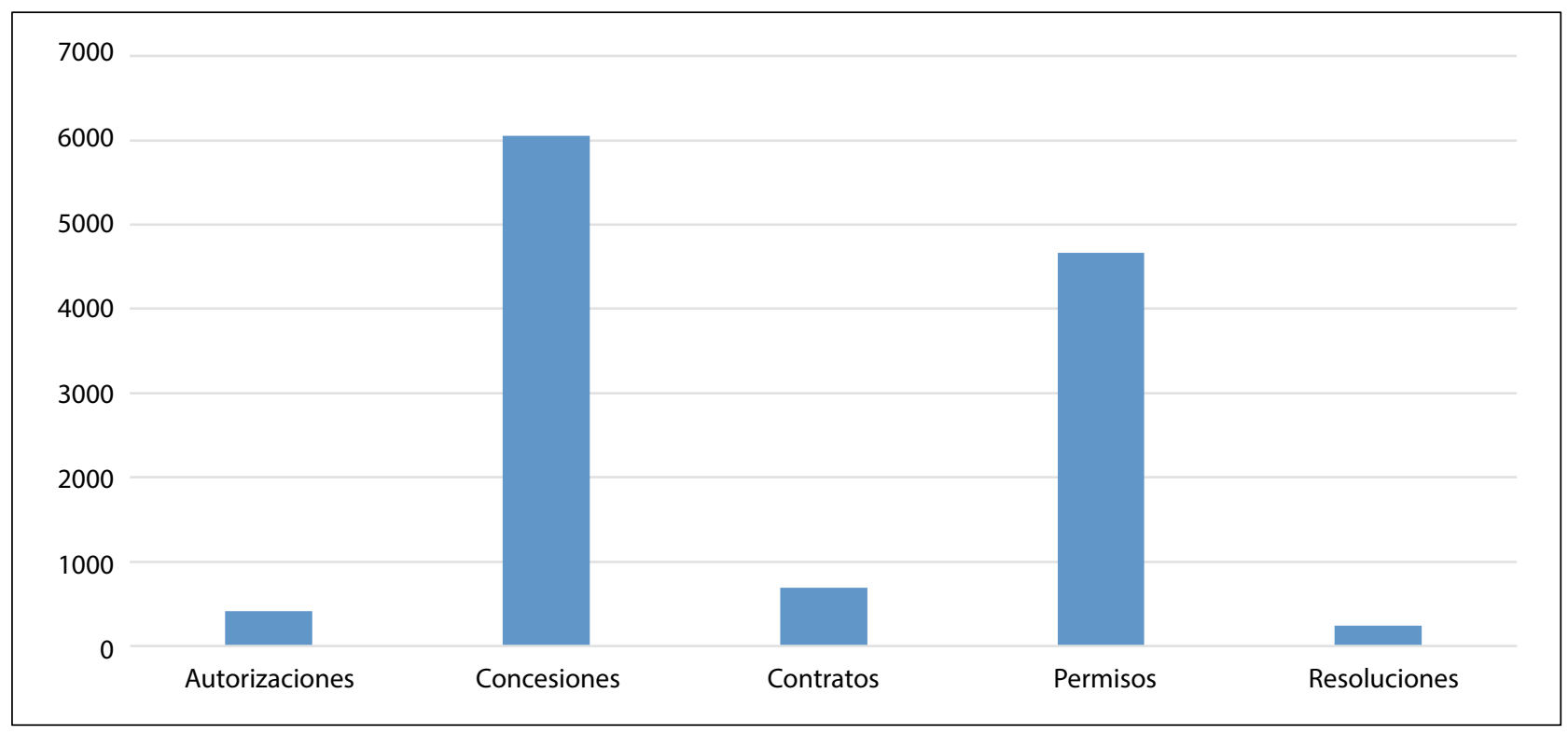

Figura 5. Madera autorizada por zafra y movilizada entre 2003 y 2012 según título habilitante a través de las oficinas técnicas de Ucayali (miles de $\mathrm{m}^{3}$ )

Fuente: Elaboración propia con los datos de la Oficina de la Dirección Forestal y de Fauna Silvestre Ucayali.

Nota: a) Los datos representan los volúmenes que generaron una guía de movilización entre 2003 y 2013; sin embargo, no significa que en años futuros no existan volúmenes de zafras anteriores que pueden agregarse al volumen presentado. Se analizaron 65.533 GTF. b) Los datos que se detallan de las GTF representan: i) las autorizaciones de productos no maderables; ii) los permisos forestales en tierras de propiedad privada, bosques secundarios y de plantaciones forestales y en bosques locales; iii) los contratos se refieren a la adjudicación de 1000 hectáreas que responden al manejo previo a las concesiones; iv) las concesiones forestales son las áreas asignadas por el Estado para el aprovechamiento forestal a largo plazo; y v) las resoluciones, que representan madera devuelta o decomisada. Un mayor detalle se puede encontrar en la página electrónica oficial de OSINFOR (www.osinfor.gob.pe).

Cuadro 13. Producción por proveedores y compradores en Ucayali de 2009 a 2012

\begin{tabular}{|c|c|c|c|c|c|c|}
\hline \multirow[t]{2}{*}{ Tamañoa } & \multicolumn{5}{|c|}{ Volúmenes en miles de $\mathrm{m}^{3}$} & \multirow{2}{*}{$\begin{array}{c}\text { Participación } \\
\text { respecto al } \\
\text { total (en \%) }\end{array}$} \\
\hline & 2009 & 2010 & 2011 & 2012 & $\begin{array}{c}\text { Promedio } \\
2009-12\end{array}$ & \\
\hline \multicolumn{7}{|l|}{ Proveedores } \\
\hline No definido ${ }^{b}$ & 115,4 & 127,8 & 74,3 & 126,3 & 111,0 & 17,7 \\
\hline $\begin{array}{l}\text { Total diez empresas con mayores } \\
\text { volúmenes movilizados }\end{array}$ & 269,3 & 289,4 & 242,2 & 252,7 & 263,4 & 42,1 \\
\hline Otros (179 proveedores) & 362,3 & 385,8 & 377,8 & 324,6 & 362,6 & 57,9 \\
\hline Total $^{c}$ & 631,6 & 675,2 & 620,1 & 577,3 & 626,1 & 100,0 \\
\hline \multicolumn{7}{|l|}{ Compradores } \\
\hline $\begin{array}{l}\text { Total veinte empresas con mayores } \\
\text { volúmenes movilizados }\end{array}$ & 162,3 & 187,6 & 112,3 & 85,7 & 137,0 & 21,9 \\
\hline Otros (2066 compradores) & 469,3 & 487,6 & 507,7 & 491,5 & 489,0 & 78,1 \\
\hline Total $^{c}$ & 631,6 & 675,2 & 620,1 & 577,3 & 626,1 & 100,0 \\
\hline
\end{tabular}

Fuente: Elaboración propia con base en los datos proporcionados por la Dirección Regional Forestal y de Fauna Silvestre de Ucayali y los datos parciales proporcionados por la Dirección General Forestal y de Fauna Silvestre del Ministerio de Agricultura a través de la base de datos institucional de las GTF en versión pdf y la base disponible de la SUNAT para reconocer el estatus de empresa.

Nota: a) Se definen como proveedores/compradores muy grandes cuando transportan más de $3501 \mathrm{~m}^{3}$; los grandes, de $2001 \mathrm{~m}^{3}$ a $3500 \mathrm{~m}^{3}$; los medianos, de $1001 \mathrm{~m}^{3}$ a $2000 \mathrm{~m}^{3}$; los pequeños, de $501 \mathrm{~m}^{3}$ a $1000 \mathrm{~m}^{3}$; y los muy pequeños, de $1 \mathrm{~m}^{3}$ a $500 \mathrm{~m}^{3}$. b) $\mathrm{No}$ registra ningún nombre o RUC. c) No incluye productos maderables como carbón o leña. 


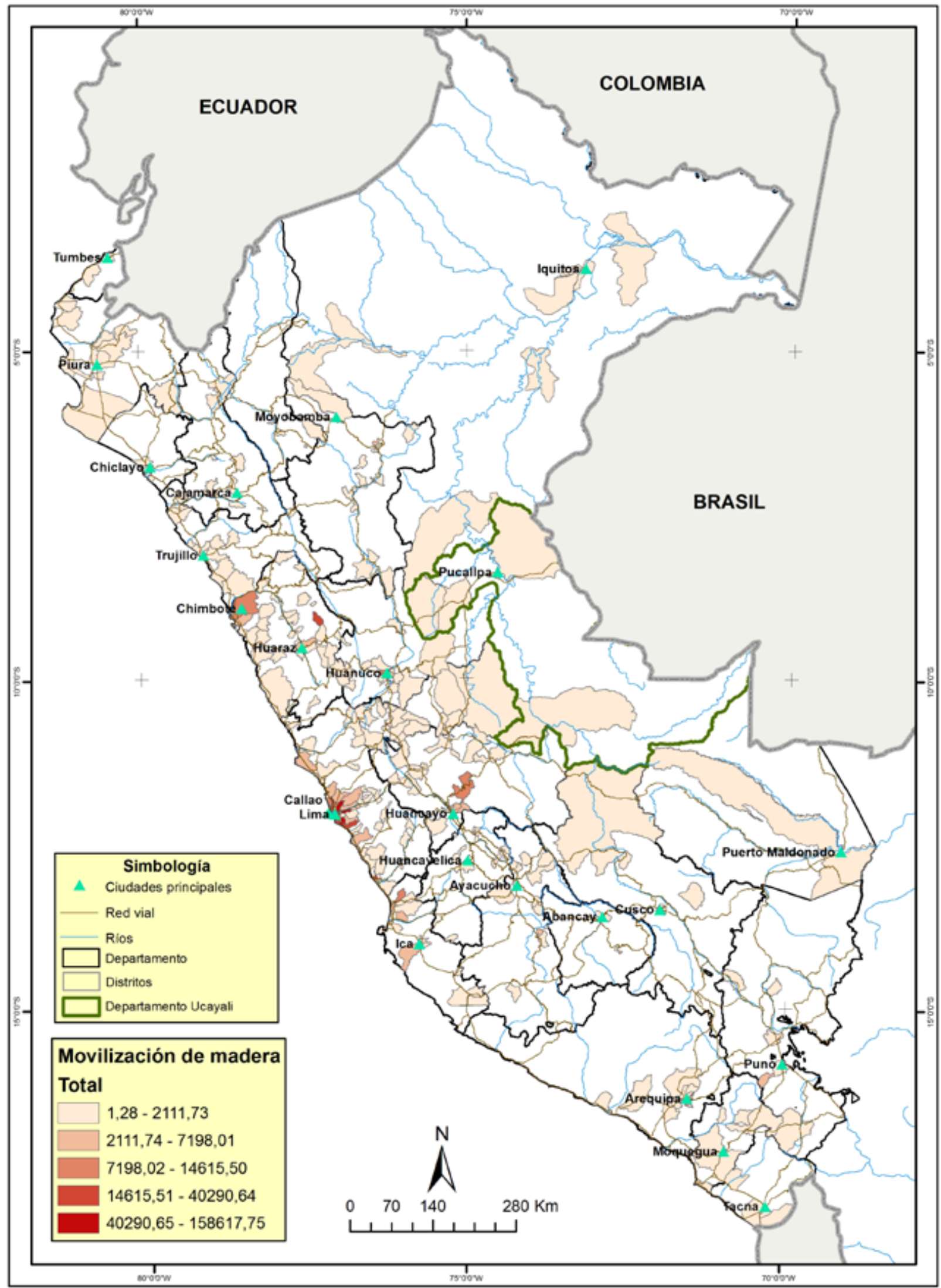

Mapa 4. Principales destinos a nivel de distrito de la madera producida en Ucayali

Fuente: Elaboración propia de los autores con base en información de las guías de transporte forestal. 
Cuadro 14. Movilización de madera del departamento de Ucayali según el tamaño de proveedores y compradores entre 2009 y 2012 (en miles de $\mathrm{m}^{3}$ )

\begin{tabular}{|c|c|c|c|c|c|c|c|}
\hline \multirow[t]{2}{*}{ Tamañoa } & \multicolumn{5}{|c|}{ Volúmenes en miles de $\mathrm{m}^{3}$} & \multirow{2}{*}{$\begin{array}{l}\text { Participación } \\
\text { respecto al } \\
\text { total (en \%) }\end{array}$} & \multirow[t]{2}{*}{ Número } \\
\hline & 2009 & 2010 & 2011 & 2012 & $\begin{array}{c}\text { Promedio } \\
2009-12\end{array}$ & & \\
\hline \multicolumn{8}{|l|}{ Proveedor } \\
\hline Muy grande & 356,6 & 409,7 & 335,0 & 353,3 & 363,7 & 58,1 & 71 \\
\hline Grande & 196,5 & 143,4 & 159,9 & 117,5 & 154,3 & 24,6 & 88 \\
\hline Medianos & 63,6 & 112,9 & 112,4 & 93,1 & 95,5 & 15,3 & 139 \\
\hline Pequeños & 9,8 & 4,6 & 6,2 & 6,6 & 6,8 & 1,1 & 38 \\
\hline Muy pequeños & 5,2 & 4,7 & 6,7 & 6,9 & 5,9 & 0,9 & 158 \\
\hline Total $^{\mathrm{b}}$ & 631,7 & 675,3 & 620,1 & 577,4 & 626,1 & 100,0 & 494 \\
\hline \multicolumn{8}{|l|}{ Comprador } \\
\hline Muy grande & 93,7 & 127,5 & 39,8 & 42,2 & 75,8 & 12,1 & 19 \\
\hline Grandes & 54,9 & 41,8 & 43,7 & 19,9 & 40,1 & 6,4 & 24 \\
\hline Mediano & 159,9 & 183,4 & 191,1 & 168,6 & 175,8 & 28,1 & 399 \\
\hline Pequeño & 114,8 & 122,8 & 125,1 & 134,8 & 124,4 & 19,9 & 718 \\
\hline Muy pequeño & 208,4 & 199,9 & 220,5 & 211,9 & 210,2 & 33,6 & 7.187 \\
\hline Total $^{b}$ & 631,7 & 675,3 & 620,1 & 577,4 & 626,1 & 100,0 & 8347 \\
\hline
\end{tabular}

Fuente: Elaboración propia con base en los datos proporcionados por la Dirección Regional Forestal y de Fauna Silvestre de Ucayali y los datos parciales proporcionados por la Dirección General Forestal y de Fauna Silvestre del Ministerio de Agricultura a través de la base de datos institucional de las GTF en versión pdf y la base disponible de la SUNAT para reconocer el estatus de empresa.

Nota: a) Se definen como proveedores/compradores muy grandes cuando transportan más de $3501 \mathrm{~m}^{3}$; los grandes, de $2001 \mathrm{~m}^{3}$ a $3500 \mathrm{~m}^{3}$ los medianos, de $1001 \mathrm{~m}^{3}$ a $2000 \mathrm{~m}^{3}$; los pequeños, de $501 \mathrm{~m}^{3}$ a $1000 \mathrm{~m}^{3}$; y los muy pequeños de $1 \mathrm{~m}^{3}$ a $500 \mathrm{~m}^{3}$. b) $\mathrm{No}$ incluye productos maderables como carbón o leña.

Cuadro 15. Tipo de origen y destino entre 2009 y 2012 en Ucayali según guía de transporte forestal (en porcentajes)

\begin{tabular}{lccc}
\hline Compradores Proveedores & $\begin{array}{c}\text { Depósitos y establecimientos } \\
\text { comerciales }\end{array}$ & $\begin{array}{c}\text { Industria de } \\
\text { transformación primaria }\end{array}$ & $\begin{array}{c}\text { Total } \\
\text { general }\end{array}$ \\
\hline Industria de transformación primariaa $^{\mathrm{a}}$ & 80,4 & 0,4 & 80,8 \\
Depósitos y establecimientos comerciales & 17,5 & 0,0 & 17,5 \\
No definido & 1,5 & 0,0 & 1,5 \\
Área de aprovechamiento & 0,1 & 0,0 & 0,1 \\
Total general $^{\mathrm{b}}$ & $\mathbf{9 9 , 6}$ & $\mathbf{0 , 4}$ & $\mathbf{1 0 0 , 0}$ \\
\hline
\end{tabular}

Fuente: Elaboración propia con base en los datos proporcionados por la Dirección Regional Forestal y de Fauna Silvestre de Ucayali y los datos parciales proporcionados por la Dirección General Forestal y de Fauna Silvestre del Ministerio de Agricultura. Nota: a) La industria de transformación primaria se refiere a los aserraderos, reaserraderos, tableros y parihuelas. b) No incluye productos maderables como carbón o leña. 
El Cuadro 14 presenta información más detallada por tipo de proveedor y comprador según cinco categorías definidas de acuerdo al volumen anual movilizado. Estos datos sugieren que los proveedores de madera muy grandes (que transportan más de $3501 \mathrm{~m}^{3}$ ) concentran el $58 \%$ de la producción total de madera, mientras que los compradores muy pequeños (menos de $500 \mathrm{~m}^{3}$ / año) representan un $38 \%$ del total.

En Ucayali, el 99,6\% de las GTF son canjeadas en la industria de transformación primaria o aserraderos y reaserraderos, por lo cual el principal tipo de origen son los depósitos y establecimientos comerciales (Cuadro 15). Los segundos receptores de madera son los depósitos y establecimientos comerciales que luego revenden sus productos fuera de la región. Según el análisis, el 99,7\% de la madera movilizada con GTF sale de Ucayali con diferentes destinos y únicamente el $0,3 \%$ se queda en Ucayali, es decir, $76,6 \mathrm{~m}^{3}$, lo cual sugiere que la madera comercializada en el mercado local no cuenta con documentación.

\subsubsection{Circuito Bajo Ucayali-Pucallpa-Lima- Callao}

El circuito de bajo Ucayali comparte territorio entre los departamento de Ucayali y Loreto. El área analizada comprende los distritos de Requena, Contamana, Iparia, Callería, Nueva Requena y Yarinacocha. De estos lugares proviene madera especialmente cuartoneada y aprovechada por pequeńos extractores informales y pequeños productores. El puerto de Yarinacocha recibe madera constantemente durante el año con una mayor concentración entre los meses de diciembre y marzo. La madera es comercializada en pequeñas cantidades que son posteriormente negociadas a través de intermediarios-corredores que tienen pedidos de transformadores de pisos en búsqueda de shihuahuaco y también de intermediarios-externos que llegan en búsqueda de bolaina. Es difícil establecer el origen formal de esta madera debido a que se comercializa con GTF de diferentes sitios. El Cuadro 16 muestra los datos oficiales de producción de los distritos de este corredor. En esta región, como parte de este estudio, se analizaron las subcuencas del río Ucayali: Iparia, Utiquinia y Callería, principales orígenes de la madera que se comercializa en el Puerto de Yarinacocha.

Los pequeños extractores realizan la extracción utilizando motosierras y cubotas ${ }^{32}$ que facilitan el transporte de la madera cuartoneada hasta las orillas de los ríos para ser posteriormente transportadas por quebradas y luego por el río Ucayali. Los pequeños extractores buscan sitios alejados de bosques, en los cuales puedan realizar la corta de madera dura, en especial shihuahuaco, quinilla, capirona y tornillo. En el caso de que exista la posibilidad, compran árboles en pie en parcelas de productores. Los extractores de maderas Cuadro 16. Producción de madera en el bajo Ucayali y los distritos de Requena, Contamana, Iparia,
Callería, Nueva Requena y Yarinacocha

\begin{tabular}{|c|c|c|c|c|c|c|}
\hline & \multicolumn{5}{|c|}{ Volúmenes en miles de $\mathrm{m}^{3}$} & \multirow{2}{*}{$\begin{array}{l}\text { Participación } \\
\text { respecto al total } \\
\text { (en \%) }\end{array}$} \\
\hline & 2009 & 2010 & 2011 & 2012 & $\begin{array}{c}\text { Promedio } \\
2009-12\end{array}$ & \\
\hline Permisos & 15,5 & 10,8 & 5,6 & 1,8 & 8,4 & 48,2 \\
\hline Concesiones & 8,1 & 5,0 & 4,5 & 0,2 & 4,4 & 25,5 \\
\hline Autorizaciones & 0,5 & 4,3 & 2,0 & 4,9 & 2,9 & 16,8 \\
\hline Contratos & 3,8 & 2,3 & 0,4 & 0,0 & 1,6 & 9,3 \\
\hline Total general ${ }^{a}$ & 27,9 & 22,3 & 12,4 & 6,9 & 17,4 & 100,0 \\
\hline
\end{tabular}

Fuente: Elaboración propia con base en los datos proporcionados por la Oficina Técnica de Pucallpa y datos parciales proporcionados por la Dirección General Forestal y de Fauna Silvestre del Ministerio de Agricultura.

Nota: a) Sin datos de carbón y leña de monte o chacra.

32 La cubota es un cuatrimotor adaptado con una pequeña plataforma, y que tiene aproximadamente $1,5 \mathrm{~m}$ de ancho y unos $4 \mathrm{~m}$ de largo. Su tamańo facilita su movilización entre los árboles en el bosque y es utilizada para cargar madera cuartoneada. 
duras, en especial shihuahuaco, transportan la madera en cuartones que luego se transforman en tablillas que se venden directamente a compradores en Pucallpa o a través de intermediarios-corredores a terceros. Esta especie es utilizada para la fabricación de frisas o decking en general para la exportación (principalmente a China). En Pucallpa existe un clúster de empresas de origen asiático que se dedica a la comercialización de estas especies, el cual es un mercado local importante.

Existen otros extractores en este corredor que se dedican exclusivamente a la extracción de bolaina, por lo cual buscan rodales de esta especie para su extracción o la compran de las regeneraciones en predios de pequeños productores. Sin embargo, según nuestras entrevistas, esta especie se extrae mayoritariamente de la subcuenca del río Pisque. Los extractores medianos de esta zona se dedican a la extracción de madera blanda y dura. Durante este estudio se entrevistaron a extractores medianos que trabajan únicamente con especies blandas como catahua (Hura Crepitans) para la industria de las parihuelas. Estos extractores tienen relaciones directas con la industria primaria Otros se dedican a la extracción de capirona y quinilla, que se encuentran particularmente en la subcuenca del río Iparía. Esta extracción coincide con las principales especies movilizadas según los datos oficiales presentados en el Cuadro 17.
Los datos oficiales muestran una similitud con las especies informadas dentro de las entrevistas realizadas (Figura 6). El cedro está considerado entre las más importantes especies comercializadas en este circuito; no obstante, durante el trabajo de campo no se pudo apreciar la comercialización del cedro por extractores o productores pequeños en el puerto de Yarinacocha. Los datos de cedro aparecen en el puerto del distrito Manantay, conocido como "la papelera", y en Pucallpa, en el puerto conocido como "La Marina", en donde desembarcan los medianos y grandes extractores. Siendo que la madera extraída por los pequeños extractores posee guía de transporte forestal, los datos suministrados dan un claro panorama de las especies que se movilizan en este corredor aunque podrían no tener el origen exacto que estas señalan.

De acuerdo a la información obtenida en las entrevistas realizadas a los actores de este circuito, el punto final de entrega de madera por los pequeños productores y extractores es Yarinacocha o Pucallpa cuando la producción es vendida a intermediarios locales ligados a aserraderos y reaserraderos. Posteriormente, la madera es comercializada a otros intermediarios o es transportada hasta depósitos propios en Pucallpa y Lima (68\%), para la venta directa a compradores finales, especialmente los que se dedican a la fabricación de pisos en Pucallpa (18\%), habilitadores $(8 \%)$ y directamente a

\section{Cuadro 17. Volúmenes de las principales especies aprovechadas en la zona del Bajo Ucayali}

\begin{tabular}{|c|c|c|c|c|c|c|}
\hline \multirow[t]{2}{*}{ Especies } & \multicolumn{5}{|c|}{ Volúmenes en miles de $\mathrm{m}^{3}$} & \multirow{2}{*}{$\begin{array}{l}\text { Participación } \\
\text { respecto al } \\
\text { total (en \%) }\end{array}$} \\
\hline & 2009 & 2010 & 2011 & 2012 & $\begin{array}{c}\text { Promedio } \\
2009-12\end{array}$ & \\
\hline Calycophyllum spruceanum (Capirona) & 6,3 & 2,8 & 1,3 & 4 & 3,6 & 15,5 \\
\hline Cariniana domesticata (Cachimbo) & 4,6 & 4,1 & 1,9 & 0,3 & 2,7 & 11,7 \\
\hline Cedrela odorata (Cedro) & 2,2 & 2,7 & 1 & - & 2,0 & 8,5 \\
\hline Cedrelinga catenaeformis (Tornillo) & 1,6 & 1,9 & 1,3 & 0,3 & 1,3 & 5,5 \\
\hline Chorisia integrifolia (Lupuna) & 3,4 & 1,3 & 0 & - & 1,6 & 6,7 \\
\hline Copaifera reticulata (Copaiba) & 6,3 & 2,8 & 1,3 & 4 & 3,6 & 15,5 \\
\hline Coumarouna odorata (Shihuahuaco) & 4,6 & 4,1 & 1,9 & 0,3 & 2,7 & 11,7 \\
\hline Guazuma crinita (Bolaina blanca) & 2,2 & 2,7 & 1 & - & 2,0 & 8,5 \\
\hline Hura crepitans (Catahua) & 1,6 & 1,9 & 1,3 & 0,3 & 1,3 & 5,5 \\
\hline Virola sp. (Cumala) & 3,4 & 1,3 & 0 & - & 1,6 & 6,7 \\
\hline Otras (78 especies) & 4,6 & 4,1 & 1,9 & 0,3 & 2,7 & 11,7 \\
\hline Total general $^{\mathrm{a}}$ & 40,8 & 29,7 & 12,9 & 9,5 & 23,2 & 100,0 \\
\hline
\end{tabular}

Fuente: Elaboración propia con base en los datos proporcionados por la Oficina Técnica de Pucallpa entre 2009 y 2012 y datos parciales proporcionados por la Dirección General Forestal y de Fauna Silvestre del Ministerio de Agricultura.

Nota: a) Sin datos de carbón y leña de monte o chacra. 


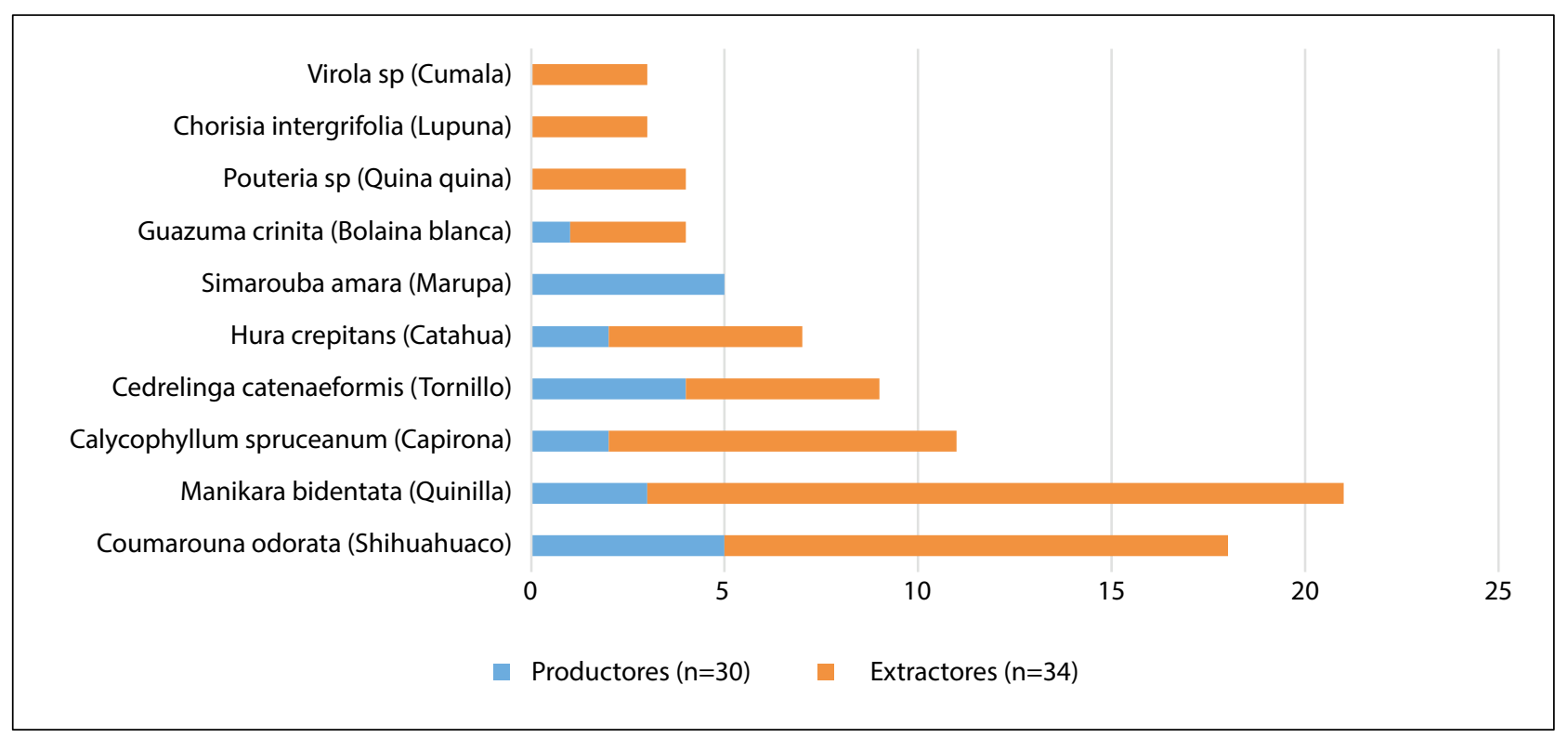

Figura 6. Diez principales especies extraída por pequeños productores y pequeños extractores en el bajo Ucayali en las zonas de Iparía, Utiquinía y Callería

Fuente: Elaboración propia con datos recolectados entre julio de 2013 y abril de 2014.

Cuadro 18. Principales destinos de la madera proveniente de Bajo Ucayali

\begin{tabular}{|c|c|c|c|c|c|c|}
\hline \multirow[t]{2}{*}{ Destinos } & \multicolumn{5}{|c|}{ Volúmenes en miles de $\mathrm{m}^{3}$} & \multirow{2}{*}{$\begin{array}{l}\text { Participación } \\
\text { respecto al total } \\
\text { (en \%) }\end{array}$} \\
\hline & 2009 & 2010 & 2011 & 2012 & $\begin{array}{c}\text { Promedio } \\
2009-12\end{array}$ & \\
\hline Lima & 22,4 & 17,2 & 8,8 & 5,9 & 13,6 & 83,9 \\
\hline Callao & 1,9 & 1,7 & 1,0 & 0,1 & 1,2 & 7,2 \\
\hline La libertad & 0,6 & 0,8 & 0,5 & 0,1 & 0,5 & 3,0 \\
\hline Ica & 0,8 & 0,6 & 0,2 & 0,4 & 0,5 & 3,0 \\
\hline Junín & 0,4 & 0,6 & 0,5 & 0,0 & 0,4 & 2,4 \\
\hline Total generala & 26,0 & 21,0 & 11,1 & 6,5 & 16,2 & 100,0 \\
\hline
\end{tabular}

Fuente: Elaboración propia con base en los datos proporcionados por la Oficina Técnica de Pucallpa y datos parciales proporcionados por la Dirección General Forestal y de Fauna Silvestre del Ministerio de Agricultura.

Nota: a) Sin datos de carbón y leña de monte o chacra.

intermediarios externos (8\%). Por otro lado, los datos oficiales coinciden en señalar que el principal destino de la madera de este corredor es la ciudad de Lima (Cuadro 18).

\subsubsection{Circuito Alto Ucayali-Pucallpa-Lima}

Este circuito se provee de la madera producida en las provincias de Atalaya y Purús, además del distrito de Masisea dentro de la provincia de Coronel Portillo. En estas provincias destacan las subcuencas del Abujao, Tamaya y Pisquis. Es importante recalcar que para la provincia de Purús los datos oficiales proporcionados muestran títulos habilitantes en un $0,19 \%$, lo que significa que los datos aquí presentados solo reflejan $339 \mathrm{~m}^{3}$ entre 2009 y $2012^{33}$, por lo cual en el Cuadro 19 casi el $100 \%$ de los datos reportan a la provincia de Atalaya y el distrito de Masisea. La madera de alta densidad o dura que proviene del alto Ucayali es transportada en embarcaciones "chatas", la madera blanda o semiblanda es traída en balsas por arrastre de la corriente del río hasta Pucallpa,

33 De los datos proporcionados para nuestro análisis. 
Cuadro 19. Producción de madera en las provincias de Atalaya y el distrito de Masisea

\begin{tabular}{|c|c|c|c|c|c|c|}
\hline \multirow[t]{2}{*}{ Modalidad } & \multicolumn{5}{|c|}{ Volúmenes en miles de $\mathrm{m}^{3}$} & \multirow{2}{*}{$\begin{array}{l}\text { Participación } \\
\text { respecto al total } \\
\text { (en \%) }\end{array}$} \\
\hline & 2009 & 2010 & 2011 & 2012 & $\begin{array}{c}\text { Promedio } \\
2009-12\end{array}$ & \\
\hline Permisos & 0,1 & 5,0 & 5,3 & 10,3 & 5,2 & 12,2 \\
\hline Concesiones & 5,2 & 26,8 & 23,6 & 19,9 & 18,9 & 44,5 \\
\hline Autorizaciones & 0,7 & 3,3 & 1,9 & 0,8 & 1,7 & 3,9 \\
\hline Contratos & 5,5 & 24,8 & 21,7 & 14,9 & 16,7 & 39,4 \\
\hline Total generala & 11,5 & 59,9 & 52,5 & 45,9 & 42,5 & 100,0 \\
\hline
\end{tabular}

Fuente: Elaboración propia con base en los datos proporcionados por la Oficina Técnica de Pucallpa y Atalaya, así como los datos parciales proporcionados por la Dirección General Forestal y de Fauna Silvestre del Ministerio de Agricultura.

Nota: a) Sin datos de carbón y leña de monte o chacra.

Cuadro 20. Volúmenes de las principales especies aprovechadas en la zona del Bajo Ucayali

\begin{tabular}{|c|c|c|c|c|c|c|}
\hline \multirow[t]{2}{*}{ Especies } & \multicolumn{5}{|c|}{ Volúmenes en miles de $\mathrm{m}^{3}$} & \multirow{2}{*}{$\begin{array}{l}\text { Participación } \\
\text { respecto al total } \\
\text { (en \%) }\end{array}$} \\
\hline & 2009 & 2010 & 2011 & 2012 & $\begin{array}{l}\text { Promedio } \\
2009-12\end{array}$ & \\
\hline $\begin{array}{l}\text { Calycophyllum spruceanum } \\
\text { (Capirona) }\end{array}$ & 1,6 & 8,1 & 8,1 & 5,7 & 5,9 & 13,9 \\
\hline Guazuma crinita (Bolaina blanca) & 1,0 & 5,0 & 3,4 & 7,9 & 4,3 & 10,1 \\
\hline $\begin{array}{l}\text { Coumarouna odorata } \\
\text { (Shihuahuaco) }\end{array}$ & 1,5 & 5,5 & 4,3 & 3,7 & 3,8 & 8,9 \\
\hline Chorisia integrifolia (Lupuna) & 2,1 & 8,4 & 3,1 & 0,5 & 3,5 & 8,2 \\
\hline Cedrelinga catenaeformis (Tornillo) & 1,9 & 3,0 & 4,5 & 4,6 & 3,5 & 8,2 \\
\hline Virola sp. (Cumala) & 0,7 & 2,9 & 3,9 & 4,8 & 3,1 & 7,3 \\
\hline Copaifera reticulata (Copaiba) & 0,4 & 2,2 & 3,9 & 2,9 & 2,4 & 5,6 \\
\hline $\begin{array}{l}\text { Aspidosperma macrocarpon } \\
\text { (Pumaquiro) }\end{array}$ & 0,0 & 4,2 & 3,8 & 0,1 & 2,0 & 4,7 \\
\hline Cariniana domesticata (Cachimbo) & 0,5 & 1,1 & 2,9 & 2,6 & 1,8 & 4,2 \\
\hline Cedrela odorata (Cedro) & 0,0 & 2,2 & 1,8 & 1,6 & 1,4 & 3,3 \\
\hline Otras (93 especies) & 1,6 & 17,3 & 12,7 & 11,3 & 10,7 & 25,2 \\
\hline Total general ${ }^{\mathrm{a}}$ & 11,5 & 59,9 & 52,5 & 45,9 & 42,5 & 100,0 \\
\hline
\end{tabular}

Fuente: Elaboración propia con base en los datos proporcionados por la Oficina Técnica de Pucallpa y Atalaya, así como los datos parciales proporcionados por la Dirección General Forestal y de Fauna Silvestre del Ministerio de Agricultura.

Nota: a) Sin datos de carbón y leña de monte o chacra.

principalmente a los puertos de Manantay "La papelera" y de Pucallpa "La Marina". Es esta facilidad de ir a favor de la corriente lo que para muchos pequeños productores es una ventaja al no tener que pagar el transporte de su madera.

Las principales especies comercializadas en el corredor de Alto Ucayali, se indican en el Cuadro 20. En esta zona existe una cantidad considerable de bolaina, en especial en el distrito de Masisea donde pequeños productores dejan crecer esta especie pionera en sus parcelas y realizan raleos para mejorar el crecimiento de los árboles que serán posteriormente comercializados de manera individual, con extractores o intermediarios. A pesar de que bolaina es una especie pionera, necesita de guías de transporte forestal para ser movilizada. En este sentido, durante el período en estudio (de 2009 a 2012), el $90 \%$ de las guías de transporte forestal otorgadas para esta especie provinieron de autorizaciones y permisos; sin embargo, es poco probable garantizar el origen real 


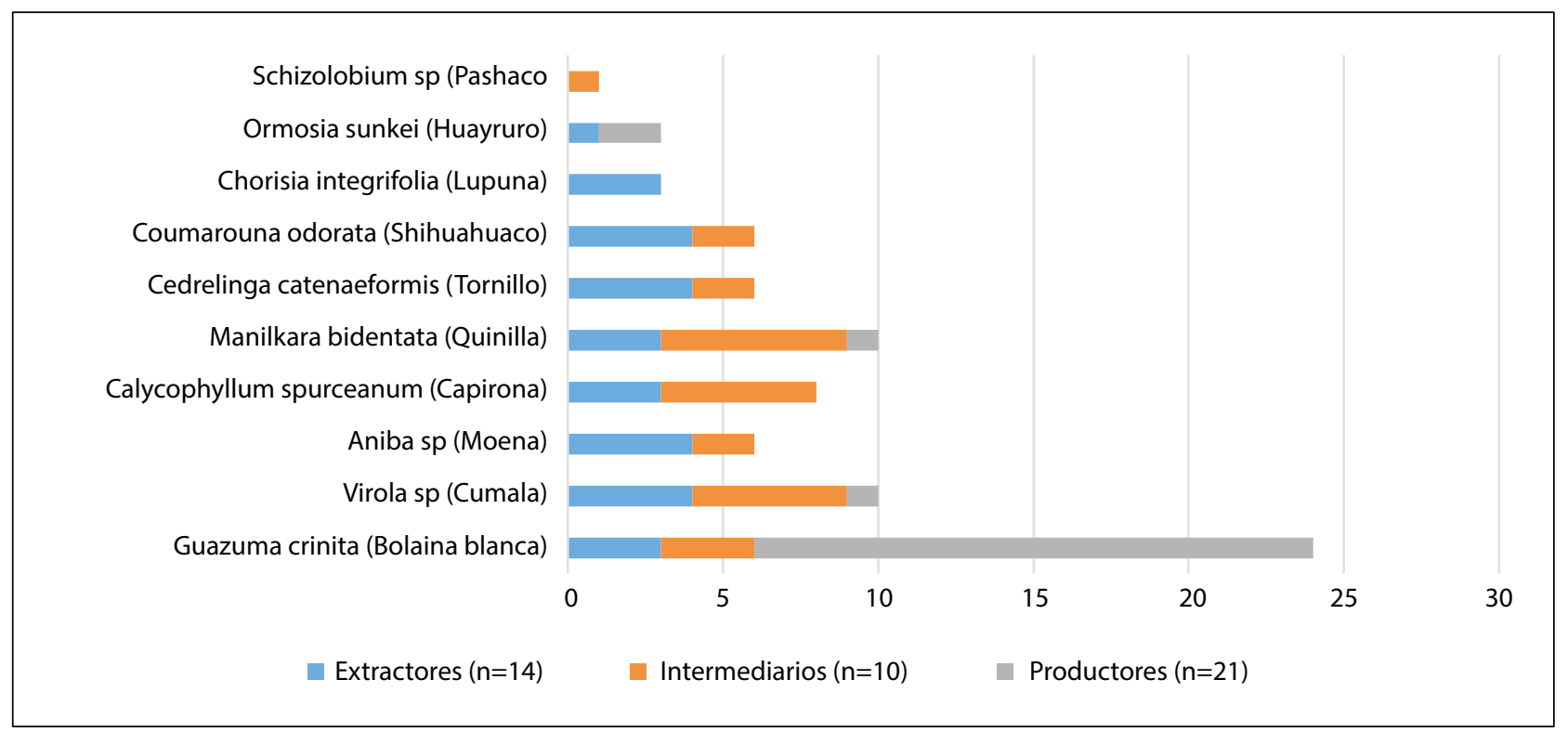

Figura 7. Frecuencia de las diez principales especies comercializadas por extractores, productores e intermediarios en la zona del Alto Ucayali

Nota: "Bolaina" puede referirse a otras especies blancas y blandas que son clasificadas como Guazuma sp.

Cuadro 21. Principales destinos de la madera proveniente del Alto Ucayali

\begin{tabular}{|c|c|c|c|c|c|c|}
\hline & \multicolumn{5}{|c|}{ Volúmenes en miles de $\mathrm{m}^{3}$} & \multirow{2}{*}{$\begin{array}{l}\text { Participación en } \\
\text { el total (en \%) }\end{array}$} \\
\hline & 2009 & 2010 & 2011 & 2012 & $\begin{array}{c}\text { Promedio } \\
2009-12\end{array}$ & \\
\hline Lima & 9,0 & 48,3 & 39,9 & 33,1 & 32,6 & 76,7 \\
\hline Callao & 1,1 & 5,1 & 4,5 & 4,5 & 3,8 & 9,0 \\
\hline La libertad & 0,1 & 1,3 & 1,8 & 1,0 & 1,1 & 2,5 \\
\hline Ica & 0,4 & 0,9 & 1,2 & 1,4 & 1,0 & 2,3 \\
\hline Junín & 0,3 & 0,9 & 1,1 & 1,2 & 0,9 & 2,1 \\
\hline Otros & 0,7 & 3,5 & 4,0 & 4,8 & 3,3 & 7,7 \\
\hline Total generala & 11,5 & 59,9 & 52,5 & 45,9 & 42,5 & 100,0 \\
\hline
\end{tabular}

Fuente: Elaboración propia con base en los datos proporcionados por la Oficina Técnica de Pucallpa y Atalaya, así como los datos parciales proporcionados por la Dirección General Forestal y de Fauna Silvestre del Ministerio de Agricultura.

Nota: a) Sin datos de carbón y leña de monte o chacra.

\section{Recuadro 1. El caso de la comunidad Puerto Alegre del distrito de Masisea, Ucayali}

La comunidad nativa de Puerto Alegre fue visitada durante la fase de campo de esta investigación. Los comuneros han trabajado con empresas anteriormente en la extracción de madera en la modalidad 80-20. Las ganancias generadas por la venta de madera entre los años de 2007 y 2012 han sido en promedio 10.000 nuevos soles/año o aproximadamente USD 3500. La comunidad utilizó este dinero para comprar un bote, motores y arreglos de sitios comunitarios. Asimismo, estas interacciones entre empresarios y comuneros han generado la compra de cubotas y motosierras que son utilizadas actualmente por los comuneros para generar ingresos familiares. Entre el trabajo con los empresarios y la extracción individual los comuneros entrevistados $(n=20)$ prefieren el trabajo individual, que les da mejores ganancias $y$, además, la potestad de decidir en qué reinvierten el dinero. 
de esta especie debido a que su densidad en estas modalidades no es tan alta. Además, la bolaina es utilizada como flotador de otras especies semiduras, en este caso no es contabilizada dentro de las guías de transporte forestal.

La bolaina, según los datos de las entrevistas realizadas, es la principal especie comercializada por pequeños productores y extractores (Figura 7). Los datos indican que el $100 \%$ de los entrevistados transportaron esta madera sin documentos hasta Pucallpa, donde otros intermediarios fueron los encargados de legalizar esta especie para su transporte final.

El principal destino de la madera de este corredor llega a Lima, a los depósitos y la industria de transformación primaria. En este corredor se ubican las transacciones de las empresas proveedoras y receptoras muy grandes que fueron analizadas al inicio de este capítulo. El 13\% de la madera movilizada a Lima es bolaina ${ }^{34}$ (Cuadro 21).

\subsubsection{Circuito de la Carretera Federico Basadre: Puerto Inca-Padre Abad- Lima}

En este circuito se moviliza madera proveniente de las cortas realizadas a lo largo de la Carretera Federico Basadre, en especial de las provincias de Padre Abad en Ucayali y sus distritos Curimaná, Irazola y Padre Abad; la provincia de Coronel Portillo y su distrito Campoverde y la provincia de Puerto Inca del departamento de Huánuco. Este circuito se provee de la producción de los ríos Aguatía, Pachitea y Súngaro. La madera generada en esta zona llega a Curimaná, Puerto Inca y Puerto Súngaro, donde es comercializada por intermediarios para ser transformada y luego transportada a Lima. Los pequeños productores y extractores que trabajan en este corredor dependen de la época de lluvia para movilizar la madera, debido a que en época de sequía los ríos no son de fácil navegación. Sin embargo, la gran parte de madera de las concesiones no tiene este problema, por estar conectadas con vías carrozables que les permite el acceso a la corta y movilización durante todo el ańo. La mayor parte de la madera según datos oficiales proviene de estas concesiones forestales, como lo muestra el Cuadro 22.

Este circuito se caracteriza por el aprovechamiento de especies diferentes de las comercializadas por vía fluvial del bajo y alto Ucayali. El Cuadro 23, muestra las especies movilizadas según los datos de las guías de transporte forestal. La capirona es la especie más aprovechada, seguida del Tahuarí que es una especie que se origina en un $98 \%$ en la provincia de Puerto Inca (Huánuco) y no está registrada en otros circuitos de Ucayali.

Los datos levantados en las entrevistas en este circuito muestran que, para los pequeños extractores e intermediarios de este corredor, la capirona es una de las principales especies comercializadas (Figura 8). En este circuito aparece la madera de cedro siendo comercializada en la ciudad de Aguaytía y Huánuco; sin embargo, los datos oficiales no indican movilización alguna de

Cuadro 22. Producción de madera en las provincias de Puerto Inca y Padre Abad

\begin{tabular}{|c|c|c|c|c|c|c|}
\hline \multirow[t]{2}{*}{ Modalidad } & \multicolumn{5}{|c|}{ Volúmenes en miles de $\mathrm{m}^{3}$} & \multirow{2}{*}{$\begin{array}{l}\text { Participación } \\
\text { respecto al tota } \\
\text { (en \%) }\end{array}$} \\
\hline & 2009 & 2010 & 2011 & 2012 & $\begin{array}{c}\text { Promedio } \\
2009-12\end{array}$ & \\
\hline Permisos & 21,3 & 32,5 & 13,2 & 3,5 & 17,6 & 69,3 \\
\hline Concesiones & 5,2 & 5,9 & 8,9 & 2,5 & 5,6 & 22,1 \\
\hline Autorizaciones & 0,5 & 0,8 & 4,1 & 1,9 & 1,8 & 7,2 \\
\hline Contratos & 0,2 & 0,7 & 0,4 & 0,1 & 0,4 & 1,4 \\
\hline Total general ${ }^{\mathrm{a}}$ & 27,2 & 39,9 & 26,6 & 8,1 & 25,5 & 100,0 \\
\hline
\end{tabular}

Fuente: Elaboración propia con base en los datos proporcionados por la Oficina Técnica de Pucallpa y Atalaya, así como los datos parciales proporcionados por la Dirección General Forestal y de Fauna Silvestre del Ministerio de Agricultura.

Nota: a) Sin datos de carbón y leña de monte o chacra.

34 Es necesario anotar que "bolaina" puede referirse a las especies blancas blandas. 
Cuadro 23. Volúmenes de las principales especies aprovechadas en las provincias de Puerto Inca y Padre Abad

\begin{tabular}{|c|c|c|c|c|c|c|}
\hline \multirow[t]{2}{*}{ Especies } & \multicolumn{5}{|c|}{ Volúmenes en miles de $\mathrm{m}^{3}$} & \multirow{2}{*}{$\begin{array}{l}\text { Participación } \\
\text { respecto al total } \\
\text { (en \%) }\end{array}$} \\
\hline & 2009 & 2010 & 2011 & 2012 & $\begin{array}{c}\text { Promedio } \\
2009-12\end{array}$ & \\
\hline $\begin{array}{l}\text { Calycophyllum spruceanum } \\
\text { (Capirona) }\end{array}$ & 5,1 & 7,6 & 4,7 & 0,8 & 4,6 & 17,9 \\
\hline Tabebuia sp. (Tahuari) & 1,8 & 7,4 & 3,9 & 0,0 & 3,3 & 12,9 \\
\hline Manilkara bidentata (Quinilla) & 0,1 & 8,6 & 0,2 & 0,1 & 2,3 & 8,8 \\
\hline $\begin{array}{l}\text { Coumarouna odorata } \\
\text { (Shihuahuaco) }\end{array}$ & 2,5 & 2,9 & 2,8 & 0,5 & 2,2 & 8,5 \\
\hline Ormosia sunkei (Huayruro) & 0,8 & 2,0 & 3,7 & 0,1 & 1,7 & 6,5 \\
\hline Cedrelinga catenaeformis (Tornillo) & 2,5 & 0,6 & 1,6 & 0,8 & 1,4 & 5,4 \\
\hline Virola sp. (Cumala) & 2,5 & 0,7 & 1,1 & 0,9 & 1,3 & 5,1 \\
\hline Chorisia integrifolia (Lupuna) & 2,1 & 1,9 & 0,6 & 0,1 & 1,2 & 4,6 \\
\hline $\begin{array}{l}\text { Aspidosperma macrocarpon } \\
\text { (Pumaquiro) }\end{array}$ & 3,7 & 0,1 & 0,1 & 0,0 & 1,0 & 3,8 \\
\hline Pouteria sp. (Quina quina) & 0,3 & 2,3 & 1,0 & 0,0 & 0,9 & 3,5 \\
\hline Otras (79 especies) & 5,9 & 5,7 & 6,9 & 4,7 & 5,8 & 22,8 \\
\hline Total general $^{\mathrm{a}}$ & 27,2 & 39,9 & 26,6 & 8,1 & 25,5 & 100,0 \\
\hline
\end{tabular}

Fuente: Elaboración propia con base en los datos proporcionados por la Oficina Técnica de Pucallpa y Atalaya, así como los datos parciales proporcionados por la Dirección General Forestal y de Fauna Silvestre del Ministerio de Agricultura.

Nota: a) Sin datos de carbón y leña de monte o chacra.

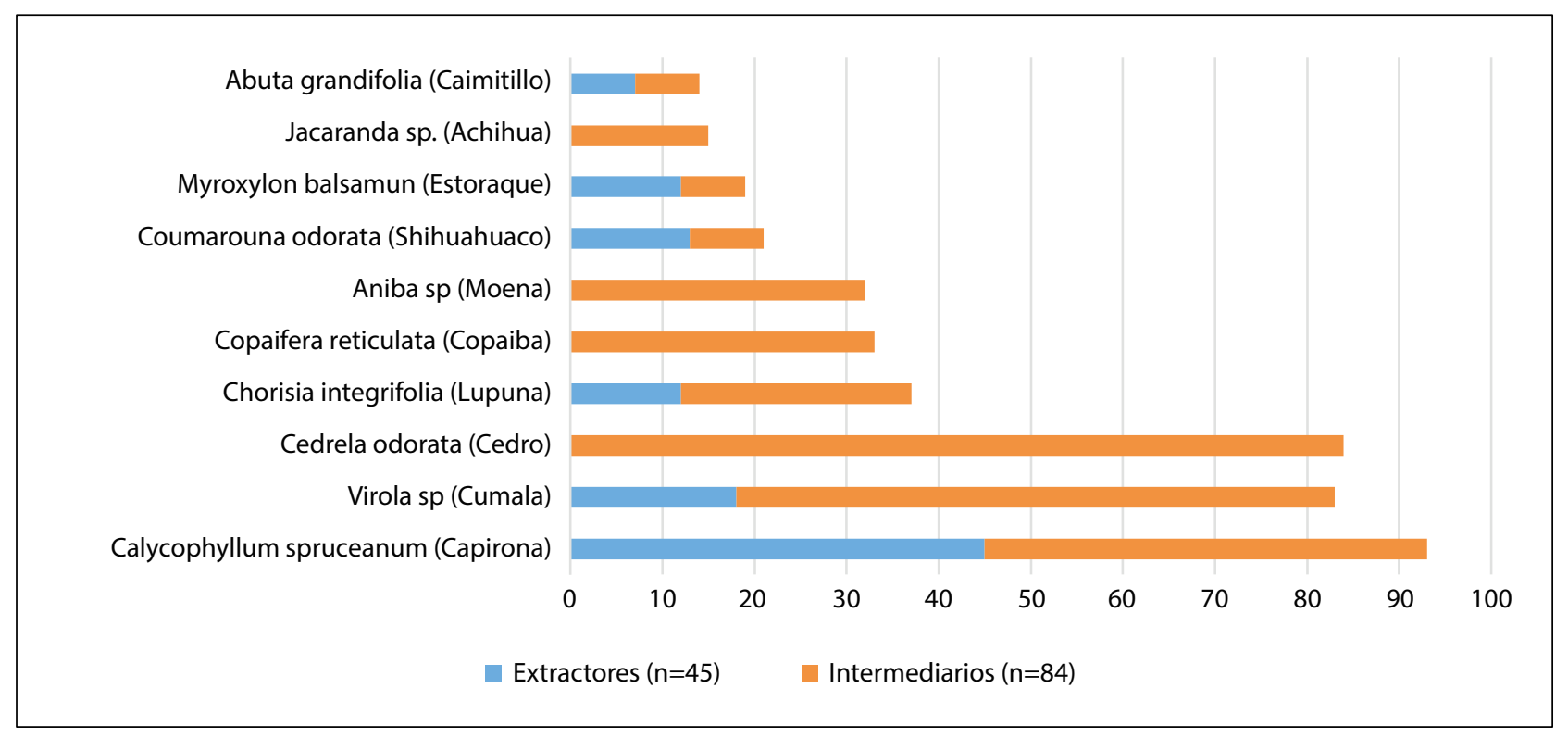

Figura 8. Frecuencia de las diez principales especies comercializadas por extractores e intermediarios en la zona de Padre Abad y Puerto Inca

Fuente: Elaboración propia con datos recolectados entre octubre de 2013 y marzo de 2014.

Nota: Los intermediarios fueron entrevistados en las ciudades de Aguaytía y Huánuco. 
Cuadro 24. Principales destinos de la madera producida en Padre Abad y Puerto Inca

\begin{tabular}{|c|c|c|c|c|c|c|}
\hline & \multicolumn{5}{|c|}{ Volúmenes en miles de $\mathrm{m}^{3}$} & \multirow{2}{*}{$\begin{array}{c}\text { Participación } \\
\text { respecto al } \\
\text { total (en \%) }\end{array}$} \\
\hline & 2009 & 2010 & 2011 & 2012 & $\begin{array}{c}\text { Promedio } \\
2009-12\end{array}$ & \\
\hline Lima & 22,0 & 37,0 & 22,8 & 6,1 & 22,0 & 86,3 \\
\hline Callao & 1,6 & 1,5 & 1,4 & 0,5 & 1,3 & 4,9 \\
\hline Junín & 0,8 & 0,2 & 0,3 & 0,2 & 0,4 & 1,5 \\
\hline La libertad & 0,5 & 0,4 & 0,5 & 0,2 & 0,4 & 1,6 \\
\hline Ancash & 0,4 & 0,2 & 0,5 & 0,1 & 0,3 & 1,2 \\
\hline Ica & 0,5 & 0,1 & 0,4 & 0,2 & 0,3 & 1,2 \\
\hline Otros (18 dptos.) & 1,4 & 0,5 & 0,8 & 0,8 & 0,9 & 3,4 \\
\hline Total generala $^{a}$ & 27,2 & 39,9 & 26,6 & 8,1 & 25,5 & 100,0 \\
\hline
\end{tabular}

Fuente: Elaboración propia con base en los datos proporcionados por la Oficina Técnica de Pucallpa y Atalaya, así como los datos parciales proporcionados por la Dirección General Forestal y de Fauna Silvestre del Ministerio de Agricultura.

Nota: a) Sin datos de carbón y leña de monte o chacra.

esta especie con destino final en estas ciudades, por lo cual se estima que la comercialización de esta madera en los mercados locales es totalmente informal y abastece a un sector de la población que demanda muebles de finos acabados.

El destino principal como en el caso de los otros circuitos de Ucayali es Lima y en menor intensidad a otros departamentos de la costa norte del Perú (Cuadro 24). A diferencia de los otros casos, el 98\% de la madera de este corredor es comercializada hacia depósitos y comercios y no a la industria de transformación primaria, lo cual puede deberse a que las empresas concesionarias de la región también cuentan con sus propios depósitos.

\subsection{Loreto: Producción y circuitos de comercialización}

El departamento de Loreto tiene una de las economías más vigorosas de la región amazónica. La extracción forestal es uno de los rubros más importantes para los actores rurales y urbanos. $\mathrm{Al}$ igual que en Ucayali, las concesiones siguen proporcionando la mayor parte de la producción oficial de madera, seguida de las autorizaciones y permisos (Figura 9). En los últimos años el flujo de madera ha disminuido debido a la falta de tecnificación en los aserraderos y reaserraderos locales $^{35}$. Iquitos, el principal puerto fluvial, no cuenta con una carretera de salida hacia los

35 Entrevistas informales y semiestructuradas con actores locales durante los meses de julio de 2013 y marzo de 2014 . principales mercados de Perú, por lo cual la producción de madera de Loreto es transportada hacia Pucallpa. Allí es transformada y movilizada a través de la carretera Federico Basadre.

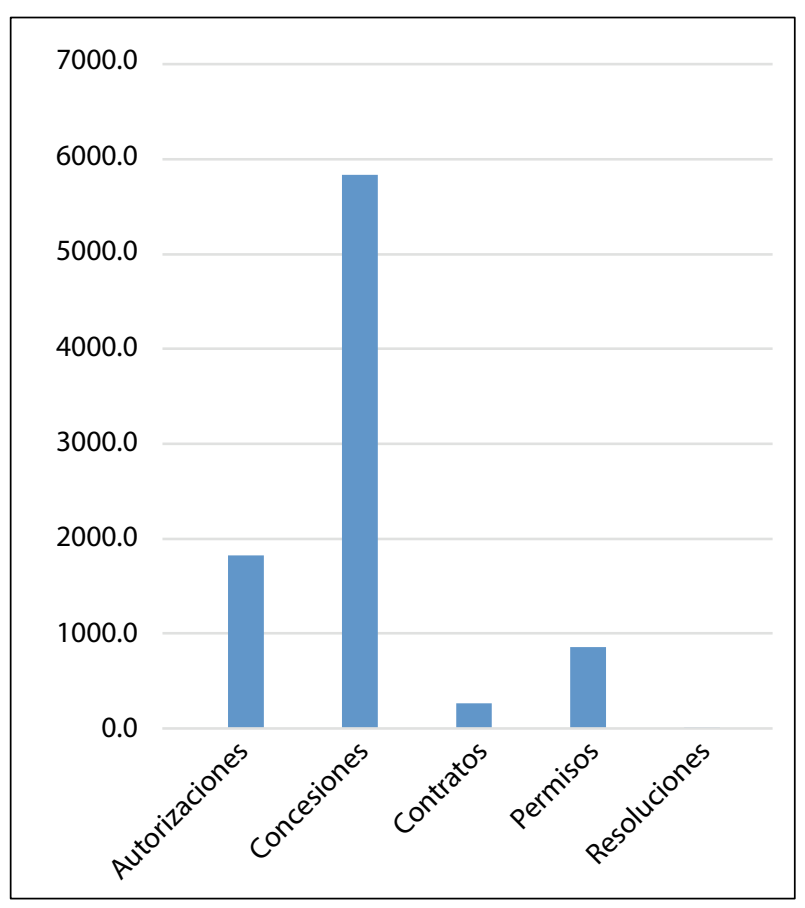

Figura 9. Datos aglomerados de madera movilizada entre 2003 y 2013 según modalidad de corta a través de las oficinas de Loreto (miles de $\mathrm{m}^{3}$ )

Fuente: Elaboración propia con los datos del Programa Regional de Manejo de Recursos Forestales y de Fauna Silvestre (PRMRFFS).

Nota: a) Los datos representan los volúmenes que generaron una guía de movilización entre 2003 y 2012; sin embargo, no significa que en años futuros no existan volúmenes de zafras anteriores que pueden agregarse al volumen presentado. 


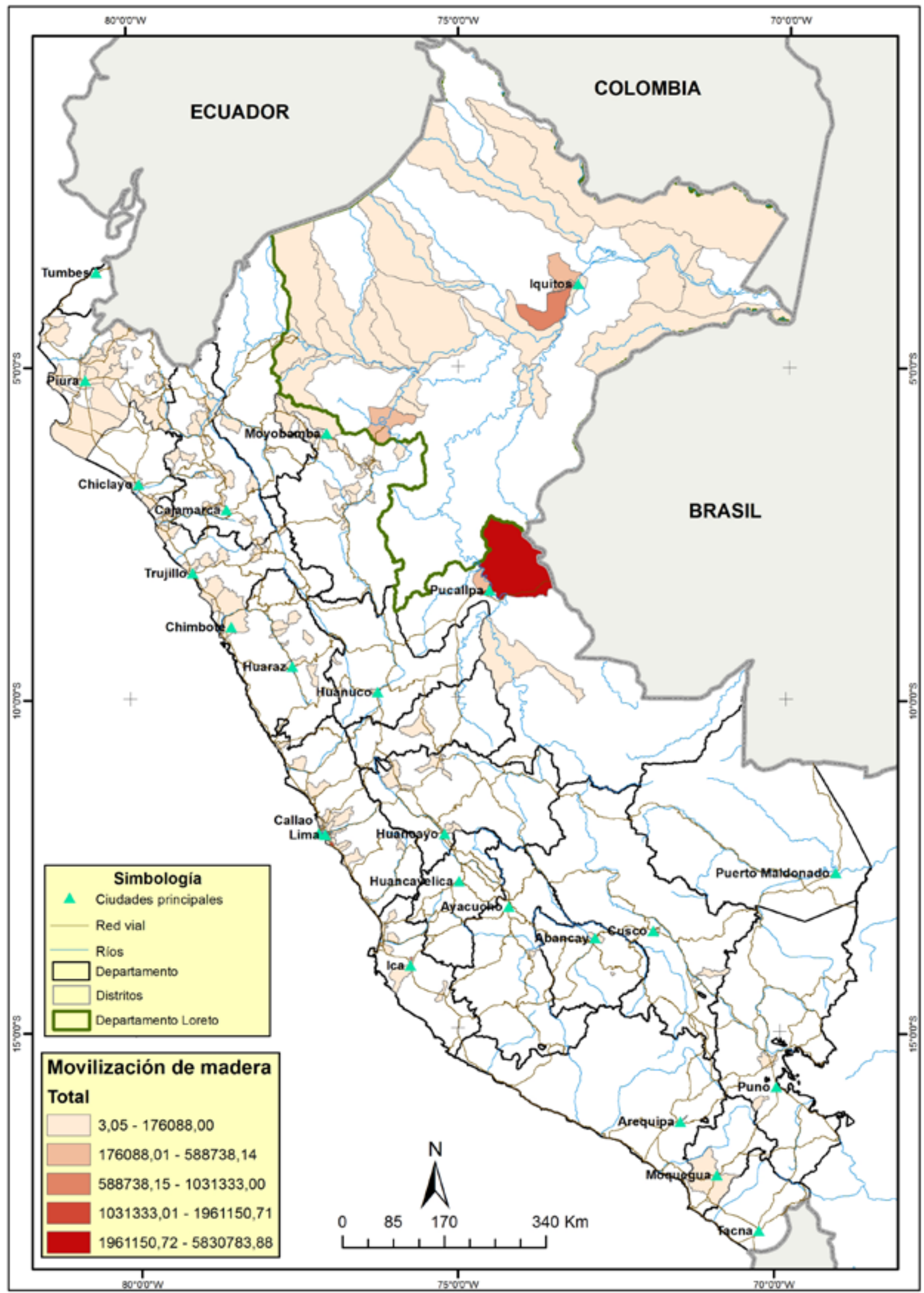

Mapa 5. Principales destinos a nivel de distritos de la madera producida en Loreto

Fuente: Elaborado por los autores con base en información de las guías de transporte forestal. 
Cuadro 25. Proveedores y compradores de madera en Loreto según producción entre 2009 y 2012

\begin{tabular}{|c|c|c|c|c|c|c|}
\hline & \multicolumn{4}{|c|}{ Volúmenes en miles de $\mathrm{m}^{3}$} & \multirow{2}{*}{$\begin{array}{l}\text { Promedio } \\
2009-12\end{array}$} & \multirow{2}{*}{$\begin{array}{c}\text { Participación } \\
\text { respecto al } \\
\text { total (en \%) }\end{array}$} \\
\hline & 2009 & 2010 & 2011 & 2012 & & \\
\hline \multicolumn{7}{|l|}{ Proveedor } \\
\hline $\begin{array}{l}\text { Total diez empresas más } \\
\text { importantes }\end{array}$ & 249,7 & 278,8 & 249,0 & 303,1 & 270,2 & 37,4 \\
\hline Depósitos no definidos & 17,4 & 19,4 & 17,3 & 21,1 & 18,8 & 2,6 \\
\hline Otros (225 proveedores) & 400,6 & 447,3 & 399,4 & 486,2 & 433,4 & 60,0 \\
\hline Total & 667,6 & 745,5 & 665,7 & 810,3 & 722,3 & 100,0 \\
\hline \multicolumn{7}{|l|}{ Comprador } \\
\hline $\begin{array}{l}\text { Total veinte empresas más } \\
\text { importantes }\end{array}$ & 367,2 & 410,0 & 366,1 & 445,7 & 397,3 & 55,0 \\
\hline Otros (501 compradores) & 300,4 & 335,5 & 299,5 & 364,6 & 325,0 & 45,0 \\
\hline Total $^{\mathrm{a}}$ & 667,6 & 745,5 & 665,7 & 810,3 & 722,3 & 100,0 \\
\hline
\end{tabular}

Fuente: Elaboración propia con los datos del Programa Regional de Manejo de Recursos Forestales y de Fauna Silvestre (PRMRFFS).

Nota: a) Sin datos de carbón y leña de monte o chacra.

Cuadro 26. Movilización de madera en Loreto según tamaño de proveedores y compradores entre 2009 y 2012

\begin{tabular}{|c|c|c|c|c|c|c|c|}
\hline \multirow[t]{2}{*}{ Tamaño $^{a}$} & \multicolumn{5}{|c|}{ Volúmenes en miles de $\mathrm{m}^{3}$} & \multirow{2}{*}{$\begin{array}{l}\text { Participación } \\
\text { en el total } \\
\text { (en \%) }\end{array}$} & \multirow[t]{2}{*}{ Número } \\
\hline & 2009 & 2010 & 2011 & 2012 & $\begin{array}{c}\text { Promedio } \\
2009-12\end{array}$ & & \\
\hline \multicolumn{8}{|l|}{ Proveedor } \\
\hline Muy grande & 24,7 & 27,6 & 24,6 & 30,0 & 26,7 & 37,0 & 8,0 \\
\hline Mediano & 20,0 & 22,4 & 20,0 & 24,3 & 21,7 & 30,0 & 66,0 \\
\hline Grande & 16,0 & 17,9 & 16,0 & 19,4 & 17,3 & 24,0 & 17,0 \\
\hline Pequeño & 3,3 & 3,7 & 3,3 & 4,1 & 3,6 & 5,0 & 32,0 \\
\hline Muy pequeño & 2,7 & 3,0 & 2,7 & 3,2 & 2,9 & 4,0 & 112,0 \\
\hline Total $^{\mathrm{b}}$ & 66,8 & 74,6 & 66,6 & 81,0 & 72,3 & 100,0 & 235,0 \\
\hline \multicolumn{8}{|l|}{ Comprador } \\
\hline Muy grande & 29,4 & 32,8 & 29,3 & 35,7 & 31,8 & 44,0 & 11,0 \\
\hline Mediano & 20,0 & 22,4 & 20,0 & 24,3 & 21,7 & 30,0 & 66,0 \\
\hline Grande & 8,7 & 9,7 & 8,7 & 10,5 & 9,4 & 13,0 & 10,0 \\
\hline Pequeño & 2,7 & 3,0 & 2,7 & 3,2 & 2,9 & 4,0 & 29,0 \\
\hline Muy pequeño & 6,0 & 6,7 & 6,0 & 7,3 & 6,5 & 9,0 & 394,0 \\
\hline Total $^{\mathrm{b}}$ & 66,8 & 74,6 & 66,6 & 81,0 & 72,3 & 100,0 & 510,0 \\
\hline
\end{tabular}

Fuente: Elaboración propia con los datos del Programa Regional de Manejo de Recursos Forestales y de Fauna Silvestre (PRMRFFS).

Nota: a) No incluye productos maderables como carbón o leña. b) Se definen como proveedores/compradores muy grandes cuando transportan más de $3501 \mathrm{~m}^{3}$; los grandes, de $2001 \mathrm{~m}^{3}$ a $3500 \mathrm{~m}^{3}$; los medianos, de $1001 \mathrm{~m}^{3}$ a $2000 \mathrm{~m}^{3}$, los pequeños, de $501 \mathrm{~m}^{3}$ a $1000 \mathrm{~m}^{3}$; y los muy pequeños, de $1 \mathrm{~m}^{3}$ a $500 \mathrm{~m}^{3}$. 


\section{Cuadro 27. Tipo de origen y destino según guía de movilización entre 2009 y 2012 en Loreto (en porcentajes)}

\begin{tabular}{|c|c|c|c|c|c|c|}
\hline $\begin{array}{l}\text { Destino } \\
\text { Origen }\end{array}$ & $\begin{array}{l}\text { Depósitos y } \\
\text { establecimientos } \\
\text { comerciales }\end{array}$ & Exportación & $\begin{array}{l}\text { Industria de } \\
\text { transformación } \\
\text { primaria }\end{array}$ & $\begin{array}{c}\text { No } \\
\text { definido }\end{array}$ & Otros & $\begin{array}{l}\text { Total } \\
\text { general }\end{array}$ \\
\hline Área de aprovechamiento & 0,0 & 0,0 & 32,0 & 0,0 & 0,0 & 32,0 \\
\hline $\begin{array}{l}\text { Depósitos y } \\
\text { establecimientos } \\
\text { comerciales }\end{array}$ & 1,0 & 2,0 & 0,0 & 0,0 & 0,1 & 3,0 \\
\hline $\begin{array}{l}\text { Industria de } \\
\text { transformación primaria }\end{array}$ & 25,0 & 32,0 & 4,0 & 0,1 & 4,0 & 65,0 \\
\hline No definido ${ }^{\mathrm{a}}$ & 0,0 & 0,0 & 0,0 & 0,0 & 0,0 & 0,1 \\
\hline Otros & 0,0 & 0,0 & 0,0 & 0,0 & 0,1 & 0,1 \\
\hline Total general ${ }^{\mathrm{b}}$ & 26,0 & 34,0 & 35,0 & 0,05 & 5,0 & 100,0 \\
\hline
\end{tabular}

Fuente: Elaboración propia con los datos del Programa Regional de Manejo de Recursos Forestales y de Fauna Silvestre (PRMRFFS).

Nota: a) No registra RUC. b) Sin datos de carbón y leña de monte o chacra.

En este sentido, la oficina técnica de Pucallpa reporta al menos un millón de metros cúbicos de madera originados en Loreto que han sido movilizados entre 2009 y 2012 a través de Ucayali, siendo uno de los principales receptores de madera, como se muestra en el Mapa 5.

A diferencia de Ucayali, en Loreto los proveedores y compradores son menos en número, pero aglomeran aproximadamente un 30\% más que las principales empresas en Ucayali. En general, los diez principales proveedores manejan el $37 \%$ de la producción total de madera de la zona, y los veinte compradores más importantes aglomeran el 55\% de la producción total (Cuadro 25).

Para entender mejor el tipo de empresas que participan en la comercialización de madera, se dividieron a los proveedores y compradores por el volumen comercializado, como se indica en el Cuadro 26. Los proveedores muy grandes y compradores muy grandes son quienes aglomeran la mayor parte de la producción de madera y tienen los medios para transformarla antes de la movilización final. En el caso de Loreto cinco de los principales proveedores y compradores de madera muy grandes son el mismo grupo empresarial, según los datos obtenidos de la SUNAT. Este grupo empresarial también aglomera madera de Ucayali y Madre de Dios.

Loreto es el único departamento en que las GTF indican el destino final de exportación. Demuestran que el 34\% de la producción entre 2009 y 2012 ha sido movilizada fuera del departamento, principalmente hacia México. Este país importa madera aserrada y tableros dirigidos al mercado más grandes del país, la ciudad de México. El restante $66 \%$ de la madera, se comercializó a destinos nacionales. El Cuadro 27, muestra que el principal origen y destino de la madera fue la industria de transformación primaria, lo cual indica que se movilizó, en su mayoría, madera aserrada.

\subsubsection{Circuito Islandia-Caballo Cocha- Iquitos-Pucallpa: La cuenca del Yavarí}

El sistema de comercialización de madera en Islandia ${ }^{36}$ consiste en la extracción y transporte de madera rolliza en las concesiones forestales otorgadas y en comunidades nativas y campesinas. El corte y extracción de los árboles es realizada entre los meses de septiembre, octubre y noviembre, y la madera es transportada en la época de creciente de los ríos y quebradas entre los meses de enero y junio de cada año, dependiendo siempre de la creciente de los ríos. En el Cuadro 28 se presenta la producción registrada por zafra para las sedes correspondientes a este corredor.

De acuerdo con las entrevistas realizadas entre julio y diciembre de 2013 ( $\mathrm{n}=27)$, muchas de las especies maderables provendrían no solamente de las concesiones forestales autorizadas sino

36 Islandia es la capital del Distrito de Yavarí en la provincia de Mariscal Ramón Castilla en el departamento de Loreto. 
Cuadro 28. Zafras registradas en Islandia, Caballo Cocha y San Pablo en la provincia de Mariscal Ramón Castilla, Loreto

\begin{tabular}{|c|c|c|c|c|c|c|}
\hline \multirow[t]{2}{*}{ Modalidad } & \multicolumn{4}{|c|}{ Volúmenes en miles de $\mathbf{m}^{3}$} & \multirow{2}{*}{$\begin{array}{c}\text { Promedio } \\
2009-12\end{array}$} & \multirow{2}{*}{$\begin{array}{l}\text { Participación } \\
\text { respecto al total } \\
\text { (en \%) }\end{array}$} \\
\hline & 2009 & 2010 & 2011 & 2012 & & \\
\hline Concesiones & 57,6 & 28,6 & 45,4 & 18,7 & 37,6 & 91,0 \\
\hline Permisos & 7,3 & 1,2 & 4,8 & 1,5 & 3,7 & 9,0 \\
\hline Total general ${ }^{\mathrm{a}}$ & 64,9 & 29,8 & 50,2 & 20,2 & 41,3 & 100,0 \\
\hline
\end{tabular}

Fuente: Elaboración propia con los datos del Programa Regional de Manejo de Recursos Forestales y de Fauna Silvestre (PRMRFFS).

Nota: a) Sin datos de carbón y leña de monte o chacra.

\section{Cuadro 29. Especies aprovechadas en la región del Yavarí, Loreto}

\begin{tabular}{|c|c|c|c|c|c|c|}
\hline \multirow[t]{2}{*}{ Especie } & \multicolumn{5}{|c|}{ Volúmenes en miles de $\mathrm{m}^{3}$} & \multirow{2}{*}{$\begin{array}{c}\text { Participación } \\
\text { respecto al } \\
\text { total (en \%) }\end{array}$} \\
\hline & 2009 & 2010 & 2011 & 2012 & $\begin{array}{l}\text { Promedio } \\
2009-12\end{array}$ & \\
\hline Chorisia integrifolia (Lupuna) & 16,7 & 4,5 & 12,0 & 3,6 & 9,2 & 22,3 \\
\hline Virola sp. (Cumala) & 14,5 & 6,3 & 8,0 & 1,9 & 7,7 & 18,6 \\
\hline Cedrela odorata (Cedro) & 8,0 & 6,2 & 7,9 & 6,4 & 7,1 & 17,3 \\
\hline Cedrelinga catenaeformis (Tornillo) & 7,7 & 3,3 & 6,2 & 1,8 & 4,8 & 11,5 \\
\hline Virola sebifera (Cumala) & 2,7 & 1,6 & 3,0 & 0,6 & 2,0 & 4,8 \\
\hline Simarouba amara (Marupa) & 2,0 & 2,1 & 1,9 & 0,5 & 1,6 & 3,9 \\
\hline Virola albidiflora (Aguano cumala) & 1,5 & 1,4 & 2,3 & 1,0 & 1,6 & 3,8 \\
\hline $\begin{array}{l}\text { Calycophyllum spruceanum } \\
\text { (Capirona) }\end{array}$ & 4,3 & 0,2 & 0,9 & 0,7 & 1,5 & 3,7 \\
\hline $\begin{array}{l}\text { Iryanthera grandis (Cumala } \\
\text { colorada) }\end{array}$ & 2,1 & 1,5 & 1,1 & 0,8 & 1,4 & 3,3 \\
\hline Virola pavonis (Cumala blanca) & 0,4 & 0,9 & 0,6 & 1,8 & 0,9 & 2,2 \\
\hline Otras (87 especies) & 5,1 & 1,8 & 6,2 & 1,3 & 3,6 & 8,7 \\
\hline Total general & 64,9 & 29,8 & 50,2 & 20,2 & 41,3 & 100,0 \\
\hline
\end{tabular}

Fuente: Elaboración propia con los datos del Programa Regional de Manejo de Recursos Forestales y de Fauna Silvestre (PRMRFFS).

Nota: Sin datos de carbón y leña de monte o chacra.

también de áreas de la Comunidad Nativa Nueva Esperanza. Las extracciones madereras estarían también ocurriendo en el área propuesta como zona reservada del Yavarí y que forma parte del territorio de la comunidad debido a la alta demanda de especies como tornillo. Las especies más aprovechadas en este corredor se muestran en el Cuadro 29.

Según los intermediarios-habilitadores entrevistados, estos se proveen de madera principalmente de comunidades nativas, concesionarios y propietarios privados. Las operaciones de extracción forestal se dan a través del sistema de "habilitación" y "subhabilitación" de manera informal entre el contratista, concesionario o habilitador y los productores locales de las comunidades para que realicen el trabajo de corta, extracción y arrastre de la madera. El intermediario-habilitador generalmente realiza acuerdos informales de ofertas de "habilitación" a moradores de las comunidades o dirigentes comunales, con el aval del teniente gobernador o del Apu (jefe de la comunidad) en el caso de las comunidades nativas. El adelanto de habilitación en este corredor varía entre USD 9000 y 15.000 para iniciar el trabajo, que e extiende desde USD 25.000 hasta 30.000 de acuerdo con la 
permanencia de los habilitados-extractores en el campo y de las trozas que consigan transportar en ese período. Solo un intermediario-habilitador mencionó que realiza acuerdos notariales por escrito con sus habilitados e incluso con un concesionario con el que trabaja.

\subsubsection{Circuito Alto Amazonas-San Martín- Cajamarca-Libertad-Lambayeque-Piura}

Alto Amazonas es una provincia del departamento de Loreto, cuya capital es Yurimaguas, una ciudad que se encuentra más cerca de Tarapoto, la principal ciudad del departamento de San Martín, que de Iquitos, la capital de Loreto. En este sentido, la madera producida en esta región ha generado un corredor terrestre que llega hasta el departamento de Piura al norte del Perú. La madera comercializada en este corredor proviene principalmente de permisos concedidos en bosques locales y comunidades nativas (Cuadro 30). Las especies que llegan a Yurimaguas provienen en parte del Abanico del Pastaza, un área donde abundan las especies aluviales.

Los principales destinos para la comercialización de madera son la industria de transformación primaria $(86 \%)$ y los depósitos y establecimientos comerciales (14\%) de las ciudades de Cajamarca, Trujillo, Chiclayo y Piura (Cuadro 31). En estas ciudades se realizaron entrevistas con los compradores finales $(n=28)$ que correspondían a pequeńos y medianos negocios por sus volúmenes de compra no mayores a $1000 \mathrm{~m}^{3}$. Estos establecimientos están ubicados en las zonas industriales de cada ciudad. Según las estadísticas de las oficinas técnicas, estos actores llegan a constituir aproximadamente 3000 comercios entre informales y formales ${ }^{37}$. Las oficinas entrevistadas no tienen un seguimiento adecuado de la madera

Cuadro 30. Zafras registradas en la oficina de Alto Amazonas, entre 2009 y 2012

\begin{tabular}{|c|c|c|c|c|c|c|}
\hline \multirow[t]{2}{*}{ Modalidad } & \multicolumn{5}{|c|}{ Volúmenes en miles de $\mathrm{m}^{3}$} & \multirow{2}{*}{$\begin{array}{l}\text { Participación } \\
\text { respecto al total } \\
\text { (en \%) }\end{array}$} \\
\hline & 2009 & 2010 & 2011 & 2012 & $\begin{array}{c}\text { Promedio } \\
2009-12\end{array}$ & \\
\hline Permisos & 10,1 & 20,7 & 27,1 & 34,4 & 23,1 & 46,5 \\
\hline Concesiones & 14,9 & 15,1 & 17,0 & 6,0 & 13,3 & 26,7 \\
\hline Contratos & 0,3 & 1,9 & 21,8 & 17,1 & 10,3 & 20,7 \\
\hline Autorizaciones & 3,8 & 3,3 & 0,4 & 4,7 & 3,1 & 6,1 \\
\hline Total general ${ }^{\mathrm{a}}$ & 29,1 & 41,0 & 66,3 & 62,2 & 49,7 & 100,0 \\
\hline
\end{tabular}

Fuente: Elaboración propia con los datos del Programa Regional de Manejo de Recursos Forestales y de Fauna Silvestre (PRMRFFS).

Nota: a) Sin datos de carbón y leña de monte o chacra.

Cuadro 31. Principales destinos de la madera producida en Alto Amazonas

\begin{tabular}{|c|c|c|c|c|c|c|}
\hline & \multicolumn{5}{|c|}{ Volúmenes en miles de $\mathrm{m}^{3}$} & \multirow{2}{*}{$\begin{array}{l}\text { Participación } \\
\text { respecto al total } \\
\text { (en \%) }\end{array}$} \\
\hline & 2009 & 2010 & 2011 & 2012 & $\begin{array}{l}\text { Promedio } \\
20019-12\end{array}$ & \\
\hline Piura & 10,2 & 12,2 & 14,0 & 9,3 & 11,4 & 43,1 \\
\hline Lambayeque & 3,5 & 6,5 & 8,7 & 6,9 & 6,4 & 24,2 \\
\hline La Libertad & 3,3 & 5,1 & 6,4 & 4,2 & 4,8 & 17,9 \\
\hline San Martín & 2,2 & 2,2 & 3,0 & 2,7 & 2,5 & 9,5 \\
\hline Cajamarca & 0,9 & 1,6 & 1,7 & 1,5 & 1,4 & 5,4 \\
\hline Total general ${ }^{\mathrm{a}}$ & 20,1 & 27,6 & 33,9 & 24,7 & 26,6 & 100,0 \\
\hline
\end{tabular}

Fuente: Elaboración propia con base en los datos proporcionados por la Oficina Técnica de Yurimaguas y los datos parciales proporcionados por la Dirección General Forestal y de Fauna Silvestre del Ministerio de Agricultura.

Nota: a) Sin datos de carbón y leña de monte o chacra. 
proveniente de la Amazonía, debido a que se dedican más al control de las maderas locales, como el caso del algarrobo que se utiliza para abastecer de carbón a restaurantes locales y de Lima.

El Cuadro 32, muestra las especies más comercializadas hacia a los destinos del norte de Perú. El principal destino de la madera dura es el sector de la construcción y de las blandas el agrícola (parihuelas y paquetería de fruta). En Piura la madera de tornillo es utilizada en la industria de la construcción de barcos para armar los "esqueletos" de estas embarcaciones. En Cajamarca, existe también una demanda estable para madera de vigas que se utilizan en la minería subterránea.

\subsection{Madre de Dios: Producción y circuitos de comercialización}

El departamento de Madre de Dios es peculiar debido a que en esta zona se concentran concesiones de castańa (Bertholletia excelsa) que desde hace algunos años han sido importantes protagonistas en la producción de madera en esta región. En comparación con las otras regiones Madre de Dios produce en promedio un 40\% menos de madera. Al igual que en Ucayali y Loreto, las concesiones son la modalidad que provee más madera, seguidas muy de cerca por los permisos (Figura 10). Las guías de transporte forestal muestran madera proveniente de Loreto

Cuadro 32. Volúmenes de las principales especies aprovechadas en la zona de Alto Amazonas

\begin{tabular}{|c|c|c|c|c|c|c|}
\hline \multirow[t]{2}{*}{ Especie } & \multicolumn{5}{|c|}{ Volúmenes en miles de $\mathrm{m}^{3}$} & \multirow{2}{*}{$\begin{array}{c}\text { Participación } \\
\text { respecto al total } \\
(\text { en } \%)\end{array}$} \\
\hline & 2011 & 2010 & 2011 & 2012 & Total & \\
\hline Cedrelinga catenaeformis (Tornillo) & 8,7 & 15,0 & 17,5 & 17,2 & 14,6 & 29,4 \\
\hline Virola sp. (Cumala) & 4,8 & 6,7 & 10,6 & 5,5 & 6,9 & 13,9 \\
\hline Guazuma crinita (Bolaina blanca) & 1,1 & 1,0 & 6,3 & 8,2 & 4,2 & 8,4 \\
\hline Chorisia integrifolia (Lupuna) & 1,3 & 1,6 & 4,1 & 3,5 & 2,6 & 5,3 \\
\hline $\begin{array}{l}\text { Calycophyllum spruceanum } \\
\text { (Capirona) }\end{array}$ & 0,9 & 1,1 & 4,7 & 1,7 & 2,1 & 4,2 \\
\hline $\begin{array}{l}\text { Cariniana decandra (Papelillo } \\
\text { caspi) }\end{array}$ & 1,5 & 1,4 & 3,1 & 2,7 & 2,2 & 4,4 \\
\hline Copaifera reticulata (Copaiba) & 0,8 & 1,9 & 3,5 & 1,4 & 1,9 & 3,8 \\
\hline Ormosia sunkei (Huayruro) & 0,9 & 1,4 & 1,9 & 3,7 & 2,0 & 4,0 \\
\hline Croton lechleri (Sangre de grado) & & & & 6,8 & 6,8 & 13,7 \\
\hline Guazuma crinita (Bolaina) & & & 0,3 & 4,7 & 2,5 & 5,0 \\
\hline Otros (117 especies) & 9,2 & 11,1 & 14,2 & 7,0 & 10,4 & 20,9 \\
\hline Total general ${ }^{a}$ & 29,1 & 41,0 & 66,3 & 62,3 & 49,7 & 100,0 \\
\hline
\end{tabular}

Fuente: Elaboración propia con base en los datos proporcionados por la Oficina Técnica de Yurimaguas y los datos parciales proporcionados por la Dirección General Forestal y de Fauna Silvestre del Ministerio de Agricultura.

Nota: a) Sin datos de carbón y leña de monte o chacra.

\section{Recuadro 2. Pequeños extractores y comunidades nativas de Yurimaguas}

Durante la investigación en campo, se mantuvieron reuniones con pequeños extractores y productores para conocer la manera en que se comercializa la madera en esta zona. Los pequeños extractores están vinculados con pequeñas carpinterías que transforman la madera en muebles que son comercializados a nivel local o en la ciudad de Tarapoto. Debido a la falta de mecanismos para transportar legalmente la madera, tienen que acceder a los pagos de sobornos, en particular a la policía local. En ocasiones anteriores, a través de una huelga, lograron que la autoridad de Loreto extendiera permisos para transportar hasta $4 \mathrm{~m} 3$ mensuales. Las entrevistas con dirigentes de las comunidades nativas de Alto Amazonas revelaron que estos actores se beneficiaron más con la opción de comercializar su madera de manera individual y con permisos adaptados a sus necesidades. Según su opinión, esto evitaría que los intermediarios-madereros sean la única opción para generar una renta del bosque. 


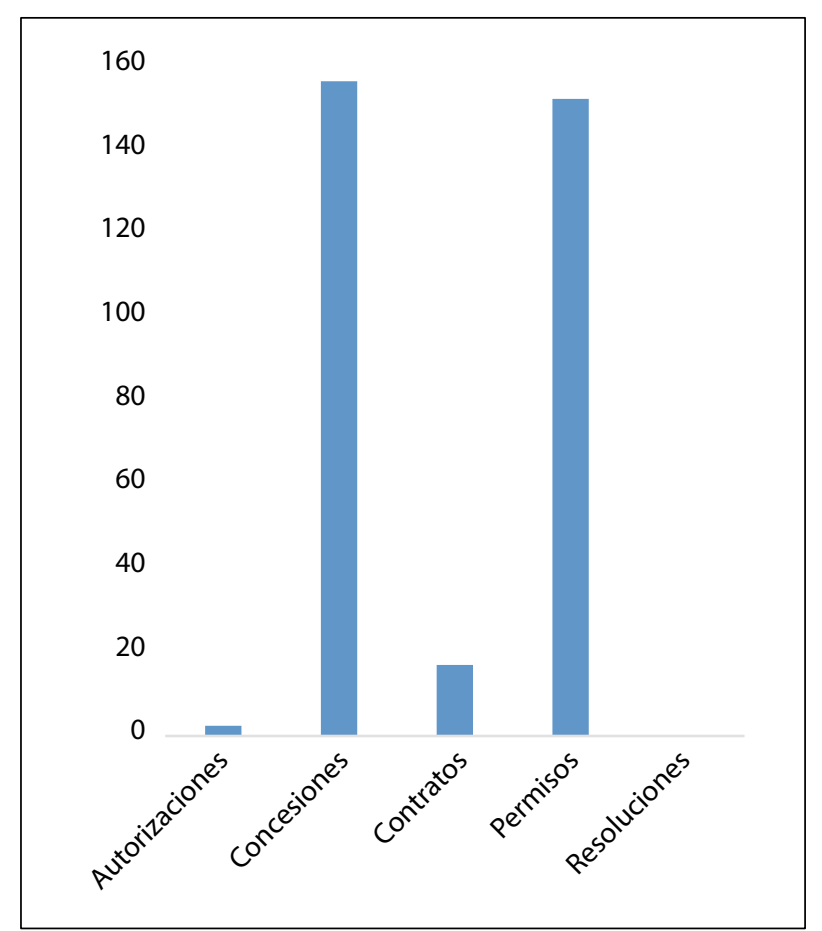

Figura 10. Madera autorizada por zafra y movilizada entre 2003 y 2012 según modalidad de corta a través de las oficinas técnicas de Madre de Dios (en miles de $\mathrm{m}^{3}$ ) que ha sido transportada por esta región hacia otras regiones, algo que resulta especialmente extraño, ya que no existe vinculación caminera o fluvial entre ambas regiones. Esto probablemente puede explicarse en aprovechamientos ilegales de madera que se blanquean a través de reexpediciones entre regiones, una estrategia que ya fue escuchada en las entrevistas realizadas en Madre de Dios. El 4\% de la madera que se origina en Madre de Dios se queda en Puerto Maldonado, según los datos oficiales analizados (Mapa 6).

En el caso de Madre de Dios, los proveedores muy grandes aglomeran el 52\% del total de la producción, mientras que los compradores principales son los muy pequeños que concentran el 38\% de la madera (Cuadro 33). Lo interesante de Madre de Dios es que los proveedores muy pequeños también tienen un porcentaje importante de madera (28\%), y los grandes y muy grandes, solo el $11 \%$.

Madre de Dios al igual que Ucayali, tiene como origen principal las industrias de transformación primaria o aserraderos y reaserraderos. En la región

Cuadro 33. Movilización de madera según tamaño proveedor y comprador entre 2009 y 2012

\begin{tabular}{|c|c|c|c|c|c|c|c|}
\hline \multirow[t]{2}{*}{ Tamañoa } & \multicolumn{5}{|c|}{ Volúmenes en miles de $\mathrm{m}^{3}$} & \multirow{2}{*}{$\begin{array}{l}\text { Participación } \\
\text { en el total } \\
\text { (en \%) }\end{array}$} & \multirow[t]{2}{*}{ Número } \\
\hline & 2009 & 2010 & 2011 & 2012 & $\begin{array}{c}\text { Promedio } \\
2009-12 \\
\end{array}$ & & \\
\hline \multicolumn{8}{|l|}{ Proveedor } \\
\hline Muy grande & 33,4 & 40,8 & 46,7 & 161,9 & 70,7 & 51,9 & 5,0 \\
\hline Muy pequeño & 47,1 & 37,4 & 27,5 & 41,9 & 38,5 & 28,3 & 1545,0 \\
\hline Mediano & 9,7 & 5,4 & 8,1 & 35,6 & 14,7 & 10,8 & 32,0 \\
\hline Pequeño & 5,7 & 12,2 & 6,8 & 13,3 & 9,5 & 7,0 & 55,0 \\
\hline Grande & 5 & 0,0 & 5,8 & 0,0 & 2,7 & 2,0 & 2,0 \\
\hline Total $^{b}$ & 100,9 & 95,8 & 94,9 & 252,6 & 136,1 & 100,0 & 1639,0 \\
\hline \multicolumn{8}{|l|}{ Comprador } \\
\hline Muy grande & 0,0 & 0,0 & 30,2 & 30,2 & 30,2 & 12,2 & 2,0 \\
\hline Grande & 0,0 & 12,5 & 14,7 & 27,2 & 18,1 & 7,3 & 4,0 \\
\hline Mediano & 24,6 & 20,8 & 102,4 & 170,1 & 79,5 & 32,2 & 102,0 \\
\hline Pequeño & 25,6 & 22,3 & 36,3 & 111,5 & 48,9 & 19,8 & 162,0 \\
\hline Muy pequeño & 45,6 & 39,4 & 69,1 & 205,3 & 89,9 & 36,4 & 1784,0 \\
\hline Total $^{\mathrm{b}}$ & 95,8 & 94,9 & 252,6 & 544,2 & 246,9 & 100,0 & 2054,0 \\
\hline
\end{tabular}

Fuente: Elaboración propia con base en los datos proporcionados por la Dirección Regional Forestal y de Fauna Silvestre de Madre de Dios, así como los datos parciales proporcionados por la Dirección General Forestal y de Fauna Silvestre del Ministerio de Agricultura.

Nota: a) Se definen como muy grandes compradores/proveedores cuando transportan más de $3501 \mathrm{~m}^{3}$; los grandes, de $2001 \mathrm{~m}^{3}$ a $3500 \mathrm{~m}^{3}$; los medianos, de $1001 \mathrm{~m}^{3}$ a $2000 \mathrm{~m}^{3}$; los pequeños, de $501 \mathrm{~m}^{3}$ a $1000 \mathrm{~m}^{3}$; y los muy pequeños, de $1 \mathrm{~m}^{3}$ a $500 \mathrm{~m}^{3}$. b) $\mathrm{No}$ incluye productos maderables como carbón o leña. 


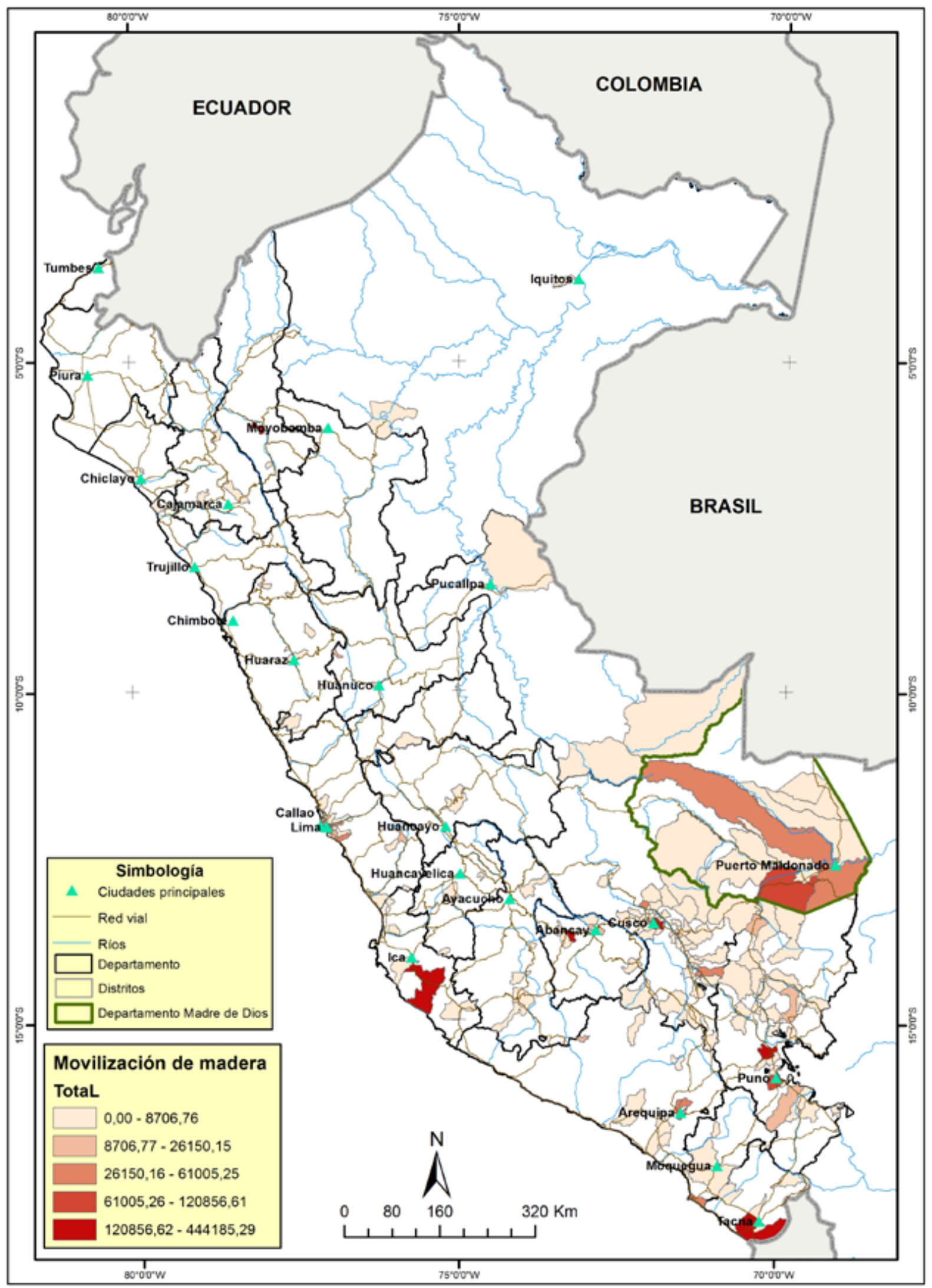

Mapa 6. Principales destino a nivel de distrito de la madera producida en Madre de Dios

Fuente: Elaborado por los autores con base en información de las guías de transporte forestal. 
Cuadro 34. Tipo de origen y destino según guía de movilización entre 2009 y 2012 en Madre de Dios (en porcentajes)

\begin{tabular}{lccc}
\hline $\begin{array}{l}\text { Destino } \\
\text { Origen }\end{array}$ & $\begin{array}{c}\text { Depósitos y establecimientos } \\
\text { comerciales }\end{array}$ & $\begin{array}{c}\text { Industria de } \\
\text { transformación primaria }\end{array}$ & $\begin{array}{c}\text { Total } \\
\text { general }\end{array}$ \\
\hline Área de aprovechamiento & 0,03 & 0,0 & 0,03 \\
$\begin{array}{l}\text { Depósitos y establecimientos } \\
\text { comerciales }\end{array}$ & 0,04 & 0,0 & 0,04 \\
$\begin{array}{l}\text { Industria de transformación primaria } \\
\text { Total general }\end{array}$ & 99,5 & 0,3 & 99,9 \\
\hline
\end{tabular}

Fuente: Elaboración propia con base en los datos proporcionados por la Dirección Regional Forestal y de Fauna Silvestre de Madre de Dios, así como los datos parciales proporcionados por la Dirección General Forestal y de Fauna Silvestre del Ministerio de Agricultura.

Nota: a) Sin datos de carbón y leña de monte o chacra.

se asierra la madera antes de su transporte final por la carretera (Cuadro 34). En este sentido, la industria primaria de esta región tiene un crecimiento constante, y debido a la inauguración de la carretera internacional, se prevé un repunte siguiendo los pasos de Ucayali.

\subsubsection{Circuito Tambopata-Cusco-Ica/Lima}

Tambopata es una de las regiones con más concesiones forestales en Madre de Dios; sin embargo, los registros oficiales muestran que los permisos forestales han experimentado un ligero incremento en el volumen acumulado entre 2009 y 2012 (Cuadro 35). Esto se debe al aumento en la extracción de madera de concesiones castañeras debido a las facilidades comparativas para la obtención de autorizaciones de aprovechamiento en relación a las concesiones de madera y a los volúmenes posibles de extraer. Según las entrevistas realizadas para este estudio, una concesión castañera puede elaborar planes de manejo complementarios por volúmenes que pueden variar entre 70 y $188 \mathrm{~m}^{3} /$ año.

A diferencia de otras regiones, en Madre de Dios existen métodos de extracción de madera desarrollados para las condiciones ambientales específicas de la zona. Los medianos extractores informales son los más abundantes y operan utilizando camiones medianos con tracción en todos sus ejes denominados "triplex", así como la utilización simultánea de dos motosierras acopladas una con otra para el aserrío de troncas. Uno de estos extractores tiene la capacidad de aserrar $4,7 \mathrm{~m}^{3}$ en aproximadamente dos horas (a este sistema lo denominan "la torre"). Debido al medio de transporte con el que cuentan, no requieren abrir caminos o sendas para llegar hasta los árboles que se cortarán, debido a que el propio vehículo

Cuadro 35. Producción de madera en la provincia de Tambopata

\begin{tabular}{|c|c|c|c|c|c|c|}
\hline \multirow[t]{2}{*}{ Modalidad } & \multicolumn{5}{|c|}{ Volúmenes en miles de $\mathrm{m}^{3}$} & \multirow{2}{*}{$\begin{array}{l}\text { Participación } \\
\text { respecto al total } \\
\text { (en \%) }\end{array}$} \\
\hline & 2009 & 2010 & 2011 & 2012 & $\begin{array}{c}\text { Promedio } \\
2009-12\end{array}$ & \\
\hline Permisos & 294,6 & 71,7 & 124,0 & 112,2 & 150,6 & 50,1 \\
\hline Concesiones & 102,7 & 20,9 & 55,6 & 374,6 & 138,5 & 46,1 \\
\hline Autorizaciones & 0,2 & 0,1 & 21,5 & 17,8 & 9,9 & 3,3 \\
\hline Contratos & 0,3 & 1,0 & 0,6 & 3,8 & 1,4 & 0,5 \\
\hline Total generala & 397,8 & 93,7 & 201,7 & 508,4 & 300,4 & 100,0 \\
\hline
\end{tabular}

Fuente: Elaboración propia con base en los datos proporcionados por la Dirección Regional Forestal y de Fauna Silvestre de Madre de Dios, así como los datos parciales proporcionados por la Dirección General Forestal y de Fauna Silvestre del Ministerio de Agricultura.

Nota: a) Sin datos de carbón y leña de monte o chacra. 
Cuadro 36. Volúmenes de las principales especies de la madera producida en Tambopata

\begin{tabular}{|c|c|c|c|c|c|c|}
\hline \multirow[t]{2}{*}{ Especies } & \multicolumn{5}{|c|}{ Volúmenes en miles de $\mathrm{m}^{3}$} & \multirow{2}{*}{$\begin{array}{c}\text { Participación } \\
\text { respecto al } \\
\text { total (en \%) }\end{array}$} \\
\hline & 2009 & 2010 & 2011 & 2012 & $\begin{array}{c}\text { Promedio } \\
2009-12\end{array}$ & \\
\hline $\begin{array}{l}\text { Aspidosperma macrocarpon } \\
\text { (Pumaquiro) }\end{array}$ & 305,5 & 58,6 & 113,9 & 223,6 & 175,4 & 58,4 \\
\hline $\begin{array}{l}\text { Cedrelinga catenaeformis } \\
\text { (Tornillo) }\end{array}$ & 58,6 & 0,4 & 52,2 & 206,7 & 79,5 & 26,4 \\
\hline $\begin{array}{l}\text { Coumarouna odorata } \\
\text { (Shihuahuaco) }\end{array}$ & 7,1 & 2,9 & 11,8 & 23,6 & 11,4 & 3,8 \\
\hline Couratari guianensis (Misa) & 3,4 & 5,0 & 2,1 & 7,0 & 4,4 & 1,5 \\
\hline Dipterys ssp. (Shihuahuaco) & 4,2 & 4,6 & 2,2 & 5,3 & 4,1 & 1,4 \\
\hline $\begin{array}{l}\text { Hymenaea spp. (Azúcar } \\
\text { huayo) }\end{array}$ & 2,2 & 2,7 & 1,3 & 4,6 & 2,7 & 0,9 \\
\hline $\begin{array}{l}\text { Myroxylon balsamun } \\
\text { (Estoraque) }\end{array}$ & 0,6 & 5,6 & 2,6 & 1,4 & 2,6 & 0,8 \\
\hline Schizolobium sp. (Pashaco) & 3,4 & 1,5 & 1,5 & 3,2 & 2,4 & 0,8 \\
\hline Otro (130 especies) & 12,9 & 12,5 & 14,2 & 33,0 & 18,2 & 6,0 \\
\hline Total generala & 397,8 & 93,8 & 201,8 & 508,4 & 300,5 & 100,0 \\
\hline
\end{tabular}

Fuente: Elaboración propia con base en los datos proporcionados por la Oficina Técnica de Puerto Maldonado, así como los datos parciales proporcionados por la Dirección General Forestal y de Fauna Silvestre del Ministerio de Agricultura.

Nota: a) Sin datos de carbón y leña de monte o chacra.

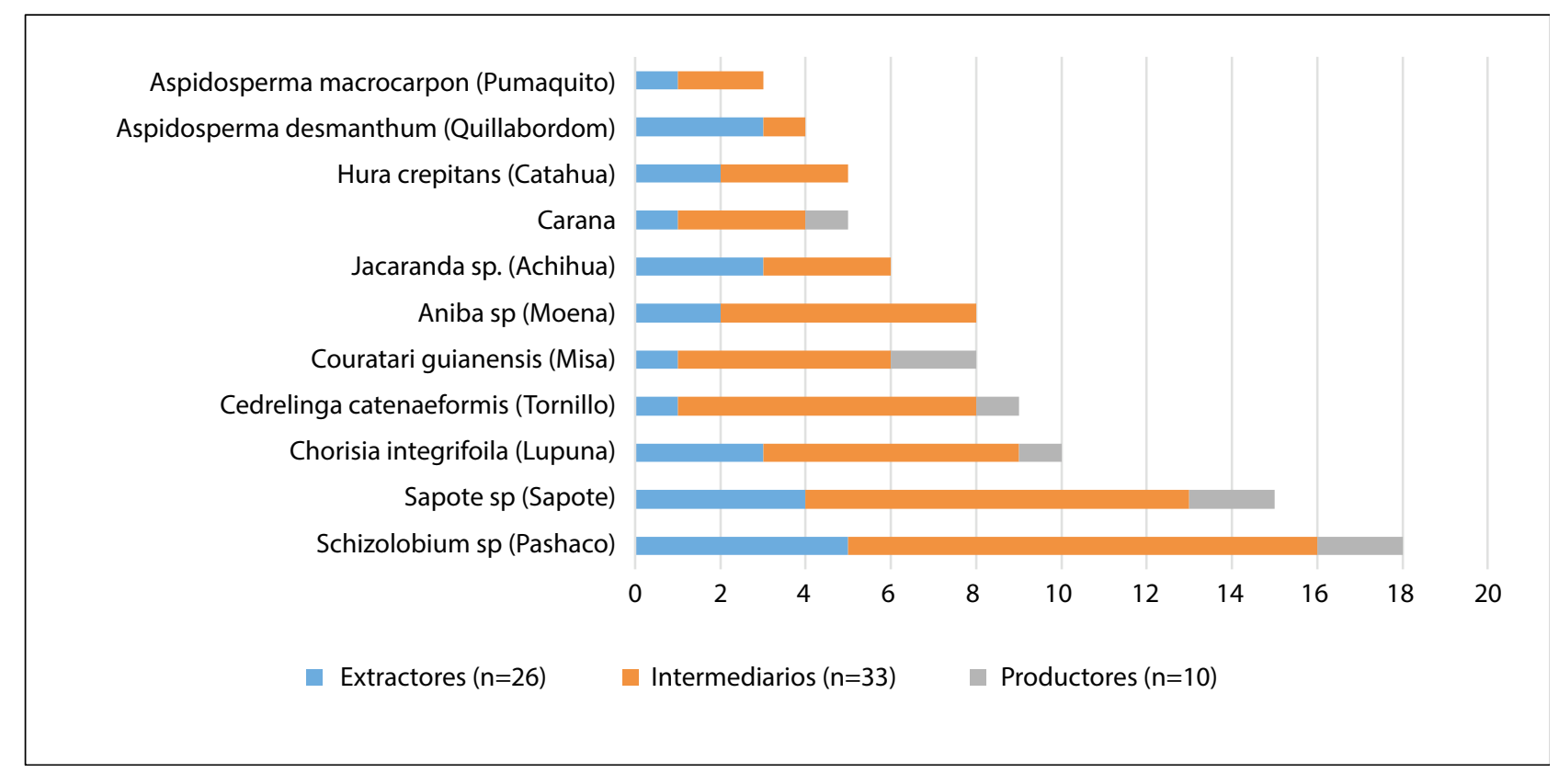

Figura 11. Frecuencia de las diez principales especies comercializadas por extractores e intermediarios en la provincia de Tambopata

Fuente: Elaboración propia con datos recolectados entre octubre de 2013 y marzo de 2014. 
Cuadro 37. Principales destinos de la madera producida en Tambopata

\begin{tabular}{|c|c|c|c|c|c|c|}
\hline & \multicolumn{5}{|c|}{ Volúmenes en miles de $\mathrm{m}^{3}$} & \multirow{2}{*}{$\begin{array}{l}\text { Participación } \\
\text { respecto al total } \\
\text { (en \%) }\end{array}$} \\
\hline & 2009 & 2010 & 2011 & 2012 & $\begin{array}{c}\text { Promedio } \\
2012-09\end{array}$ & \\
\hline Cusco & 386,7 & 86,6 & 188,7 & 454,9 & 279,2 & 92,9 \\
\hline Lima & 11,1 & 7,3 & 13,1 & 49,5 & 20,3 & 6,7 \\
\hline Ica & & & & 4,0 & 4,0 & 1,3 \\
\hline Total general ${ }^{a}$ & 397,8 & 93,8 & 201,8 & 508,4 & 300,5 & 100,0 \\
\hline
\end{tabular}

Fuente: Elaboración propia con base en los datos proporcionados por la Oficina Técnica de Puerto Maldonado, así como los datos parciales proporcionados por la Dirección General Forestal y de Fauna Silvestre del Ministerio de Agricultura.

Nota: a) Sin datos de carbón y leña de monte o chacra.

tiene la capacidad de abrir su propio camino. Estos actores poseen concesiones castañeras o madereras; extraen madera de sus propias tierras, pero también compran de otros concesionarios castañeros y madereros pequeńos que no cuentan con medios propios para extraer su madera.

El punto de venta de esta madera es en las viviendas de los extractores localizadas sobre la carretera transoceánica. En Madre de Dios se visitaron seis poblaciones distribuidas entre la frontera con Brasil y la ciudad de Puerto Maldonado. Todos los extractores de madera residen en estas poblaciones, pero operan en áreas de extracción que distan hasta tres horas de sus residencias. Las ocho especies más aprovechadas en Madre de Dios se describen en el Cuadro 36. De este grupo, las maderas blandas se comercializan generalmente en los mercados domésticos, mientras que las maderas duras son vendidas a las grandes empresas forestales exportadoras, que las comercializan luego de transformarlas en parquet y decking.

Como se observa en la Figura 11, en Tambopata y en Madre de Dios en general, existe una estrecha relación entre intermediarios y extractores y una reducida participación de pequeños productores en la movilización de madera. Esto se debe a que los intermediarios y extractores tienen establecidos sus métodos y redes de producción, que dependen en buena medida de lograr buenas relaciones de trabajo y de confianza. Para los actores de este corredor, las especies de mayor interés comercial son tornillo, lupuna, pashacho y sapote, que tienen cuatro destinos principales en el mercado doméstico.

La demanda de madera de Cusco alimenta una creciente industria del mueble y de la construcción. Según la Dirección Forestal de Madre de Dios, en Cusco existen 430 empresas de transformación, distribución y/o venta de madera para el mercado local. En Ica, la mayor demanda de madera es para la fabricación de parihuelas, cajas para productos agrícolas, industria del mueble y construcción en menor porcentaje. En esta ciudad existen solo 10 empresas de transformación y venta de madera. Una de estas está especializada en la fabricación de parihuelas y cajas de madera con una capacidad de procesamiento de $2300 \mathrm{~m}^{3} /$ año. En los distritos de Pisco, Chincha y Nazca existen empresas que compiten en la fabricación de estos mismos productos y que en conjunto pueden demandar más de $4000 \mathrm{~m}^{3}$ /año de madera. Ica produce el $25 \%$ de los espárragos que exporta el Perú, por tanto, tiene una gran demanda de cajas de madera y parihuelas. Los principales destinos de la madera de la provincia de Tambopata se describen a continuación, en el Cuadro 37.

\subsubsection{Circuito provincia de Tambopata- Arequipa-Puno-Moquegua-Tacna.}

El circuito inicia en la provincia de Tambopata en el departamento de Madre de Dios. Este presenta una mayor producción de madera de concesiones seguida por permisos, contratos y autorizaciones respectivamente, aunque el mayor porcentaje de la producción corresponde a las dos primeras modalidades (Cuadro 38). Esto se explica por los mercados de destino que demandan mayor calidad y pagan mejores precios para especies, blandas y duras, que se utilizan en la industria del mueble y la construcción, así como la fabricación de manufacturas para exportación de productos agrícolas. Estos estándares de calidad solo pueden ser alcanzados por empresas madereras grandes que cuentan con la tecnología y recursos para el tratamiento y transformación de madera, según los requerimientos del mercado. 
Cuadro 38. Producción de madera en las provincias de Tambopata con destino al corredor Arequipa y otros

\begin{tabular}{|c|c|c|c|c|c|c|}
\hline \multirow[t]{2}{*}{ Modalidad } & \multicolumn{5}{|c|}{ Volúmenes en miles de $\mathrm{m}^{3}$} & \multirow{2}{*}{$\begin{array}{l}\text { Participación } \\
\text { respecto al total } \\
\text { (en \%) }\end{array}$} \\
\hline & 2009 & 2010 & 2011 & 2012 & $\begin{array}{l}\text { Promedio } \\
2009-12\end{array}$ & \\
\hline Permisos & 31,7 & 18,8 & 211,9 & 389,6 & 163,0 & 55,0 \\
\hline Concesiones & 78,8 & 74,8 & 124,7 & 219,1 & 124,4 & 42,0 \\
\hline Autorizaciones & 0,2 & 0,1 & 5,8 & 25,3 & 7,9 & 2,7 \\
\hline Contratos & 0,5 & 1,0 & 0,6 & 1,8 & 1,0 & 0,3 \\
\hline Total general ${ }^{a}$ & 111,3 & 94,7 & 343,0 & 635,8 & 296,2 & 100,0 \\
\hline
\end{tabular}

Fuente: Elaboración propia con base en los datos proporcionados por la Oficina Técnica de Puerto Maldonado, así como los datos parciales proporcionados por la Dirección General Forestal y de Fauna Silvestre del Ministerio de Agricultura.

Nota: a) Sin datos de carbón y leña de monte o chacra.

\section{Cuadro 39. Volúmenes de las principales especies aprovechadas en Tambopata con destino Arequipa y otros destinos}

\begin{tabular}{|c|c|c|c|c|c|c|}
\hline \multirow[t]{2}{*}{ Especie } & \multicolumn{5}{|c|}{ Volúmenes en miles de $\mathrm{m}^{3}$} & \multirow{2}{*}{$\begin{array}{c}\text { Participación } \\
\text { respecto al } \\
\text { total (en \%) }\end{array}$} \\
\hline & 2009 & 2010 & 2011 & 2012 & $\begin{array}{l}\text { Promedio } \\
2009-12\end{array}$ & \\
\hline $\begin{array}{l}\text { Coumarouna odorata } \\
\text { (Shihuahuaco) }\end{array}$ & 48,4 & 35,6 & 124,3 & 282,9 & 122,8 & 41,5 \\
\hline Dipterys ssp (Shihuahuaco) & & & 145,9 & 169,7 & 157,8 & 53,3 \\
\hline $\begin{array}{l}\text { Cedrelinga catenaeformis } \\
\text { (Tornillo) }\end{array}$ & 19,7 & 17,9 & 18,0 & 36,1 & 22,9 & 7,7 \\
\hline Chorisia integrifolia (Lupuna) & 6,2 & 8,2 & 10,2 & 28,6 & 13,3 & 4,5 \\
\hline $\begin{array}{l}\text { Brosimum alicastrum } \\
\text { (Manchinga) }\end{array}$ & 0,3 & 0,3 & 0,2 & 31,7 & 8,1 & 2,7 \\
\hline Schizolobium sp. (Pashaco) & 6,1 & 6,4 & 6,6 & 11,2 & 7,6 & 2,6 \\
\hline $\begin{array}{l}\text { Hymenaea spp. (Azúcar } \\
\text { huayo) }\end{array}$ & 0,1 & 2,4 & 6,3 & 18,1 & 6,7 & 2,3 \\
\hline Couratari guianensis (Misa) & 5,4 & 6,2 & 4,2 & 10,0 & 6,5 & 2,2 \\
\hline Aniba sp. (Moena) & 3,9 & 4,5 & 4,9 & 8,1 & 5,4 & 1,8 \\
\hline Otras especies & 21,4 & 13,1 & 22,3 & 39,5 & 24,1 & 8,1 \\
\hline Total general $^{\mathrm{a}}$ & 111,3 & 94,7 & 343,0 & 635,8 & 296,2 & 100,0 \\
\hline
\end{tabular}

Fuente: Elaboración propia con base en los datos proporcionados por la Oficina Técnica de Puerto Maldonado, así como los datos parciales proporcionados por la Dirección General Forestal y de Fauna Silvestre del Ministerio de Agricultura.

Nota: a) Sin datos de carbón y leña de monte o chacra.

Los procedimientos para la extracción de madera en este circuito son los mismos que los descritos para el circuito anterior. No obstante, las relaciones de negocios entre extractores e intermediarios son menos formales. Los extractores venden su madera al mejor postor, no tienen tratos duraderos con intermediarios. Por este motivo, las utilidades pueden ser muy buenas en épocas de gran demanda de madera, o muy malos cuando la oferta sobrepasa la demanda local. Quienes no poseen depósitos para almacenaje venden la madera de forma rápida y a menor precio.

Las especies más movilizadas en este corredor no difieren sustancialmente del grupo identificado para el corredor Tambopata-Cusco-Ica-Lima, aunque el mayor volumen aprovechado corresponde al shihuahuaco, cuya madera es 
Cuadro 40. Principales destinos de la madera producida en Tambopata con destino Arequipa y otros destinos

\begin{tabular}{|c|c|c|c|c|c|c|}
\hline & \multicolumn{5}{|c|}{ Volúmenes en miles de $\mathrm{m}^{3}$} & \multirow{2}{*}{$\begin{array}{c}\text { Participación } \\
\text { respecto al } \\
\text { total (en \%) }\end{array}$} \\
\hline & 2009 & 2010 & 2011 & 2012 & $\begin{array}{l}\text { Promedio } \\
2009-12\end{array}$ & \\
\hline Arequipa & 41,8 & 52,7 & 163,9 & 244,0 & 125,6 & 42,4 \\
\hline Puno & 48,1 & 32,2 & 69,9 & 208,2 & 89,6 & 30,2 \\
\hline Tacna & 7,5 & 7,9 & 107,5 & 179,0 & 75,5 & 25,5 \\
\hline Moquegua & 13,9 & 1,9 & 1,7 & 4,5 & 5,5 & 1,9 \\
\hline Total general ${ }^{a}$ & 111,3 & 94,7 & 343,0 & 635,8 & 296,2 & 100,0 \\
\hline
\end{tabular}

Fuente: Elaboración propia con base en los datos proporcionados por la Oficina Técnica de Puerto Maldonado, así como los datos parciales proporcionados por la Dirección General Forestal y de Fauna Silvestre del Ministerio de Agricultura.

Nota: a) Sin datos de carbón y leña de monte o chacra.

utilizada en la industria del mueble (Cuadro 39). La lupuna no es una madera con valor industrial y comercial en Madre de Dios debido a su rápido proceso de deterioro en climas húmedos y cálidos; no obstante, es muy cotizada en climas secos y fríos, como Arequipa o Puno, donde se utiliza para trabajos de mueblería.

Los principales destinos de la madera de este corredor son Arequipa, Puno, Tacna y Moquegua (Cuadro 40). En la ciudad de Arequipa existe una importante industria maderera especializada en la fabricación de muebles de diferente calidad y manufactura para la industria de la construcción. También se consumen aglomerados que se fabrican en Lima con madera procedente de Tambopata o importada de Ecuador y Chile. Un consumidor importante de madera es la industria del acero localizada en esta ciudad, que demanda embalajes y soportes para productos semiprocesados que se comercializan en el Perú y países vecinos como Bolivia, Brasil, Chile y Argentina. La actividad minera es otro consumidor de madera en Arequipa. El proceso de modernización que ha experimentado este rubro en los últimos 10 años, junto al crecimiento de otros importantes rubros productivos, han permitido que Arequipa tenga el segundo PIB más alto del Perú, luego de Lima, y se constituya en un importante mercado de la madera. Actualmente en Arequipa existen registradas 1173 instalaciones de transformación, distribución y/o venta de madera, aunque según el Programa Produce del Ministerio de Agricultura, esta cifra podría ser mucho mayor, debido a que existen muchas empresas informales.
Puno, Tacna y Moquegua son ciudades en crecimiento, cuya demanda de madera está concentrada en los rubros de la construcción y mueblería en general. Tacna y Moquegua tienen actividades agrícolas en desarrollo que se destinan en buena medida a la exportación, lo que demanda madera para la construcción de embalajes de productos agrícolas.

\subsubsection{Circuito Tahuamanu-Puno-Moquegua}

En Tahuamanu se concentra la mayor cantidad de concesiones de castańa otorgadas en toda la región de Madre de Dios. No obstante, el mayor porcentaje de madera se produce en concesiones madereras (Cuadro 41). Esto puede deberse a vínculos entre empresas madereras grandes e intermediarios. Estos últimos acopian madera de extractores y productores con derechos en áreas de concesión de castańa que venden al mejor precio ofertado por empresas madereras grandes. Según las versiones de los actores entrevistados en este circuito, la empresa Bozovich ha estado utilizando esta estrategia desde hace algún tiempo.

En este mismo corredor se encuentra el único ejemplo de manejo forestal entre comunidad indígena y empresa forestal de Madre de Dios. La empresa Maderija SAC tiene un contrato de extracción de madera con la Comunidad Indígena La Bélgica. La empresa ha estado extrayendo entre 9000 y $10.000 \mathrm{~m}^{3} /$ año de shihuahuaco, azúcar huayo e ishpingo, aunque en el contrato figuran 12 especies. Esta empresa provee de madera a la empresa Nature Wood Pte Ltd, una de las más grandes exportadoras de pisos y "decking" a China. 
Cuadro 41. Producción de madera en la provincia de Tahuamanu

\begin{tabular}{lrrrrrr}
\hline Modalidad & \multicolumn{3}{c}{ Volúmenes en miles de $\mathbf{m}^{3}$} & \multicolumn{2}{c}{$\begin{array}{c}\text { Participación } \\
\text { respecto al total } \\
\text { (en \%) }\end{array}$} \\
\cline { 2 - 6 } & $\mathbf{2 0 0 9}$ & $\mathbf{2 0 1 0}$ & $\mathbf{2 0 1 1}$ & $\mathbf{2 0 1 2}$ & $\begin{array}{c}\text { Promedio } \\
\mathbf{2 0 0 9 - 1 2}\end{array}$ & $\begin{array}{c}\text { (2012 } \\
\text { Permisos }\end{array}$ \\
Concesiones & 12,7 & 11,9 & 5,6 & 5,3 & 8,9 & 69,4 \\
Autorizaciones & 4 & 2,4 & 2,4 & 5,2 & 3,5 & 27,4 \\
Contratos & 0,2 & 0,2 & 0,3 & 0,1 & 0,2 & 1,6 \\
Total general $^{\mathrm{a}}$ & 0 & 0 & 0 & 0,8 & 0,2 & 1,6 \\
\hline
\end{tabular}

Fuente: Elaboración propia con base en los datos proporcionados por la Oficina Técnica de Puerto Maldonado, así como los datos parciales proporcionados por la Dirección General Forestal y de Fauna Silvestre del Ministerio de Agricultura.

Nota: a) Sin datos de carbón y leña de monte o chacra.

Cuadro 42. Volúmenes de las principales especies extraídas en Tahuamanu

\begin{tabular}{|c|c|c|c|c|c|c|}
\hline \multirow[t]{2}{*}{ Especie } & \multicolumn{5}{|c|}{ Volúmenes en miles de $\mathrm{m}^{3}$} & \multirow{2}{*}{$\begin{array}{c}\text { Participación en } \\
\text { el total } \\
\text { (en \%) }\end{array}$} \\
\hline & 2009 & 2010 & 2011 & 2012 & $\begin{array}{l}\text { Promedio } \\
2009-12\end{array}$ & \\
\hline Couratari guianensis (Misa) & 3,4 & 3,2 & 1,4 & 1,5 & 2,4 & 18,6 \\
\hline $\begin{array}{l}\text { Cedrelinga catenaeformis } \\
\text { (Tornillo) }\end{array}$ & 2,7 & 1,6 & 0,8 & 0,8 & 1,5 & 11,5 \\
\hline Schizolobium sp. (Pashaco) & 2,1 & 1,7 & 1,1 & 1,0 & 1,5 & 11,5 \\
\hline $\begin{array}{l}\text { Chorisia integrifolia } \\
\text { (Lupuna) }\end{array}$ & 1,9 & 1,5 & 0,8 & 1,3 & 1,4 & 10,7 \\
\hline Otras (105 especies) & 5,6 & 5,5 & 3,8 & 6,3 & 5,3 & 41,4 \\
\hline Total general ${ }^{\mathrm{a}}$ & 16,9 & 14,6 & 8,3 & 11,4 & 12,8 & 100,0 \\
\hline
\end{tabular}

Fuente: Elaboración propia con base en los datos proporcionados por la Oficina Técnica de Puerto Maldonado, así como los datos parciales proporcionados por la Dirección General Forestal y de Fauna Silvestre del Ministerio de Agricultura.

Nota: a) Sin datos de carbón y leña de monte o chacra.

Cuadro 43. Principales destinos de la madera producida en Tahuamanu

\begin{tabular}{|c|c|c|c|c|c|c|}
\hline & \multicolumn{5}{|c|}{ Volúmenes en miles de $\mathrm{m}^{3}$} & \multirow{2}{*}{$\begin{array}{l}\text { Participación } \\
\text { en el total } \\
\text { (en \%) }\end{array}$} \\
\hline & 2009 & 2010 & 2011 & 2012 & $\begin{array}{c}\text { Promedio } \\
2009-12\end{array}$ & \\
\hline Puno & 16,6 & 14,4 & 8,2 & 11,4 & 12,7 & 98,8 \\
\hline Moquegua & 0,1 & 0,1 & 0,1 & 0,0 & 0,1 & 0,6 \\
\hline Tacna & 0,2 & 0,0 & 0,0 & 0,0 & 0,1 & 0,4 \\
\hline Total general & 16,9 & 14,6 & 8,3 & 11,4 & 12,8 & 100,0 \\
\hline
\end{tabular}

Fuente: Elaboración propia con base en los datos proporcionados por la Oficina Técnica de Puerto Maldonado, así como los datos parciales proporcionados por la Dirección General Forestal y de Fauna Silvestre del Ministerio de Agricultura.

Nota: a) Sin datos de carbón y leña de monte o chacra. 


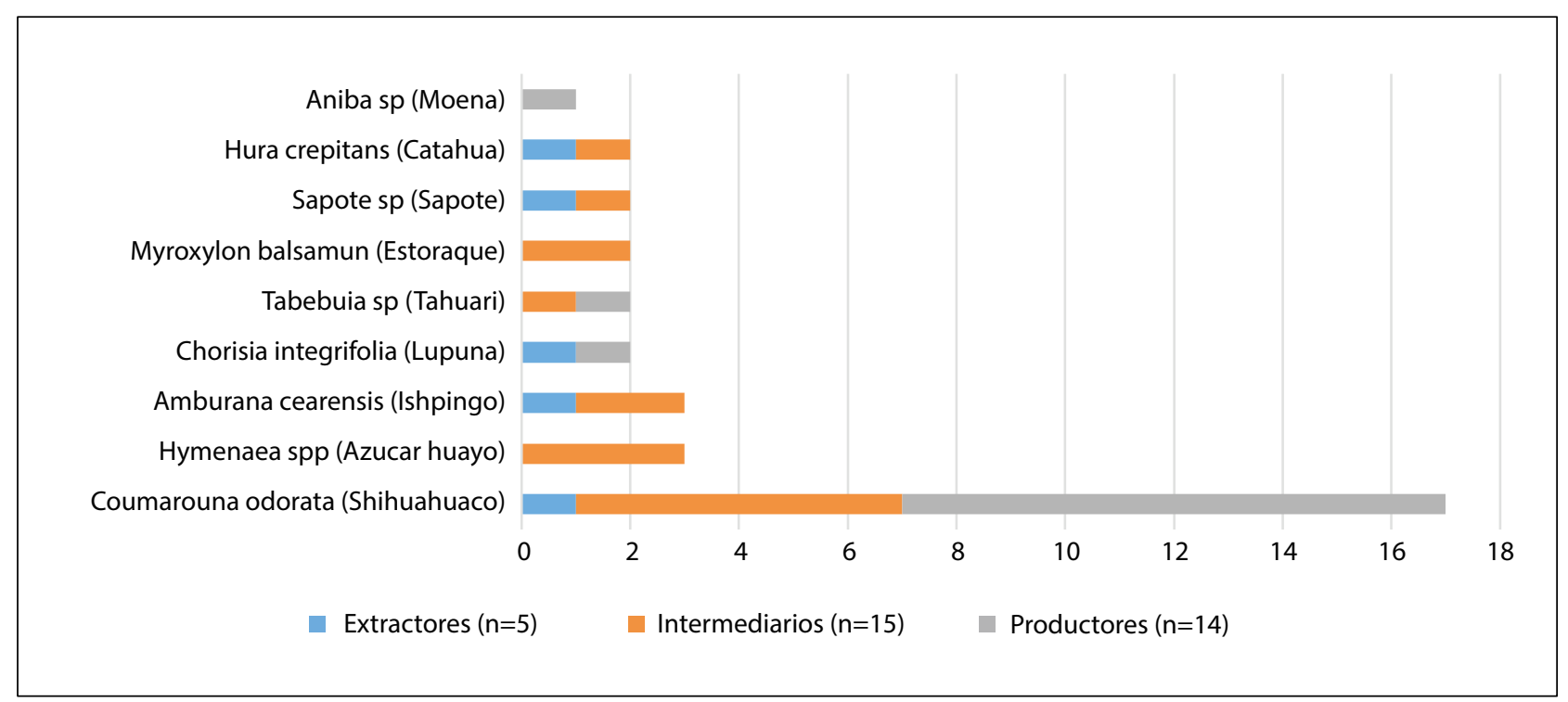

Figura 12. Frecuencia de las nueve principales especies comercializadas por extractores, intermediarios y productores en la provincia de Tahuamanu

Fuente: Elaboración propia con datos recolectados entre julio de 2013 y marzo de 2014.

Las especies más movilizadas en este corredor son misa, tornillo, pashaco y lupuna, especies muy utilizadas en la industria del mueble y la construcción (Cuadro 42). Es importante resaltar que en Tahuamanu están instalados la mayor cantidad de aserraderos de empresas madereras con concesiones forestales. De esta región sale madera reaserrada en tablillas y madera comercial larga y corta. El bajo volumen de extracción de madera en comparación con los anteriores circuitos se debe a que en Tahuamanu se encuentra la mayor cantidad de concesiones forestales de gran tamaño, cuyo destino es la exportación y no el mercado doméstico.

Debido a la presencia de aserraderos, existe una mayor participación de productores en la extracción de shihuahuaco, una especie muy cotizada por estas empresas (Figura 12). Según entrevistas de campo, la venta de madera de productores a empresas madereras puede ser a través de intermediarios o de forma directa, en ambos casos siguiendo estrategias informales. El paso más complicado para la venta de madera es la obtención de GTF, que son adquiridas irregularmente por tramitadores.

El destino principal de la madera que sale de Tahuamanu es Puno, Moquegua y Tacna, en ese orden de importancia (ver Cuadro 43). El uso final de la madera en estos destinos es el mismo descrito en el corredor Tambopata-Arequipa-Moquegua-Tacna.

\subsection{Circuitos internacionales}

En el caso de las exportaciones, los datos analizados de las guías de transporte forestal muestran varios países de destino para las exportaciones de madera. Tomando los datos analizados en este capítulo sobre los circuitos internos, en el período de 2009 a 2012, se puede observar que para las tres regiones el $98 \%$ de las cantidades movilizadas terminan en un destino nacional. En este sentido y al no contar con un sistema de información integrado es difícil seguir la trazabilidad de la madera hasta el destino de exportación final. Sin embargo con los datos de exportaciones de Aduanas y UN-COMTRADE (2012 y 2013) se realizó el análisis de los quince exportadores más importantes del Perú relacionados a los mercados de Loreto, Ucayali y Madre de Dios, para intentar definir los destinos principales y las cantidades movilizadas fuera del Perú. Los resultados de este análisis se presentan en los Cuadros 44 y 45.

Los principales circuitos asociados a Loreto tienen sus principales destinos en México y Estados Unidos, debido a que existen empresas con capitales de estos países en la región. En el mismo sentido, el principal destino internacional del corredor de Ucayali es China, dado que un clúster fuerte de empresas con financiamiento de este país se ubica en Pucallpa. Madre de Dios, tiene una relación más variada de destinos hacia 
China, Estados Unidos y Europa, debido a que sus operaciones se encuentran financiadas por empresas nacionales que exportan a diferentes destinos y un pequeño clúster de empresas con capital chino. A pesar del seguimiento realizado de los datos oficiales, es difícil definir el origen real de la madera a nivel de distrito, por lo cual la confiabilidad de los análisis está más relacionada con las regiones.

Los datos muestran que existen diez empresas que aglomeran las exportaciones de madera en el Perú y que son también las compradoras más grandes de los circuitos nacionales analizados en este capítulo. Por citar un ejemplo, en el caso de una empresa exportadora para el período 2009-2012, la SUNAT (2013) registra 46.090,3 $\mathrm{m}^{3}$ exportados. En el mismo período los registros del Ministerio de Agricultura muestran que esta empresa captó aproximadamente $100.000 \mathrm{~m}^{3}$ de madera, o un promedio de $25.000 \mathrm{~m}^{3} /$ ańo, proveniente de concesiones, permisos y autorizaciones de Loreto, Ucayali y Madre de Dios. Sin embargo, al revisar las GTF, no se indica el país final de la madera, sino el destino final en el distrito de Lurín en Lima, donde se encuentra la oficina y planta principal de esta empresa. Posteriormente esta empresa para exportación tendrá que pedir los permisos respectivos a la Dirección General Forestal y entonces mostrar las GTF de la madera a exportar como requisito. La trazabilidad de este procedimiento se puede únicamente seguir para maderas CITES: caoba y cedro, a través del portal de información pública. Estas dos especies representan el $30 \%$ de las exportaciones, quedando un vacío del otro $70 \%$ exportado. Esta empresa exporta principalmente a China y Estados Unidos y, a pesar de su volumen de producción, no tiene ninguna concesión o área asignada.

Por otro lado, a pesar de la aglomeración de madera para exportación en pocas empresas, existen otros pequeńos exportadores considerados pequeñas y medianas empresas (PYMES), que mantienen cierto tipo de tecnificación y cubren con pequeños volúmenes sus costos operativos. Sin embargo, según entrevistas realizadas a lo largo de este estudio, la falta de inversión adecuada mantiene a estos actores apartados de mejoras en su producción y en consecuencia de una mejor participación en el mercado. Asimismo, estos actores no tienen acceso a áreas de producción como concesiones y en muchos casos no tienen interés en integrar sus operaciones debido a que no encuentran un incentivo económico adecuado, por lo que fungen como intermediarios y transformadores de madera.

Únicamente el 30\% de las empresas exportadoras entrevistadas tienen zonas de producción en los bosques de las regiones aquí analizadas, mientras que el $70 \%$ restante compran madera para transformarla y enviarla a su destino final fuera del Perú. Ninguno de los entrevistados realiza inversiones relacionadas a mejorar el volumen de madera en los bosques nativos aunque admitieron el interés en las plantaciones forestales. Asimismo, estas empresas no trabajan al $100 \%$ de la capacidad de planta debido a que no son abastecidos con materia prima. En promedio, las empresas manifestaron procesar madera al $67 \%$ de su capacidad. 
Cuadro 44. Principales vendedores (exportadores) y destinos finales entre 2009 y 2012 (en miles de USD FOB)

\begin{tabular}{|c|c|c|c|c|c|c|c|c|c|c|c|}
\hline & Canadá & China & R. Dominicana & Francia & $\begin{array}{l}\text { Hong Kong } \\
\text { (China) }\end{array}$ & México & Suecia & $\begin{array}{l}\text { Estados } \\
\text { Unidos }\end{array}$ & Venezuela & $\begin{array}{c}\text { Total } \\
\text { general }\end{array}$ & $\%$ \\
\hline Empresa 1 & - & 6046,1 & - & 225,2 & - & 34,5 & - & 304,8 & - & 6610,5 & 1,1 \\
\hline Empresa 2 & - & 8867,4 & 14,0 & 385,0 & 25,1 & 88,9 & - & 206,1 & - & 9586,4 & 1,5 \\
\hline Empresa 3 & - & - & 200,7 & - & - & $11.723,1$ & - & 3987,7 & - & $15.911,6$ & 2,6 \\
\hline Empresa 4 & - & 9212,4 & - & - & - & - & - & - & - & 9212,4 & 1,5 \\
\hline Empresa 5 & - & $35.029,3$ & - & 2698,4 & 111,8 & - & - & 256,6 & - & $38.096,2$ & 6,1 \\
\hline Empresa 6 & - & 7077,5 & - & 157,3 & 58,6 & 9037,8 & - & - & 2989,9 & $19.374,1$ & 3,1 \\
\hline Empresa 7 & 571,6 & 78,1 & 861,1 & - & - & 9640,7 & - & 2299,5 & 19,3 & $13.470,3$ & 2,2 \\
\hline Empresa 8 & - & 511,3 & - & - & - & $13.010,8$ & - & 1705,5 & - & $15.227,6$ & 2,4 \\
\hline Empresa 9 & 3045,1 & $19.278,0$ & 7825,2 & 1035,8 & 512,6 & $25.041,3$ & 5572,0 & $19.175,8$ & - & $81.552,0$ & 13,1 \\
\hline Empresa 10 & 570,0 & 3879,1 & 5253,5 & 1167,3 & 166,7 & 3305,2 & 218,2 & $12.134,6$ & 47,5 & $26.741,9$ & 4,3 \\
\hline Empresa 11 & 189,0 & $11.925,1$ & - & 19,4 & 22,0 & - & - & 3312,1 & - & $15.502,1$ & 2,5 \\
\hline Empresa 12 & - & - & 332,7 & - & - & $34.673,3$ & - & - & 1705,0 & $36.739,5$ & 5,9 \\
\hline Empresa 13 & 597,3 & 5777,1 & - & 337,3 & 192,7 & 33,0 & - & 7404,3 & - & $14.457,8$ & 2,3 \\
\hline Empresa 14 & - & 7100,0 & - & - & 14,7 & - & - & - & - & 7114,7 & 1,1 \\
\hline Total 14 mejores & 4973,0 & $134.377,6$ & $14.835,7$ & 6025,6 & 1773,6 & $111.743,3$ & 5790,2 & $50.836,5$ & 4761,6 & $335.415,2$ & 53,8 \\
\hline Otros (1282 vendedores) & 2,1 & 119,4 & 10,9 & 5,8 & 3,7 & 79,5 & 0,2 & 58,6 & 1,0 & 287,7 & 46,2 \\
\hline Total general & 7,1 & 253,8 & 25,7 & 11,9 & 5,5 & 191,2 & 6,0 & 109,5 & 5,7 & 623,1 & 100,0 \\
\hline
\end{tabular}

Fuente: Elaboración propia con base en datos de Aduanas y COMTRADE (2013). 
Cuadro 45. Principales vendedores (exportadores) y destinos finales entre 2009 y 2012 (en miles de $\mathrm{m}^{3}$ )

\begin{tabular}{|c|c|c|c|c|c|c|c|c|c|c|c|c|}
\hline & China & Costa rica & Francia & Israel & Italia & México & Polonia & Suecia & Estados unidos & Venezuela & Total general & $\%$ \\
\hline Empresa 1 & 47,8 & - & 23,8 & 0,01 & - & 0,1 & 0,0 & - & - & - & 71,8 & 4,6 \\
\hline Empresa 2 & 183,9 & - & 0,3 & 0,1 & - & 0,1 & - & - & 0,1 & - & 184,5 & 11,9 \\
\hline Empresa 3 & - & 39,3 & 48,9 & - & - & - & - & - & - & - & 88,2 & 5,7 \\
\hline Empresa 4 & 78,6 & - & - & - & - & - & - & - & 0,0 & - & 78,6 & 5,1 \\
\hline Empresa 5 & 52,1 & - & 1,3 & 0,0 & - & - & 0,1 & - & 0,0 & - & 53,5 & 3,5 \\
\hline Empresa 6 & 50,2 & 0,9 & 0,0 & 23,7 & 2,0 & - & 18,0 & - & 0,1 & - & 95,0 & 6,1 \\
\hline Empresa 7 & 103,6 & 0,1 & 0,1 & - & - & 16,6 & - & - & - & 5,5 & 125,9 & 8,1 \\
\hline Empresa 8 & 52,8 & - & - & - & - & 0,0 & - & - & - & - & 52,9 & 3,4 \\
\hline Empresa 9 & 20,5 & - & 0,6 & 0,9 & - & 17,9 & - & 3,6 & 2,6 & - & 46,1 & 3,0 \\
\hline Empresa 10 & - & - & - & - & - & - & - & - & 94,0 & - & 94,0 & 6,1 \\
\hline $\begin{array}{l}\text { OTROS (1287 } \\
\text { vendedores) }\end{array}$ & - & - & - & - & - & - & - & - & - & - & 657,0 & 42,5 \\
\hline Total general & 589,7 & 40,3 & 75,1 & 24,8 & 2,0 & 34,6 & 18,1 & 3,6 & 96,7 & 5,5 & 1547,4 & 100,0 \\
\hline
\end{tabular}

Fuente: Elaboración propia con base en datos de Adunas y COMTRADE (2013). 


\section{Factores asociados con la ilegalidad en el aprovechamiento forestal}

Distintas son las dimensiones de la informalidad vinculadas con el aprovechamiento y la comercialización de la madera en la Amazonía peruana. Estas dimensiones están relacionadas con la tenencia y el acceso a los recursos forestales, los mecanismos que define la normativa sobre el aprovechamiento del bosque, y el uso de la habilitación y otros créditos informales. Estos temas que se analizan a continuación fueron identificados en entrevistas con los actores forestales.

\subsection{Acceso informal al bosque y corta ilegal}

El acceso informal al bosque es el primer paso en la corta ilegal de madera. Los actores que operan con escalas mayores son quienes de cierta forma logran sobrepasar los conflictos inmediatos de acceso al bosque, en especial con las autoridades forestales en el momento de la obtención de los permisos y con las entidades que financian las operaciones de aprovechamiento. A medida que las operaciones decrecen en tamaño, los conflictos por el acceso al bosque aumentan, en parte porque las instituciones del Estado y la legislación están mejor diseñadas para apoyar el manejo de grandes extensiones de bosque. Sin embargo, las operaciones a pequeña escala son importantes en la obtención de madera. Estas operaciones están relacionadas con actores pequeńos conocidos como pequeños extractores y pequeños productores ${ }^{38}$.

Según la información empírica de este estudio, los actores más pequeños acceden a los bosques de manera informal o realizan cortas dentro de sus propiedades sin ninguna autorización. Asimismo, algunos medianos extractores optan por cortas informales para compensar piezas o árboles con daños patológicos o de corta dentro de los programas formales o para el comercio transfronterizo de

38 "Pequeños extractores" denota al grupo de actores que utilizan motosierras y realizan pequeñas cortas selectivas de madera dura. madera, que implica también la corta de madera en zonas no autorizadas.

Los extractores informales pequeños y medianos prefieren trabajar en lugares alejados, por lo general en asentamientos sin titulación o invasiones ${ }^{39}$ debido a que existe más madera disponible de las especies con demanda, como shihuahuaco y tornillo. El 65\% de los pequeños extractores entrevistados afirmaron trabajar en los últimos tres pueblos de las subcuencas analizadas, es decir, aproximadamente a dos días de viaje desde el inicio de la subcuenca. También se distinguió que los pueblos más cercanos, entre dos y cinco horas de viaje por río ${ }^{40}$, suministran más especies de regeneración como bolaina, topa y capirona. En muchos de los casos, la presencia de los pequeños extractores se da cuando ya existen pobladores en asentamientos sin título de propiedad.

Las invasiones ocurren por lo general en zonas de amortiguamiento de las áreas protegidas, bosques de producción permanente sin adjudicación (dentro o fuera de comunidades indígenas) y concesiones forestales. Las invasiones ocurren por parte de migrantes, quienes cortan la madera encontrada en una porción del terreno invadido, en parte incentivados por la idea de demostrar posesión a través de cultivos agrícolas como lo sugiere la ley. En el caso de este estudio se documentaron tres casos diferentes en los cuales la principal causa que impulsó estas invasiones fue el tráfico de tierras. Las tierras se comercializan a través de redes de personas que otorgan títulos ficticios a las personas invasoras con promesas de créditos productivos o simplemente posesión formal. Una vez que un miembro de la familia realiza este procedimiento, es más probable que otro miembro de la familia decida iniciar un proceso de invasión ${ }^{41}$.

39 Nuevos asentamientos o invasiones de tierra del patrimonio del Estado.

40 En embarcación peke-peke, un bote de aproximadamente 2 toneladas de capacidad con un motor de hasta $13 \mathrm{hp}$ de potencia.

41 Entrevistas realizadas en la zona de Yurimaguas en febrero de 2014. 


\section{Recuadro 3. El caso de la concesiones de Padre Abad, Ucayali}

Las concesiones de Padre Abad tienen la mejor accesibilidad por carretera, a diferencia de las concesiones del Alto y Bajo Ucayali; por tal razón, uno de los principales problemas que enfrentan son las invasiones. Estas son principalmente de personas en búsqueda de tierras para formar asentamientos humanos con el propósito de construir viviendas y en otros casos para cultivar coca. Este fenómeno no ha podido ser controlado por la autoridad ni por los titulares debido a que existe un fuerte componente de tráfico de tierras. Durante este estudio, se pudo realizar entrevistas informales con grupos de personas que mantienen propiedades dentro de las concesiones, quienes opinaron que esas tierras cuentan con permisos entregados por las personas que les vendieron los lotes de terreno. Sin embargo, el Ministerio de Agricultura, por su parte, garantiza que no se han entregado títulos de ninguna índole en tierras de concesiones.

\subsection{Mecanismos para sobrepasar las barreras legales}

Muchos de los problemas entre los actores y la autoridad forestal y de control se relacionan con el pago de los sobornos. De los entrevistados, 176 afirmaron haber pagado "sobornos por un total de 445.710 nuevos soles (USD 16.000) para movilizar $224.065 \mathrm{~m}^{3}$, o sea 1,8 nuevos soles $/ \mathrm{m}^{3}$ (USD $0,52 / \mathrm{m}^{3)}$. En promedio quienes pagaron más sobornos fueron los concesionarios, extractores e intermediarios de los grupos denominados grandes, seguidos de los pequeños extractores e intermediarios. Según la información recogida, este dinero principalmente se utilizó para los siguientes propósitos, en orden de importancia: a) para el pago a la policía en los principales puertos y en las carreteras y b) para el pago de las autoridades en las oficinas técnicas.

Los concesionarios entrevistados aseguraron que la gestión de cualquier trámite relativo al aprovechamiento forestal, sin importar el volumen a ser aprovechado o el tipo de actor, resulta extremadamente burocrático. Los grandes usuarios del bosque recurren a sobornos para acelerar sus trámites y aceptan esta situación porque consideran que los salarios en las instituciones estatales de fiscalización y control forestal son muy bajos. En vista de este comportamiento se han implementado varias regulaciones, siendo la más reciente la Resolución Ministerial Nº 0280-2014-MINAGRI, la que se enmarca dentro del Plan Sectorial de Lucha contra la Corrupción del MINAGRI; período 2014-2016 (16/05/14) y que busca mejorar la transparencia de la institución ${ }^{42}$.

42 Disponible en http://minagri.gob.pe/portal/download/ $\mathrm{pdf} / \mathrm{marcolegal} /$ normaslegales/resolucionesministeriales/2014/ mayo/rm280-2014-minagri.pdf.
Los concesionarios entrevistados proporcionaron información sobre los conflictos que tienen con la autoridad, sea el SERFOR o el OSINFOR. El $85 \%$ de los entrevistados tanto en las concesiones de madera como de castańa respondieron haber tenido un problema con la autoridad forestal entre 2012 y 2013. Los principales problemas de los concesionarios se detallan en la Figura 13, siendo el más mencionado el cobro de sobornos y la venta de guías de transporte forestal ficticias por parte de las autoridades a terceras personas, lo cual crea una competencia desleal. Asimismo, objetan que la ley y los reglamentos no están acorde a la realidad y es por esta razón que OSINFOR ha cerrado o multado a varios concesionarios. A pesar de que los concesionarios han tenido problemas con el control por parte de la autoridad, el 61\% de los entrevistados manifestaron que perdieron más madera por causa del clima y el pobre estado de las vías de acceso, que por las confiscaciones o retenciones de la madera.

Los pequeños extractores son los actores que indicaron tener más conflicto con la autoridad forestal y de control (Figura 14). En este sentido, existe una clara disputa sobre los pagos de sobornos tanto para la autoridad forestal y la policía, quienes, según los entrevistados, han formado redes importantes de extorsión. La situación de informalidad de los pequeños actores ha creado enfrentamientos directos con estas redes, como el caso de Yurimaguas y Pucallpa. En estas localidades los pequeños extractores han formado asociaciones para exigir su inclusión dentro de la nueva Ley Forestal No 29763. Esta ley únicamente ha reforzado la noción de los bosques locales ${ }^{43} y$

43 Los bosques locales son otorgados mediante autorizaciones y permisos a las poblaciones rurales y centros poblados para el aprovechamiento sostenible de los recursos forestales. 


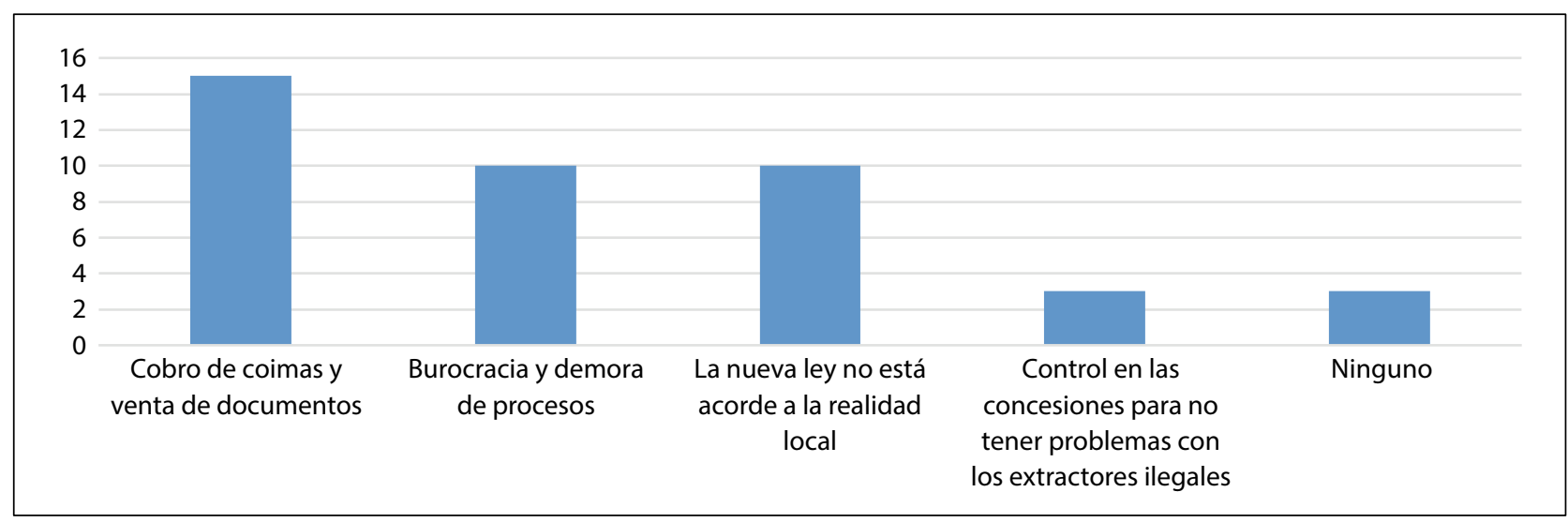

Figura 13. Conflictos de los concesionarios con la autoridad $(n=22)$

Fuente: Elaboración propia con base en entrevistas conducidas entre julio de 2013 y marzo de 2014.

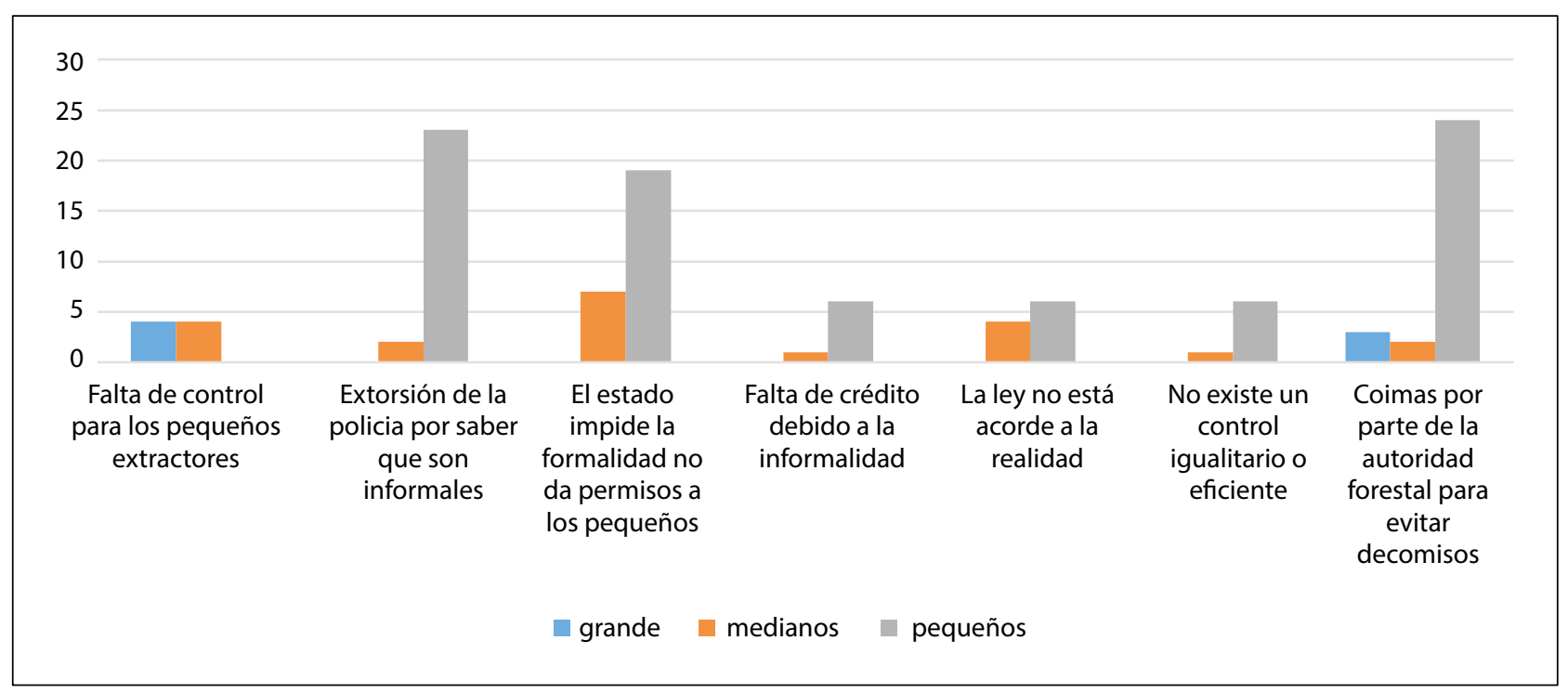

Figura 14. Conflictos de los extractores con la autoridad forestal y de control $(n=110)$

Fuente: Elaboración propia con base en las entrevistas realizadas entre julio de 2013 y marzo de 2014.

permisos como alternativa para los más pequeños, aunque no enfatiza ningún tipo de mecanismo financiero para que estos actores logren competir en mercados formales ${ }^{44}$.

Los extractores medianos y grandes manifestaron tener problemas serios con los sobornos en menor grado. En estos grupos los entrevistados opinaron que la autoridad debería poner más control sobre los pequeños extractores para evitar que la madera ilegal afecte los precios en el mercado

44 Participación del Presidente de los pequeños productores de Ucayali en el debate de la Ley No 29763 realizado en la ciudad de Pucallpa en octubre de 2014. local. Los problemas de legalidad para estos actores están relacionados con el tiempo de espera por aprobación de los POA, que pueden demorar entre tres meses y un año y las resoluciones de corta que, a pesar de estar disponibles en diciembre de cada año, son efectivas en agosto, mientras que la corta, por cuestiones del clima, se inicia en abril y mayo.

Los intermediarios grandes manifestaron no tener problemas con la autoridad, debido a que los pagos de sobornos representan un costo mínimo dentro de sus operaciones. Son los intermediarios medianos a muy pequeños quienes se ven con mayor frecuencia inmersos en conflictos por esta causa. La percepción de estos actores es que 


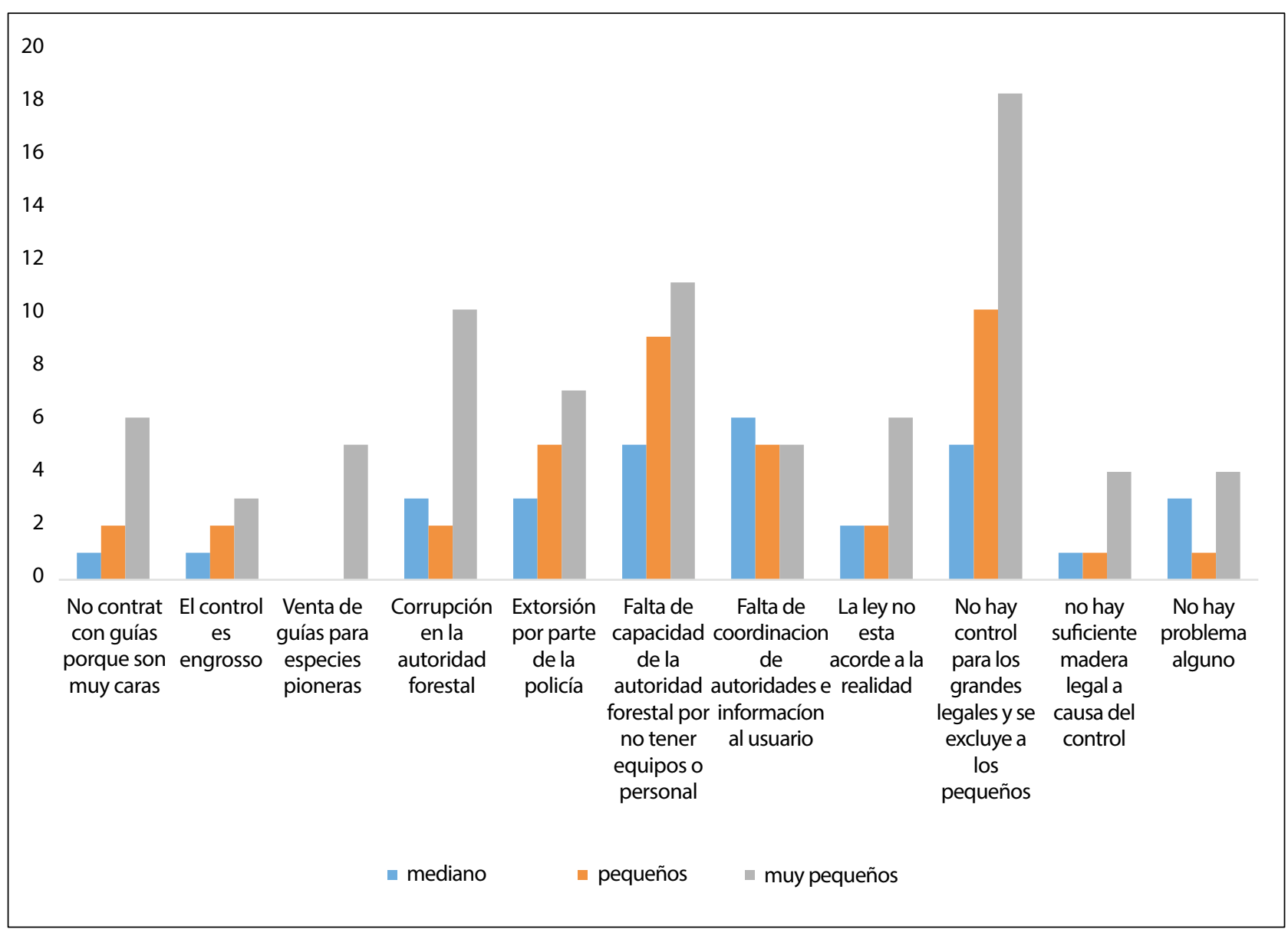

Figura 15. Conflictos de los intermediarios con la autoridad $(n=250)$

Fuente: Elaboración propia con base en las entrevistas realizadas entre julio de 2013 y marzo de 2014.

la autoridad ejerce mayor control sobre ellos en comparación con otros intermediarios más grandes (Figura 15). Por parte de la autoridad, la principal razón para el control es que estos negocios no han formalizado sus actividades ante la autoridad forestal, lo cual se debe a que muchos negocios, en especial los pequeños y muy pequeños, son esporádicos. En una muestra de 285 establecimientos inscritos en la SUNAT para Madre de Dios, Ucayali y Loreto, el 65\% han estado activos por menos de tres años antes de disolverse ${ }^{45}$.

En este contexto de disputas con la autoridad, sin duda la estrategia más importante para evadir el control es el blanqueo de la madera a través de la compra de guías de transporte forestal. En el análisis aquí descrito, el 30\% de los entrevistados

45 Datos obtenidos de la página web de la SUNAT para los usuarios registrados que tienen como principal rubro la madera. afirmaron haber comprado guías ficticias para poder comercializar la madera extraída de manera informal. Para la generación de estos volúmenes ficticios, se realizan diferentes acciones antes, durante y después del aprovechamiento y movilización de la madera. Esta compra y venta es posible debido a que el actual sistema de impresión de guías es poco eficiente y no cuenta con una base centralizada de información.

Antes del aprovechamiento, los actores formales realizan pagos extras para poder agilizar la aprobación de los Planes Generales de Manejo Forestal (PGMF) en el caso de las concesiones y los POA para todas las modalidades. Los consultores forestales entrevistados explicaron que ellos realizan POA de al menos 250 hectáreas porque no es rentable realizar planes de menor tamańo. Los ingenieros forestales tienen asistentes que son los que toman los datos en el campo y realizan los inventarios. Uno de los asistentes entrevistados comentó: "Existen pocos profesionales forestales que 


\section{Recuadro 4. El caso de la bolaina}

La necesidad de tener GTF para movilizar madera de bolaina ha creado un caso especial de informalidad. Bolaina no crece mayormente en el bosque nativo, sino en áreas de regeneración natural. En este sentido, para justificar la norma legal se crean volúmenes ficticios de esta especie para ser movilizados porque tiene un mercado constante en las principales ciudades como Pucallpa e lquitos. El metro cúbico de bolaina en el mercado de guías ficticias puede llegar a costar 23 nuevos soles. Los extractores pequeños y medianos que se dedican al comercio de esta especie deben comprar estas guías para movilizar la madera por el río y hasta el destino final en el aserradero. Los intermediarios también se proveen de guías para poder movilizar la madera de bolaina, que una vez transformada en tablillas, son entregadas a los compradores. La mayoría de las guías de bolaina analizadas en este estudio son guías de transporte terrestre desde los aserraderos hasta los destinos finales. Los pequeños productores no sacan guías para movilizar esta especie, sino que simplemente pagan sobornos en los puestos de control a lo largo de los ríos y en los puertos.

realizan el trabajo completo, es decir, viajar hasta el sitio y realizar el inventario de los árboles" 46. No se sabe cuántos POA han sido realizados de manera rigurosa según la normativa y cuántos han sido creados con el fin de vender volúmenes ficticios. Una vez que los inventarios son realizados, los informes son derivados a las Direcciones Regionales Forestales para su reconocimiento y verificación. Sin embargo, no siempre es posible realizar la visita inicial o inspección ocular para verificar que este inventario sea real, por cuestiones de presupuestos. Uno de los entrevistados manifestó: "Los presupuestos no son adecuados para realizar la verificación de todos los POA al inicio de la zafra. Se intenta, pero los funcionarios no son suficientes" ${ }^{47}$.

Una vez que los planes son aprobados, es posible realizar las descargas de madera por parte de los concesionarios y las Direcciones Regionales Forestales. Los concesionarios pueden emitir sus guías de transporte forestal con la madera autorizada para la zafra de un año e incluso con los saldos de zafras anteriores; sin embargo, no todos los concesionarios realizan aprovechamiento de sus bosques. Esto se debe a varios factores como falta de capital, poco conocimiento del mercado, entre otros, y en cambio, se dedican a la venta de los volúmenes ficticios a terceros.

Las guías de transporte forestal ficticias son comercializadas en las ciudades principales por los denominados "vendedores de volúmenes", quienes

46 Entrevista a consultor forestal en el departamento de Loreto.

47 Entrevista a funcionario de la Oficina Técnica de Ucayali. se encargan de intermediar entre el concesionario y el interesado, ganando comisiones conocidas como "puntos" ${ }^{4}$. El valor de un metro cúbico de guía legal, según los datos de este análisis, puede costar entre 27 y 30 nuevos soles $/ \mathrm{m}^{3}$ (USD 9 y 10) incluyendo los costos de realizar el POA, el pago de derechos de aprovechamiento y otros gastos indirectos como transporte, comida, etc. El valor de realizar un POA ficticio es equivalente a 2 nuevos soles $/ \mathrm{m}^{3}$ (USD 0,70), pudiendo venderse en el mercado informal hasta por 40 nuevos soles/ $\mathrm{m}^{3}$ (USD 13) dependiendo de la especie, así como de la disponibilidad de guías de transporte forestal en diferentes momentos del año.

Además de las concesiones, existen volúmenes ficticios de otras modalidades de corta como autorizaciones y permisos, pero en este caso las guías son generadas por las oficinas regionales ${ }^{49}$. Entrevistas con los encargados de área de OSINFOR en las zonas de estudio indicaron que desde que las competencias forestales fueron transferidas a las oficinas regionales; esta entidad ha sido testigo de que existe blanqueo de madera a través de POA de los cuales no se descargan los volúmenes ${ }^{50}$. Por ejemplo, durante el trabajo de campo para este estudio, se evidenció movimiento de madera con guías forestales del año 2004 en el año 2012, entre otros ejemplos similares.

48 Cada punto corresponde a 10 centavos por cada pie tablar.

49 Un caso de estos fue citado por diarios locales: "Se capturó a personas inescrupulosas dedicadas a falsificar o clonar guias de transporte forestal. Durante la intervención se logró encontrar sellos presumiblemente pertenecientes a la autoridad forestal y documentación falsificada, hechos que constituyen un ilícito penal'.

50 Entrevistas realizadas el 27/08/2013. 


\section{Recuadro 5. Pasos para transportar ilegalmente madera de Ucayali a Lima}

Según se documenta en Ucayali las chatas llegan a los puertos con cargas de madera del alto y bajo Ucayali (ver capítulo II). Estas embarcaciones movilizan entre $700 \mathrm{~m}^{3}$ y $1000 \mathrm{~m}^{3}$. Los pagos de especies duras como el shihuahuaco se realiza por chata a un costo de 500 nuevos soles, de los cuales 250 nuevos soles se destinan a la policía. Posteriormente se ingresan los papeles y, para agilizar el proceso, se pagan 250 nuevos soles en las Oficinas Técnicas, seguido de un pago de 50 nuevos soles/camión para verificación de especies una vez que la madera está cargada en los camiones. Esta verificación consiste en que el ingeniero forestal mira cada camión y verifica que sea la especie que está registrada en la guía forestal. Una vez que la madera se encuentra en orden, esta sale a la carretera con destino a Lima. Esta madera pasa por ocho puestos de control: del km11, Campo Verde, Aguaytía, Tingo María, Rancho, La Aurora, La entrada a Lima y el Aserradero. En cada puesto se paga 200 nuevos soles (USD 87), o sea, un total de 1600 nuevos soles (USD 695) por viaje. Sin embargo, en alguno de los controles se deben pagar hasta 800 nuevos soles (347) cuando existe la participación en el control de la fiscalía y la policía.

Debido a que existe mayor demanda de ciertas especies de las que se pueden encontrar en los inventarios forestales, por lo general, se sobrestiman los volúmenes de estas especies en los inventarios forestales. Estas especies son, principalmente, shihuahuaco, tornillo, cedro y caoba. Muchos de estos volúmenes no son extraídos de las áreas de operación anual aprobadas en los POA, sino que se obtienen de fuera de las áreas autorizadas y se justifican con documentos de origen legal. Esta modalidad de blanqueo es una de las principales denuncias que existen sobre las concesiones forestales. Por ejemplo, en el 2010 un concesionario de Ucayali fue detenido por OSINFOR debido a la movilización de $213 \mathrm{~m}^{3}$ de madera de cedro y caoba. El parte legal emitido indicó lo siguiente: "OSINFOR señaló que dicho concesionario habría falseado información sobre el volumen de madera en el área otorgada en concesión, lo cual habría permitido extraer caoba y cedro de un área exterior a la autorizada; por ello, OSINFOR inició un procedimiento administrativo único por presunta infracción a la legislación forestal y de fauna silvestre. Al concesionario se le suspendió la entrega de las guías de transporte forestal ${ }^{51}$ ".

Dentro del cambio de especies, se pudo conocer que una estrategia común para reducir la posibilidad de fiscalización es eliminar del censo las especies muy valiosas que son aprovechadas, pero que son transportadas con el nombre de una especie de menor valor. Es usual mezclar especies valiosas con especies sin valor comercial en los camiones de transporte, para evitar la fiscalización en carretera. En caso de que las autoridades revisen las anomalías, se recurre a sobornos.

51 Tomado del Diario Ímpetu del 10 de Agosto de 2013.
Para evitar el pago de sobornos, los extractores y productores pequeños, prefieren movilizar sus cargas durante horas de la madrugada o en la noche. Las redes de extorsión están bien organizadas entre los actores, quienes se ubican en los principales puertos y en las carreteras. Los miembros de estas redes están en constante comunicación por celular. Los casos más notorios reportados por la prensa local están relacionados con las maderas de la lista de CITES anexo II: caoba y cedro.

\subsection{Habilitación y créditos informales}

La habilitación es una práctica conocida en el sector forestal como un mecanismo de crédito informal que consiste en el adelanto de dinero por parte de habilitadores a extractores, lo cual garantiza a los primeros el abastecimiento de madera. Muchas personas sugieren que la habilitación es el principal medio de financiamiento del sector. Durante este estudio esta práctica fue reconocida por los actores medianos y grandes, así como por algunas comunidades indígenas.

El grupo de extractores que afirmó utilizar la habilitación recibe de los habilitadores en promedio 15.500 nuevos soles (USD 5535) cada dos meses durante una zafra de 8 meses. Dependiendo del grado de confianza, los habilitadores pueden llegar a requerir garantías por parte de los madereros, como títulos de propiedad de casas y vehículos. La habilitación implica una promesa anticipada de venta de madera al habilitador. Este aplica los precios de compra descontando el crédito $y$, muchas veces, no se logran cubrir todos los costos, por lo que el habilitador mantiene una deuda constante. 


\section{Recuadro 6. Habilitación en comunidades indígenas}

Una de las comunidades entrevistadas, cuyos miembros se dedican a la corta de madera y cuentan con herramientas propias (motosierra y cubota), inició el proceso de negociación con un habilitador de la ciudad de Pucallpa. La comunidad recibió un adelanto para la zafra de 35.000 nuevos soles (USD 11.600) seguido de otros 17.000 nuevos soles (USD 5600). Alrededor de 24 personas de la comunidad participaron de la corta. El acuerdo se realizó directamente entre el intermediario-habilitador y la comunidad y estableció la entrega de árboles en trozas a ser cubicados al final de la zafra. Las especies aprovechadas mayormente fueron cedro, lagarto caspi y tornillo. El costo total contabilizado por la comunidad fue de 52.000 nuevos soles (USD 17.000) para extraer $800 \mathrm{~m}^{3}$ de madera en troza. El pago total fue de 75.000 nuevos soles (USD 25.000), de los cuales se descontó el adelanto inicial, dejando 23.000 nuevos soles (USD 7600) líquidos que fueron divididos para las 24 familias que participaron en la corta, recibiendo cada una 958 nuevos soles (USD 342) aproximadamente.

Los pequeños extractores indicaron no acudir a la habilitación como el principal recurso de crédito. Ellos recurren a casas de empeño ubicadas en las principales ciudades de Iquitos, Pucallpa y Puerto Maldonado, las que prestan dinero a un interés del $24 \%$ mensual. Las casas de empeño tienen pocos requisitos (como la copia del Documento Nacional de Identidad) y reciben en garantía varias prendas, como embarcaciones, motores, títulos de propiedad de carros, entre otros. Los préstamos se encuentran en alrededor 4500 nuevos soles (USD 1600). Los pequeños productores, también utilizan estos medios para capitalizar la corta de madera, recibiendo en promedio 237 nuevos soles (USD 84). En general, estos créditos son preferidos por los pequeños productores, extractores e intermediarios porque permiten transformar pequeñas cantidades de madera rolliza o cuartones en subproductos con mayor valor agregado utilizando a los aserraderos como prestadores de servicios y no como compradores finales. El no vender la madera a los aserraderos permite que los pequeños extractores y productores puedan vender directo a otros compradores finales, aumentando así su ganancia. Sin embargo, los pequeños productores prefieren vender directamente a los aserraderos la madera en bruto debido a que no pueden esperar los largos períodos de tiempo en los puertos hasta que la madera consiga ser aserrada.

Otro método menos utilizado debido a que los intereses son del 10\% diario, son los cambistas de divisas. Estos actores cuentan con cantidades de dinero que son facilitadas por otros actores del sector forestal local y utilizan este dinero para apalancar ganancias en cortos períodos de tiempo como uno o dos días. El mecanismo consiste en prestar hasta 10.000 nuevos soles (USD 3500) por 24 horas a extractores o intermediarios que necesitan cubrir costos finales de las zafras, por ejemplo, para pagar costos relacionados a sobornos o pago por los fletes de transporte a Lima. Los cambistas trabajan de cerca con los compradores de especies duras para el mercado asiático. Usualmente, estos últimos entregan dinero en dólares, los que son administrados por los cambistas para realizar los pagos en soles a pequeños extractores e intermediarios.

En Ucayali y Loreto, los medianos extractores (pequeños concesionarios y empresarios forestales) tienen el sistema de habilitación como principal fuente de crédito informal y, en menor proporción, las cajas de crédito o bancos, los cuales tienden a prestar dinero a través de créditos hipotecarios. Los extractores más grandes trabajan con créditos formales, debido al volumen de sus negocios y maquinarias. En Madre de Dios, los pequeños y medianos extractores, así como los intermediarios en general recurren a las cajas de crédito. Los medianos intermediarios son los que trabajan con más frecuencia con este sistema de financiamiento porque cuentan con antecedentes crediticios obtenidos generalmente por contar con espacios físicos propios y maquinaria.

\subsection{Interacciones entre el aprovechamiento formal e informal}

La línea divisoria entre lo informal y formal es bastante tenue porque la informalidad puede evolucionar hacia prácticas más formales, lo cual depende de las cuestiones geográficas y de la capacidad de adaptación a nuevas reglas por parte de quienes realizan actividades informales (Sojo y Grynspan, 2002). Los datos analizados en este capítulo sugieren que las prácticas formales e informales se fusionan a lo largo de las operaciones forestales que comprenden las fases de planeamiento y legalización, zafra y comercialización. 
Según nuestra información de campo, las comunidades indígenas y campesinas, no muestran especial interés en dejar de aprovechar el bosque de manera informal y de forma individual, en especial porque las alternativas legales son costosas o requieren de esfuerzos organizativos adicionales, tal como lo indican Gaviria y Sabogal (2013) y Cossío et al. (2014). Los pequeńos extractores no piensan parar sus actividades de corta, pero buscan la formalización para evitar la coerción. Los actores medianos buscan un sistema más eficiente de otorgamiento de permisos. En general, los actores menos visibles por su exclusión de la Ley Forestal buscan la consideración de sus prácticas forestales como válidas dentro de las regulaciones vigentes.

Los factores que limitan el acceso de los extractores al bosque son la obtención de permisos legales y los créditos para el desarrollo de la actividad forestal. Estas limitantes tienen a ser más severas cuando se trata de pequeños usuarios del bosque tanto productores, extractores, transformadores y comerciantes, quienes desarrollan sus actividades de manera informal. A su vez, las actividades informales estimulan la creación de redes de extorsión, las mismas que ejercen un efecto más coercitivo sobre los pequeños actores quienes se sobreponen a estas barreras pagando sobornos los que implican costos importantes. En este contexto, el actual sistema de manejo forestal está adecuado para favorecer a medianos y grandes actores que pueden realizar cortas de volúmenes más grandes. Un claro ejemplo es el actual sistema de manejo de áreas de bosque del Estado, el cual enfoca su atención en las concesiones forestales de más de 5000 ha.

Las concesiones forestales en el Perú buscan realizar un manejo más extenso de los bosques; sin embargo, varios autores señalan la ineficiencia en cuestiones administrativas y ecológicas (Cossío et al., 2011; EIA, 2012; Finer et al., 2014; Ministerio de Agricultura, 2014). Se han registrado varias anomalías en las concesiones forestales por parte de la autoridad de control OSINFOR entre las cuales destacan el uso de guías de transporte forestal de las concesiones para el blanqueo de madera proveniente de otros lugares fuera de la concesión autorizada y el cambio de especies que significa la hiperinflación de volúmenes de corta de ciertos árboles con mayor valor económico (OSINFOR, 2014). En este sentido, el sistema de concesiones ha servido en gran parte para generar documentos legales que luego son comercializados en el mercado negro, desde donde se regulan los precios por $\mathrm{m}^{3}$ según la existencia de documentos para ciertas especies.

En este contexto, el concepto de manejo forestal sostenible (MFS) adoptado por la normativa, debe ser debatido. Evidentemente, existen cortas que son realizadas por fuera de las cláusulas del manejo forestal sostenible y que provienen de propiedades individuales o colectivas. Los pequeños actores no pueden realizar MFS y, por lo tanto, hacen uso generalmente de motosierras que les permite realizar talas selectivas prohibidas por la Ley. El concepto de MFS impulsa ciertos estándares para aprovechar madera como el ciclo de corta, el uso de maquinaria, los inventarios y finalmente la legalización, los que están muy por fuera del alcance de muchos de los actores. Este sistema necesita incluir las prácticas locales de extracción y simplificar los procedimientos para no dejar en la informalidad a todos los que no logran hacer un manejo a gran escala. Existen experiencias de simplificación de la normativa forestal facilitando los procedimientos administrativos para pequeños extractores en Ecuador y Bolivia (ver Mejia y Pacheco, 2013 y Cano et al., 2014). 


\section{Costos y beneficio en el aprovechamiento y comercialización de la madera}

Este capítulo analiza los costos del aprovechamiento y comercialización de la madera desde una visión de los actores que participan en los diferentes circuitos que abastecen a mercados urbanos. Los costos se calculan con base en los costos de mano de obra, insumos, transporte y legalización incurridos a lo largo de una operación de corta específica en un tiempo determinado y para una cantidad de madera determinada. Los beneficios se calculan de las ventas directas de esa madera según el producto puesto en puerto y especie. Se podría decir que se realiza una evaluación económica "estática" de costo beneficio, sin recurrir a generar escenarios futuros o de retorno de la inversión (TIR o VAN) debido a las dificultades de definir áreas de corta y activos en las cortas informales, así como de las cortas formales. Algunos autores han realizado este tipo de análisis financiero más amplio con estimaciones generales (ver Colan et al., 2007 y Giudice et al., 2012).

El análisis realizado sugiere que los actores no son homogéneos. Ellos se caracterizan como extractores, intermediarios y/o transformadores según su grado de acceso a la tecnología y capital. Además del enfoque en costos y beneficios, en esta sección se realiza un análisis de eficiencia técnica para determinar el uso que los actores dan a los recursos disponibles. El análisis de eficiencia técnica se realiza por actor y se incluyen los costos asociados a la formalización. Según las entrevistas realizadas, la mayoría de los extractores aprovechan madera de especies duras, excepto en el caso de los pequeños productores que trabajan principalmente con especies blandas. Durante el período de levantamiento de datos se contabilizó un volumen total de 335.129,2 $\mathrm{m}^{3}$ de madera que se movilizó por vía fluvial, de los cuales $60 \%$ representan madera rolliza y $40 \%$ madera aserrada. Según los datos recolectados el $62 \%$ de la madera no tenía permisos legales antes de su llegada a los puertos de acopio.

\subsection{Costos y beneficios del aprovechamiento forestal}

\subsubsection{Operaciones manejadas por extractores}

Los extractores son el grupo que se dedica a la corta o extracción de madera como actividad principal, aunque también pueden comprar y vender madera. En el caso que compren y vendan madera, se los ha clasificado como extractores-intermediarios, los cuales serán analizados posteriormente como un grupo separado. Para fines de este análisis, los extractores se los ha clasificado en cuatro grupos: muy pequeños, pequeños, medianos y grandes. Esto considera el volumen de extracción, el tiempo que el extractor se dedica a extraer madera y los trabajadores que emplea. Un detalle de los diferentes grupos se ofrece en el Cuadro 46.

Los principales lugares de donde se obtiene madera para los extractores son las comunidades nativas, seguidas de las áreas bajo concesiones. Los extractores grandes y medianos, a pesar de contar con áreas adjudicadas, admitieron comprar madera de terceros debido a que no logran suplir la demanda. Los pequeños y muy pequeños no tienen áreas asignadas, por lo cual la madera aprovechada es de origen informal siendo que se abastecen especialmente de la extracción directa o a través de compras en comunidades nativas y predios privados (Figura 16).

Los extractores realizan cortas de especies conocidas como duras y blandas, predominando la corta selectiva de madera de mayor valor comercial. La combinación de especies y los productos comercializados determinan los costos y beneficios de una operación. Estos son proporcionales a la calidad de la madera aprovechada. La variación de los beneficios se debe a los productos comercializados, siendo las tablillas las que tienen mayor transformación, aumentando los costos 
Cuadro 46. Características de los extractores según su tamaño

\begin{tabular}{lcccc}
\hline Variables & Grande & Mediano & Pequeño & Muy pequeño \\
\hline Número de actores & 6,0 & 7,0 & 48,0 & 101,0 \\
Número de veces que extrae madera al año & 1,0 & 1,4 & 7,2 & 8,2 \\
Días al año por operación de corta & 259,0 & 192,0 & 40,0 & 23,1 \\
Número de trabajadores que emplea en promedio & 19,7 & 10,0 & 6,3 & 5,4 \\
por operación de corta & & & & \\
Metros cúbicos extraídos en la última operación & 3172,4 & 1377,6 & 52,9 & 8,7 \\
\hline
\end{tabular}

Fuente: Elaboración propia con base en entrevistas realizadas entre julio de 2013 y marzo de 2014.

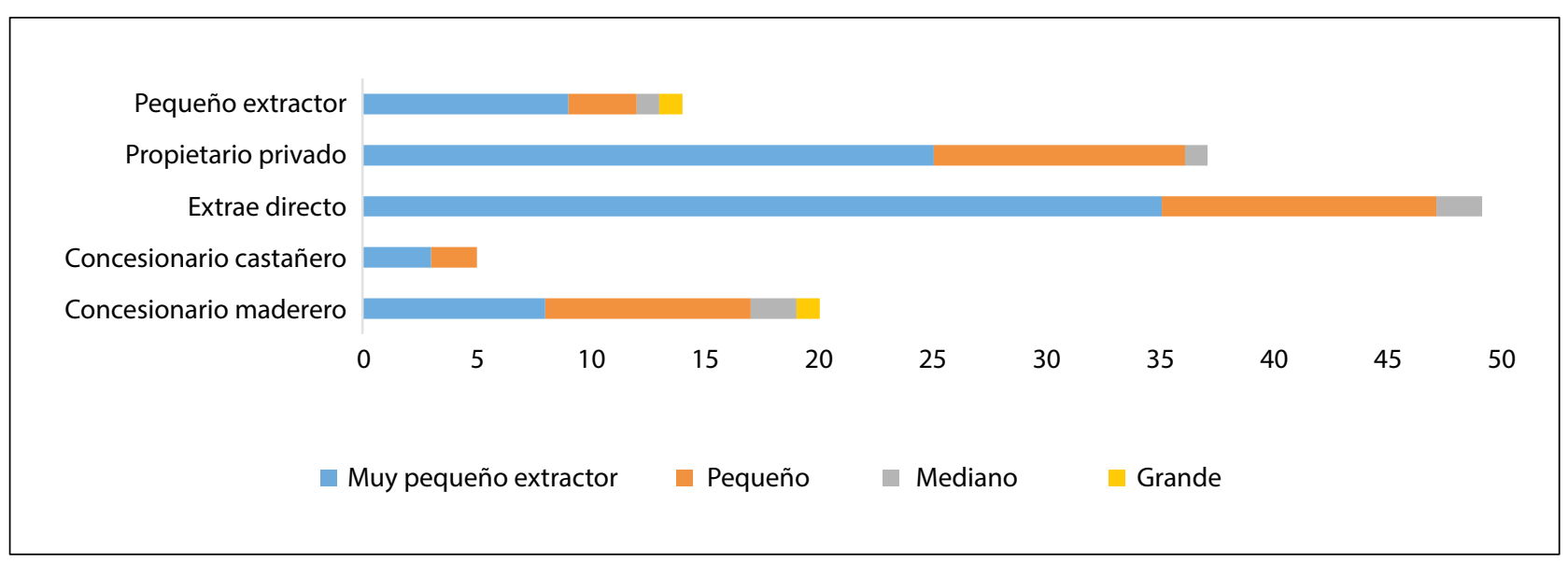

Figura 16. Principales sitios donde los extractores realizan zafras

Fuente: Elaboración propia con base en entrevistas realizadas entre julio de 2013 y marzo de 2014.

de aserrío, pero también los beneficios. Especies duras como shihuahuaco se comercializan sin procesamiento a USD $230 / \mathrm{m}^{3}$ y en forma de tablillas alcanza precios de hasta USD $852 / \mathrm{m}^{3}$. Los principales productos comercializados por los extractores, según la muestra en este estudio, se indican en el Cuadro 47, al igual que sus precios referenciales durante el tiempo de la toma de datos para este reporte. El precio por especie se detalla en el Anexo 4.

En general los costos más representativos de las operaciones para los extractores pequeños y muy pequeños están relacionados con la mano de obra (ver Cuadro 48 y Figura 18). Esto porque principalmente utilizan la motosierra para el corte, tumbado y troceado. El 40\% de los entrevistados utilizan cubotas para transportar la madera y el $60 \%$ transportan la madera a hombro y por quebradas por flotación. Por otro lado, los costos más representativos para los medianos y grandes extractores son los insumos y el transporte, debido a que utilizan maquinarias para sus operaciones y transportan sus productos en embarcaciones fluviales.
En ninguno de los cuatro casos, los pagos de coimas representan un porcentaje significativo en la composición de los costos, aunque para

\section{Cuadro 47. Rentabilidad según tipo de madera y productos predominantes en los mercados de madera analizados (USD $/ \mathrm{m}^{3}$ )}

\begin{tabular}{lcc}
\hline Producto & Costo & Beneficio \\
\hline Dura & 220,3 & 198,8 \\
Cuartones & 191,2 & 173,1 \\
Rolliza & 100,1 & 191,0 \\
Tablillas & 416,6 & 293,4 \\
Mixta & 120,0 & 196,7 \\
Cuartones & 140,0 & 205,0 \\
Rolliza & 39,0 & 77,8 \\
Blanda & 112,5 & 99,3 \\
Cuartones & 129,5 & 29,8 \\
Rolliza & 88,0 & 86,9 \\
Tablillas & 153,4 & 44,3 \\
\hline
\end{tabular}

Fuente: Elaboración propia con base en las entrevistas realizadas entre julio de 2013 y marzo de 2014. 
los pequeños sí son una limitante. Las coimas representan en promedio por operación USD 1669,6 para los grandes, USD 6517,8 para los medianos, USD 247 para los pequeños y USD 41,2 para los muy pequeños. En el caso de los extractores medianos, los costos de aprovechamiento son mayores en comparación con los incurridos por los grandes extractores debido a que estos incluyen los costos por legalizar la madera que es comprada a terceros. En comparación con sus pares más grandes, los extractores medianos no tienen suficientes zonas de corta para satisfacer las órdenes de madera de compradores finales; además, estos actores son quienes (como se mencionó en el capítulo 4) acceden a la habilitación para obtener capital que les da la facilidad de realizar acciones de intermediación y compra de guías de transporte forestal ficticias, lo cual acrecienta el costo de legalización (Figura 17).
Los costos y beneficios por grupo de actores se presentan en el Cuadro 48. Esta información sugiere que son los extractores medianos quienes obtienen la rentabilidad más alta por metro cúbico de madera, seguidos por los grandes, pequeños y muy pequeños extractores. Esto se debe a que los medianos diversifican más su portafolio de especies, al igual que los sitios de donde se abastecen de madera. Esto porque su nivel de producción les permite realizar este tipo de arreglos. Los grandes, a diferencia de los medianos extractores, no presentan la rentabilidad más alta debido a que sus ganancias están más relacionadas con los grandes volúmenes que comercializan.

La capacidad de reinversión de estos actores es similar sin importar su tamaño. Los muy pequeños, pequeńos y medianos reinvierten en promedio entre el $65 \%$ y el $66 \%$ de sus ganancias en insumos para la corta de madera, siempre y cuando sus

Cuadro 48. Análisis costo beneficio por tamaño de extractor (en USD $/ \mathrm{m}^{3}$ )

\begin{tabular}{lccccc}
\hline Tamaño & Costo USD $/ \mathbf{m}^{3}$ & DS & Beneficio USD $/ \mathbf{m}^{3}$ & DS & Rentabilidad USD $/ \mathbf{m}^{3}$ \\
\hline Grande & 76,9 & 54,4 & 85,9 & 31,1 & 1,1 \\
Mediano & 110,0 & 66,1 & 188,0 & 117,3 & 1,7 \\
Pequeños & 174,9 & 147,3 & 180,3 & 221,2 & 1,0 \\
Muy pequeños & 199,6 & 142,7 & 200,7 & 205,3 & 1,0 \\
\hline
\end{tabular}

Fuente: Elaboración propia con base en las entrevistas realizadas entre julio de 2013 y marzo de 2014.

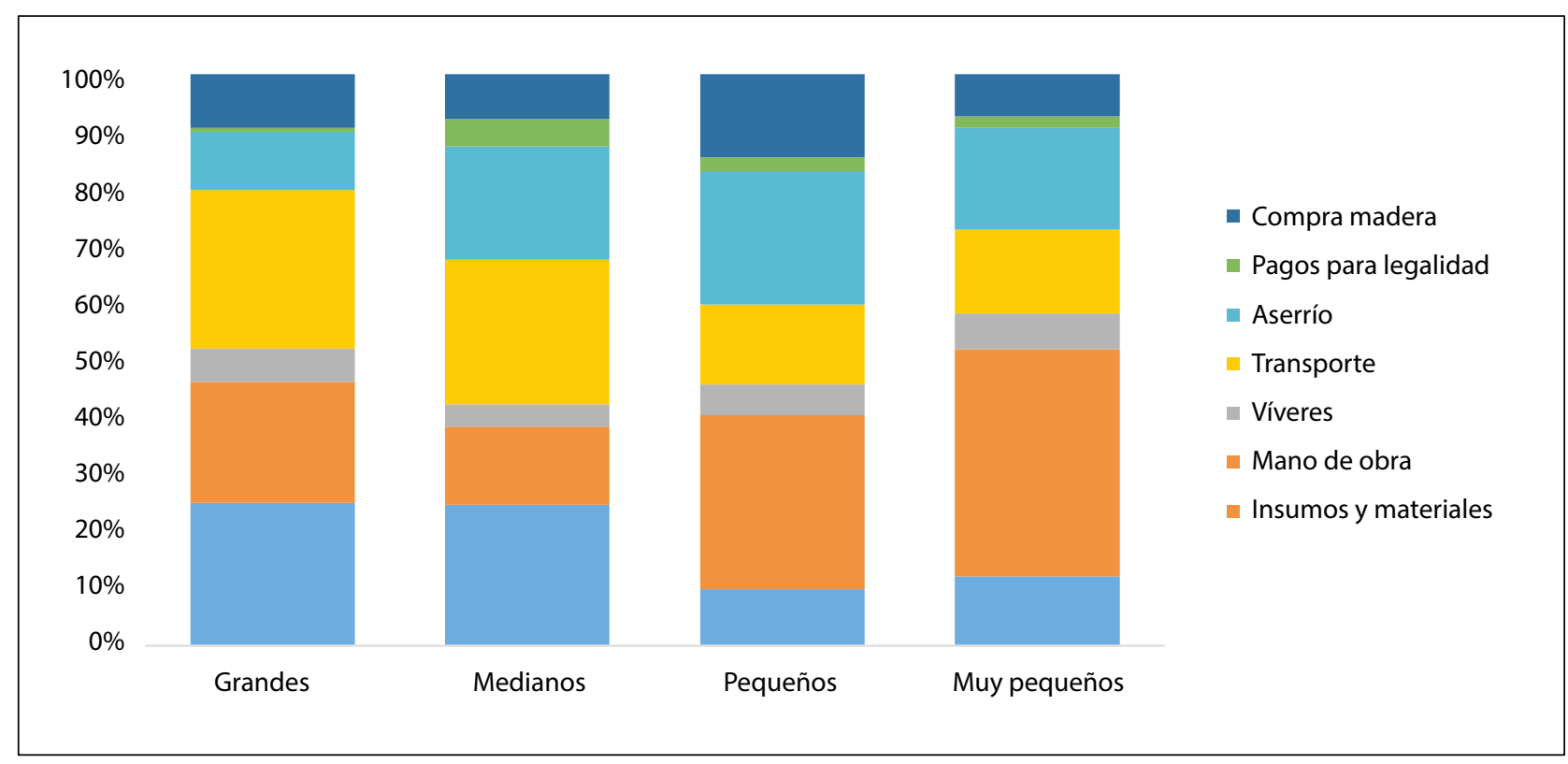

Figura 17. Porcentaje de costos de las operaciones de extracción según tamaño de extractor

Fuente: Elaboración propia con base en las entrevistas realizadas entre julio de 2013 y marzo de 2014. 
ganancias no sean destinadas exclusivamente a cubrir costos de salud o educación. En el caso de los grandes extractores, la reinversión alcanza en promedio el $70 \%$ de las ganancias. En todos los casos las inversiones se destinan a aumentar los volúmenes de corta. Las prácticas de manejo y reposición de especies fueron mencionadas solo por los muy pequeños y pequeños extractores para el caso de bolaina. Los pequeños y muy pequeños invierten aproximadamente el 20\% de las ganancias que obtienen de las operaciones de aprovechamiento forestal en insumos para la agricultura.

\subsubsection{Operaciones manejadas por extractores-transformadores}

Este grupo se dedica, además de extraer madera del bosque, a la transformación y comercialización de la madera. La madera obtenida es distribuida tanto en locales a nivel de las urbes amazónicas de Iquitos, Pucallpa y Puerto Maldonado; como en otras ciudades, por ejemplo, Aguaytía, Piura,
Cajamarca, Ica, etc., en donde estos actores cuentan con negocios propios o familiares. Dentro de este grupo están algunas de las empresas que realizan exportación, pero también pequeños negocios como las carpinterías (Cuadro 49).

Los principales lugares de donde este grupo obtiene madera son las comunidades nativas. Los extractores-transformadores grandes cuentan con zonas adjudicadas de donde se abastecen de madera, por lo general en concesiones y en menor proporción en comunidades nativas. Los medianos recurren a las zonas legalmente adjudicadas, pero también a las cortas informales. Los pequeños y muy pequeños cortan de manera informal en varios sitios (Figura 18).

Debido a que estos actores no venden la madera a terceros, se calculó los beneficios de la madera transformada en el destino final a través de estimaciones de los entrevistados sobre sus ventas por metro cúbico transformado en diferentes tipos de productos como tablillas, varios tipos de madera

\section{Cuadro 49. Características de los extractores según su tamaño}

\begin{tabular}{lcccc}
\hline Variables & Grandes $^{\text {a }}$ & Medianos & Pequeños & Muy pequeños \\
\hline Número de actores entrevistados & 7,0 & 13,0 & 35,0 & 7,0 \\
Número de veces que extrae madera al año & & 3,3 & 4,4 & 10,8 \\
Días al año que operan & & 78,4 & 49,8 & 16,6 \\
Número de trabajadores que emplea en la extracción & & 9,1 & 6,6 & 3,3 \\
Última operación de extracción (m $\left.{ }^{3}\right)$ & & 379,5 & 39,2 & 8,0 \\
Número de trabajadores en la transformación & & 4,2 & 3,9 & 1,0 \\
Promedio comercializado al año $\left(m^{3}\right)$ & 2880,0 & 406,9 & 194,1 & 72,7 \\
\hline
\end{tabular}

Fuente: Elaboración propia con base en las entrevistas realizadas entre julio de 2013 y marzo de 2014.

Nota: a) Datos parciales debido a que estos actores solo facilitaron información general de sus operaciones.

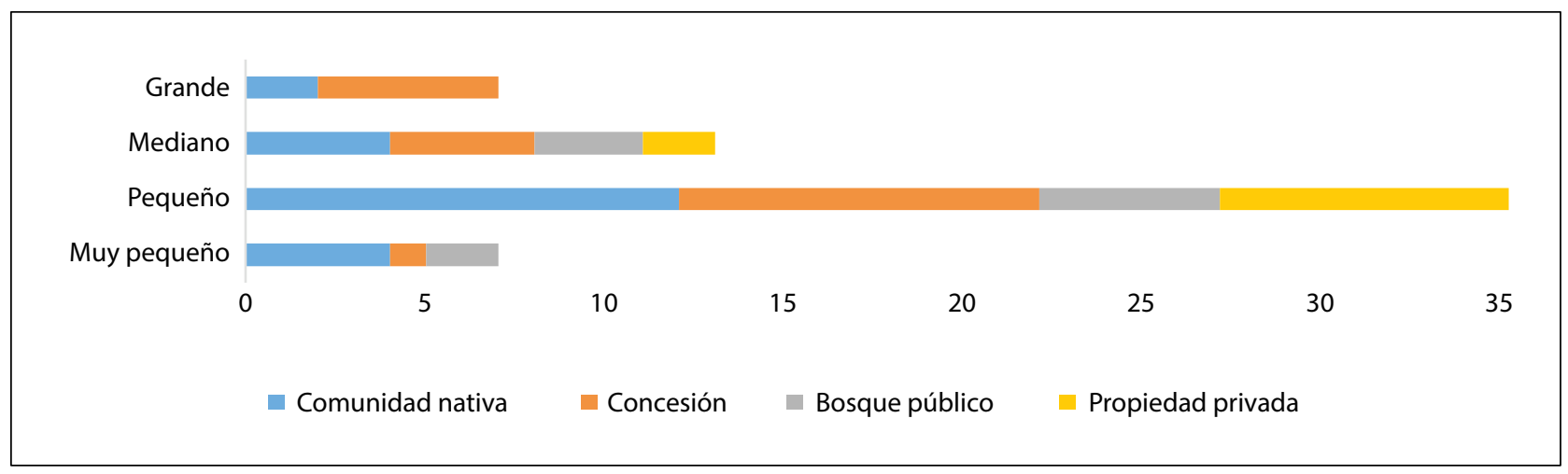

Figura 18. Principales sitios de extracción de madera de los extractores transformadores

Fuente: Elaboración propia con base en las entrevistas realizadas entre julio de 2013 y marzo de 2014. 
Cuadro 50. Análisis de costo beneficio por tamaño de extractor-transformador (USD/ $\mathrm{m}^{3}$ )

\begin{tabular}{lccccc}
\hline Tamaño & Costo USD $/ \mathbf{m} 3$ & DS & Beneficio USD $/ \mathbf{m}^{3}$ & DS & Rentabilidad USD $/ \mathbf{m}^{3}$ \\
\hline Grande & $600,0^{\mathrm{a}}$ & 89,4 & 1080,0 & 383,4 & $1,8\left(3,5^{\mathrm{b}}\right)$ \\
Mediano & 107,2 & 66,8 & 344,2 & 94,0 & 3,2 \\
Pequeño & 198,0 & 133,4 & 357,7 & 348,9 & 1,8 \\
Muy pequeño & 161,8 & 76,5 & 289,5 & 290,0 & 1,7 \\
\hline
\end{tabular}

Fuente: Elaboración propia con base en las entrevistas realizadas entre julio de 2013 y marzo de 2014.

Nota: a) Estos costos incluyen los costos de la certificación FSC. b) Rentabilidad que incluye las devoluciones a los exportadores.

dimensionada y pisos (frisas). Los productos más rentables a nivel nacional son las tablillas de especies duras como shihuahuaco y quinilla. Estas, una vez comercializadas en Lima, llegan a venderse por USD $645 / \mathrm{m}^{3}$ versus la madera dimensionada, que genera en promedio hasta USD $265 / \mathrm{m}^{3}$. En el caso de los mercados internacionales, el metro cúbico de shihuahuaco transformado en pisos o “decking" puede llegar a USD 1500 (valor FOB). El Cuadro 50 muestra los costos y beneficios que obtienen estos actores clasificados según su tamaño.

\subsubsection{Operaciones manejadas por concesionarios}

Los concesionarios entrevistados tienen adjudicadas para aprovechamiento entre 5000 y 7000 hectáreas, lo que los sitúa como pequeños concesionarios. Los grandes concesionarios no fueron analizados en este estudio debido a que no se pudo tener acceso a información sobre sus aprovechamientos, excepto en casos en los cuales fungieron como extractorestransformadores. Las concesiones de castańa realizan un aprovechamiento menor que las concesiones madereras, según los datos proporcionados por las entrevistas. Estos datos contradicen la literatura que reconoce que estas concesiones realizarían cortas mayores que las concesiones maderables (Cossío et al., 2011). La extracción en las concesiones de madera según lo reportado por los entrevistados es de $3,1 \mathrm{~m}^{3} / \mathrm{ha}$ y en el caso de las concesiones de castańa de 2,8 $\mathrm{m}^{3} / \mathrm{ha}$ (Cuadro 51)

\section{Cuadro 51. Características de las operaciones conducidas en pequeñas concesiones}

\begin{tabular}{lcc}
\hline Variables & Madera & Castaña \\
\hline $\begin{array}{l}\text { Número de actores } \\
\text { entrevistados }\end{array}$ & 17 & 44 \\
$\begin{array}{l}\text { Número de POA al año } \\
\text { (promedio) }\end{array}$ & 1 & 1 \\
$\begin{array}{l}\text { Hectáreas en POA al año } \\
\text { (promedio) }\end{array}$ & 427 & 64 \\
$\begin{array}{l}\text { Días al año por operación } \\
\text { (promedio) }\end{array}$ & 116 & 137 \\
Promedio por año $\left(m^{3}\right)$ & 1275 & 180 \\
\hline
\end{tabular}

Fuente: Elaboración propia con base en las entrevistas realizadas entre julio de 2013 y marzo de 2014.

Los costos en las concesiones se recolectaron de manera global, siendo los costos menores los relacionados a los inventarios forestales. Los costos operativos y de legalización son los más altos. Los beneficios en las concesiones de castańa son menores que en las concesiones de madera, como se muestra en el Cuadro 52. Uno de los factores que explica esto es el volumen obtenido por operación.

La reinversión de estos actores en sus concesiones es menor que en el grupo de extractores.

Los concesionarios que extraen madera en las concesiones de castaña presentan en promedio una

Cuadro 52. Análisis de costo beneficio por tipo de concesionario $\left(\mathrm{m}^{3}\right)$

\begin{tabular}{lccccc}
\hline & Costos USD $/ \mathrm{m}^{3 \mathrm{a}}$ & DS & Beneficios USD $/ \mathrm{m}^{3}$ & DS & Rentabilidad USD $/ \mathrm{m}^{3}$ \\
\hline Castaña $(\mathrm{n}=29)$ & 26,5 & 12,4 & 27,1 & 35,6 & 1,0 \\
Madera $(\mathrm{n}=17)$ & 59,6 & 74,0 & 154,1 & 170,6 & 2,6 \\
\hline
\end{tabular}

Fuente: Elaboración propia con base en las entrevistas realizadas entre julio de 2013 y marzo de 2014.

Nota: a) Se consideran los costos operativos cuando son asumidos por el intermediario y/o cuando son asumidos por los propios concesionarios. 
reinversión del 49,5\% ( $\mathrm{n}=13)$ en nuevas cortas de madera y quienes extraen madera de concesiones madereras $(\mathrm{n}=8)$ reinvierten únicamente el $24,4 \%$. El dinero de las ganancias de ventas de madera proveniente de las concesiones de castaña en un $20 \%$ es utilizado para implementar prácticas relacionadas a la castaña. En el caso de las concesiones madereras, el dinero que no es reinvertido para generar más cortas es, en orden de importancia, alocado en ganadería y agricultura (cacao).

\subsubsection{Operaciones manejadas por pequeños productores}

Para fines de este estudio, se considera como pequeños productores a aquellos agricultores mestizos o indígenas que venden madera de manera individual como actividad secundaria y complemento de su ingreso anual. En el caso de este análisis, se dividieron según la participación en la corta. El aprovechamiento de madera es una de las actividades a las cuales se dedican estos productores, además de la venta de maíz, arroz, pescado, carne de monte, plátano y yuca. Estos actores son informales y realizan la corta de manera directa o venden sus árboles a terceros, como los pequeños extractores, que son quienes realizan la corta. En este sentido, la mayoría de los productores $(83 \%)$ prefieren la extracción y comercialización directa (Cuadro 53).

Según las entrevistas realizadas, la madera proviene de purmas (vegetación sucesional) $47 \%$ y de bosques $53 \%$. Asimismo, el $72 \%$ de las ventas la realizan directamente a sus compradores y en el otro $28 \%$ utilizan intermediarios-circuitos para vender sus productos (Figura 19).

\section{Cuadro 53. Características de los productores según su participación en el aprovechamiento}

\begin{tabular}{lccc}
\hline Variables & Aprovecha directo & $\begin{array}{c}\text { Aprovecha terceros } \\
\text { pequeños }\end{array}$ & $\begin{array}{c}\text { Aprovecha terceros } \\
\text { medianos }^{\mathrm{a}}\end{array}$ \\
\hline Número de actores & 83 & 17 & 7 \\
Número de veces que extrae madera al año & 1,4 & 1,2 & nd \\
Días al año que invierte en sacar la madera & 33,1 & 21,3 & nd \\
$\mathrm{m}^{3} /$ última operación & 12,7 & 24,3 & 56,05 \\
\hline
\end{tabular}

Fuente: Elaboración propia con base en las entrevistas realizadas entre julio de 2013 y marzo de 2014.

Nota: a) Información proporcionada por los productores y no por los extractores.

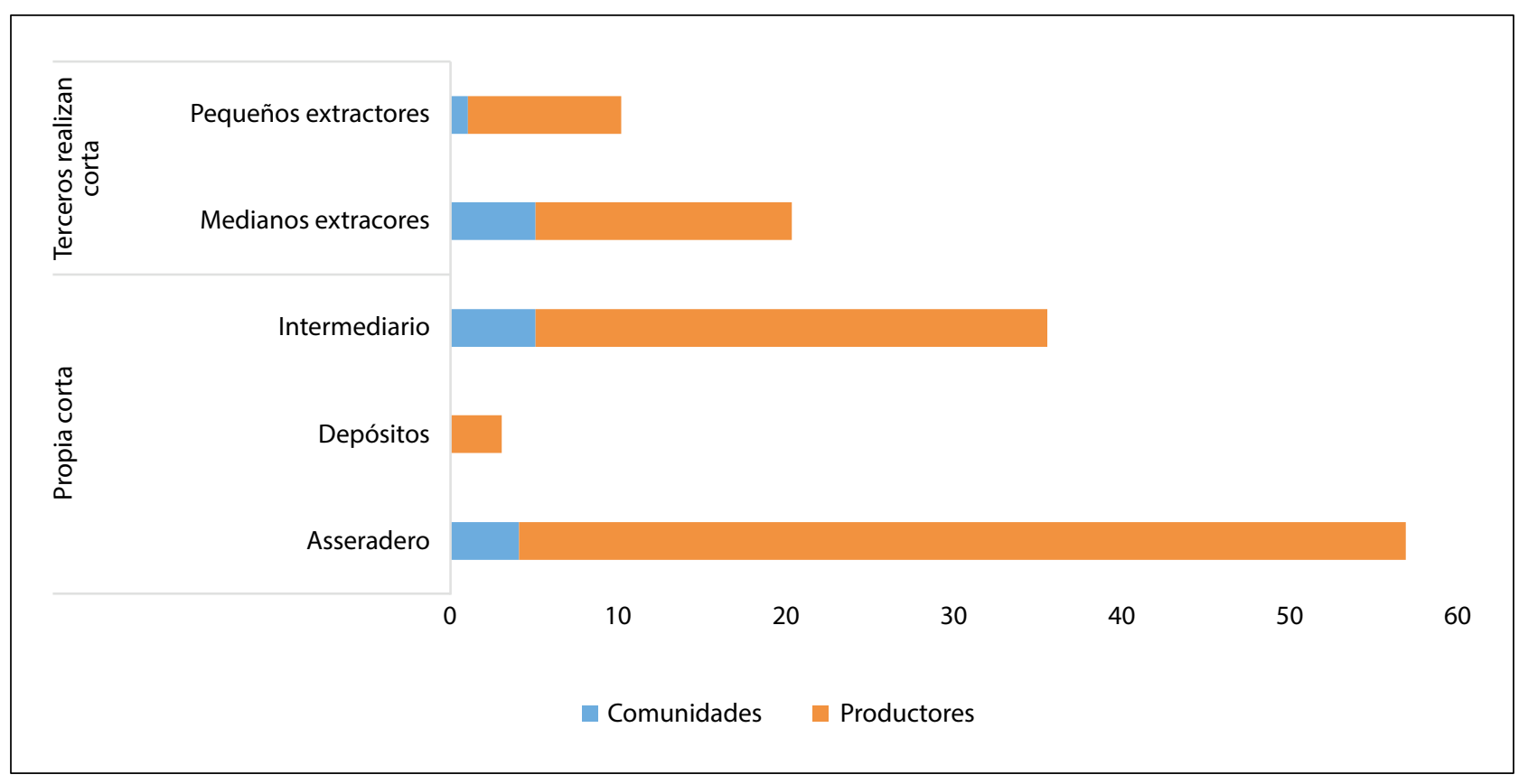

Figura 19. Destino de venta de la madera ofertada por comunidades y productores

Fuente: Elaboración propia con base en las entrevistas realizadas entre julio de 2013 y marzo de 2014. 


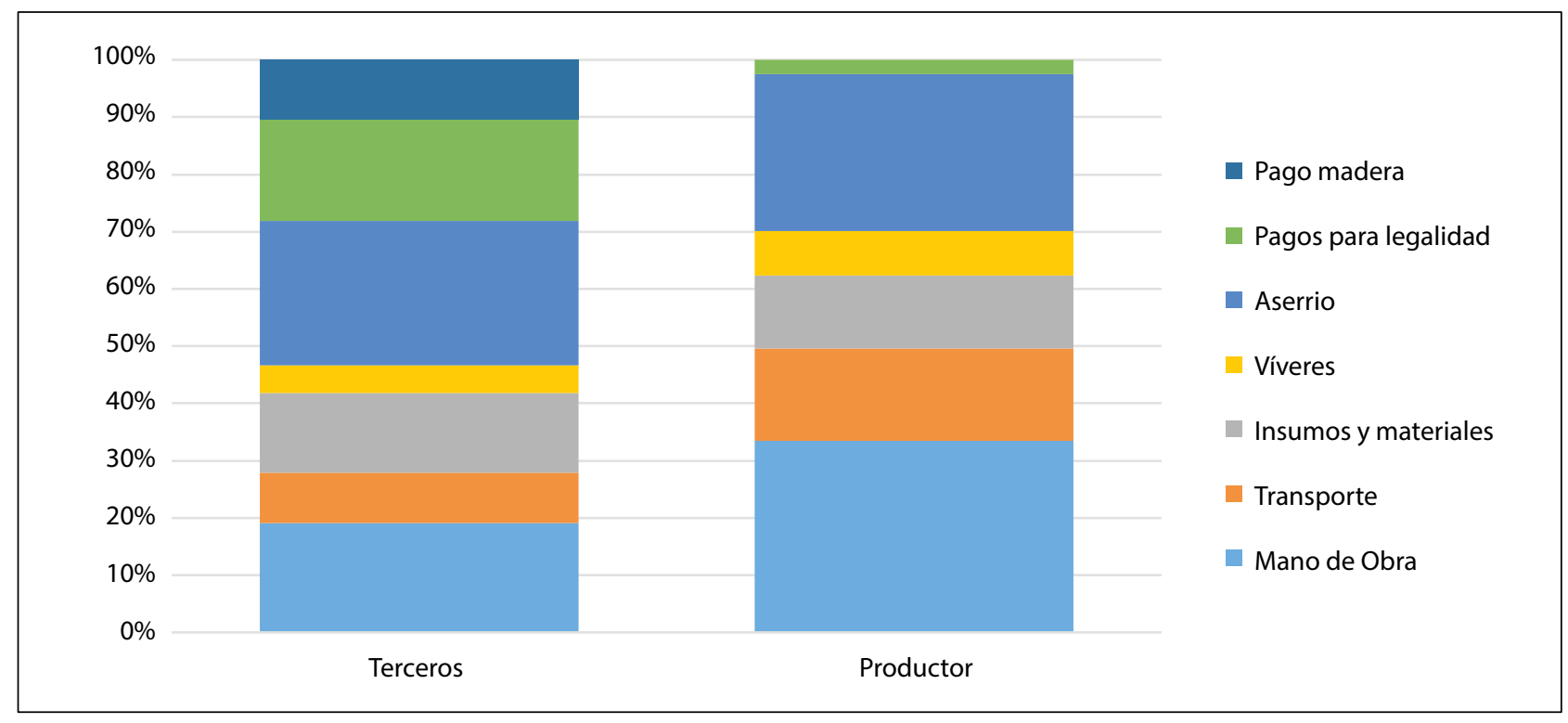

Figura 20. Distribución de costos entre productores que aprovechan directamente y con ayuda de terceros en predios privados $(n=107)$

Fuente: Elaboración propia con base en las entrevistas realizadas entre julio de 2013 y marzo de 2014.

Nota: Los costos de terceros fueron estimados por los propios productores.

\section{Cuadro 54. Análisis costo-beneficio según participación de los pequeños productores en el aprovechamiento dentro de sus tierras $\left(\mathrm{USD} / \mathrm{m}^{3}\right)$}

\begin{tabular}{lccccc}
\hline Aprovechamiento & Costo USD $/ \mathrm{m}^{3}$ & DS & Beneficio USD $/ \mathrm{m}^{3}$ & DS & Rentabilidad USD $/ \mathbf{m}^{3}$ \\
\hline Directo & \multicolumn{7}{l}{} & & & \\
\hline Productor & 124,4 & 81,1 & 103,5 & 152,6 & 0,8 \\
\hline Terceros & & & & & \\
\hline Extractores pequeños & 108,0 & 55,1 & 106,7 & 94,9 & 1,0 \\
Pago a productor por madera en pie & - & - & 37,0 & 78,2 & - \\
Extractores medianos & 113,5 & 72,4 & 193,8 & 97,3 & 1,7 \\
Pago a productor por madera rolliza $^{\mathrm{b}}$ & - & - & 60,3 & 22,4 & - \\
\hline
\end{tabular}

Fuente: Elaboración propia con base en las entrevistas realizadas entre julio de 2013 y marzo de 2014.

Nota: a) Los productores venden árboles en pie. b) Los productores venden cuando esta ha sido cortada y apeada.

Según las entrevistas realizadas, los productores venden principalmente madera blanda de las especies de catahua, cumala, lupuna y bolaina, que representan en promedio el $75 \%$ del total de la madera comercializada por estos actores. Las maderas duras representan el $25 \%$, de las cuales shihuahuaco representa el 20\%, y el restante 5\% consiste en otras maderas como tornillo, capirona y quinilla (Anexo 5). Los costos principales incurridos por los productores cuando realizan la corta y comercializan directamente son la mano de obra y el aserrío, como lo muestra la Figura 20. La mano de obra a la que se refieren los datos aquí recolectados es la mano de obra que los agricultores pagan fuera de la mano de obra familiar.

Los beneficios que los productores obtienen cuando realizan la corta y comercialización por sí mismos son mayores en un $64 \%$ que cuando estos realizan la venta de madera en pie a terceros. Esta mayor ganancia se debe a los ingresos recibidos por la mano de obra utilizada por el productor. El Cuadro 54 muestra los beneficios según la participación de los productores y la rentabilidad para los actores que extraen madera de sus propiedades. 
Los pequeños productores dependen más de los mercados locales y contadas especies de valor comercial, las cuales son abastecidas a los mercados urbanos de forma continua sin que esto signifique que hay un pedido de por medio. El 58\% de los pequeños productores entrevistados, prefieren vender de forma directa a los aserraderos que fungen como intermediarios de otros compradores finales. Los pequeños productores realizan la corta y luego el transporte a través de las embarcaciones fluviales, en balsas que son arrastradas a favor de la corriente del río o en botes que son conocidos como pekes-pekes. El 24\% de los pequeños productores prefieren que extractores realicen el proceso de corta y el $18 \%$ restante prefieren vender la madera cuartoneada a intermediarios que pasan por sus comunidades o caseríos.

Las redes de comercialización vinculadas a los pequeños productores son totalmente informales y se enlazan a los mercados más grandes a través de los intermediarios locales que se dedican a la compra y venta de madera o aserraderos que, por su lado, transforman la madera para enviarla a los compradores finales en las grandes urbes en forma de tablas, tablillas, etc. Además, estas redes suplen de maderas duras a la industria local de pisos que ubican sus plantas en las ciudades de Pucallpa, Iquitos y Puerto Maldonado y la demanda de especies blandas en Lima. Durante la última comercialización de madera, el $42 \%$ de los entrevistados vendieron tablillas de bolaina; el 29\%, cuartones de shihuahuco y capirona (más otras especies duras); y el 29\%, madera en pie de varias especies.

En Ucayali y Loreto, los pequeños productores trabajan en la extracción de madera en promedio un total de tres meses a lo largo del año, en especial durante la época de inicio de clases de sus hijos y Navidad. Hay excepciones cuando existe enfermedad o una actividad demandante de dinero corriente como bodas o cultivos (insumos agrícolas). En Madre de Dios, la mayor parte de los pequeños productores tienen acceso a sus tierras a través carreteras y caminos secundarios en buen estado, lo que les permite trabajar hasta seis meses al año en la extracción de madera.

Por su parte, las comunidades indígenas realizan ventas individuales y son consideradas como pequeños productores, o como colectivos que establecen acuerdos con extractores medianos que realizan los trámites de legalización y desarrollan la corta. Estos arreglos son variados y dependen de la experiencia que tenga la comunidad para negociar. En Ucayali y Loreto el acuerdo más común es conocido como 80-20, que significa que de la madera rolliza obtenida de una zafra se divide el $80 \%$ de la madera para las empresas (extractores) y el $20 \%$ para la comunidad.

\subsubsection{Operaciones en comunidades indígenas}

Las comunidades indígenas en las zonas de estudio realizan la extracción de manera terciarizada a través de extractores grandes, medianos y pequeños, aunque también las familias realizan extracciones individuales esporádicas y periódicas. Las extracciones medianas y grandes por lo general cuentan con permisos otorgados por la autoridad forestal regional en los cuales se registran las áreas a intervenir en número de hectáreas y las especies a aprovechar. La participación de la comunidad, en muchos de los casos, es mínima en la planificación, pero usualmente un miembro local funge como "matero" en la ubicación de los árboles comerciales $\mathrm{y}$ algunas veces algunas personas son utilizadas como mano de obra remunerada. En pocos casos, la misma comunidad realiza el trabajo de corta.

En este estudio se analizaron 15 comunidades, de las cuales diez negociaron directamente con el extractor, tres comunidades negociaron a

\section{Cuadro 55. Venta de madera según tipo de negociación en comunidades indígenas}

\begin{tabular}{lccl}
\hline Negociación & $\begin{array}{c}\text { Participación } \\
\text { en la corta }\end{array}$ & $\begin{array}{c}\text { Promedio } \\
\text { beneficio/ } \mathbf{m}^{3}\end{array}$ & Tipo de madera predominante \\
\hline ONG & no & 74,6 & Capirona \\
Intermediario & sí & 40,0 & Capirona, catahua \\
Empresa & no & 28,9 & Capirona, catahua, shihuahuaco, lupuna \\
Empresa Maderija & no & 96,1 & Shihuahuaco, azúcar huayo, ishpingo \\
\hline
\end{tabular}

Fuente: Elaboración propia con base en las entrevistas realizadas entre julio de 2013 y marzo de 2014. 
través de una organización no gubernamental y la empresa realizó la corta, y por último, dos comunidades realizaron la corta directamente y la negociación fue con un intermediario-habilitador. Otra modalidad de aprovechamiento - y que fue el único caso registrado- se observó en Madre de Dios, donde la comunidad vende madera a la empresa Maderija a través de un contrato de extracción. Mensualmente la empresa entrega 1600 nuevos soles/familia/mes. La venta de madera por metro cúbico según el tipo de negociación se detalla en el Cuadro 55.

\subsection{Costos y beneficios de la comercialización de la madera}

Los compradores locales son dinámicos y se especializan en ciertos rubros, por lo tanto, necesitan un suministro de madera de ciertas características de manera constante. Son diversas las estrategias que estos compradores utilizan para abastecerse de madera. La más común es la interacción con intermediarios de todo tipo y la segunda es vincularse directamente a la corta de madera como intermediarios-habilitadores, aunque esta última es utilizada en menor proporción. El tipo de interacciones establecidas depende mucho de la capacidad de inversión de los compradores. Los compradores pequeños son carpinteros, los medianos son dueños de depósitos y los compradores más grandes son los aserraderos en las principales ciudades de Pucallpa, Iquitos y Puerto Maldonado. En la región de esta última, Madre de Dios, los compradores trabajan generalmente con intermediarios, pero no se involucran directamente en el proceso de extracción.

La interacción de los actores del comercio de madera depende de los intermediarios. A su vez, estos dependen de los pedidos de compradores urbanos en Lima, Trujillo, Piura, Cusco o
Arequipa. La ventaja de los intermediarios locales sobre los externos es que cuentan con espacios de almacenaje para acumular madera de diferentes especies hasta tener suficiente carga para transportar hasta su destino final. Además, tienen establecidas sus redes comerciales de acopio de madera a lo largo de las poblaciones intermedias entre el bosque y las ciudades grandes. Por esta razón los intermediarios externos tienen que establecer tratos con sus pares locales.

Los compradores (empresas) de las principales ciudades emplean sus propios intermediarios para abastecerse de madera de ciertas especies. Estos circuitos tienen que usar los servicios de aserraderos locales para transformar la madera antes de transportarla. El aserrío es un servicio y no representa ninguna intermediación entre ellos. Las empresas analizadas en este estudio se proveen de madera de intermediarios ubicados en los principales puertos de producción de madera en las regiones de Loreto, Ucayali y Madre de Dios. La transacción comercial se realiza al contado y el intermediario-bróker recibe una comisión sobre un sueldo básico dependiendo del volumen y de la calidad del producto.

\subsubsection{Comercialización realizada por intermediarios}

Los intermediarios analizados se dedican únicamente a la compra y venta de madera, y no se involucran en las operaciones de aprovechamiento, aunque un $30 \%$ de los entrevistados sí realizan transformaciones secundarias para comercializar la madera, en especial como tablillas (Cuadro 56). Los intermediarios muy pequeños se dedican al paso de madera entre proveedores y compradores, ganando un pago por pie comercializado de 0,10 nuevos soles (Ucayali y Loreto) y 0,20 nuevos soles (Madre de Dios). Los pequeños rentan depósitos donde comercializan la madera a nivel local, pero

\section{Cuadro 56. Características de los intermediarios por tamaño}

\begin{tabular}{lrrrr}
\hline Tamaño & Grande & Mediano & Pequeño & Muy pequeño \\
\hline Número entrevistados & 12 & 19 & 101 & 33 \\
Número de trabajadores & 12,0 & 7 & 4,4 & 2,7 \\
Promedio comercializado al año $\left(\mathrm{m}^{3}\right)$ & 1316,53 & 172,9 & 67,2 & 28,5 \\
m $^{3}$ de la última comercialización & 605,39 & 120,4 & 41,4 & 5,4 \\
Días que necesita para comercializar & 81 & 75 & 67 & 66 \\
\hline
\end{tabular}

Fuente: Elaboración propia con base en las entrevistas realizadas entre julio de 2013 y marzo de 2014. 


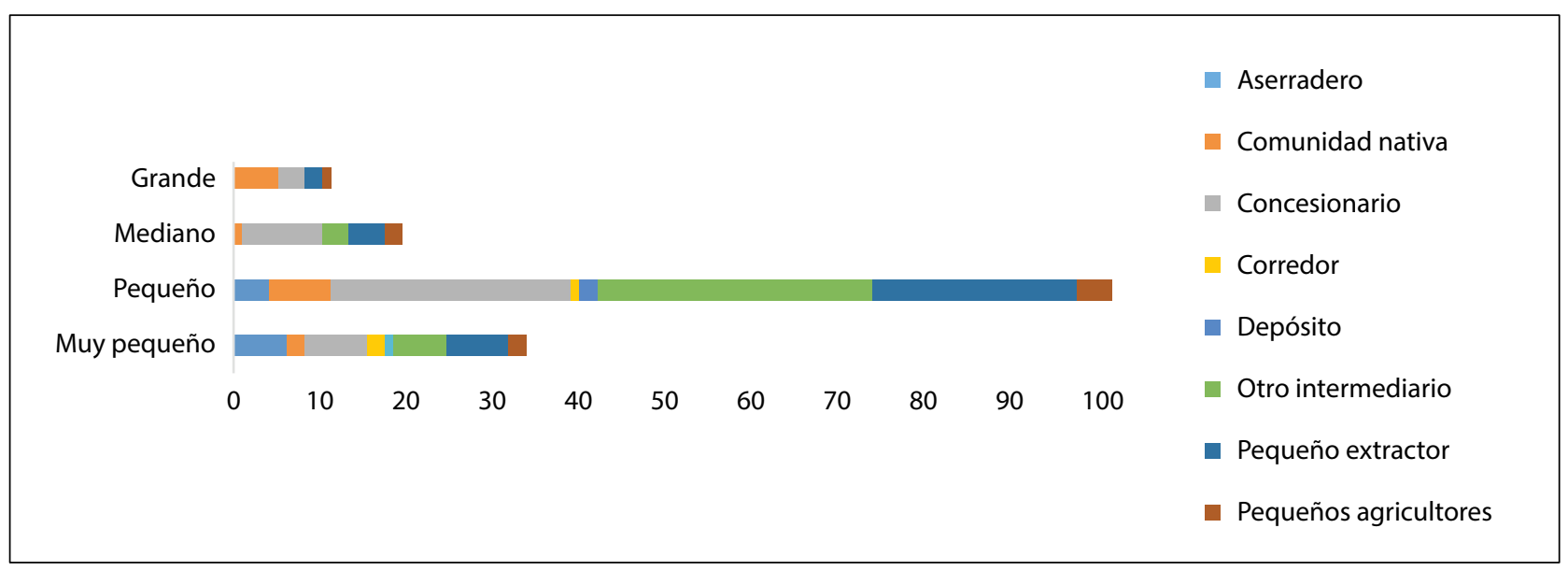

Figura 21. Principales proveedores de la madera comercializada por los intermediarios

Fuente: Elaboración propia con base en las entrevistas realizadas entre julio de 2013 y marzo de 2014.

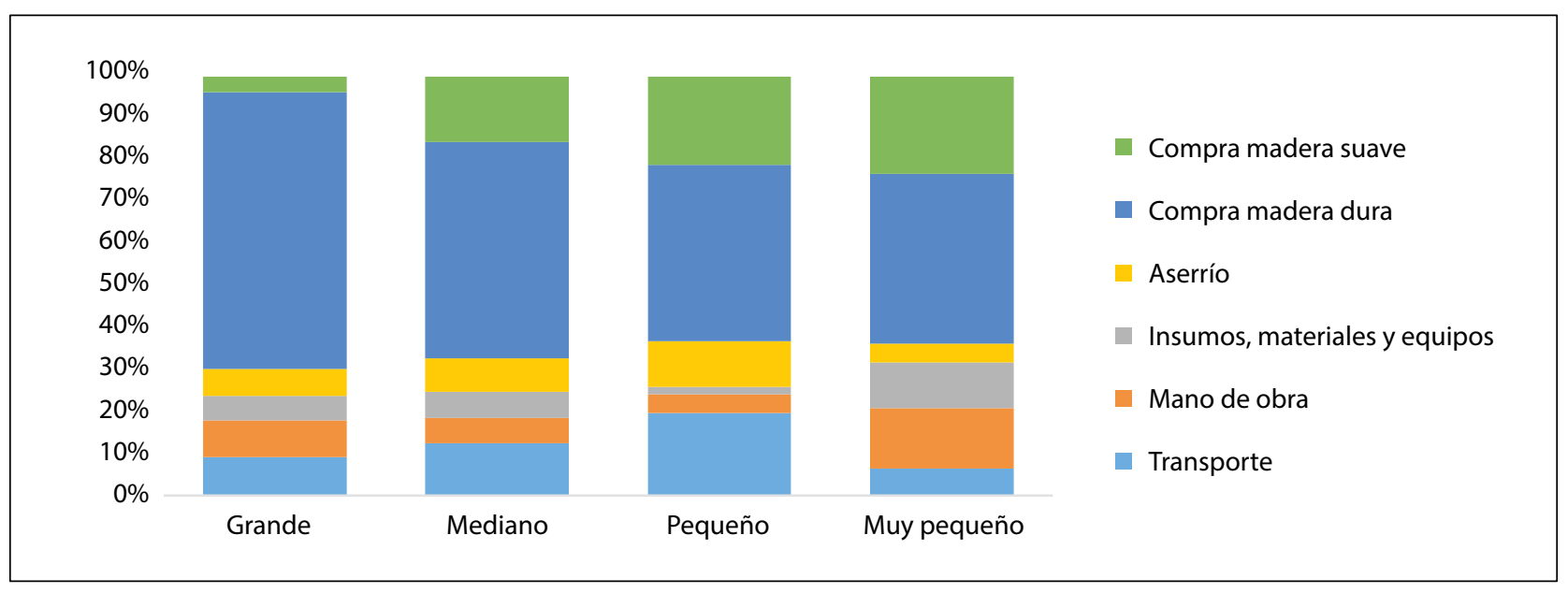

Figura 22. Distribución de los costos de la comercialización de la madera según el tamaño de los intermediarios

Fuente: elaboración propia con base en entrevistas realizadas entre julio de 2013 y marzo de 2014.

no transportan madera fuera de las urbes. Por otro lado, medianos y grandes intermediarios cuentan con comercialización externa sea directa o a través de los intermediarios externos.

Los intermediarios se proveen de madera principalmente de concesionarios; sin embargo, desconocen si es que en realidad la madera proviene de las concesiones, sino más bien estos aseguran que los documentos están avalados bajo esta modalidad. Los más grandes realizan compras directas y no utilizan los servicios de otros intermediarios, excepto cuando cuentan con un pedido más grande. Los pequeños extractores son proveedores importantes de madera para todos los intermediarios (Figura 21). Los intermediarios, esperan la madera en los principales puertos, en donde, dependiendo del volumen negociado, asumen los costos de grúas, izajes y camiones para el transporte de la madera hacia los aserraderos. Además, los intermediarios se encargan de tener listas las guías de transporte forestal para la respectiva movilización de la madera.

El costo más representativo para estos actores son los relacionados al pago de la madera que representan más del $50 \%$ de los costos totales (Figura 22). La compra de la madera por parte de los pequeños y muy pequeños es $100 \%$ al contado, mientras que entre los actores medianos y grandes existen tiempos de pagos según el proveedor de la madera. Por lo general estos actores pagan $70 \%$ al contado y el $30 \%$ entre cinco y quince días. 


\section{Cuadro 57. Costos y beneficios por tipo de madera y producto (USD/m ${ }^{3}$ )}

\begin{tabular}{llrlr}
\hline Producto & $\begin{array}{c}\text { Costo } \\
\text { USD } / \mathbf{m}^{3}\end{array}$ & DS & $\begin{array}{c}\text { Beneficio } \\
\text { USD } / \mathbf{m}^{3}\end{array}$ & DS \\
\hline Dura & 221,7 & 164,0 & 164,2 & 136,6 \\
Comercial & 235,5 & 171,4 & 130,8 & 106,3 \\
Cuartón & 215,4 & 148,8 & 279,8 & 153,4 \\
Rolliza & 123,3 & 120,7 & 106,5 & 94,2 \\
Tablillas & 258,6 & 109,0 & 163,1 & 172,6 \\
Tablones & 382,3 & 368,5 & 178,0 & 218,6 \\
Blanda & 172,2 & 101,1 & 79,8 & 100,0 \\
Comercial & 190,8 & 111,1 & 68,0 & 82,3 \\
Rolliza & 112,9 & 122,6 & 15,6 & 2,1 \\
Tablillas & 178,3 & 86,2 & 56,0 & 76,6 \\
\hline
\end{tabular}

Fuente: elaboración propia con base en entrevistas realizadas entre julio de 2013 y marzo de 2014.

$\mathrm{Al}$ igual que en el caso de los extractores, los costos y beneficios de la madera dura son un $22 \%$ y un $51 \%$ mayores que la madera blanda respectivamente. En este sentido, la preferencia de los intermediarios por comercializar madera dura se debe a una rentabilidad por cada dólar invertido de 0,74 , que es más alta en comparación con 0,46 en madera blanda (Cuadro 57). Los precios referenciales por especie se pueden revisar en el Anexo 6.

Los beneficios para los intermediarios son muy variables. Existen varios factores que influyen en los costos y beneficios, como la existencia de compradores fijos y la capacidad de almacenamiento con la que cuentan. Los grandes y medianos proveen a empresas exportadoras o intermediarios externos madera blanda y dura destinada hacia la industria de transformación primaria y de pisos. Estos compradores son por lo general habituales. Los pequeños y muy pequeños tienen que buscar compradores que suelen ser ocasionales y no cuentan con suficiente capacidad de almacenamiento o capital para comprar madera. Los beneficios mayores en el caso de los pequeños y muy pequeños intermediarios se deben principalmente a que comercializan solo especies duras (Cuadro 58).

\subsubsection{Comercialización realizada por empresas exportadoras}

Las empresas exportadoras se proveen en un $67 \%$ de extractores e intermediarios medianos, en un $27 \%$ de sus propias concesiones y en un $7 \%$ de otros como pequeños extractores. El 100\% de las transacciones son compras directas en efectivo a contra entrega del producto, aunque en algunos casos pueden realizarse a plazos según la relación de confianza existente entre comprador $\mathrm{y}$ vendedor. Estas empresas trabajan a base de pedidos verbales de sus compradores en el exterior, que se formalizan posteriormente al momento de responder sobre la disponibilidad del producto requerido. El 100\% de las empresas exportadoras entrevistadas realizan un contrato formal en algún momento antes de la entrega del producto.

Los intermediarios que fungen como agentes comerciales se encuentran mejor organizados para proveer madera hacia las empresas exportadoras. Son actores que tienen acceso a capital y buenas relaciones comerciales con los extractores medianos y pequeños. Acopian madera de estos últimos a través de compras directas. Aunque su producto tiene como destino las grandes empresas exportadoras, operan en base a oferta y demanda, es decir, venden su madera al mejor postor, que por lo general son empresas acumuladoras muy grandes.

El principal destino de las exportaciones peruanas es China y Hong Kong. En este sentido se realizó un análisis más detallado de estas empresas para conocer mejor su modalidad de trabajo. De las empresas entrevistadas el $70 \%$ tiene como destino

Cuadro 58. Costos y beneficios por tamaño de intermediarios (USD $/ \mathrm{m}^{3}$ )

\begin{tabular}{lccccc}
\hline Tamaño & Costo USD $/ \mathbf{m}^{3}$ & DS & Beneficios USD $/ \mathbf{m}^{3}$ & DS & Rentabilidad USD $/ \mathbf{m}^{3}$ \\
\hline Grande & 106,2 & 74,5 & 105,2 & 111,5 & 1,0 \\
Mediano & 251,6 & 146,5 & 110,2 & 87,5 & 0,4 \\
Pequeño & 185,2 & 139,5 & 139,1 & 156,9 & 0,8 \\
Muy pequeño & 231,3 & 140,0 & 127,2 & 101,9 & 0,6 \\
\hline
\end{tabular}

Fuente: elaboración propia con base en entrevistas realizadas entre julio de 2013 y marzo de 2014. 
final exclusivo China, y el 30\%, destinos variados como Estados Unidos, Europa y otros países de Asia. Las transacciones comerciales se realizan con adelanto de pago en algunas ocasiones, otras con orden de pedido y de acuerdo a la confianza comercial de ambas empresas. La mayoría de las empresas cuentan con capitales chinos. Las especies que comercializan son madera dura para pisos y decking (shihuahuaco, tahuari, estoraque, quinilla, palo bastón (Crepidospermum goudotianum), huairuro y otros).

Las empresas exportadoras consideradas medianas a grandes, despachan entre 6 y 8 contenedores mensuales (contenedores de 20 y $40 \mathrm{~m}^{3}$ ) es decir un rango de $1440 \mathrm{~m}^{3}$ a $3840 \mathrm{~m}^{3}$ al año. El tiempo de entrega del pedido desde que se inicia la orden de compra formal a través de un contrato entre las partes es de 1 a 3 meses y el tiempo de espera del pago total es de 30 días; este pago se realiza al contado y por medio de transacciones bancarias. Las empresas que exportan madera y mantienen clientes exclusivos se solventan con capitales del cliente y no requieren de préstamos de los sistemas financieros nacionales. Estas empresas trabajan con cartas de créditos emitidas por los clientes a través de bancos locales que fungen como corresponsales.

Las empresas que se encuentran ubicadas en Lima, dedicadas a la exportación de madera, tienen proveedores de Pucallpa (56\%), Loreto (26\%) y Madre de Dios (18\%). La transacción comercial se realiza al contado, de acuerdo a la cubicación de madera pagada, con excepciones en el caso de relaciones de confianza más largas entre proveedor y comprador. Las especies de mayor comercialización son shihuahuaco, tahuari, estoraque, quinilla, palo bastón y huairuro. En este análisis se entrevistaron a 17 empresas que se encargan de realizar la transformación de la madera para pisos, por lo cual demandan madera de alta calidad. El 100\% de estas empresas venden a otras empresas ubicadas en los destinos finales en especial de China y Hong Kong, en menor proporción a Estados Unidos y Europa.

\subsection{Rentabilidad versus eficiencia}

Como se describió a lo largo de este capítulo, la rentabilidad para los diferentes actores varía según las especies comercializadas y el grado de transformación de la madera, asimismo, el tamaño de las operaciones que realizan. Sin embargo, por sí sola la rentabilidad no expresa la eficiencia del uso

\section{Cuadro 59. Análisis de costos-beneficios para las empresas exportadoras (USD/m $\mathrm{m}^{3}$ )}

\begin{tabular}{lcccc}
\hline & Ingresos & Costos & Beneficios $^{\mathrm{a}}$ & Rentabilidad $^{\mathrm{a}}$ \\
\hline 2010 & 1082,9 & 270,7 & 812,1 & 3,0 \\
2011 & 831,4 & 249,4 & 582,0 & 2,3 \\
2012 & 687,2 & 137,4 & 549,8 & 4,0 \\
Promedio & 867,2 & 219,2 & 648,0 & 3,1 \\
\hline
\end{tabular}

Fuente: elaboración propia con base en entrevistas realizadas entre julio de 2013 y marzo de 2014 a 17 de empresas exportadoras.

Nota: a) Se toma en cuenta el "draw-back" (devolución de impuestos) y otros beneficios a los exportadores, calculados en base a la información disponible en http://www.sunat.gob.pe/ estad-comExt/modelo_web/Bol2013.htm.

de los factores de producción. En este sentido, es necesario determinar si los actores forestales se encuentran produciendo a su máxima capacidad o no. Para ello, se debe conocer la proporción entre la producción actual, con respecto a la que obtendrían si los actores utilizaran sus recursos con eficiencia técnica ${ }^{52}$. Para determinar este índice, fue necesario determinar primero la forma funcional ${ }^{53}$ con la que se trabajaría y las variables a utilizar de la información obtenida, tales como: el número de trabajadores que participaron en la última extracción forestal, la productividad del trabajador, los costos medios, el tiempo que demoró la extracción y, finalmente, el ratio de beneficio costo ${ }^{54}$; para luego realizar el análisis de eficiencia. Con este índice su busca conocer si el nivel de extracción que realizan los actores forestales está de acuerdo a la cantidad de insumos que estos tienen.

\section{$52 E T=\frac{\left.f\left(x_{i}, x_{j}, \beta\right) e^{\left(v_{i-}\right.} u_{i}\right)}{f\left(x_{i}, x_{j} \beta\right) e^{\left(v_{i}\right)}}=e^{-u_{i}}$}

Si el resultado de la medida de eficiencia técnica es cercano a uno significa que es eficiente técnicamente, es decir, donde ningún actor forestal puede producir más, dada una cantidad de insumos. Caso contrario, si es cercano a cero, se considera ineficiente. Para obtener mayor información, véase Perdomo (2010) "Funciones de producción y eficiencia técnica en el eje cafetero colombiano".

53 Función de producción Translogarítmica:

$\ln q=\beta_{0}+\sum_{i=1}^{n} \beta_{i} \ln x_{i}+-\sum_{i=1}^{n} \sum_{j=1}^{n} \ln x_{i} \ln x j \Rightarrow \beta_{i j}=\beta_{j i}$ véase en Perdomo (2010)

$54 Q=\propto_{0}+\propto_{1} L+\propto_{2} \frac{Q}{L}+\propto_{3} \frac{C T}{Q}+\propto_{4} T+\propto_{5} \frac{B}{C}$

Se consideró que L: $\mathrm{N}^{\circ}$ trabajadores; $\mathrm{Q}:$ Total extracción; CT: Costos totales; $\mathrm{T}$ : $\mathrm{N}^{\circ}$ de días que se demoró en sacar madera. La función que se eligió fue la translogarítmica, por tratarse de una forma funcional que no impone ninguna restricción sobre las características en el proceso productivo, en este caso el extractivo. 
La comparación de rentabilidad y eficiencia muestra que los extractores-transformadores son los que presentan un grado más alto de eficiencia y rentabilidad debido a que integran sus factores de producción al máximo de su capacidad. Incluso los más pequeños que se definen como las carpinterías muestran un mejor desempeño que sus pares que se dedican únicamente a la extracción. Los extractores presentan los niveles de eficiencia y rentabilidad más baja, debido a que podrían generar mayores beneficios con cambio, pequeños en los factores de producción. El Cuadro 60 resume el desempeño de los actores analizados.

\section{Cuadro 60. Rentabilidad de los diferentes actores}

\begin{tabular}{lcc}
\hline Tipo de actores & Rentabilidad $\mathbf{~}^{3}$ & Índice de eficiencia técnica \\
\hline Extracción de madera & 1,1 & 0,2 \\
\hline Extractores grande & 1,7 & 0,2 \\
Extractores medianos & 1,0 & 0,3 \\
Extractores pequeños & 1,0 & 0,4 \\
Extractores muy pequeños & $3,5^{\mathrm{a}}$ & - \\
Extractor transformador grande (exportador) & 3,2 & 1,5 \\
Extractor transformador mediano & 1,8 & 1,5 \\
Extractor transformador pequeño & 1,7 & - \\
Extractor transformador muy pequeño & 1,0 & - \\
Concesionario castañero & 2,5 & - \\
Concesionario maderero & 0,8 & 0,4 \\
Pequeño productor & & 0,7 \\
\hline Intermediación de la madera & 0,9 & 0,6 \\
\hline Intermediario grande & 0,4 & 0,5 \\
Intermediario mediano & 0,7 & - \\
Intermediario pequeño & 0,5 & 1,0 \\
Intermediario muy pequeño & 3,1 abc & \\
Intermediarios empresas exportadoras & $2013 y$ mazode & \\
\hline
\end{tabular}

Fuente: elaboración propia con base en entrevistas realizadas entre julio de 2013 y marzo de 2014.

Nota: a) Estimaciones del "draw-back" realizadas con base en la información disponible en la SUNAT http://www. sunat.gob.pe/estad-comExt/modelo_web/Bol2013.htm. b) Principalmente especies duras para pisos. c) Estimaciones para 2011 y 2012. 


\section{Discusión}

Para varios autores, el sector forestal peruano es un sector en el que históricamente se han mantenido elevados niveles de informalidad, vinculada en muchos casos con prácticas de corrupción (Kishor y Damania, 2009; EIA, 2012; INTERPOL, 2014; García, 2014). Nuestro análisis sugiere que la creciente demanda de los mercados urbanos, nacionales e internacionales, es uno de los principales factores que impulsan el aprovechamiento informal debido a las barreras legales que dificultan suplir los mercados solo con madera de origen legal. Para suplir esta demanda, los actores han construido redes de intermediación que se basan en vínculos de confianza y lazos familiares. Estas redes sobrepasan el comercio dentro del Perú y alcanzan mercados distantes en China, Estados Unidos y Europa. Estas redes se sustentan en los usuarios más cercanos a los bosques que aquí denominamos extractores y pequeńos productores. Estos, a su vez, venden la madera a intermediarios, quienes sirven de vínculo con los transformadores o compradores, que son quienes acumulan madera en las ciudades. Los transformadores o compradores finales ejercen mayor poder sobre los demás miembros de las redes analizadas, debido a que forman parte de élites locales que manejan los canales de abastecimiento y distribución. Esto último también fue mencionado por Cuellar (2005) para el caso de Ucayali.

Si comparamos los resultados de Ucayali, Loreto y Madre de Dios, el aprovechamiento informal involucra a una gran parte de pequeños productores y extractores quienes tienden a cortas selectivas de pequeña escala utilizando motosierras que están prohibidas por la legislación para realizar transformación a productos terminados, siendo que su uso es permitido únicamente para el canteo de trozas. Estos actores operan al margen de la ley y se vinculan a los mercados locales, nacionales y extranjeros a través de medianos y grandes intermediarios quienes se encargan de vender los documentos para legalizar la madera y/o establecer vínculos con compradores. Esto contradice lo argumentado por quienes sugieren que existiría una débil vinculación de los pequeńos productores a los mercados (ADEX, 2011; AIDER, 2012). Este estudio detalla varios mecanismos que son utilizados por los pequeńos productores para comercializar la madera, sugiriendo que son los pequeños actores quienes, a pesar de contar con condiciones desiguales para acceder a mercados, mayores costos de producción y menor rentabilidad, constituyen parte importante del abastecimiento de los mercados locales analizados. El mismo patrón fue evidenciado por Mejia y Pacheco (2013) en Ecuador y Cano (2014) en Bolivia.

Los pequeños extractores y transformadores tienen pocas posibilidades para formalizar sus operaciones y no cuentan con alternativas viables para un posible cambio de prácticas hacia otras más formales, las que dependen fuertemente en la capacidad de usar los recursos y el capital disponible. La nueva Ley Forestal refuerza el mecanismo de los bosques locales como recurso de acceso a los pequeños extractores; sin embargo, estos bosques están sujetos a los mismos procedimientos que las concesiones en cuanto a realización de inventarios y trámites de aprobación por parte de la autoridad, además del uso de tecnologías adecuadas y capital de trabajo. Los beneficios de los actores más pequeños según nuestro análisis de costos y beneficios, no serían suficientes para cubrir los costos asociados a la legalidad y tampoco suplirían los costos de reinversión para operaciones mayores a $270 \mathrm{~m}^{3} / \mathrm{anno}$. Estas pequeñas cantidades no son económicamente atractivas para realizar un plan de manejo formal, que necesita al menos un volumen de $500 \mathrm{~m}^{3}$ de madera por operación de corta para justificar su implementación. 
Los pequeños productores tanto de comunidades nativas como mestizas son los más excluidos del sistema legal y están al margen de cualquier oportunidad para la legalización de cortas pequeñas de madera extraída de sus propiedades, a pesar de que este reclamo ha sido parte de las peticiones de las organizaciones de comunidades nativas durante el proceso de discusión de la legislación. Estos actores de forma individual no están considerados en la Ley Forestal, a pesar de que en la realidad corten y comercialicen madera en pequeñas cantidades a lo largo del año. En el presente estudio, se calculó que el volumen que un productor corta al año comprende entre $7 \mathrm{~m}^{3}$ y 23 $\mathrm{m}^{3} / \mathrm{anno}^{55}$, volumen que está más relacionado a su disponibilidad de mano de obra y capital.

La venta de madera sigue siendo la opción más rentable para los pequeños productores, comparada a otras actividades agrícolas y productos no maderables como también lo evidenciaron Guariguata et al. (2012) y Porro et al. (2014). Sin embargo, son los pequeños productores quienes obtienen la rentabilidad más baja en el comercio de madera, dentro del universo de actores analizados. Estos también presentan los niveles más bajos de transformación de madera y son quienes aprovechan mayores volúmenes de especies blandas, como bolaina, y menores volúmenes de especies duras, como shihuahuaco, tornillo y capirona, que son las que representan mayores ganancias. El preferir especies blandas está fuertemente relacionado a los costos más bajos de operación, lo cual denota la falta de capitalización de los pequeños productores.

En general, la rentabilidad estuvo asociada a la eficiencia en el uso de los factores de producción analizados y las especies escogidas. En este sentido, los transformadores son quienes tienen mejor desempeño sin importar el tamaño de sus operaciones, es decir, que tanto los pequeños carpinteros como los grandes que cuentan con sus propios aserraderos llegan a obtener mejores ingresos por cada dólar invertido que aquellos que solo extraen madera del bosque. La diferencia es marcada con los transformadores exportadores, que, sobre todos los demás actores analizados, son los quienes obtienen la rentabilidad más alta. Esto se debe en parte a la calidad en la transformación

55 Según los datos obtenidos en campo de 118 pequeños productores. y las conexiones establecidas en mercados internacionales, pero también a los retornos por incentivos desde el Estado, sin los cuales su rentabilidad disminuiría en un $30 \%$.

Adicionalmente, debe señalarse que las políticas de comercio legal de madera, en gran parte apoyadas en iniciativas como FLEGT en la Unión Europea y el Lacey Act en Estados Unidos, favorecen ciertos estándares para el aprovechamiento de madera los que incluyen la práctica de manejo sostenible basada en ciclos de corta y el uso de inventarios, refrendados con permisos de aprovechamiento. Estos parámetros toman como referencia aprovechamiento en áreas grandes, y por lo tanto fuera del alcance de pequeńas propiedades individuales o de cortas selectivas, que son las que predominan en el sector peruano. En este sentido, el sistema de manejo forestal nacional necesita incluir las prácticas locales de extracción y simplificar los procedimientos para permitir que prácticas informales vinculadas a aprovechamiento de pequeña escala consigan enmarcarse en la normativa forestal formal. Esto ya ha sido señalado en otros estudios como Smith et al. (2006) y Colan et al. (2006). La inclusión de las prácticas locales de aprovechamiento beneficiaría a que el sector se desarrolle de una manera más transparente, teniendo en cuenta que la mayor parte de la madera extraída permanece en la industria nacional. Estos sistemas más simples han sido implementados en Ecuador y Bolivia como primeros pasos en la formalización, como lo señalan Mejia y Pacheco (2013) y Pokorny et al. (2012).

Los actores que realizan operaciones en gran escala representan en promedio el $29 \%$ de los proveedores analizados (extractores o intermediarios) y han manejado en promedio el $81 \%$ del volumen de madera movilizada entre 2009 y 2012. Estos actores, denominados grandes para propósitos de este documento, consiguen legalizar sus actividades de aprovechamiento, controlar los precios, acumular mayor cantidad de madera $y$ en algunos casos transformarla en productos terminados para su venta final dentro o fuera del Perú. Esta situación ya fue identificada por la OEA en 1987, que declaraba en un estudio publicado sobre la selva central: "La acumulación de madera en manos de unos pocos industriales e inversionistas es común". Además, en el presente estudio se identificaron grandes compradores que en promedio representan el 6\% de los actores de 
la demanda y quienes han acumulado entre 2009 y 2012 en promedio el $60 \%$ de la producción en zonas industriales cercanas a Lima. Estos hallazgos de concentración de la demanda también fueron reportados para el Perú por Dablin (2014), Burneo (2011) y Comité PIF (2013).

Según los datos obtenidos en esta investigación, la acumulación de madera es posible en gran parte debido a las inversiones extranjeras y los créditos formales a grandes empresarios, que alientan sistemas de financiamiento conocidos como habilitación para cortas mayores a los $500 \mathrm{~m}^{3}$ o simplemente compiten con pagos directos en pequeñas compras. Datos similares fueron obtenidos en el 2006 por el Banco Mundial, que argumentó que los exportadores inyectan dinero mediante la habilitación a fin de crear sobreoferta y comprar después la madera a menor precio, manteniendo de esta manera stock constante (Banco Mundial, 2006). La información obtenida sugiere que, aunque es común entre los más grandes y algunos medianos concesionarios de castańa en Madre de Dios, la habilitación no es una práctica usual para los pequeños, quienes son considerados "no viables" por los habilitadores. Las cortas a pequeña escala se financian de otros sistemas informales, como créditos prendarios en casas de empeño o préstamos a través de cambistas o a través de otros ingresos propios. No obstante, estudios como el de Sears y Pinedo-Vasquez (2011) consideran que la habilitación ocurre en las operaciones de todo tamaño.

Las inversiones informales como la habilitación o las casas de empeño son débiles para garantizar la mejora de los procesos en la extracción y transformación de la madera a largo plazo. En este sentido se considera que este modelo ha desencadenado un círculo vicioso entre una extracción maderera orientada a obtener ganancias en el corto plazo y la rápida degradación del recurso forestal, en especial cuando no existen claros incentivos por parte del Estado (ITTO, 2003; ONUDI, 2013). En este estudio se calculó que la reinversión de las ganancias de la corta de madera se realiza en mayor proporción $(80 \%)$ por parte de los pequeños extractores, intermediarios y productores, mientras que los grandes y medianos reinvierten apenas el 30\% de sus ganancias, diversificando a otros sectores como el agrícola extensivo (palma, cacao), lo que les permite crear mecanismos de seguridad en caso de caída de precios. Sin importar el tamaño del actor, esta reinversión se enfoca en cubrir los costos de las operaciones de corta y de legalización para generar operaciones más grandes, sin pensar en la inversión en mejoras en la calidad de los bosques o en mejores prácticas de transformación de la madera. Estos hallazgos han sido reportados ya en años anteriores por Southgate y Elgegren (1995), León y Mego (2007) y Cossío et al. (2011). Además, sin la intervención oportuna de inversión pública, la participación equitativa de los pequeños actores en el sector forestal será poco factible (Urban y Ullilén, 2011).

$\mathrm{Al}$ parecer, mientras las inversiones, los créditos, las opciones de legalización y de manejo sostenible del bosque estén adaptados solo a un grupo reducido de actores, la formalización de la actividad forestal en el Perú a todo nivel será poco probable, al igual que la justa distribución de los beneficios de la comercialización de la madera. A pesar de los esfuerzos por parte del Estado y de organizaciones no gubernamentales por controlar la tala ilegal, los volúmenes aprovechados bajo esta modalidad siguen siendo desconocidos $y$, por lo expuesto en este trabajo, crecen a ritmo constante junto con la demanda. Esto se debe en gran parte al simple hecho de que los instrumentos de gestión como concesiones, permisos y autorizaciones no puedan suministrar datos verdaderos del origen de la madera, que en muchas ocasiones, como lo señaló OSINFOR (2014), es aprovechada por fuera de estas modalidades. Los debates sobre la factibilidad de estos instrumentos de gestión han sido discutidos también por Galarza y Serna (2005) y Giudice et al. (2012). Sumado a esto, la poca inversión en el sector maderero coloca también en riesgo la sostenibilidad de estos instrumentos (ver también Cuellar, 2005 y Maravi et al., 2008). 


\section{Conclusiones}

Son varios los factores que han influido para que el sector forestal considere como viables solo a las operaciones mecanizadas a gran escala, entre ellas, el reconocimiento por parte del Estado de otras organizaciones internacionales y de la sociedad civil de que el manejo forestal sostenible es posible únicamente en áreas que faciliten la realización de POA y que las actividades rentables están mayormente asociadas a mercados internacionales. No obstante, las prácticas locales a pequeña escala y el mercado nacional brindan acceso a una gran cantidad de actores excluidos del manejo forestal sostenible, como demostramos a lo largo de este documento. En este sentido, los actuales conceptos de manejo forestal crean varias conjeturas sobre la viabilidad única de este modelo, que, por lo anotado por Smith et al. (2006), Colan et al. (2007); Fisher et al (2013) y OSINFOR (2014), presenta fallas notables para ser considerado como acertado para la realidad del sector peruano. La revisión de estos argumentos podría ser parte de las soluciones a los problemas de ilegalidad.

La ilegalidad, a pesar de ser uno de los temas centrales en las agendas locales y nacionales, y la amplia atención que ha recibido este fenómeno en los medios de comunicación, es todavía entendida en forma deficiente, desde una perspectiva institucional, y se enfatizan demasiado sus efectos ambientales negativos. El hecho de que las prácticas locales de aprovechamiento de madera en pequeńa escala sean consideradas — casi de manera generalizada - como ilegales ha creado una situación en la que las agencias públicas de control, y varios actores en el mercado, utilicen varios instrumentos de coerción y exclusión social para quienes no están en condiciones de sobrepasar las barreras burocráticas. Para romper este ciclo, es necesaria la revisión de las estrategias de comando y control del actual sistema de permisos y autorizaciones hacia métodos más sencillos y articulados con la realidad local. La simplificación de la gestión forestal también puede mejorar la toma de decisiones sobre la intervención al territorio teniendo en cuenta que, en la actualidad, la información disponible no tiene un grado de veracidad adecuado.

Este estudio sugiere que se debería optar por soluciones más pragmáticas y cercanas a la realidad forestal del Perú, donde son los compradores en el destino final quienes deberían asumir mayor responsabilidad en la trazabilidad de la madera $y$ en las reinversiones para sostener la calidad del bosque, debido a que también acumulan mayores ganancias. Los recursos del control estarían mejor utilizados si cubrieran estos segmentos finales de la cadena de comercialización que agrupa a pocos usuarios en comparación con el gran número de extractores e intermediarios en las zonas rurales amazónicas. Esto podría realizarse si se mejora el acceso a la información forestal a nivel de especies en tiempo real, lo cual optimizaría la trazabilidad de la madera hasta sus destinos finales. Ciertamente, bajo las condiciones actuales de aprovechamiento y comercio, mientras no se mejore la equidad dentro de las redes informales de comercio de madera y se evite la extorsión, es poco probable que los actores se empoderen lo suficiente para pensar en el futuro del bosque. 


\section{Referencias}

ADEX. (20 de junio de 2011). Extracción informal. Obtenido de http://www.adexperu.org.pe/ Web_Adex/Prensa/Notas.html

AIDER. (2012). Utilización Industrial y Mercado de Diez Especies Maderables. Lima: ITTO.

Álvarez, N. L., y Naughton-Treves, L. (2003). Linking National Agrarian Policy to Deforestation in the Peruvian Amazon: A Case Study of Tambopata, 1986-1997. AMBIO: A Journal of the Human Environment, 32(4), 269-274.

Arroyo, P. C., Torres, L. S., y Manrique, S. O. (2011). Hombres y mujeres emprendedores en la industria del mueble de madera en Lima Sur. Lima: Centro de Estudio y "Promoción del Desarrollo.

Banco Central de Reserva del Perú. (2014). Consulta a Series Estadisticas del BCPR. Obtenido de http://estadisticas. bcrp.gob.pe/ consulta.asp?sIdioma= 1 ys Tipo $=1$ ysChkCount $=237$ ysFrecuencia $=\mathrm{A}$

Banco Central del Perú. (2012). Caracterización del Departamento de Madre de Dios. Cusco: Banco Central del Perú.

Banco Mundial. (2006). Análisis preliminares sobre gobernabilidad y cumplimiento de la legislación en el sector forestal de Perú. Washington: Banco Mundial.

Banco Mundial. (2006). Fortalecimiento de la gobernabilidad y la aplicación de la legislación forestal: Confrontando un obstáculo sistémico al desarrollo sostenible. Washington: Banco Mundial.

Burneo, Z. (2011). El proceso de concentración de la tierra en el Perú. International Land Coalition.

Cano, W. (2014). Mercados de la madera en la Amazonía Boliviana. In press: CIFOR.

Cardozo, M. L. (2013). Smallholder Livelihoods and Market Accessibility in the Peruvian Amazon. Texas: The University of Texas.

CEPAL. (1999). El mercado de tierras rurales en el Perú. Santiago de Chile: CEPAL.
Chavez, A. B. (2013). Landscape dynamics of Amazonian deforestation between 1986 and 2007 in southeastern Peru: policy drivers and road implications. Journal of Land Use Science.

Climate Investment Funds. (2013). Plan Forestal Perú 2013. Lima: Climate Investment Funds.

Colan, V., Pokorny, B., Catpo, J., y Sabogal, C. (2007). Manual de monitoreo de producción $y$ costos de operaciones en concesiones forestales con fines maderables en la Amazonia Peruana. Lima: CGIAR.

Comité PIF. (2013). Resumen de la reunión de trabajo para la elaboración del Anexo 1 del Plan de Inversión Forestal. Tarapoto: MINAM.

Cossío, R. E., Guariguata, M. R., Menton, M., Capella, J. L., Ríos, L., y Peña, P. (2011). El aprovechamiento de madera en las concesiones castañeras (Bertholletia excelsa) en Madre de Dios, Perú. Bogor: CIFOR.

Cossío, R. E., Perz, S., y Kainer, K. (2011). Capacity for Timber Management in Small and Medium Forest Enterprises: A Case Study from the Peruvian Amazon. Small-Scale Forestry(4), 489-507.

Cossío, R., Menton, M., Cronkleton, P., y Larson, A. (2014). Manejo forestal comunitario en la Amazonía peruana. Bogor: CIFOR.

Cuellar, J. (2005). Determinación de la producción maderera proveniente de operaciones forestales no autorizadas en la provincia de Padre Abad-Región, Ucayali. Pucallpa: Universidad de Ucayali.

Dourojeanni, M., Barandiarán, A., y Dourojeanni, D. (2009). Amazonía Peruana en 2021. Lima: ProNaturaleza.

EIA. (2012). La máquina lavadora cómo el fraude y la corrupción en el sistema de concesiones están destruyendo el futuro de los bosques de Perú. Lima: Environmental Investigation Agency.

Falconí, T. C. (2004). Demanda de madera del corredor norte peruano. Piura: WWF. 
FAO. (2012). Estudios Sectoriales: Evaluación del cobro por derecho de aprovechamiento de madera y otras tasas sobre el manejo forestal. Roma: FAO.

FAO. (2013). Marco de Programación de País 20132016. Lima: FAO.

FAO. (2015). Evaluación de los Recursos Forestales Mundiales 2015. Roma: FAO.

Finer, M., Jenkins, C. N., Sky, M. A., y Pine, J. (2014). Logging Concessions Enable Illegal Logging Crisis in the Peruvian Amazon. Scientific Report.

Fisher, B., Edwards, D. P., y Wilcove, D. S. (2013). Logging and conservation: Economic impacts of the stocking rates and prices of commercial timber species. Forest Policy and Economics (In press).

Freitas, G. S. (2012). Desafíos para la gestión Forestal en el Perú: de la práctica a la política. Tecnología y Sociedad(9).

Galarza, E., y Serna, K. L. (2005). Son sostenibles las concesiones en el Perú. Lima: CIU.

García, T. (2014). Estado de la Gobernanza Forestal referente a la madera ilegal. Lima.

Gaviria, A., y Sabogal, C. (2013). Sistematización de Seis Experiencias de Manejo Forestal Comunitario en la Amazonía peruana. Lima: FAO.

Gironda, C. T. (2008). Diagnóstico de la demanda de productos maderables en los corredores centro y sur. Lima: ITTO.

Giudice, R., Soares-Filho, B. S., Merry, F., Rodrigues, H. O., y Bowman, M. (2012). Timber concessions in Madre de Dios: Are they a good deal? Ecological Economics(77), 158-165.

Hajek, F., Rios, M., Holle, K., Zanabria, P., y Persivale, R. (2012). Opciones de Inversión Privada e Instrumentos Financieros para el Sector Forestal del Perú. Lima: Nature Service Peru.

IBC. (2012). Amazonía Bajo Presión. Lima: Red Amazónica de Información Socioambiental Georeferenciada.

ICEX. (2013). Guia de Inversión en Perú 2013. Lima: Oficina Económica y Comercial de la Embajada de España en Lima.

INEI. (2008). II Censo de las Comunidades Indígenas de la Amazonía Peruana 2007. Lima: INEI.

INEI. (2012). Resultados definitivos: IV Censo Nacional Agropecuario 2012. Lima: INEI.

INEI. (2013). Cifras Macroeconómicas. http:// www.inei.gob.pe/estadisticas/indice-tematico/ economia/.
INTERPOL. (2014). Operación contra el comercio de madera ilegal en el Perú con el apoyo de INTERPOL y la OMA. Recuperado el julio de 2014, de http://www.interpol.int/es/Centro-deprensa/Noticias/2014/N2014-139/

ITTO. (2003). Burocracia y pobreza se consideran causantes de la extracción ilegal en Perú. ITTO.

ITTO. (2013). Report from Peru. Tropical Timber Market Report, 17(16), 10-12.

Jong, W. d., Cano, W., Zenteno, M., y Soriano, M. (2014). The legally allowable versus the informally practicable in Bolivia's domestic timber market. Forest Policy and Economics, In press.

Kishor, N., y Damania, R. (2009). Crimen y justicia en el Jardín del Edén: Mejorar la Gobernabilidad y Reducir la corrupción en el Sector Forestal. En E. Campos, Multiples Caras de la Corrupción. Washington: Banco Mundial.

León, D., y Mego, P. (2007). El cluster forestal en Madre de Dios: obstáculos y oportunidades para su crecimiento y competitividad. Apuntes.

Maravi, E., Kometter, R., y Gonzalez, V. (2008). Timber Extraction and trade in Peru. En J. Holopainen (Ed.), Financing Sustainable Forest (págs. 56-62). Wageningen: Tropenbos International.

McKechnie, L. (2006). Property Rights Reform in Peru: Why Titles do not Increase Access to Micro-Credit. Journal of Development and Social Transformation.

Mejia, E., y Pacheco, P. (2013). Aprovechamiento forestal y mercados de la madera en la Amazonia Ecuatoriana. Bogor: CIFOR.

MINCETUR. (2005). Perfil del Mercado y Competitividad Exportadora de Muebles de Madera. Lima: MINCETUR.

Ministerio de Agricultura. (2012). Palma Aceitera: Principales Aspectos de la Cadena Agroproductiva. Lima: Dirección General de Competitividad Agraria.

Ministerio de Agricultura. (2013). Estadisticas Forestales 2000-2013. Lima: MINAGRI.

Ministerio de Agricultura. (2014). Notas de prensa. Obtenido de http://www.minag.gob.pe/portal/ notas-de-prensa/notas-de-prensa-2014/11528promulgan-norma-que-impulsara-lasplantaciones-forestales

Ministerio de Agricultura. (2014). Presente y futuro del sector forestal peruano: el caso de las concesiones y plantaciones forestales. Lima: MINAG.

Ministerio de Relaciones Exteriores. (2013). Guia de Negocios e Inversión en el Perú 2013 / 2014. Lima: Ministerio de Relaciones Exteriores. 
Ministerio del Ambiente. (2011). Compendio de la Legislación Ambiental Peruana. Lima: MINAM.

Ministerio del Ambiente. (2011). El Perú de los Bosques. Lima: MINAM.

Ministerio del Ambiente. (2013). Memoria técnica: Cuantificación de la Cobertura de Bosque y Cambio de Bosque a no Bosque de la Amazonía Peruana. Periodo 20092010-2011. Lima: Dirección General de Ordenamiento Territorial.

Ministerio del Ambiente. (2014). Manual de Legislación Ambiental. Lima: MINAM.

Molnar, A., Barney, K., DeVito, M., Karsenty, A., Elson, D., Benavides, M., Soria, C. (2011). Large acquisition of rights on forest lands for tropical timber concessions and commercial wood plantations. International Land Coalition.

ONUDI. (2013). Informe sobre el Desarrollo Industrial 2013. ONU.

OSINFOR. (2014). Informe de Gestión Anual al 2014. Lima: OSINFOR.

Piu, H. C., y Menton, M. (2013). Contexto REDD+en Perú. Bogor: CIFOR.

Pokorny, B., Johnson, J., Medina, G., y Hoch, L. (2012). Market-based conservation of the Amazonian forests: Revising win-win expectations. Geoforum, 43, 387-401.

Porro, R., Lopez-Feldman, A., Vela-Alvarado, J. W., y Quiñonez-Ruíz, L. (2014). Forest Use and Agriculture in Ucayali, Peruvian Amazon: Interactions Among Livelihood Strategies, Income and Environmental Outcomes. Tropics, 23(2), 47-62.

Proinversión. (2005). Guía de Inversiones en el Sector Forestal. Lima: Proinversión.

Putzel, L. (2009). Upside-down: Global forestry politics reverses directions of ownership in PeruChina timber commodity chains. Buenos Aires: World Forestry Congress.

Putzel, L., Cronkleton, P., Larson, A., PinedoVásquez, M., Salazar, O., y Sears, R. (2013). Producción y comercialización de bolaina (Guazuma crinita), una especie amazónica de rápido crecimiento. Bogor: CIFOR.

Sabogal, C., y Sobrevilla, V. (2008). Monitoreo de Operaciones de Manejo Forestal en Concesiones con Fines Maderables de la Amazonía Peruana. Pucallpa: CIFOR.
Sears, R. R., y Pinedo-Vasquez, M. (2011). Forest Policy Reform and the Organization of Logging in Peruvian Amazonia. Oxford: International Institute of Social Studies.

Sindzingre, A. (2006). The Relevance of the Concepts of Formality and Informality: A Theoretical Appraisal. Oxford: Oxford.

SINIA. (2012). Producción de madera rolliza. Lima.

SINIA. (2014). Cifras Ambientales 2014. Lima: Ministerio del Ambiente.

Smith, J., Colan, V., Sabogal, C., y Snook, L. (2006). Why policy reforms fail to improve logging practices: The role of governance and norms in Peru.

Southgate, D., y Elgegren, J. (1995). The Peruvian Amazon: Development of Tropical Timber Resources.

Taylor, P. L. (2006). Country Case Study: Forest Tenure and Poverty in Peru. Bogor: CIFOR.

Thomson, S. (2014). Incrementando el acceso a financiamiento para PYMEs en el sector forestal 2010-2014. Lima: Finance Alliance for Sustainable Trade.

Torres, M. R. (2012). Guía para el inversionista interesado en el sector forestal peruano. Lima: The Amazon Alternative.

Ugarte, J. (2005). Migración, Carreteras y las dinámica de la deforestación en Ucayali. Quito: ICRAF.

UN-COMTRADE. (2012). Wood in the rough or roughly squared 247. United Nations.

UN-COMTRADE. (2013). Estadisticas de Comercio Exterior. Recuperado el 31 de agosto de 2013, de legacy.intracen.org/ marketanalysis/Default.aspx

Urban, R., y Ullilen, L. (2011). Mecanismos de financiamiento para el sector forestal en el Perú. Diseño participativo de un mecanismo de financiamiento para el desarrollo del sector forestal en el Perú. Lima: Fondebosques/FAO.

Wiig, H. (2013). Joint Titling in Rural Peru: Impact on Women's Participation in Household Decision-Making. World Development, 52, 104-119.

WWF-Perú. (2005). Demanda de madera del corredor norte peruano. Lima: WWF.

WWF-Perú. (2005). Demanda de madera del corredor sur peruano. Lima: WWF. 


\section{Anexos}

Anexo 1. Actores entrevistados por actividad y regiones de estudio

\begin{tabular}{|c|c|c|c|c|c|}
\hline Actores & Loreto & Madre de Dios & Ucayali & Otros & Total general \\
\hline Comunidades indígenas & 5 & & 10 & & 15 \\
\hline Extractores & 6 & 23 & 115 & & 144 \\
\hline Intermediarios & 82 & 47 & 72 & $69^{a}$ & 270 \\
\hline Productores & 12 & 25 & 80 & & 117 \\
\hline Concesionarios & 5 & 44 & 12 & & 61 \\
\hline Transportistas & 1 & 42 & 48 & & 91 \\
\hline Motoaserradores & 10 & 34 & & & 44 \\
\hline Consultores forestales & & & & $18^{\mathrm{b}}$ & 18 \\
\hline Empresas exportadoras & & & & $23^{c}$ & 23 \\
\hline Total general & 121 & 215 & 337 & 110 & 783 \\
\hline
\end{tabular}

Fuente: Elaboración propia.

Nota: a) Pertenecen a las ciudades de Arequipa, Chiclayo, Huánuco, Ica, Lima y Piura. b) Estos actores trabajan en todo el país. c) Empresas que se abastecen de madera desde las regiones de estudio. 
Anexo 2. Principales instrumentos legales para la adjudicación de tierras

\begin{tabular}{|c|c|c|c|c|c|}
\hline & & AGO 1990-JUL 1995 & AGO 1995-NOV 2000 & AGO 2001-JUL 2006 & AGO 2006-JUL 2011 \\
\hline \multirow{7}{*}{ 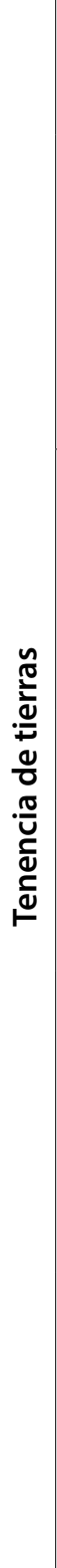 } & \multirow[t]{3}{*}{$\begin{array}{l}\text { Ordenamiento } \\
\text { Forestal }\end{array}$} & & & $\begin{array}{l}\text { Ley } N^{\circ} 27795 \text {. Ley de demarcación y } \\
\text { organización territorial }(24 / 07 / 02)\end{array}$ & $\begin{array}{l}\text { Decreto Supremo Nº17-2009-AG. Reglamento } \\
\text { de clasificación de tierras por su capacidad de uso } \\
\text { mayor (22/09/09) }\end{array}$ \\
\hline & & & & $\begin{array}{l}\text { Decreto Supremo } N^{\circ} 087-2004- \\
\text { PCM. Reglamento de zonificación } \\
\text { ecológica y económica (23/12/04) }\end{array}$ & $\begin{array}{l}\text { Resolución Ministerial Nº26-2010-MINAM. } \\
\text { Lineamientos de política para el ordenamiento } \\
\text { territorial }(23 / 02 / 10)\end{array}$ \\
\hline & & & & $\begin{array}{l}\text { Decreto del Consejo Directivo } N^{\circ} \\
010-2006-C O N A M-C D \text {. Directiva } \\
\text { metodológica para la zonificación } \\
\text { ecológica y económica }(26 / 06 / 06)\end{array}$ & \\
\hline & \multirow[t]{4}{*}{$\begin{array}{l}\text { Adjudicación } \\
\text { y Registro } \\
\text { de Títulos } \\
\text { Habilitantes }\end{array}$} & \multirow[t]{4}{*}{$\begin{array}{l}\text { Decreto Legislativo } \\
\mathrm{N}^{\circ} 667 \text {. Ley del } \\
\text { registro de predios } \\
\text { rurales }(13 / 09 / 91)\end{array}$} & $\begin{array}{l}\text { Decreto Supremo N }{ }^{\circ} 037-99-A G \text {. } \\
\text { Establece que en procedimientos } \\
\text { de adjudicación de tierras rústicas y } \\
\text { eriazas ubicadas en zonas de selva y } \\
\text { ceja de selva, se solicitará opinión al } \\
\text { INRENA (24/09/99) }\end{array}$ & $\begin{array}{l}\text { Resolución de la Superintendencia } \\
\text { Nacional de los Registros Públicos N }{ }^{\circ} \\
070-2006-S U N A R P-S N \text {. Directiva que } \\
\text { regula la inscripción de concesiones } \\
\text { forestales para forestación y } \\
\text { reforestación (14/03/06) }\end{array}$ & $\begin{array}{l}\text { Decreto Legislativo } \mathrm{N}^{\circ} 1089 \text {. Régimen temporal } \\
\text { extraordinario de formalización y titulación de } \\
\text { predios rurales }(28 / 06 / 08)\end{array}$ \\
\hline & & & $\begin{array}{l}\text { Decreto Supremo } N^{\circ} 001-2000-A G . \\
\text { Dispone que el INRENA gestione la } \\
\text { inscripción de las áreas naturales } \\
\text { protegidas como patrimonio de la } \\
\text { nación ante los Registros Públicos } \\
(11 / 01 / 00)\end{array}$ & $\begin{array}{l}\text { Resolución del Superintendente } \\
\text { Nacional de los Registros Públicos } \\
N^{\circ} 360-2006-S U N A R P-S N \text {. Directiva } \\
N^{\circ} 004-2006-S U N A R P-S N \text { que } \\
\text { regula el registro de áreas naturales } \\
\text { protegidas }(19 / 12 / 06)\end{array}$ & $\begin{array}{l}\text { Decreto Supremo } N^{\circ} \text { 032-2008-VIVIENDA. } \\
\text { Reglamento del Decreto Legislativo } N^{\circ} 1089 \\
(14 / 12 / 08)\end{array}$ \\
\hline & & & & & $\begin{array}{l}\text { Resolución Presidencial N } 217-2009-S E R N A N P \text {. } \\
\text { Precisan que no se requieren inscribir en los } \\
\text { Registros Públicos las limitaciones al derecho } \\
\text { de propiedad de los predios ubicados en áreas } \\
\text { naturales protegidas para su oponibilidad a } \\
\text { terceros, salvo que el dispositivo legal que lo } \\
\text { establezca lo ordene expresamente }(29 / 12 / 09)\end{array}$ \\
\hline & & & & & $\begin{array}{l}\text { Decreto Supremo N 056-2010-PCM. Transfieren } \\
\text { a favor de los gobiernos regionales la función de } \\
\text { formalización y titulación de predios rústicos de } \\
\text { tierras eriazas habilitados al } 31 \text { de diciembre de } \\
2004 \text {, así como la reversión de predios rústicos } \\
\text { adjudicados a título oneroso por el Estado, } \\
\text { ocupados por asentamientos humanos }(15 / 05 / 10)\end{array}$ \\
\hline
\end{tabular}




\begin{tabular}{|c|c|c|c|}
\hline \multicolumn{2}{|c|}{ Anexo 18.3.4 - Anexo sobre el manejo del sector forestal } & \multirow[b]{2}{*}{$\begin{array}{l}\text { Dispositivo legal } \\
\text { Decreto Supremo No 019-2010-AG } \\
\text { Se definen las acciones y se fortalecen los mecanismos de articulación entre } \\
\text { la Autoridad Administrativa CITES - Perú para las especies de flora y fauna } \\
\text { que se reproducen en tierra y la Autoridad Científica CITES - Perú, para la } \\
\text { determinación e implementación del cupo nacional de exportación de la } \\
\text { especie caoba comprendida en el apéndice II de la Convención sobre el } \\
\text { Comercio Internacional de Especies Amenazadas en Fauna y Flora Silvestres } \\
\text { - CITES. }\end{array}$} & \multirow[b]{2}{*}{$\begin{array}{l}\text { Fecha de vigencia } \\
\text { Aún no entra en } \\
\text { vigencia, la que } \\
\text { está sujeta a la } \\
\text { publicación de su } \\
\text { reglamento, en } \\
\text { el diario oficial El } \\
\text { Peruano. }\end{array}$} \\
\hline $\begin{array}{l}\text { Compromisos } \\
\text { asumidos en } \\
\text { el marco de la } \\
\text { cites }\end{array}$ & $\begin{array}{l}\text { 15. Cada Parte reafirma su compromiso } \\
\text { de trabajar en el marco de la CITES para } \\
\text { proteger las especies ahí enumeradas. } \\
\text { Con ese objetivo, las Partes cooperarán y } \\
\text { tomarán acciones de conformidad con el } \\
\text { presente Anexo de forma compatible con } \\
\text { las obligaciones asumidas por cada Parte en } \\
\text { virtud de la CITES, teniendo en cuenta las } \\
\text { decisiones y resoluciones de la Conferencia } \\
\text { de las Partes de la CITES, así como las de } \\
\text { su Comité, su Comité de Animales y su } \\
\text { Comité de Plantas. Asimismo, ninguna de las } \\
\text { disposiciones del presente Anexo limitará } \\
\text { las facultades de ninguna de las Partes para } \\
\text { tomar medidas consistentes con sus propias } \\
\text { Leyes de aplicación de la CITES. }\end{array}$ & & \\
\hline \multirow{6}{*}{$\begin{array}{l}\text { Fortalecimiento } \\
\text { del manejo del } \\
\text { sector forestal }\end{array}$} & \multirow{6}{*}{$\begin{array}{l}\text { 3. Para fortalecer aún más la gestión de su } \\
\text { sector forestal, el Perú deberá, en un plazo } \\
\text { máximo de } 18 \text { meses a partir de la fecha de } \\
\text { entrada en vigor del presente Acuerdo, tomar } \\
\text { las siguientes acciones: } \\
\text { (j) Identificar adecuadamente las áreas } \\
\text { protegidas y las concesiones. }\end{array}$} & Ley Forestal y de Fauna Silvestre, Ley No 29763 & \multirow{6}{*}{$\begin{array}{l}\text { Aún no entra en } \\
\text { vigencia, la que } \\
\text { está sujeta a la } \\
\text { publicación de su } \\
\text { reglamento, en } \\
\text { el diario oficial El } \\
\text { Peruano. }\end{array}$} \\
\hline & & Artículo 34. Catastro Forestal & \\
\hline & & \multirow{2}{*}{$\begin{array}{l}\text { Créase el Catastro Forestal en el que se incorpora la información cartográfica } \\
\text { y documental de las categorías, zonificación, unidades de ordenamiento } \\
\text { forestal, títulos habilitantes, plantaciones y tierras de dominio público con } \\
\text { aptitud para plantaciones forestales de producción o de protección, así } \\
\text { como tierras de las comunidades campesinas y nativas. Esta información es } \\
\text { de dominio público. }\end{array}$} & \\
\hline & & & \\
\hline & & $\begin{array}{l}\text { Este catastro está a cargo del SERFOR y se integra al Sistema Nacional } \\
\text { Integrado de Información Catastral Predial de la Superintendencia Nacional } \\
\text { de los Registros Públicos (SUNARP) y al Registro Nacional de Ordenamiento } \\
\text { Territorial y Zonificación Ecológica Económica del Ministerio del Ambiente. }\end{array}$ & \\
\hline & & $\begin{array}{l}\text { El Catastro Forestal es de observancia obligatoria para todos los sectores } \\
\text { y niveles de gobierno para el otorgamiento de cualquier derecho sobre el } \\
\text { recurso forestal y de fauna silvestre. }\end{array}$ & \\
\hline
\end{tabular}


Anexo 3. Continuado

\begin{tabular}{|c|c|c|}
\hline Anexo 18.3.4 - Anexo sobre el manejo del sector forestal & Dispositivo legal & Fecha de vigencia \\
\hline $\begin{array}{l}\text { 3. Para fortalecer aún más la gestión de su } \\
\text { sector forestal, el Perú deberá, en un plazo } \\
\text { máximo de } 18 \text { meses a partir de la fecha de } \\
\text { entrada en vigor del presente Acuerdo, tomar } \\
\text { las siguientes acciones: } \\
\text { (h) Crear y promover el uso de herramientas } \\
\text { que complementen y fortalezcan los controles } \\
\text { normativos y los mecanismos de verificación } \\
\text { relacionados con la extracción y el comercio } \\
\text { de productos madereros. En este contexto, el } \\
\text { Perú deberá: } \\
\text { i. (iv) Identificar un punto focal en el } \\
\text { gobierno del Perú, con autoridad y } \\
\text { personal suficiente y adecuado para } \\
\text { investigar las infracciones a Leyes y } \\
\text { normas para el manejo del sector forestal. } \\
\text { El punto focal deberá: a) contar con un } \\
\text { proceso transparente para la denuncia } \\
\text { de delitos cometidos en el sector forestal; } \\
\text { b) asegurar la coordinación y el flujo } \\
\text { correcto y oportuno de información } \\
\text { entre las entidades técnicas y financieras } \\
\text { pertinentes; y c) cuando corresponda, } \\
\text { llevar adelante el proceso judicial o } \\
\text { denunciar violaciones para su posterior } \\
\text { proceso judicial. }\end{array}$ & $\begin{array}{l}\text { Ley Forestal y de Fauna Silvestre, Ley No } \mathbf{2 9 7 6 3} \\
\text { Artículo 145. Potestad fiscalizadora y sancionadora } \\
\text { Otórgase potestad fiscalizadora y sancionadora a las autoridades regionales } \\
\text { forestales y de fauna silvestre en el ámbito de su competencia territorial y } \\
\text { conforme a la Ley } 27867 \text {, Ley Orgánica de Gobiernos Regionales. } \\
\text { En los procedimientos administrativos sancionadores, la autoridad regional } \\
\text { forestal y de fauna silvestre actúa como primera instancia y la alta dirección } \\
\text { del gobierno regional, como segunda y última instancia. } \\
\text { El SERFOR fiscaliza y sanciona las infracciones a la legislación forestal y de } \\
\text { fauna silvestre vinculadas a los procedimientos administrativos a su cargo, } \\
\text { conforme a la presente Ley y su reglamento. El SERFOR actúa en primera } \\
\text { instancia administrativa, siendo la segunda y última instancia el Ministerio } \\
\text { de Agricultura. }\end{array}$ & $\begin{array}{l}\text { Aún no entra en } \\
\text { vigencia, la que } \\
\text { está sujeta a la } \\
\text { publicación de su } \\
\text { reglamento, en } \\
\text { el diario oficial El } \\
\text { Peruano. }\end{array}$ \\
\hline
\end{tabular}


Anexo 3. Continuado

\begin{tabular}{|c|c|c|}
\hline Anexo 18.3.4 - Anexo sobre el manejo del sector forestal & Dispositivo legal & Fecha de vigencia \\
\hline $\begin{array}{l}\text { i. Amenazas, o violencia o intimidación } \\
\text { del personal gubernamental dedicado } \\
\text { a hacer cumplir las Leyes, las normas y } \\
\text { otras medidas del Perú en relación con } \\
\text { la extracción y el comercio de productos } \\
\text { madereros; } \\
\text { ii. A sabiendas crear, utilizar, presentar o } \\
\text { brindar información falsa en cualquier } \\
\text { documentación relativa al cumplimiento } \\
\text { de las Leyes, las normas y otras medidas } \\
\text { del Perú en relación con la extracción y } \\
\text { el comercio de productos madereros, } \\
\text { incluidos los planes de manejo forestal, } \\
\text { los planes operativos anuales, las } \\
\text { solicitudes de permisos o concesiones y la } \\
\text { documentación de transporte; } \\
\text { iii. Obstruir una investigación, verificación } \\
\text { o auditoría realizada por personal } \\
\text { gubernamental dedicado a hacer cumplir } \\
\text { las Leyes, las normas y otras medidas del } \\
\text { Perú en relación con la extracción y el } \\
\text { comercio de productos madereros; } \\
\text { iv. A sabiendas extraer o adquirir madera o } \\
\text { productos madereros de zonas o personas } \\
\text { no autorizadas por la legislación peruana; } \\
\text { o a sabiendas transportar madera o } \\
\text { productos madereros tomados de zonas o } \\
\text { personas no autorizadas por la legislación } \\
\text { peruana; y } \\
\text { v. Dar a un funcionario de gobierno, o } \\
\text { recibir como funcionario de gobierno, } \\
\text { compensación, monetaria o en especie, a } \\
\text { cambio de un acto particular al momento } \\
\text { de hacer cumplir las Leyes, las normas y } \\
\text { otras medidas del Perú en relación con } \\
\text { la extracción y el comercio de productos } \\
\text { madereros. }\end{array}$ & $\begin{array}{l}\text { Ley Forestal y de Fauna Silvestre, Ley No } 29763 \text {. Título V. Régimen de } \\
\text { fiscalización, supervisión y control } \\
\text { - Artículo 145. Potestad fiscalizadora y sancionadora } \\
\text { - Artículo 146. Infracciones } \\
\text { - Artículo 147. Acciones de control y vigilancia forestal y de fauna silvestre } \\
\text { - Artículo 148. Monitoreo, control y vigilancia comunales } \\
\text { - Artículo 149. Auditoría de productores y exportadores de productos } \\
\text { forestales y de fauna silvestre } \\
\text { - Artículo 150. Punto focal de denuncias } \\
\text { - Artículo 151. Actos administrativos derivados de la comisión de una } \\
\text { infracción a la presente Ley } \\
\text { - Artículo 152. Sanciones } \\
\text { - Artículo 153. Causales de caducidad de los títulos habilitantes } \\
\text { - Artículo 154. Ejecución coactiva } \\
\text { - Artículo 155. Medidas correctivas } \\
\text { - Artículo 156. Gastos para la obtención o presentación de medios } \\
\text { probatorios } \\
\text { - Artículo 157. Condiciones laborales }\end{array}$ & $\begin{array}{l}\text { Aún no entra en } \\
\text { vigencia, la que } \\
\text { está sujeta a la } \\
\text { publicación de su } \\
\text { reglamento, en } \\
\text { el diario oficial El } \\
\text { Peruano. }\end{array}$ \\
\hline
\end{tabular}


Anexo 3. Continuado

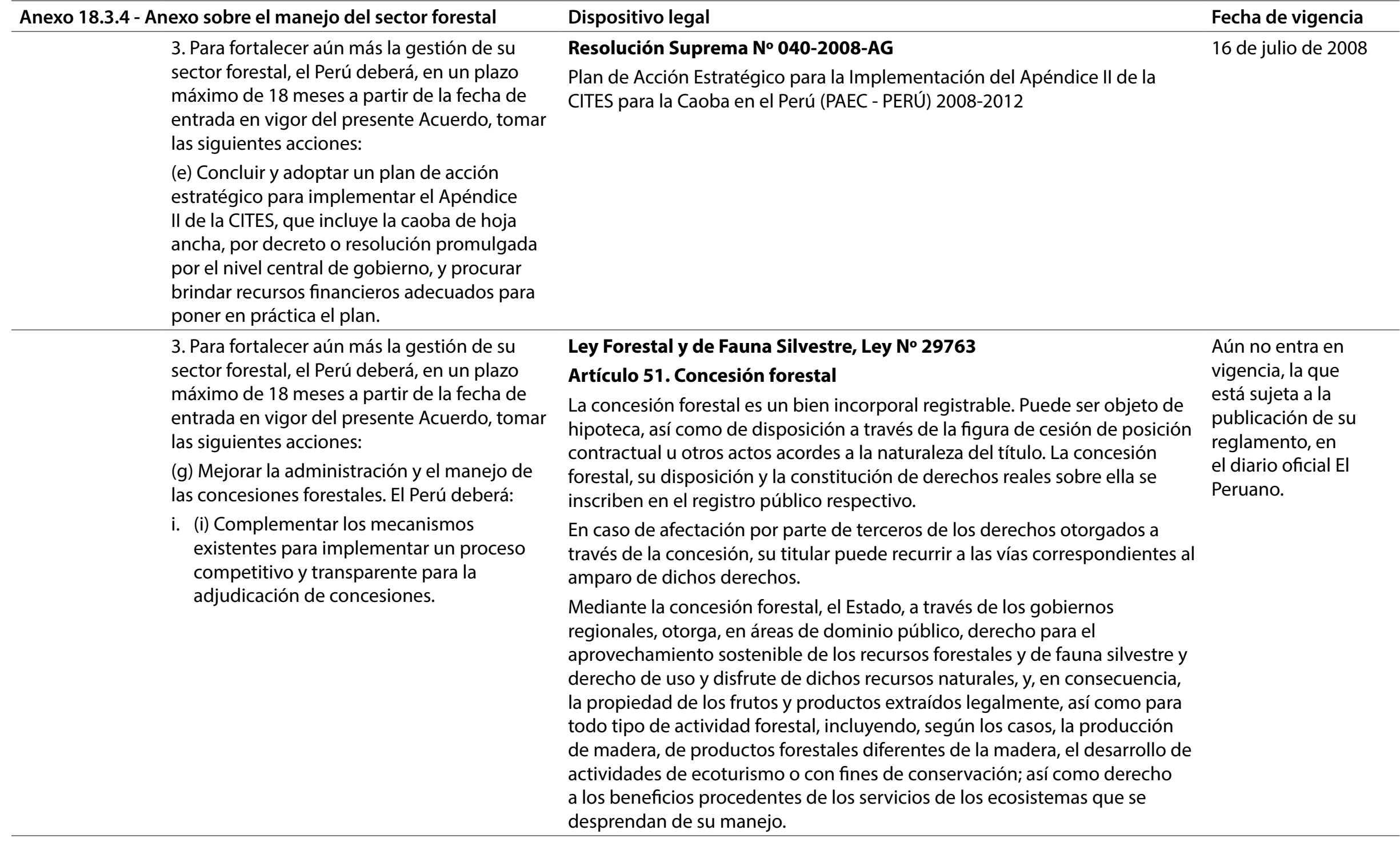


No se permite el otorgamiento de otros títulos habilitantes en materia forestal en áreas otorgadas en concesión forestal dentro del marco de la presente Ley.

El reglamento establece las condiciones de uso de cada tipo de concesión y en cada categoría del ordenamiento forestal.

El solicitante de concesión forestal acredita fehacientemente su capacidad técnica y financiera para manejar sosteniblemente la unidad concesionada. Su renovación se sujeta a las condiciones que establezca el reglamento de la presente Ley.

Fortalecimiento 3. Para fortalecer aún más la gestión de su del manejo del sector forestal, el Perú deberá, en un plazo sector forestal máximo de 18 meses a partir de la fecha de entrada en vigor del presente Acuerdo, tomar las siguientes acciones:

(g) Mejorar la administración y el manejo de las concesiones forestales. El Perú deberá:

i. (ii) Revisar los planes operativos anuales propuestos para dichas concesiones y, de ser aprobado el plan, ponerlo a disposición del público y verificar periódicamente de manera oportuna que el concesionario esté cumpliendo con los términos del plan.

\section{Ley Forestal y de Fauna Silvestre, Ley № 29763}

\section{Artículo 45. Formulación de planes de manejo forestal}

Los planes de manejo consideran la descripción de las características y estado actual del recurso o recursos a aprovechar; los objetivos de corto, mediano y largo plazo; la descripción y sustento del sistema de regeneración elegido, basado en evaluaciones poblacionales de los recursos sujetos a aprovechamiento; la intensidad y tipos de sistemas de aprovechamiento; las prácticas necesarias para garantizar la reposición de los recursos aprovechados; los impactos sobre el ecosistema y las correspondientes medidas de prevención y mitigación. Se incluye información que permita ubicar con precisión las áreas y recursos objeto de manejo, empleando instrumentos como sistemas de posicionamiento global u otros, entre otros aspectos que establezca el reglamento.

Los lineamentos técnicos y la ejecución de los planes de manejo forestal tienen en consideración las características específicas de los diferentes tipos de bosque en cada región natural del país y la intensidad de aprovechamiento. Pueden incluir medidas diferenciadas por especie, en particular para especies bajo algún nivel de amenaza y especies naturalmente poco abundantes, por categoría de bosque y por intensidad del aprovechamiento.

La autoridad forestal y de fauna silvestre que aprueba el plan de manejo publica en su portal electrónico institucional un resumen ejecutivo de los planes de manejo aprobados, elaborados por los administrados. En el reglamento, se precisa el mecanismo para la aprobación del componente ambiental del referido plan.
Aún no entra en vigencia, la que está sujeta a la publicación de su reglamento, en el diario oficial El Peruano. 
Anexo 3. Continuado

\begin{tabular}{|c|c|c|}
\hline Anexo 18.3.4 - Anexo sobre el manejo del sector forestal & Dispositivo legal & Fecha de vigencia \\
\hline \multirow{2}{*}{$\begin{array}{l}\text { 3. Para fortalecer aún más la gestión de su } \\
\text { sector forestal, el Perú deberá, en un plazo } \\
\text { máximo de } 18 \text { meses a partir de la fecha de } \\
\text { entrada en vigor del presente Acuerdo, tomar } \\
\text { las siguientes acciones: }\end{array}$} & $\begin{array}{l}\text { Decreto Legislativo No } 1085 \text {. Ley que crea el Organismo de Supervisión } \\
\text { de los Recursos Forestales y de Fauna Silvestre. }\end{array}$ & 29 de junio de 2008 \\
\hline & $\begin{array}{l}\text { El OSINFOR es la entidad encargada, a nivel nacional, de supervisar y } \\
\text { fiscalizar el aprovechamiento y la conservación de los recursos forestales } \\
\text { y de fauna silvestre, así como de los servicios ambientales provenientes }\end{array}$ & \\
\hline \multirow{2}{*}{$\begin{array}{l}\text { (h) Crear y promover el uso de herramientas } \\
\text { que complementen y fortalezcan los controles } \\
\text { normativos y los mecanismos de verificación } \\
\text { relacionados con la extracción y el comercio } \\
\text { de productos madereros. En este contexto, el } \\
\text { Perú deberá: }\end{array}$} & $\begin{array}{l}\text { del bosque, para su sostenibilidad, de acuerdo con la política y estrategia } \\
\text { nacional de gestión integrada de recursos naturales y las políticas que sobre } \\
\text { servicios ambientales establezca el Ministerio del Ambiente, en el ámbito de } \\
\text { su competencia. }\end{array}$ & \\
\hline & $\begin{array}{l}\text { Las competencias de OSINFOR no involucran a las Áreas Naturales } \\
\text { Protegidas las cuales se rigen por su propia Ley. }\end{array}$ & \\
\hline $\begin{array}{l}\text { i. (iii) Aplicar plenamente las Leyes y normas } \\
\text { existentes para la gestión del sector } \\
\text { forestal, y fortalecer las instituciones } \\
\text { responsables de hacer cumplir estas Leyes } \\
\text { y cualquier aspecto del manejo forestal } \\
\text { en el Perú. En este contexto, el Perú } \\
\text { establecerá el OSINFOR, tal como dispone } \\
\text { la Ley Forestal No } 27308 \text {. El OSINFOR será } \\
\text { una entidad independiente y separada, } \\
\text { y su mandato incluirá la supervisión de } \\
\text { la verificación de todas las concesiones y } \\
\text { permisos madereros; }\end{array}$ & & \\
\hline
\end{tabular}


Anexo 4. Precios máximos y mínimos para las principales especies aprovechadas por los extractores

\begin{tabular}{lcc}
\hline Especie & Precio máx. & Precio mín. \\
\hline Achuhua & 1,2 & 0,9 \\
Anacaspi & 1,8 & 1,7 \\
Bolaina & 1,8 & 1,6 \\
Caimitillo & 1,1 & 0,8 \\
Capirona* & 1,2 & 1,1 \\
Carahuasca & 0,9 & 0,8 \\
Cashimbo* & 1,7 & 1,1 \\
Copaiba & 0,8 & 0,6 \\
Cumala & 1,1 & 0,7 \\
Huairuro* & 1,6 & 1,4 \\
Huangana & 1,2 & 0,9 \\
Lupuna & 1,0 & 0,8 \\
Marupa & 1,1 & 0,9 \\
Moena & 1,8 & 1,7 \\
Panguana & 1,2 & 0,9 \\
Pumaquiro* & 2,8 & 2,2 \\
Quinaquina & 1,0 & 0,9 \\
Quinilla* & 1,6 & 1,2 \\
Sapote & 1,0 & 0,7 \\
Shihuahuaco* & 3,0 \\
Tornillo* & 3,7 & 2,4 \\
Utucuro & 2,5 & 0,8 \\
\hline
\end{tabular}

Fuente: Elaboración propia con base en las entrevistas realizadas entre julio de 2013 y marzo de 2014. Nota: *Especies duras de mayor valor comercial. 
Anexo 5. Precio máximo y mínimo de las principales especies comercializadas por pequeños productores

\begin{tabular}{lcc}
\hline Especie & Precio máximo & Precio mínimo \\
\hline Bolaina & 1,7 & 2,0 \\
Capirona & 1,1 & 1,3 \\
Carana & 0,9 & 0,9 \\
Catahua & 0,3 & 0,3 \\
Cumala & 1,2 & 0,8 \\
Huairuro & 1,3 & 1,2 \\
Lupuna & 0,6 & 0,7 \\
Marupa & 1,4 & 1,1 \\
Misa & 0,6 & 0,6 \\
Moena & 0,5 & 0,5 \\
Quinilla & 1,4 & 1,3 \\
Sapote & 0,9 & 0,9 \\
Shihuahuaco & 1,8 & 1,6 \\
Tahuari & 0,5 & 0,5 \\
Tornillo & 2,8 & 2,5 \\
Yacushapana & 1,2 & 0,7 \\
\hline
\end{tabular}

Fuente: Elaboración propia con base en las entrevistas realizadas entre julio de 2013 y marzo de 2014. 
Anexo 6. Precios máximos y mínimos de las principales especies comercializadas por intermediarios

\begin{tabular}{|c|c|c|}
\hline & Precio máximo & Precio mínimo \\
\hline Bolaina & 2,2 & 1,4 \\
\hline Cachimbo & 3,5 & 3,3 \\
\hline Caimitillo & 6,5 & 5,0 \\
\hline Capinuri & 0,9 & 0,8 \\
\hline Capirona & 1,9 & 1,6 \\
\hline Catahua & 1,1 & 0,8 \\
\hline Caudillo & 2,1 & 1,9 \\
\hline Cedro & 12,0 & 9,0 \\
\hline Cedro huasca & 4,0 & 2,5 \\
\hline Copaiba & 2,2 & 1,8 \\
\hline Cumala & 1,3 & 1,0 \\
\hline Estoraque & 5,1 & 4,6 \\
\hline Higuerilla & 1,0 & 1,0 \\
\hline Huayruro & 3,9 & 3,6 \\
\hline Ishpingo & 4,4 & 4,2 \\
\hline Lupuna & 3,7 & 3,1 \\
\hline Misa & 1,5 & 1,6 \\
\hline Moena & 1,9 & 1,6 \\
\hline Oje & 0,7 & 0,6 \\
\hline Panguana & 1,7 & 1,7 \\
\hline Pashaco & 1,8 & 1,6 \\
\hline Ponsiana & 1,2 & 1,1 \\
\hline Pumaquiro & 5,2 & 3,0 \\
\hline Quillosisa & 1,0 & 0,8 \\
\hline Quinaquina & 1,0 & 0,7 \\
\hline Quinilla & 4,5 & 3,9 \\
\hline Sapote & 1,0 & 1,0 \\
\hline Shihuahuaco & 3,6 & 2,9 \\
\hline Tornillo & 3,1 & 2,7 \\
\hline Utucuro & 1,3 & 1,1 \\
\hline Yacushapana & 6,0 & 5,5 \\
\hline
\end{tabular}

Fuente: elaboración propia con base en entrevistas realizadas entre julio de 2013 y marzo de 2014. 

Los Documentos ocasionales de CIFOR contienen resultados de investigación relevantes para el manejo forestal. Su contenido es revisado por pares interna y externamente.

El comercio de la madera en la Amazonía peruana descansa en una extensa red de actores que articula a pequeños agricultores, extractores, concesionarios, intermediarios y compradores, los que interactúan a través de operaciones formales e informales para abastecer la creciente demanda de madera de las zonas urbanas. Pese a que los costos de la legalización de los aprovechamientos de madera no estén entre los costos operativos más altos para los usuarios forestales, sí constituyen un obstáculo al comercio, principalmente cuando se trata de pequeños volúmenes aprovechados de madera. Nuestros resultados sugieren que los beneficios de los actores no están necesariamente relacionados con el hecho de hacer aprovechamientos legales o no, sino que tienen que ver con otro tipo de factores, como el acceso a capital, redes de intermediación y especies comercializadas. Adicionalmente, ante la ausencia de un sistema institucional más adecuado para apoyar de manera realista la formalización del aprovechamiento forestal y el desarrollo más transparente de los mercados, sea con incentivos para el aprovechamiento, préstamos diferenciados, instrumentos de gestión más flexibles, y mejor información de precios, entre otros, es posible que la madera originada en aprovechamientos ilegales siga dominando la oferta para los mercados.

\begin{tabular}{|c|c|c|}
\hline CGIAR & $\begin{array}{l}\text { PROGRAMA DE } \\
\text { INVESTIGACIÓN SOBRE } \\
\text { Bosques, Árboles y } \\
\text { Agroforestería }\end{array}$ & $\begin{array}{l}\text { Esta investigación fue realizada por CIFOR como parte del Programa de Investigación de CGIAR sobre } \\
\text { Bosques, Árboles y Agroforestería (CRP-FTA). El objetivo del programa es mejorar el manejo y uso de los } \\
\text { bosques, la agroforestería y los recursos genéticos de los árboles a lo largo del paisaje, desde bosques } \\
\text { hasta plantaciones. CIFOR dirige el programa CRP-FTA en asociación con Bioversity International, CATIE, } \\
\text { CIRAD, el Centro Internacional de Agricultura Tropical y el Centro Mundial de Agroforestería. }\end{array}$ \\
\hline
\end{tabular}

cifor.org

blog.cifor.org

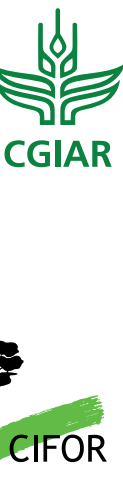

Fund

\section{Centro para la Investigación Forestal Internacional (CIFOR)}

CIFOR impulsa el bienestar humano, la conservación ambiental y la equidad mediante investigación orientada a ayudar en el diseño de políticas y prácticas que afectan a los bosques de los países en vías de desarrollo. CIFOR es un miembro del Consorcio CGIAR. Nuestra sede central se encuentra en Bogor, Indonesia, y contamos con oficinas en Asia, África y América Latina. 